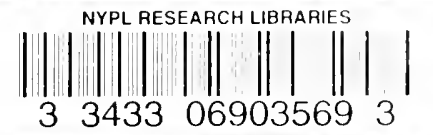

10

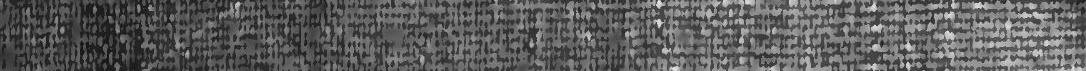
(2)

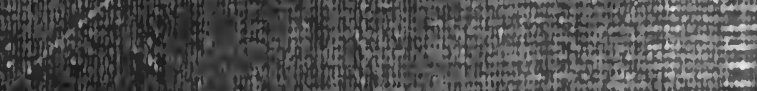
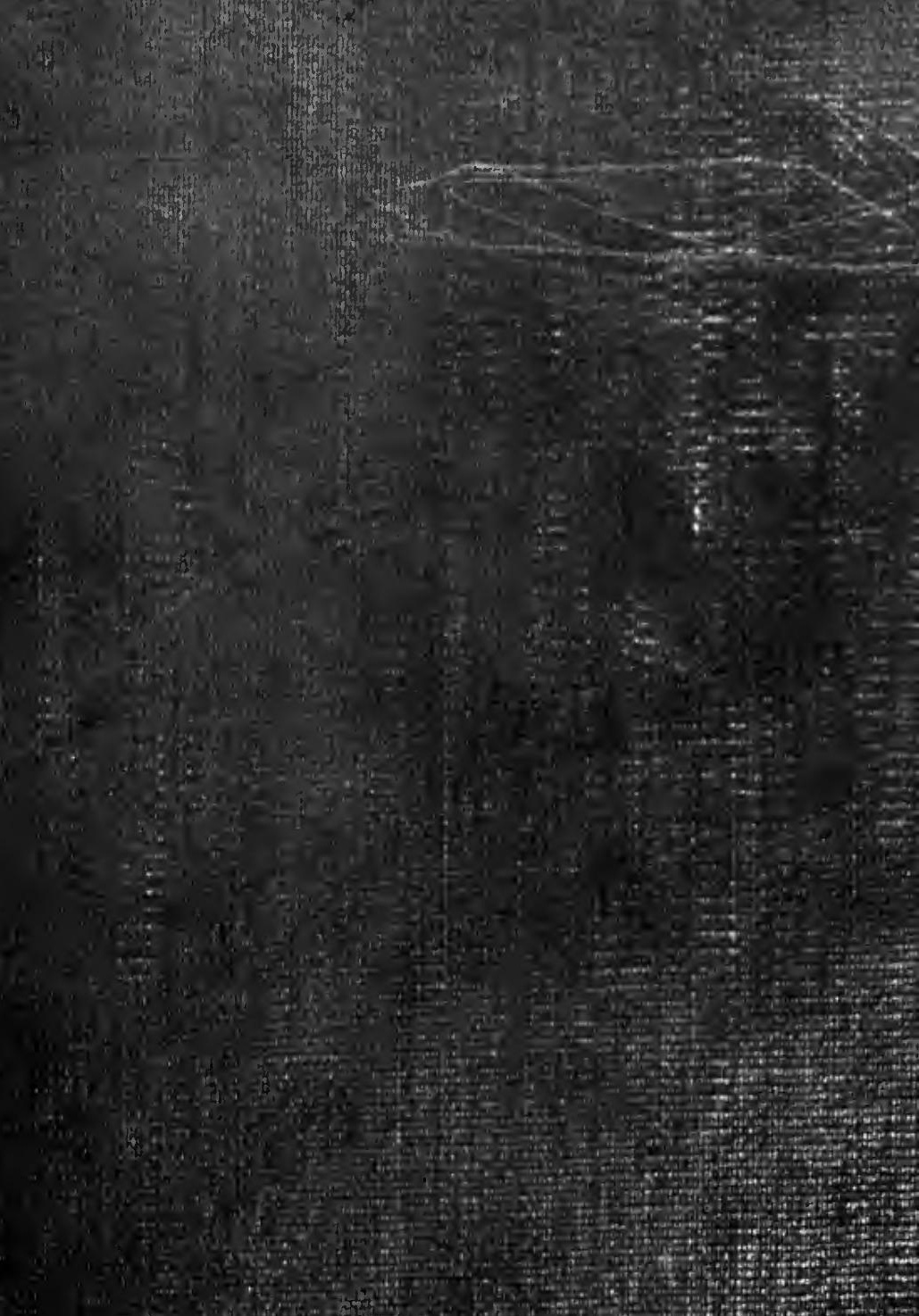


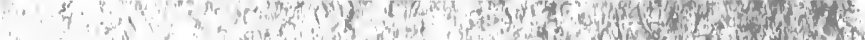

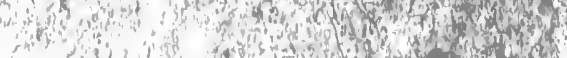

(e)

1.

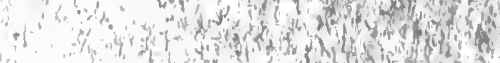

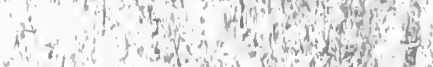

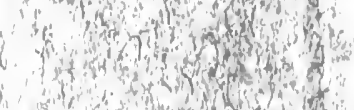

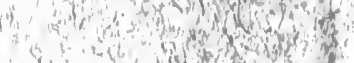

and

(n)

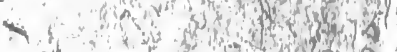

and

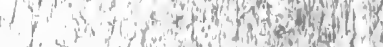

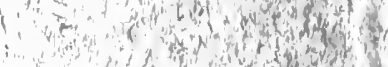

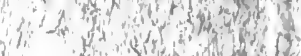
not of

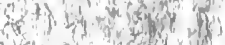

$1 \% \cdots+y_{1}$

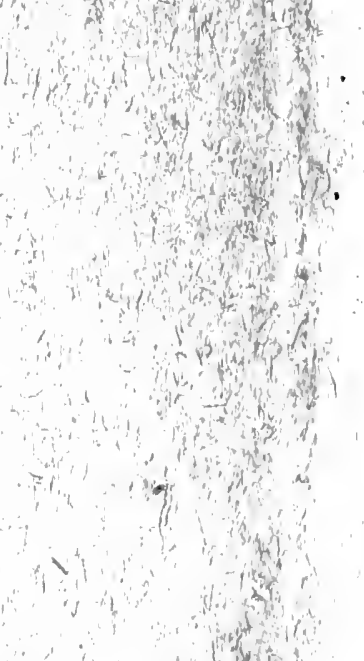

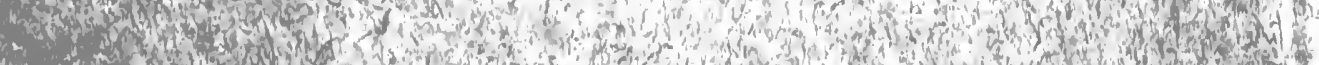

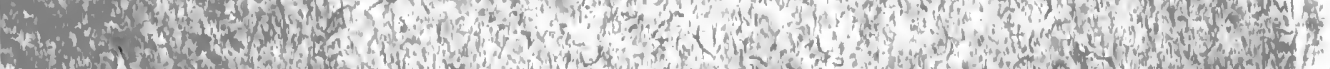
What 
(3)

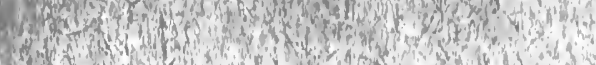

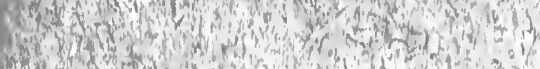

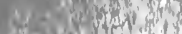

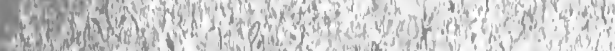

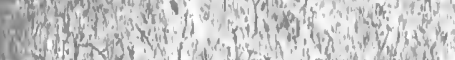

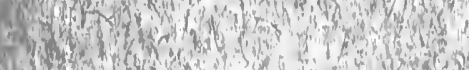

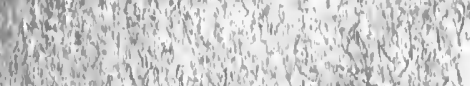

$-4 x^{2}$ dy

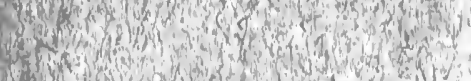

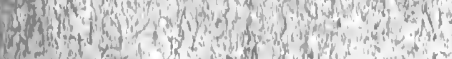

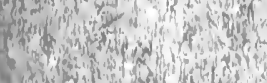

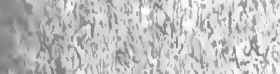

oli

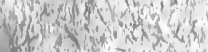

sinen of

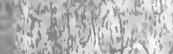

3. ning

ond of

1..

singtint

ovin wh

fortent

(n) 1

Weys

(a) 4 .

Now 10

tor on

critento

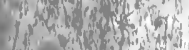

(1)

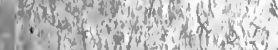

(i) 10 on

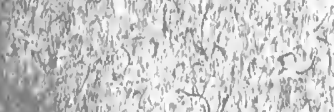

sin

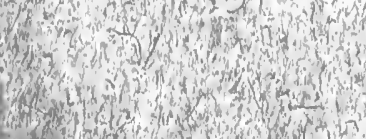

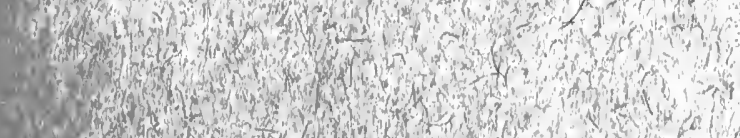

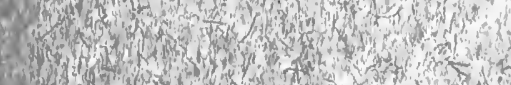

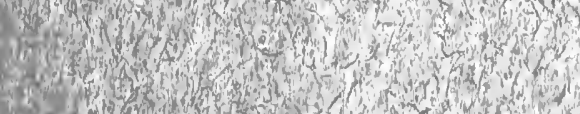

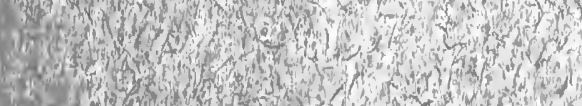

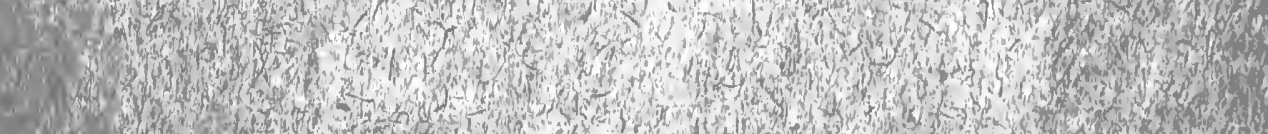

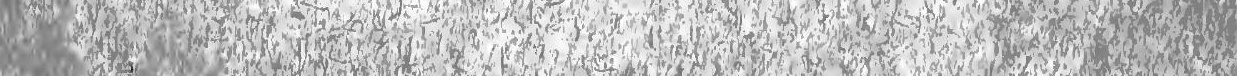
Q60

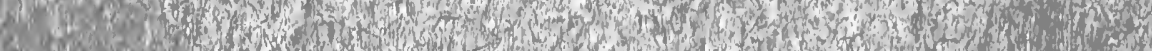

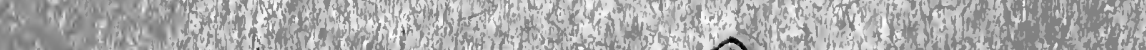

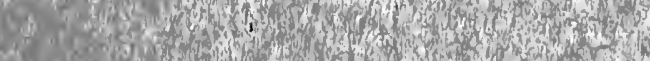




\section{Digitized by the Internet Archive in 2008 with funding from Microsoft Corporation}


The Commercial Photographer 



\section{THE}

\section{Commercial Photographer}

BY

\section{G. ROSE}

FORMER PHOTOGRAPHER FOR THE NATIONAL GEOLOGICAL SURVEY;

FORMER PHOTOGRAPHER IN THE U. S. NAVAL GUN FACTORY;

COMMERCIAL PHOTOGRAPHER TO SOME OF THE LARGEST CONCERNS IN AMERICA.

Profusely' Illustrated

PHILADELPHIA :

FRANK V. CHAMBERS, PUBLISHER

636 FRANKLIN SQUARE

1920 


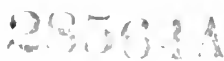

(ingrighted 1918, 1919, 1920, 19

IR.IK V.CHAMBERS

l'l. [1. 1111.1.1111

.11 riglets and translations reseried. 


\section{PREFACE}

Commercial photography has been a difficult subject to get a compilation of facts and figures in this branch of the work and until we succeeded in having Mr. Rose prepare these papers, which originally were printed in the Bulletix of Photograpir as a serial, the commercial photographer has been neglected for many years.

Though the variety of work of the commercial photographer is endless, the subjects that are treated in this book are practical and employed in the regular course of business. In fact, theory has been put aside and only actual working apparatus and formulie such that the photographer may safely use, have been recommended. 



\title{
The Commercial Photographer
}

\author{
CHAPTEK!

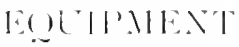

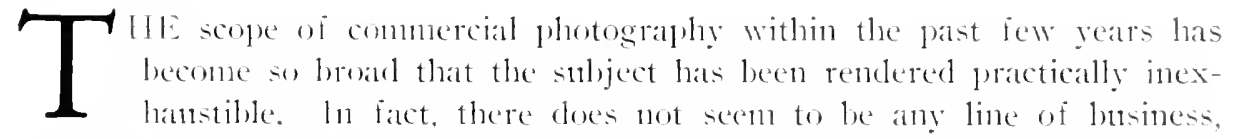
whether it be that of the promoter. manulacturer, advertiser, arehitect or lawyer, where the nse of photographs is not essential, or highly leneficial and a saving financially.

There has leeen a great deal written in this conncetion, and for this reatson I an not touching on the elementary principles, lout only intend the following articks to be a help to commercial photographers in general, ats well as the portrait man upon whom occasional or frequent calls may le narle for services of this nature.

In selecting apparatus for this work, as the commercial photographer is called upon to photograph anything and everything under all conditions of light and surromdings and yet malie good, the first itens to consider are adaptability. (lumbility and appearance. It might be well to state here, that appearance is an important factor, for many a good photographer has been misjudged as to his general ability becanse of a shabby or makeshift ontfit. Therefore, the best apparatus that can be obtained will be found to be the wisest investment in the end. and this apparatus naturally varies somewhat according to the line taken up by the photographer. The man in the large city, doing general work, will need a very nuch more extensive equipment than the one in the small city where the field is linited, or the specialist who does only architectural, legal. animal or some other one-line photography.

Probably the first thing to be considered in the way of equipment is the camera. which, for real serions commercial work, needs to have good bellows length, that is, thirty to thirty-two inches for $8 \times 10$; a large front board opening to accommodate different lenses and shutters; an excessive double swing, and a rising and falling front. This camera, for quick and sure action, must be absolutely rigid, as well as light in weight for convenience in handling. The specifications of such a camera for both $8 \times 10$ and $11 \times 1+$ are more nearly met in the Folner \& Schwing commercial camera, althongh they cannot be said to be particularly light in weight. 


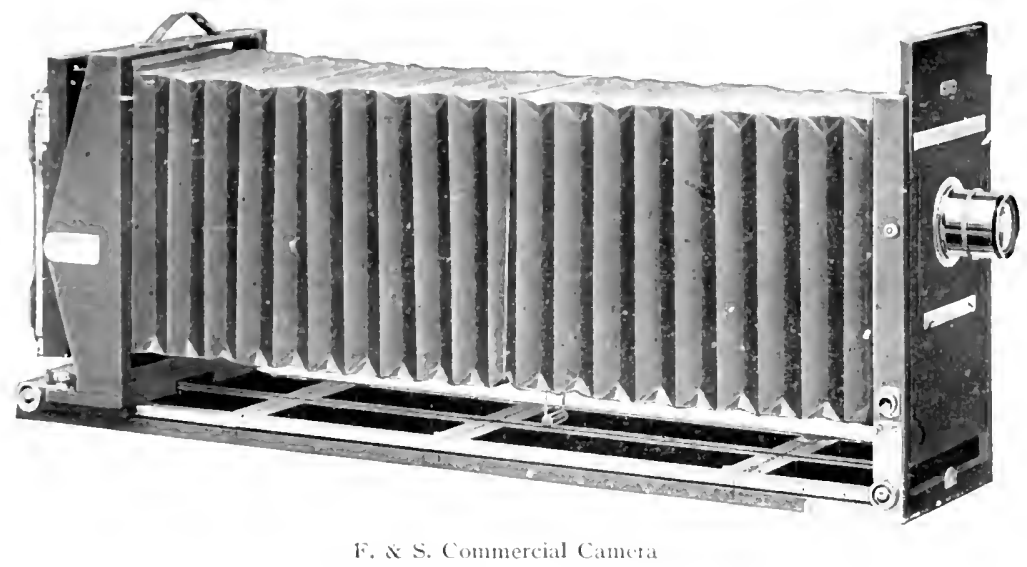

Imother good camera for this work, quite a bit cheaper and somewhat lighter, is the Eastman Iiew Xo. 2. It has not that excessive swing and some

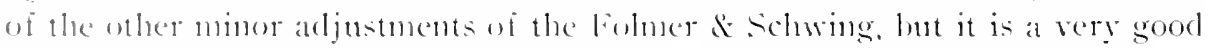
all-romul instrument.

The l'remo liew Cannera is anothere desirable selection. This has the arlantage of being still lighter in weight and possesses one excellent feature not formel in the two abore mentioned, that is, a front that can be tilted forwart. This is a woulerful help in photographing interiors from a raised position and is a feature incorporated in all banptuet cancras, and the subject of how to use it will he discussed in one of the chapters to follow.

I skycraper camera, while selelom nsed, and then only in congested quarters, is convenient to have for photographing tall huildings, but unless one has very frepuent calls for work of this kind, whe investment, which is considerable. is mmecessary, as the conmercial candera, with an extreme wide-angle lens, will do all and more than the skiseraper.

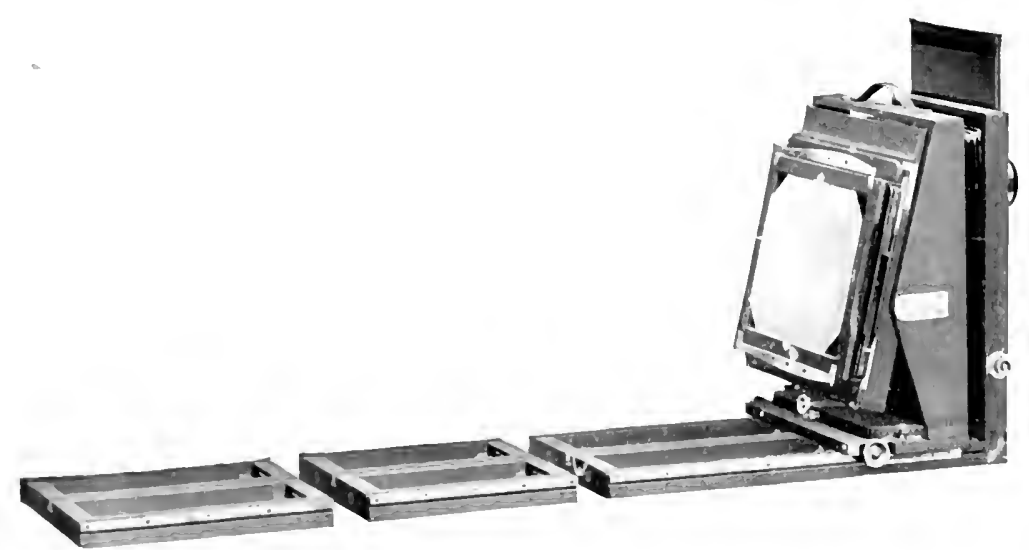


fust a word at this point about camera cases. Is those supplied by the mannfacturers are wsmally of canvats, and seldome of a quality to withetand much bard nsage, and in a very short time become very shably, many of the

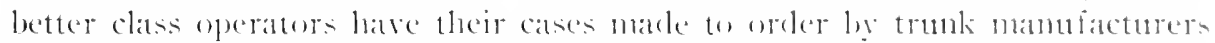
to suit their individual needs, and of a material, such as fiber or leather, which

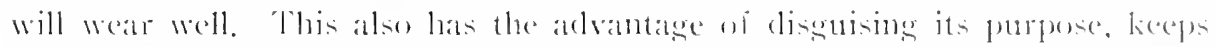
the smatl boys from following, and sets the plostegrapher in a distinet clates

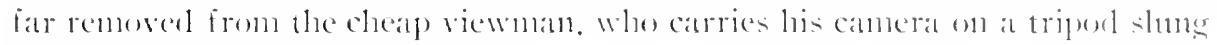
over his slombler.

Is for the number of camerats really needed for ontside work, there are sufficient. an \& $\times 10$, an $11 \times 1+$, and possibly a speed cameras. The \& $x 10$ size will be used buth insirle and outside the stutlon the more frecpuently, at it is the stambard size of today, probably due to the fact that it more readily fits office files, is a goul size from which to enlarge and is of reasomalole enst to the customer.

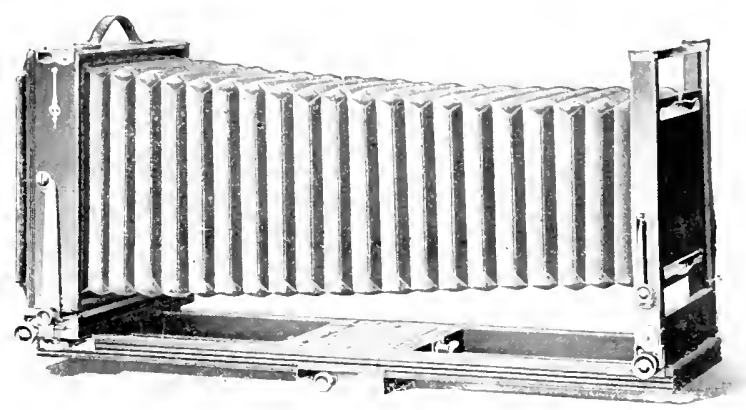

Eastman View Camera, No. 2

Is the branch of photography requiring a speed camera is more in line with that of the newspaper photographer, it is not highly profitable to the average commercial man, newspapers seldom being willing to pay what it is worth. By speed canera I refer to something with a fast shuter. which may be either of the focal plane or between the lens tyge, although, to my knowlerge. there is no really reliable ultra-speed between-the-lens shutter now on the market and the choice naturally falls to the focal plane.

However, if there is lemand for such an outfit, which womld be the case in animal and marine photography, it is well to arlopt the method pursued by many of the speed operators of today, that is, to use, for mstance. a $3^{1}+x+4$ Graphic with a direct view funder and a good speed lens, and then enlarge to the standard size of $8 \times 10$. In this way one has the increased depth of focus of the shorter lens over $5 \times 7$ and $8 \times 10$. The first cost is considerably less, as is also the cost to operate, and it is light and easy to carry, all very desirable elements.

Screral of the leading newspaper and magazine photographers with whom I have cone in contact carry their entire ontfit, inchding tripods. backgrounds, 
Hath, plate-holders. cte. in at small traveling hats. a complete and, oftentimes, very necessary disculise. and this mondel le practically impossible with the larerer sizes uf cameras.

For work in the stulio. Which is a latre part of profitable commercial photography a substantially built cannera is needed, and should be fitted with a staml permitting of erery posible atjustment and ease of control. Spare no expense in this connection and you spatre your disposition in the end, for

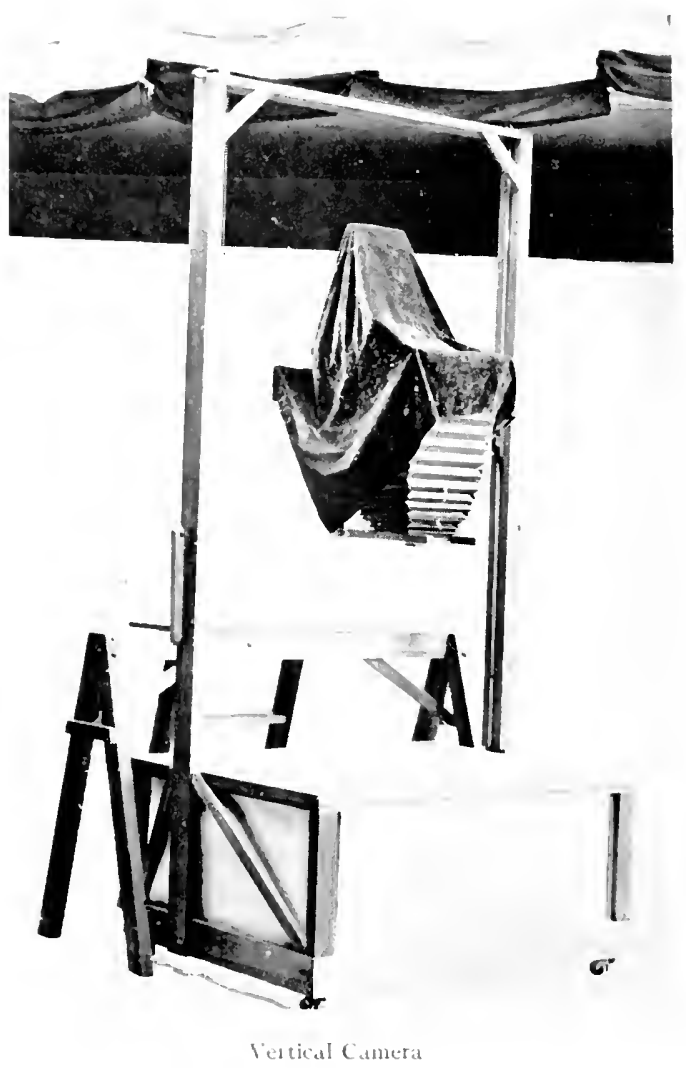

nothing is as amboying. especially when haste is in order, as to have a camera stand fail to work properly and respond quickly.

This camera should be equipeded with horizontal and vertical swings. extremely long bellows, that is, sixty inches at least, and a rising and falling front, although the latter will undoubtedly have to be constructed by a cabinet maker, as such feature is ranely foumd in studio cameras at present on the market.

As to size, while in some studios in the larger cities, especially those doing color separation and large merchandise work, plates are nsed as large as $16 \times 20$. The average man can do very well with an $11 \times 14$. with an arlapter for $8 \times 10$ and holice kits for $10 \times 12$ plates. 


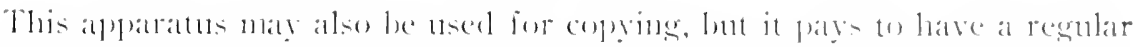

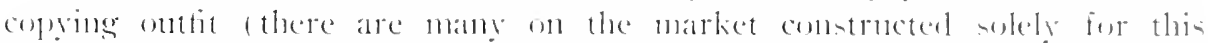

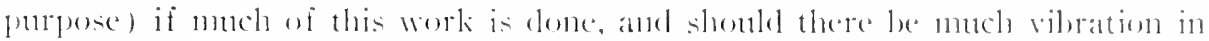
the building in which the stullio is located, it will be fomml very desirable tre

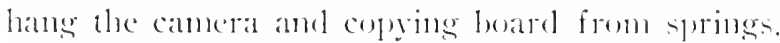

It might he well to state here that copsing, if skilfully and efficiently done,

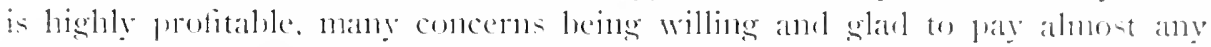
price for good copjes of poor originals, especially in patent and other learl catses.

lle next conte to a piece of apparatus which, I am sorry to say, is not frepuently foumel in commercial studios, although really a necessity, and that is a rertical or upright camera. To my knowledge there is mone mannfactured, and it has to be mirle to order.

In the larger sturlios of cities like New York, Chicago, St. Lonis, etc., which are jobbing, and therefore commercial photographic centers, one finds very elaborate vertical outtits wherein control is had of the plat form in every way from the camera above, but for the average commercial operator the outhit illustrated answers every need satisfactorily, I think. I have used this alphatus with considerable sucess for some time, aml it has many adrantages, among which might lee mentioner the fact that it is cheap and easy to construct.

I rertical camera is practically essential for morlern merchandise work. such as cut-glass, candy, cigars, machine parts, in fact, anything which must be laid out flat, and I know of one of the largest studios in the comntry which makes all copies on such a cansera.

The camera illustrated is equipeded with a $40^{\prime \prime} \mathrm{x} 50^{\prime \prime}$ sround plate glass. and the lower part is enclosed with compo-hoard and fitted with electric bulbs at points designated. the purpose of which will he talien up hy me hater. Iny size view camera may le attached by means of the tripod screw to the cross piece, and the whole is counterbalanced by weights as shown. The groundglass frame is remosable and may be substituted by one of wood for the photographing of heary machine parts not supportable by glass.

\section{TRIPODS}

Tripods for commercial work should be of the strongest and best made types obtainable. Two, at least, are needed for each camera, one of regulation size and the other ought to be at least 12 feet. I take mine to a machinist and have extra heavy screws inserted, as it is most amoying to have one give way at a critical moment. The Folmer \& Schwing Crown tripod gives very satisfactory service.

It is also well to have these tripods equipped with a tilting top, as this is oftentimes reguired when making photographs showing progress in construction and excavation work.

\section{ARTIFICIAL LIGHT}

The matter of artificial light for interiors is one of considerable immortance, and we have the choice of either flash (bag or open) and electric lights. 


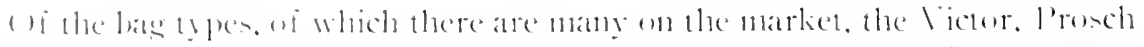

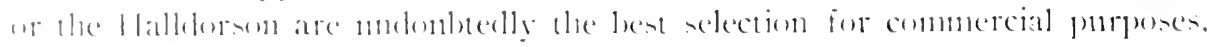

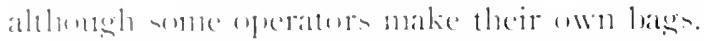

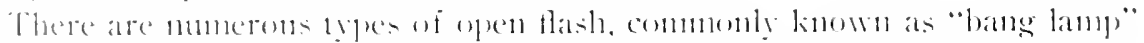

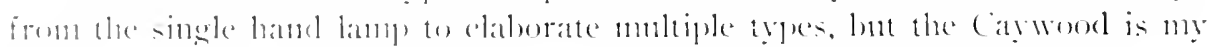
preference from longe experience. I have alwats andided the cap lamps. The calp is nerer fombl when needeel, especially when several operators have aceess

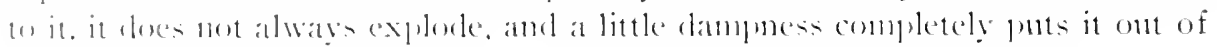
business. While there is rarefy any tromble with the frietion metal type.

In phetegraphing heaty machinery. fommeries, watrehomses, ete, where a

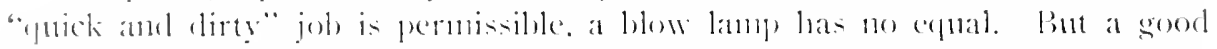
blow lants is a treasure indeed, for I hate never secen one which, with con-

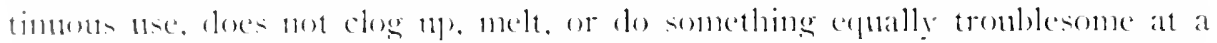
critical moment. The frosech people probably make as good a lamp of this kime as any on the matiet. Many plotograjhers male their own blow lamps. and a litte tije in this comnection is to nse what is lonown as jewelers hard soleler, as it will withstand extreme heat.

Is building snperintendents. fire marshals, etc. are beginuing to strongly

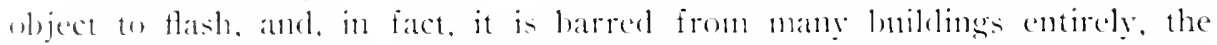
mote moslern methol of photograthing interiors is to use electrie lights.

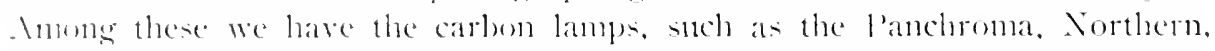
Majestic, Macbeth, and the incandescent tyge, that is. the Mazelat and Nitrogen filled bulls.

The Northern and Fanchroma give a rery strong concentrated light and atre excellent for many jols. such as indoor gromps and general studio work, but they hatse the disthantages, to my mind, of the danger of burning carbons droplying ont, the necessity for excessive current, and the further fact that they are quite heary.

Aly chosec, from many standpoints, therefore lies in the Mazela or Nitrogen tyee. The lamp I have nserl for practically three geass and like very

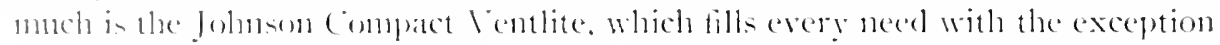
of strong light for speed stuff. These can be attached to practically any light

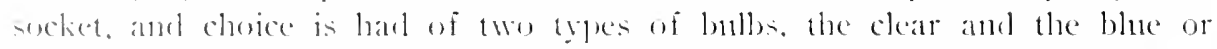

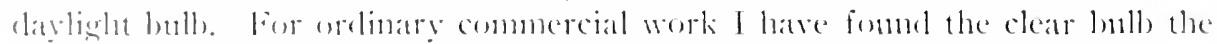

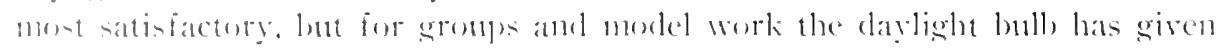

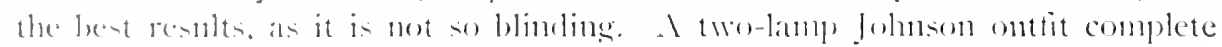

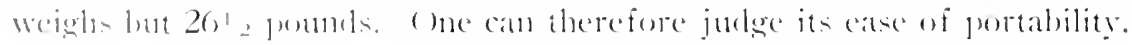




\section{CHAPTER 11}

\section{I.TSES}

I

N discussing this subject, I will take ap only those lensen which have leeen

found most practical in combunercial photograplyy.

lenses nsed in this connection must hatre extrence covering ponter. sood depth of focus and finc definition. Anastignat lenses are, of conres, the best for this purpose, although the rectilinear tyge deses very well in many instances.

If one can stand the expense it is mighty convenient to have a haltery of lenses, hut I wonld rather have a few and know their good and bate gualitics and linits thoroughly than a large number with which I was not entirely familiar. I have so often seen very good lenses lying idle and condenned because the owner dicl not know how to use them. This applies to portrait as well as commercial photographers, and only goes to show that it is not the lens but the "man behind the gun."

For studio work a long focus lens is very necessary, esprecially in photographing furniture, piamos, and the like, and this should be an anastignat if possible, although an anastignat lens of eighteen to twenty or twenty-fourinch focus rums into considerable moner. Nerertheless, it is a good investment. This lens should atso be corrected for color, otherwise it would not wive the proper results when used in connection with ray filters or are lights.

Several of the older shops use some of the old-type lenses, such as the Sutor, Somerville. Dallmeyer Rectilinear, etc., but the only arlwantage I can see in these is that they are cheap, and while they give very good defintion when stopped way down, they have not that crisp defintion of the Goerz Dagor, Cooke Series V. Turner-Reich, or Bansch \& Lomb II-B Tessar, IVollensak lelostigmat and other more modern types.

While there are possibly many other lenses on the nualiet which will do the same work very nicely, I know from experience that those just mentioned are entirely satisfactory.

1 good feature in a studio lens, even though not often used, is that of convertibility, as it is often absolutely necessary to have an extreme long focus lens.

For outside work a medium focus lens, that is, ahout twelve or thirteen inches, two of short focus, one extreme and the other, say, a series IV Bansch \& Lomb Protar, and then a lens of eighteen- to twenty-inch focus is needed. I an not in much favor of convertible lenses for outside work where but a single element is used, as they have to be stopped down so far that they are slow, and barrel or hour-glass effects develop that are anything but pleasing 


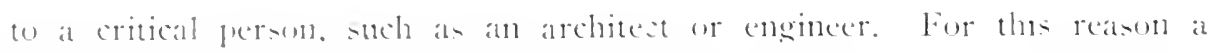
"resular lens" is alvisable if one can afford it.

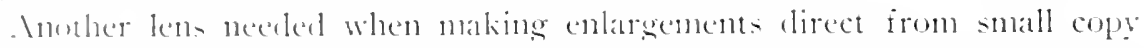
or objects, and one which I have fomml highly satistatory is a moving picture lens of about two- or three-inch foxts used in connection with a long bellums camerat. It gives fine results.

In extrente wite-angle, such as the (iverz llypergon, is a lens for which there is but little tre muless one makes a specialty of photographing large buiklings in congested districts. However, a lens of this tyge or a series $V$ l'rotar necessarily must he nsed in comnection with a skstraper camera, for the reason that the lens is often above or below the center of the plate and therefore hats to cut more than the size of the plate.

In photographing interiors a wide-angle lens should never be nsed unless the quarters are very cramperl, as the result is far from pleasing to a customer. although be may not know the reason. It is better to nse two or more plates.

It has been found that some of the better classes of anastigmat types make very gond wide-angle lenses when. for instance, a $5 x T$ is used on an \& $\times 10$ or an \& $\times 10$ on an $11 \times 1+$ plate. In this connection it is well to know that a 12-inch lens may be used rery satisfactorily on a $12 \times 20$ plate. 1 have makle many banquets with 12 × 20 plates. using a 12-inch Goerz Dagor lens. There is of course. some distortion at the edge of the plate. lout the general eftect is gouml.

1 lens of soft focus is rery nice to have on hand, as every now and then one connes unto a customer, such as an advertising concern, who does not like the old sharp stuff, whereas a pieture made with a soft focus lens just appeals to his artistic senses. Is a lens of this type is not always available, this little tip maty not come amiss: a small piece of black marquisette veiling. tied over the front of the lens, gives a very good imitation.

In commercial studios. Where different sizes of lenses are used, ranging from the small wile-angle to the large long focms types, it is somewhat of a task to keep track of the different front boards and lens flanges to fit varions camerats. The following are two good systems which are nied in two large sturlius with stecess.

The better sistem, to my mind, is to have a master flange attached to the front loard of each camera, both indoor and ontroor, this master flange being really the flange of the largest lens used. The other lenses are then fitted with a permanent flange or metal collar which will serew into the master flange. In this way there is a master flange in each eancra at all times, and ang lens in the shope, in view of its permanent flange collar. will fit any camera. The cost of installing this system is nominal, and any nachine shop can do the necessary work.

The other method is to attach permanenty a wooden fromt board to each lens, this smaller front board being of a size to fit into what might be termed the master front hoard of each camera. In this, as in the above case, the lenses are always reatly for any camera withont an! delay. 


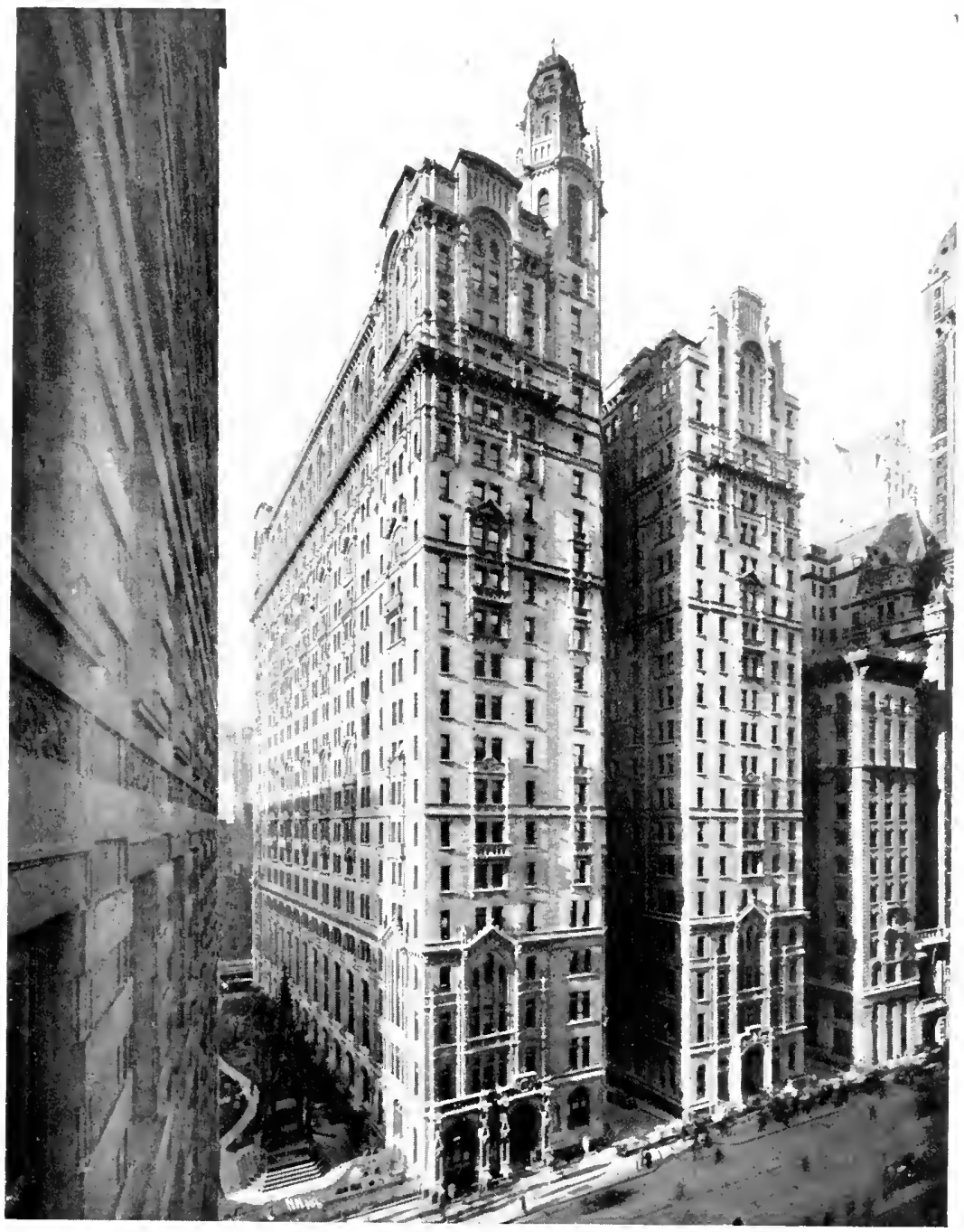

TRINITY BUILDING, NEW YORK 


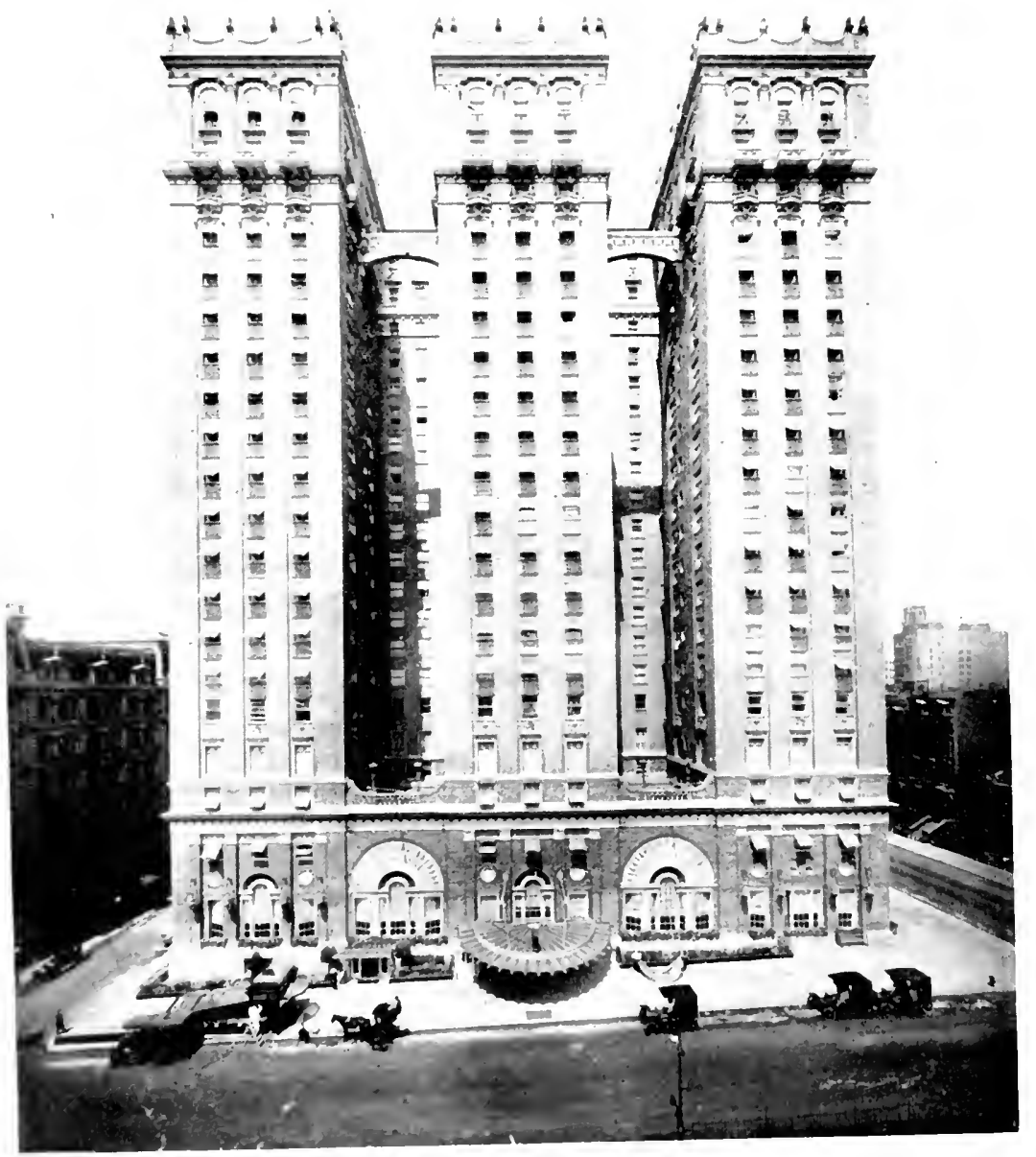

IIOTEL, VINDERBILT, NEW YORK 


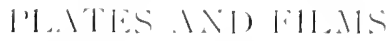

A

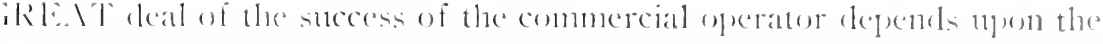

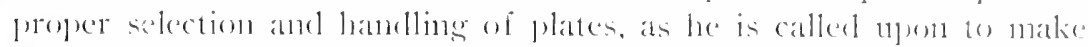
pictures in all sorts of places and mlany tindes hats no previons hnowlerlge of what he is going up against.

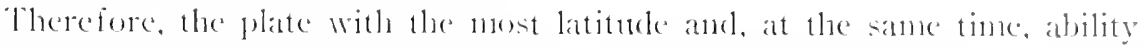
to give snayly lighlolights. with detatil in the shatows and with the least manipulation in the dark-room, is the plate to select.

such plate should be of the non-halation or double-coated type, such as the Seed or Craner Non-llalation. Hanmer furora and the stanclarel ()rthonon.

It will he foumel that the plates mostly used by the portrait photographer. that is, fast, single coated, and many tines thin emulsion withont orthochromatic properties. are not suitable for the general run of commercial work for several reasons, the chief of which is that they do not possess enough latitude for the arerage interior, exterior, or set-up work.

Of comrse. these latter plates are very good for some stuclio work where live models are used, and occasionally there will be a demand for a plate like the Stanley Commercial in cases where there is no possibility of halation, this also being single coated.

Within the past few years rapid stricles have been made in the enulsions for cut film, and for the past year I have made practically everything on film, with the exception of color work, and do not think I conld ever consider going back to the employment of plates exchusively.

Filns are much lighter in weight, easier to store and handle and very convenient for mailing. as loss due to breakige is eliminated. They possess good non-halation qualities and, last but not least, they are not as expensive as double coated plates-quite an item in a year's time.

While considerable objection has been raised to the use of films ly many commercial photographers, who claim that they are difficult to block, strip and insert titles, etc., it is quite easy to change methods to accommodate films, and their advantages more than compensate for the adcled trouble.

I might state here that, though good non-halation qualitics are possessed by films and many double-coated plates, especially those double-coated plates which have for their under coating a slow enulsion, they require the exercise of intelligence, as well as careful handling.

For outside work no better selection can be made than a film or nonhalation plate, because buildings and trees, outlined against the sky are a 
source of comsilerable hatation. Where photographs are mate from the

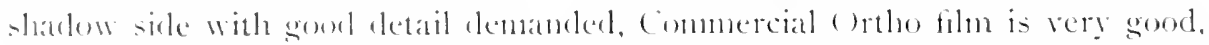
although it is a lithe slower than the l'ortrat filu, but hats more borly. The

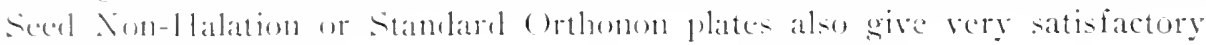
resules alonge this line.

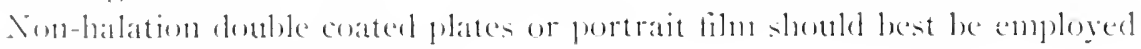
wh the photographing of interiors.

()fentines, when including life in an interior photugrath, that is, clerte at their desks, workmen at their henches, ete. and posibly toward direct light, where at very short expesture of, sils, 10 to 20 seconds is necessirs, one will need bratex plater to give the desired increased speed.

for furniture. stoves, pianos, and general merchandise work there is mothing much better than the standard orthomon or other double coated plate and (ommercial and (immercial () rthe films.

for copies the selection of the best plate or film depends upon the effect

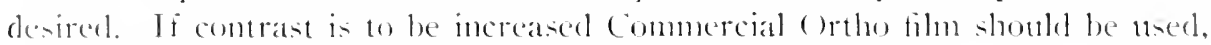
While if lese contrast is wanted portratit film will do the work.

When a prosess or other plate is used for line copies, to give the best restets, that is, do away with hatation, it should be backed. The process film now on the matiet is rery satisfactory for line copjes-in fact, it is better than the arerage process plate in view of the resultant absence of pin holes and other amosing defects.

For speed work ontsite one needs the Seed Giratlex, Lumiere signa or Hammer Red label. However, alhough very fast, the Lumiere sigma is a very difficult plate for many workmen to handle, becanse the grain is coarse amel it tends toward extreme contrast. Nlso, the emulsion is easily frilled.

For all colored subjects, especially those containing reds and greens, the IV ratten l'anchromatic or the (ramer spectrum are very necestary to good Irentilis.

I find many photographers, including some commercial men, are timial alout using these plates. l'ossibly they awve them a half-hearted trial and catst them asile, or have been told that they were hard to work. Color plates have male a wonderful progress in the past two years. and if you had anything against them, sive them another trial.

I will also say right here that, if conditions arose whereby I had to confunc myadi to one plate for all my work, the Wratten l'anchromatic would be my choice, an I consider it the best all-round plate on the market today, although at trifle higher in price. It is a single-coated plate with very thin emulsion, has a wide exposure and development latitude, fixes and dries rapidly, is backed and is all-color sensitive. It lends itself rery quickly to plate manipulations, that is, intensification and reduction, both mechanically and with chemicals, and is a very clean workings plate.

I may seem a litte over-enthusiastic about this plate, but I am quite sure the same opinion is shared by many other workmen, and is formed from consiterable experience. 


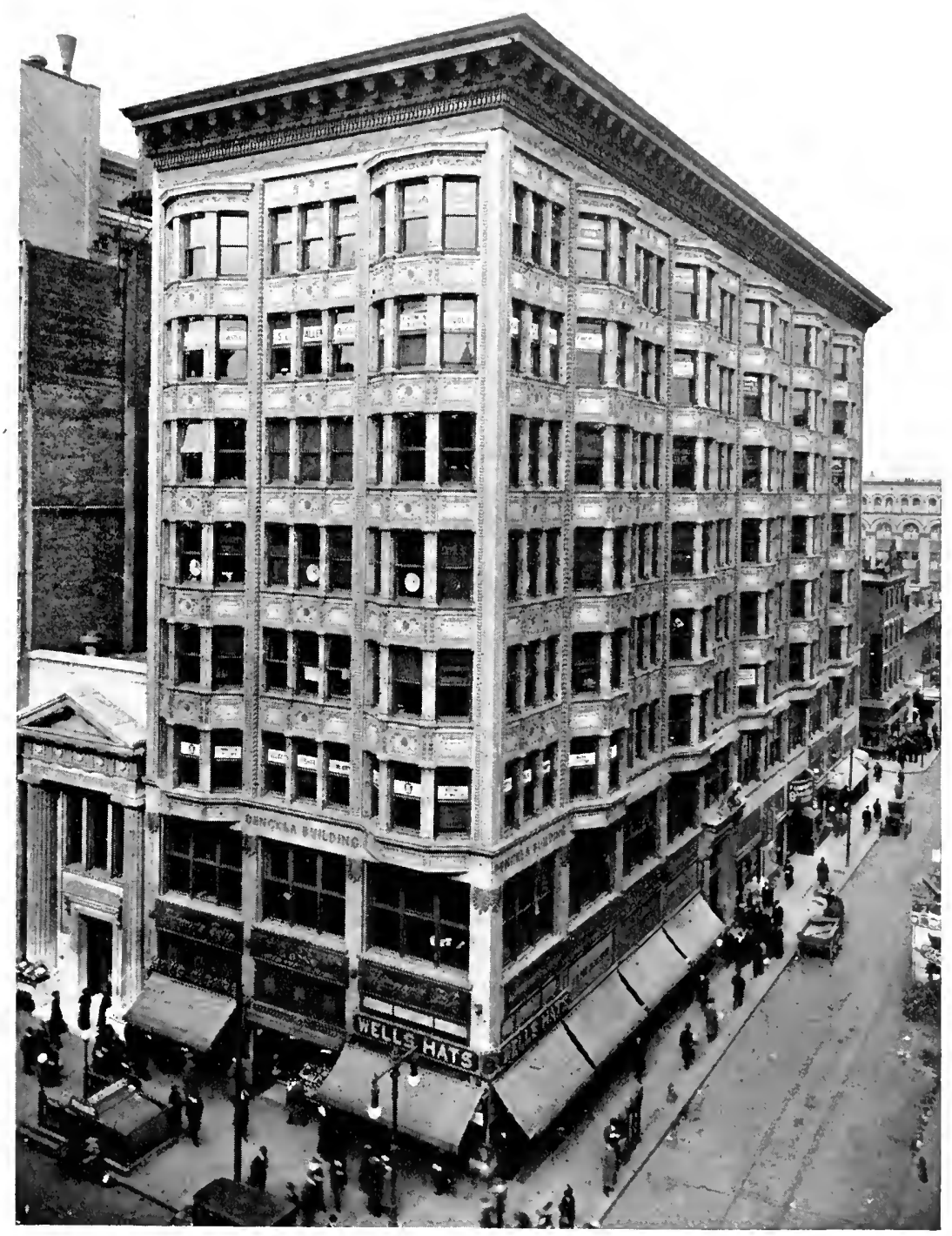

No. 6 Goerz Dagor, $8 \times 10$ lens on $11 \times 14$ plate. Exposure, $f 16 ; 1-5 t 1$ second. John Fitz, Jr., Philadelphia 


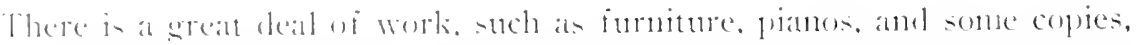
that will need a bellow filter-that is gellow eorrection. For these, you will

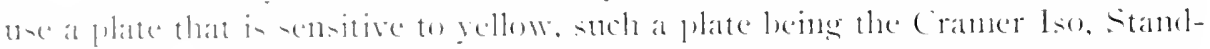

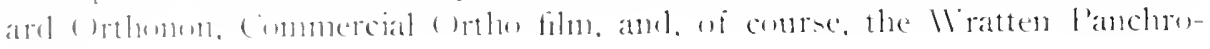
matic:

For Hablight and blow-lann work, to obtain the best ceffect, the plate shombl le at least a litnle semsitive to gellow. and possess all possible speed.

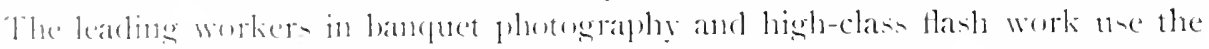

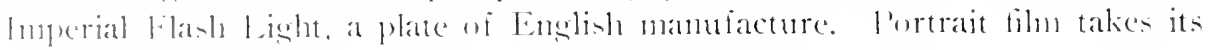
phace rery well.

Tow much stress cammet be placed on the benefits to be olstaned by backine the ordinary phate, even thomgh domble-coated. While it may seem a great deal of extra work to do this. I can assure you that it pays and you will find that mane of the keading operators hack all their plates or nse films. I negative mate on a backed plate has nuch more crispuess and brilliancy than an unbracked nexative.

There are many backing formulas. but the one I use and like as well as any, ancl one which is quickly and casty put on, is ordinary opaque. The best way is to apply it to the slass sile of a plate with a wide brush and then place it in a drying-box mutil thoronghly dry before inserting in the plate-holder. If in a hurry, though. just slip a black piece of paper over the wet opaque. smonth it lown and insert in the plate-holker. This latter method may be at little hard on the plate-holklers, which makes the drying-box plan preferable.

ln a clapter on dark-room work, I will go into more extended detail as to the handling of various plates to produce the best results.

In the matter of flates and films, as in lenses, it seems to me far preferable to have two or three varieties that one knows thoronghly than a large asortment with which one is not entirely familiar. Every make of plates has its peculiarities which can be nsed to one's own advantage in work of various kincls, and it is better to know your plates and fihns well than to work in a hitand-misis fashion.

I have foumd that I can obtain much better results by using as slow a plate as a particular piece of work will stand. In this way. one has more latitude and it is cleance working.

It is surprising how sood some of the old-timers used to get their negatives on a very slow plate. I hat the privilege, a few years ago, of looking over the Bratl. Collection in the War Department at Vatsington, which was male in Civil llar tines, and was very much astonished at the wonderful results he oldatined with that slowest possible type of plate-the wet plate. The work that was done on the first dry plates, twenty-five to thirty years ago, was atso remarkable, so one can but come to the conchusion that it is not so much the plate as a knowledge of how to work with what you have. The phofugraphers of years ago had but little choice and they learned to make the most of it. 


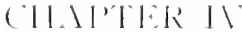

\section{ENTKR丨}

$\mathrm{M}$

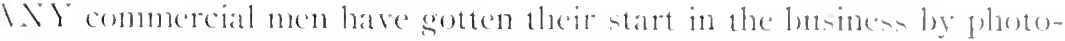
graphing exteriors and gratually working into onther lines. (one of the princigal reasons for this is undonbtedly due to the fiact that it

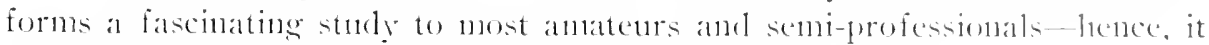
is probably more generally followed than any obler branch.

furthernore, it is exceedingly profitable when one las for his patrons high-class architects, decorators, or wealthy owners of beatutiful homes and surroundings.

Unlike other lines, in exterior work. the principal factor is time of clay, for a subject may be so photographerl as to look entirely difierent under different conditions of light, and the changes caused thereby form a very interesting study.

As most photographers, whether portrait or commercial, are fairly well acquainted with exterior work, it is hardly necessary to go into minute details as to general procedure other than to touch upon a few points.

In deciling upon the point of riew, from which to photograph any building, it is usually best to select that including part at least of the side, and either a non-halation plate. Tortrait or Commercial Ortho film is a good selection for this work. The exposure will vary according to the time of day and year, and weather conditions-one second, stopped $f 6 t$, is a fair average.

With reference to hones and gardens, this class of work brings one into contact with a class of people who appreciate the really nice things of life. and to whom price is not of much consideration. It is a subject about which volumes could be written, and the best method I know (and a source from which more information can be obtained than any other) is to consult the books and magazines to be found in any public library on homes and garlens. The customer usually knows just what he or she wants, however, and the photographer can be guided to a great extent by the instructions and by his own common and speculative sense.

Architectural photography is greatly in demand in the larger cities, and. in fact, there are a large number of specialists in this line in places such as Chicago, New York, Boston, etc.

An architect is principally interested in a picture of the whole building and details such as friezes, entrances, columms, fircplaces, doorways, mantels. ceilings and stairways.

If you have never done any of this kind of work, it would be well to consult the large files of prints which most architects have on hand. and which will give you the best illea of what they demand. However, the most im- 
purtant point in to give then exactly what they repuest, no matter how foolisin it may secm. But les sure you linow just what that is. for they are often more particulaty interested in some one little detail. I have in mind now a customere for whom I went to a great deal of troulste to obtatin the photograph of a clock ower a doomaty. I then found it was not the clock he really wanted. althum he specified that at the time-it was the eagle on top of the clock.

In the matter of a lens. the longer its focus, the more you are liable to please, for. as a general rule, they will tolerate no distortion.

Comstruction photographs are used a great deal both for records and for advertising and promotion purposes. What it repuires really is a good lens that will give critical definition, because detail more than anthing else is what is wanted. Complete instructions as to size of prints, titles, etc., are nsually furmished ly the construction companies. ats well as specific instructions as to time of day" (these photographs are generally mate on the same day each week or montly and point of view, so that the work can be handled very nicely by the arerage commerial man, and is rather protitable.

llowever. should the selection of point of view be left to the photographer. the view sould be one from which he can include the whole building, say one

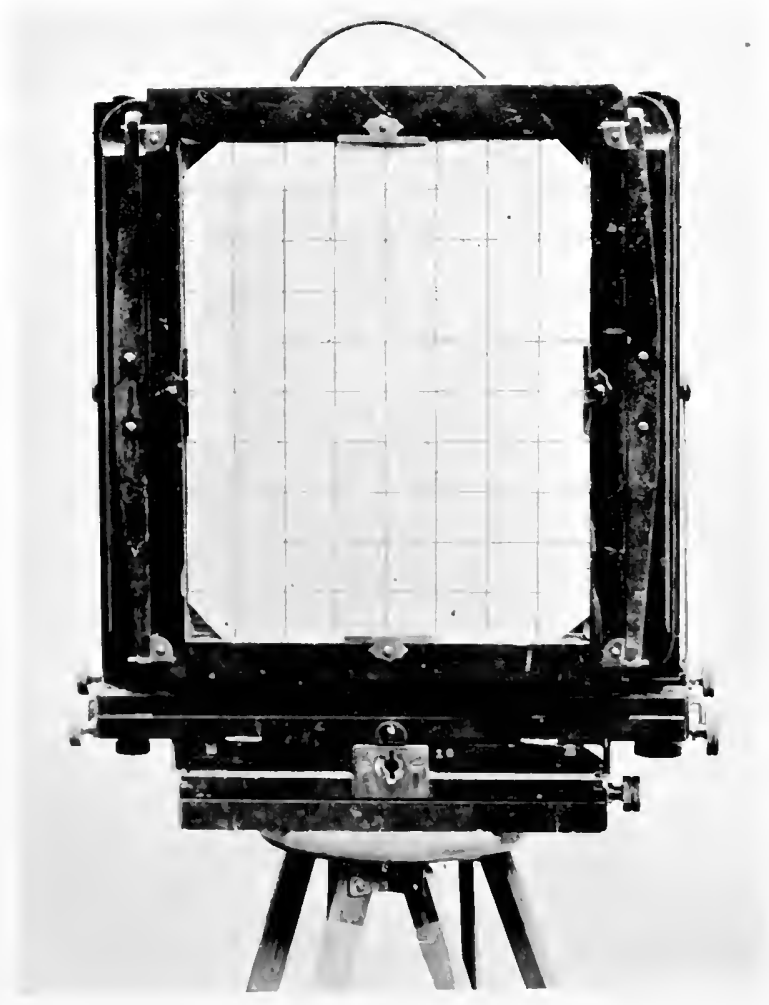

Fig. 5 


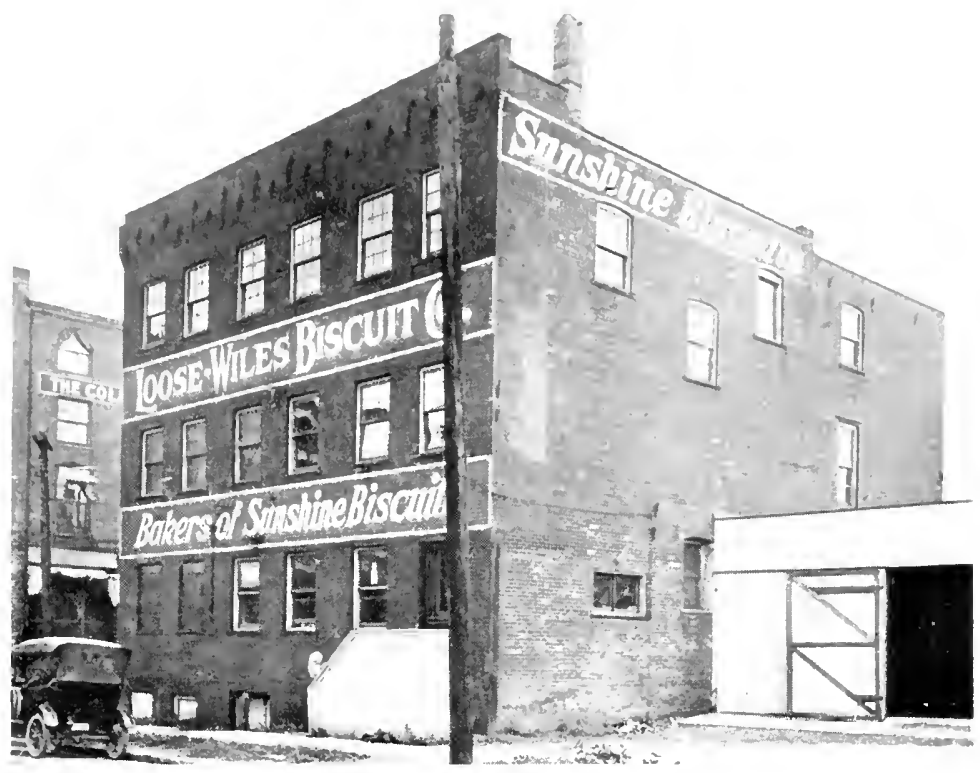

Fig. 6.1

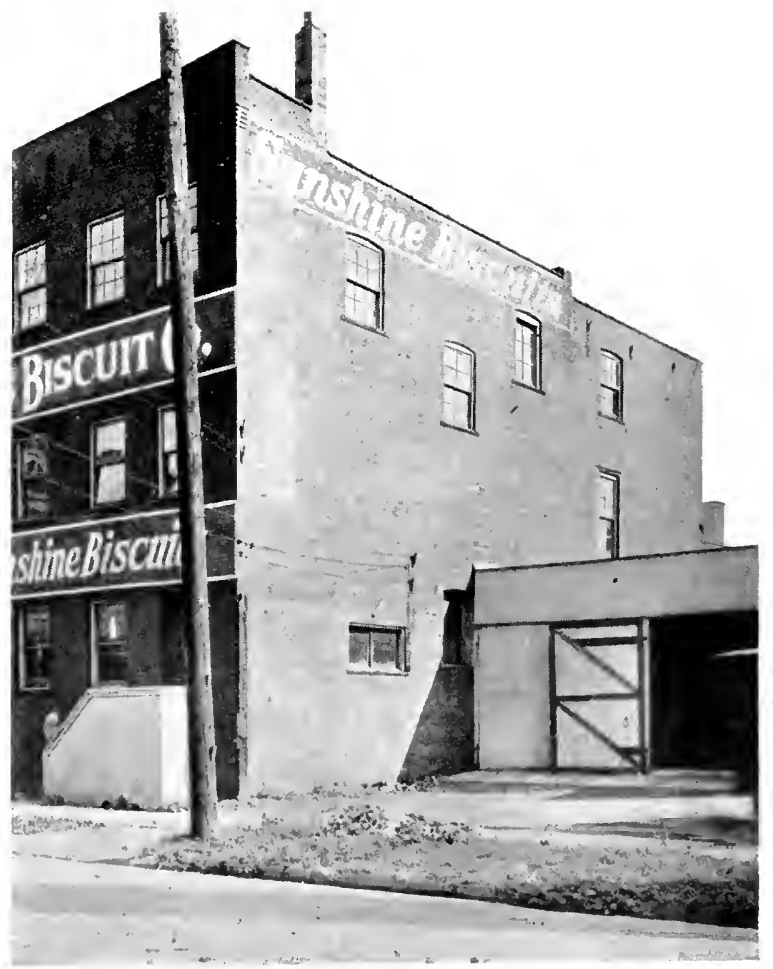

Fig. $6 \mathrm{~B}$ 


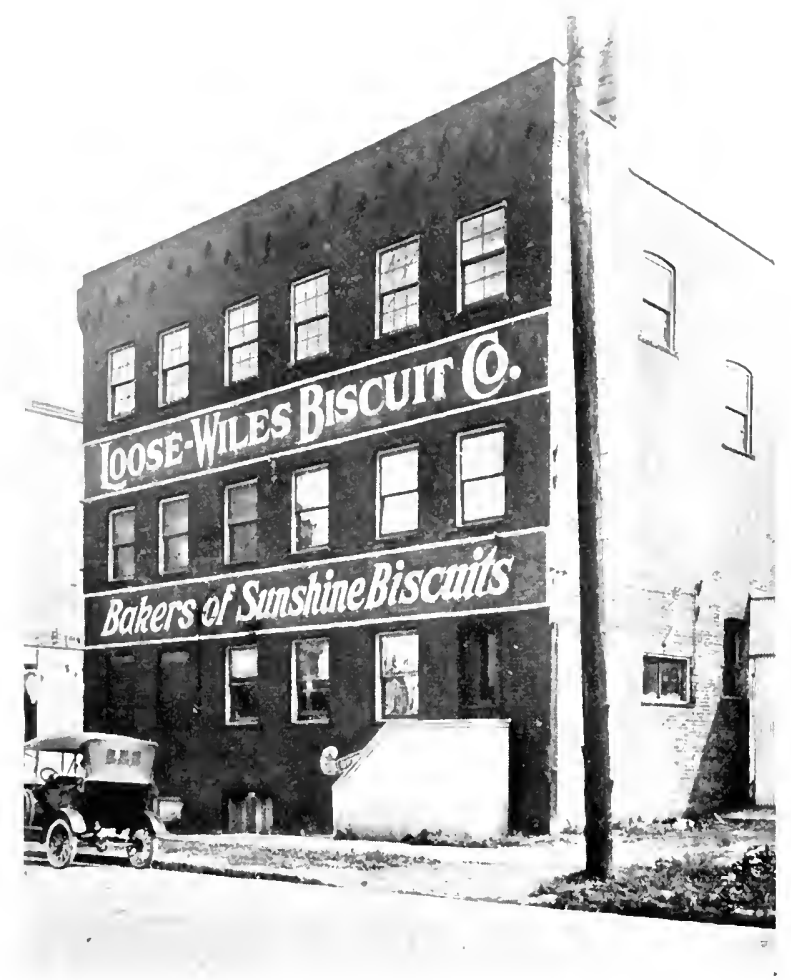

Fig. $6 \mathrm{C}$

uf ten stories, from the tine the fometation is started mutil the huibding is completerl. (therwise, it may be necessary to use a lens latter on that witl destroy the effect desired.

In making photographs where distant views of hills, trees, buildings or harbors. ete., are included, as well as in construction work, it will be found that the use of a ray filter, for instance, the $K-2$ or $C$, is a wonderful help when used in conjunction with yellow-sensitive plates or filus, as it cuts ont the lihe haze, thereby giving better distance, and also a much better general color value.

Another great help in ontrloor, as well as incloor photography, is to have the erromul-grass ruled as shown in illustration Number 5. This enables you to line up gour cancrat quickly, and where the lines of gour picture must be absolutely correct, gives gon a sure means of checking np rourself without atuy loss of time.

There are also a few tricks, or stunts one might call them, that can be worked to atrantage and generally will distinguish a clever from an arerage (נ)八erater.

In photographing haildings, especially in the manufacturing and jobbing districts. there are oftentimes objectional lamps or telegraph posts or signs, etc., in direct line of view. which the customer would like eliminated. Of 
course, this can be done by ant work, that is, retouching on the photongraph.

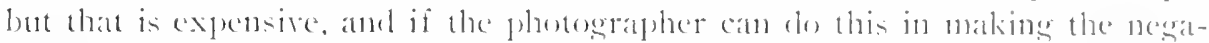
tises, it not only puts a feather in his cat), gives him leverage to charge betect prices, but makes himself "solicl" with his customese.

In illustration Number 6. the large telegraph polde obstructs the view objecetionably. To eliminate that post. two neagtives have been mate, one tor the right and the other to the left of the pole, about fiftecn feet alstet. The two photograples hate been joined together and copical and the result is really mystifying to the arerage customer. While an old and simple stunt, it is one well to be remembereal.

Number 7 is the photograth of a hotel on a bus downtown corner, with street cars, antomobiles and pedestrians constantly passing. It had to be mate at noon for the right light, and to get out of the range of the traffic, I workerl from the corner room on the third floor of a buileling on the diagonally opuosite comer. It was necessary to make it in two negatives (prints joined on the corner of the hotel building) and these were made from two windows facing different streets about fifteen feet apart. The result was very satisfactory.

It will also be noted that while this picture was mate at a busy time, all life was eliminated, and this was accomplished by closing down the diaphragm of the lens (an \& $\times 10$ Series IV Bausch \& Lomb l'rotar) to the limit, which brought the exposure up to about one minute for each plate. This is a very

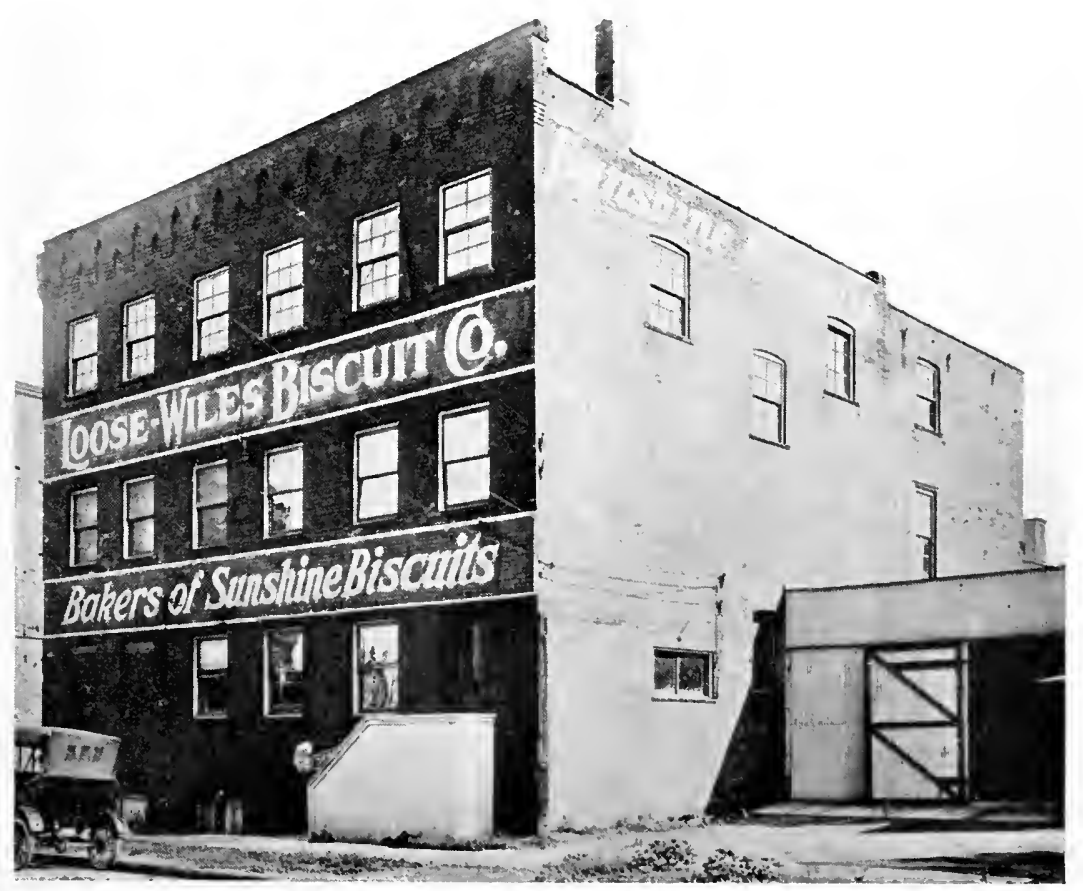

The Complete Photograpl. Fig. $6 \mathrm{D}$ 
sour thing to keep in mind. especially when it is desirable to eliminate all life irom a photogratill.

(ne thing well to be remembered in receiving orelers to do ang particular

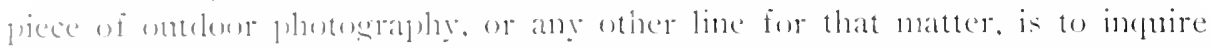
the purpore for which the photoswaph is to be need and just what they want.

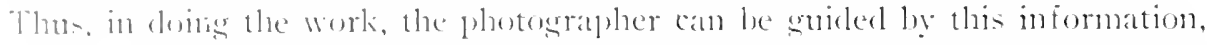
is an atrchiteat may recpure one style of pictmes an owner another, the promoter still another, and, in the case of a home, the wife maty have her own inleats which she wathts carried ont.

It will also be found, especially where the customer is not a frequent user of photographs, that his eonecotion of what the awerage photograph will take in is often rivliculous. and that he expects the operator to take in all he sees, despite the fact that he moves his eyes aromel in taking in the view himself.

It is often the case that one will tind an ormamental lamp post, tree hox, or the like, directly in front of a bulding, and a direct front view is wanted. It maty also be impratetical to make it in two negatives. in which event, the following diacram mal he of help in evaling some sinilar objectionable feature.

1. in Fing. \& represents the store, li the lamp post and $\mathrm{C}$ the camera. The

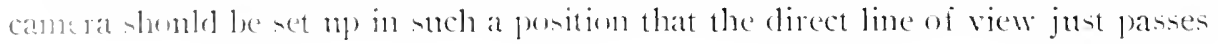

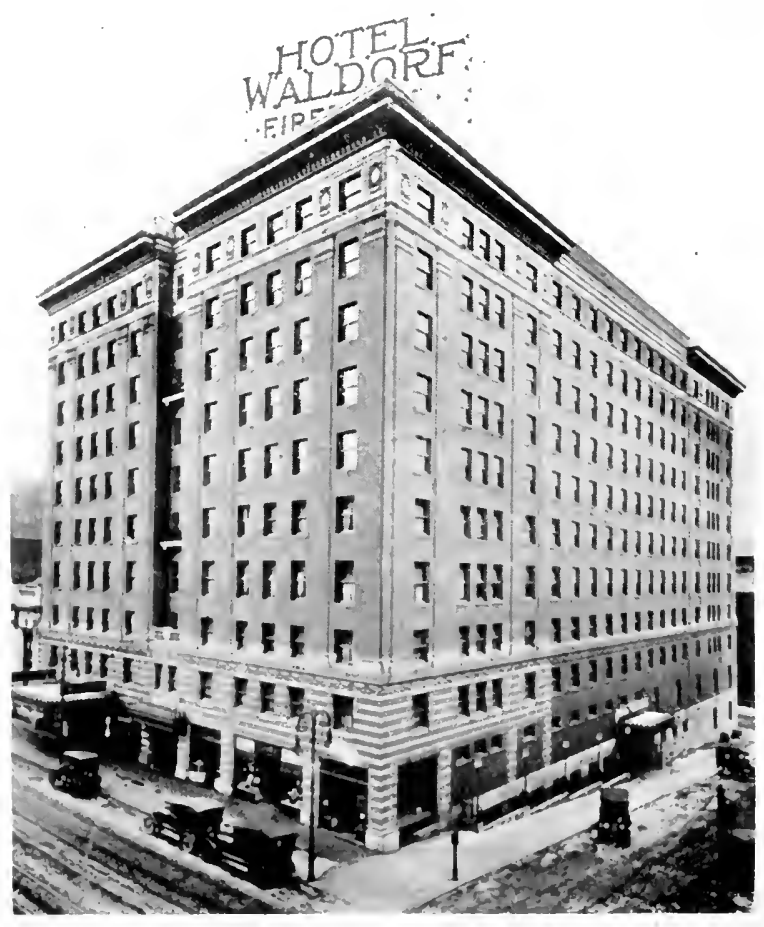


the obstruction and includes the entire frout of the store building a be photegrapherl.

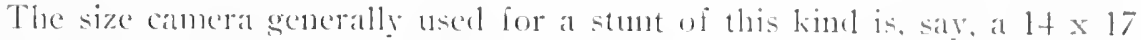
with a $5 \times 7$ or $8 \times 10$ plate in a special cardbord kit placed at a point where the inlage of the store front strikes the gromul-glass. I comparatively short focus lens shoukl be used, which will give the necessary wide-angle effect, and it should be stopped way down so as to insure its covering the plate inserted.

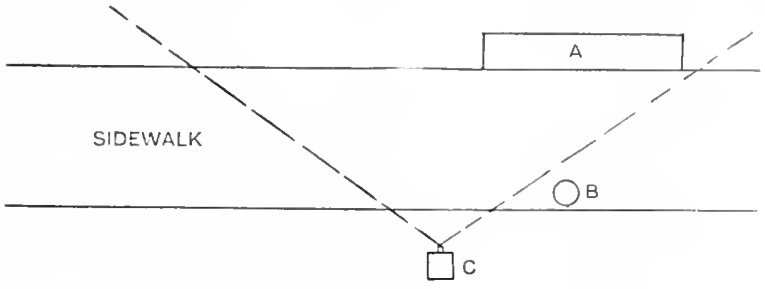

STAEET

Fig. 8

The resultant negative will show a straight front view of the building and can be enlarged to the size resired by the customer. In other words, make a wideangle view of the section of store buildings, including the store, photograph of which is wanted, and enlarge the small image thus obtained.

In this comnection, it is often the case that a very nice little order for panorantas can be worked up to the financial advantage of the photographer, and the ultimate satisfaction of the customer, if the matter is handled tactfully.

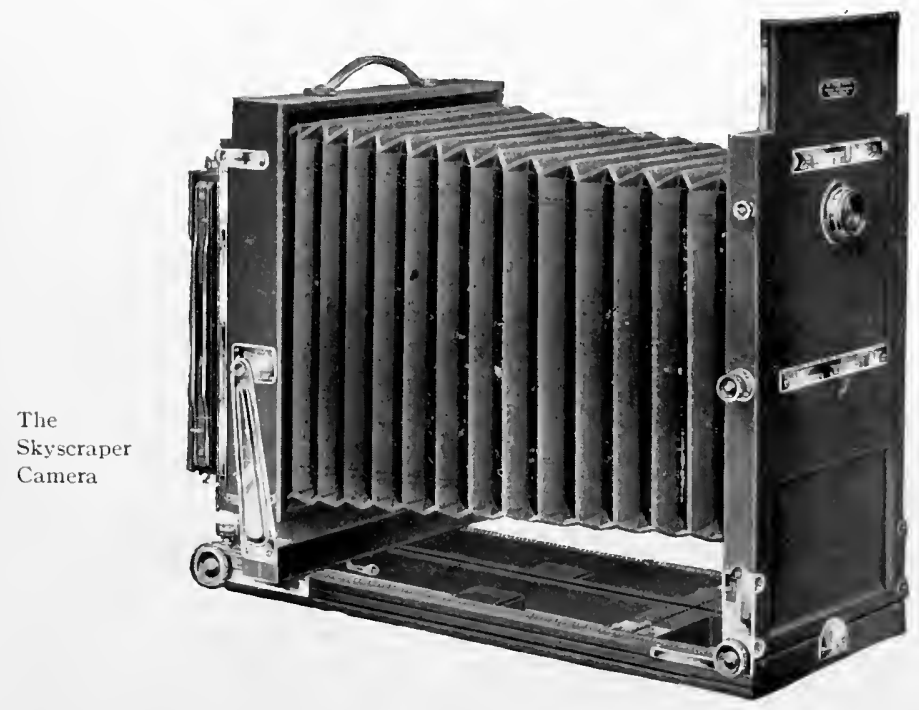




\title{
(11.11\%1\%!
}

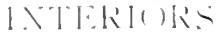

W

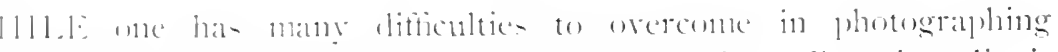
interiors, it is a branch that is as a general rule, wedl payng. dignified and, an the sante tinne, extremely interesting.

beving clesely inlentiticel with exterior work, the photographer will have fratcically the sanke customers for interiors: that is the promoter, arehitect.

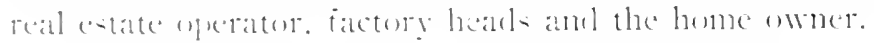

In the cance of the promenter or factory head, he will want to show as much

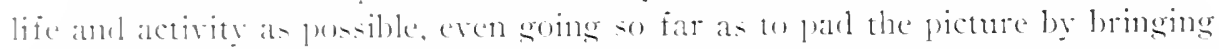
mure fixtures and life from other departments. The architect will want absolutely ne, listortion (which elininates the wide-angle lens). and the real estate man w wher wi a bulling will want to show how light and ary and commonlinus the property maty he and in practically every instance, the photographer will have the frollem of halation confronting him.

I labation, as many photographers know to their sorrow has lestroyed the aldearance of some of the hest of negatives. In combating halation, doublecoated plates help, as do alos films or a backed plate. It is often the ease that at leveloper with a very weak pereentage of carbonate will help, hut this has the disiklyantage of taking a long time to develop. Nlso, it repuires from three to fom or five times more exposme than normal, which means that it is practically imposible to inclute any life-and, when you get through, yon have a Hat, lifeles neartive, which may posibly take the whole printing force to turn cut a crosel salable print. Such a method would be strictly taboo in a large -tulio where time and overheat expense are important factors.

The only really successul way I know of to satisfactorily eliminate halation is to balance vour light. What is meant by that is this: if you are facing -trong light, use a strong, artificial light against it from your camera side. Of contse. this can be werelone, lut, if one is careful and a backed plate or film is unele no applarent hatation will be fomml.

The lensth of exposure will also be fommel a matter of considerable importance in avoling hatation. and if sufficient exposure is given to permit of rapid fevelopment in the dark-foom, less hatation will alpear.

Hewerer, in many of the better class lumes ome will find the lighting conflitions of be very smblued normally. the efiect of which will have to be preserved in the fintshed photessaph, and for this reason, the operator will have (1) he very careful in his use of strong artificial lights. or the result will be mmatural, and therefore not pleasing to the customer, even though he might le unaware of the canse. In such cases. just enongh artificial light should be need to prick up the detail in the shadows. 


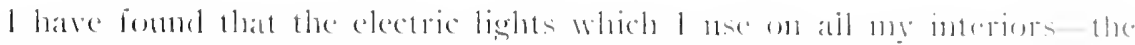

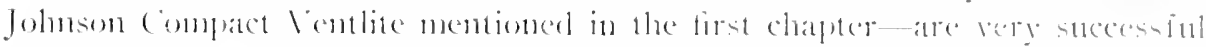

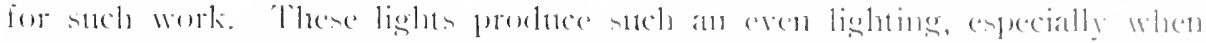

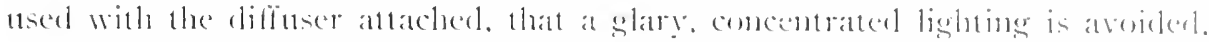

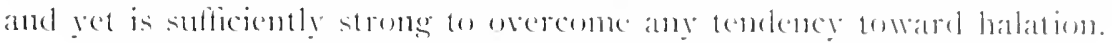

There are several other methods which maty le followed when whelous

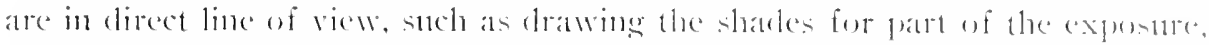
or litting collapsible opatple sereens, which are calried log some operaters, into the windows, but I have foumd that wsing electric lights to balanes the light produces much better results.

I have forme these lights also a great hely whan facing the light in the photographing of offices. In this latter connection. when life is inclunled in the picture, it is well to get as much action in close to the camera as possible, and a compratatively fast plate. stch as a ciraflex, will he found the most sattisfatetory to 11 se.

In factories where men are shown at their work, a blow-lanup or other

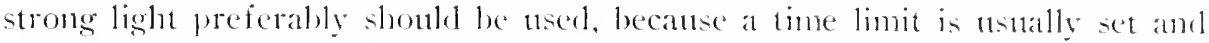
it is a bat policy to keep men away from their work long, as the discipline of the shop is easily moset. Therefore, the sooner one can get throwsh, the better,

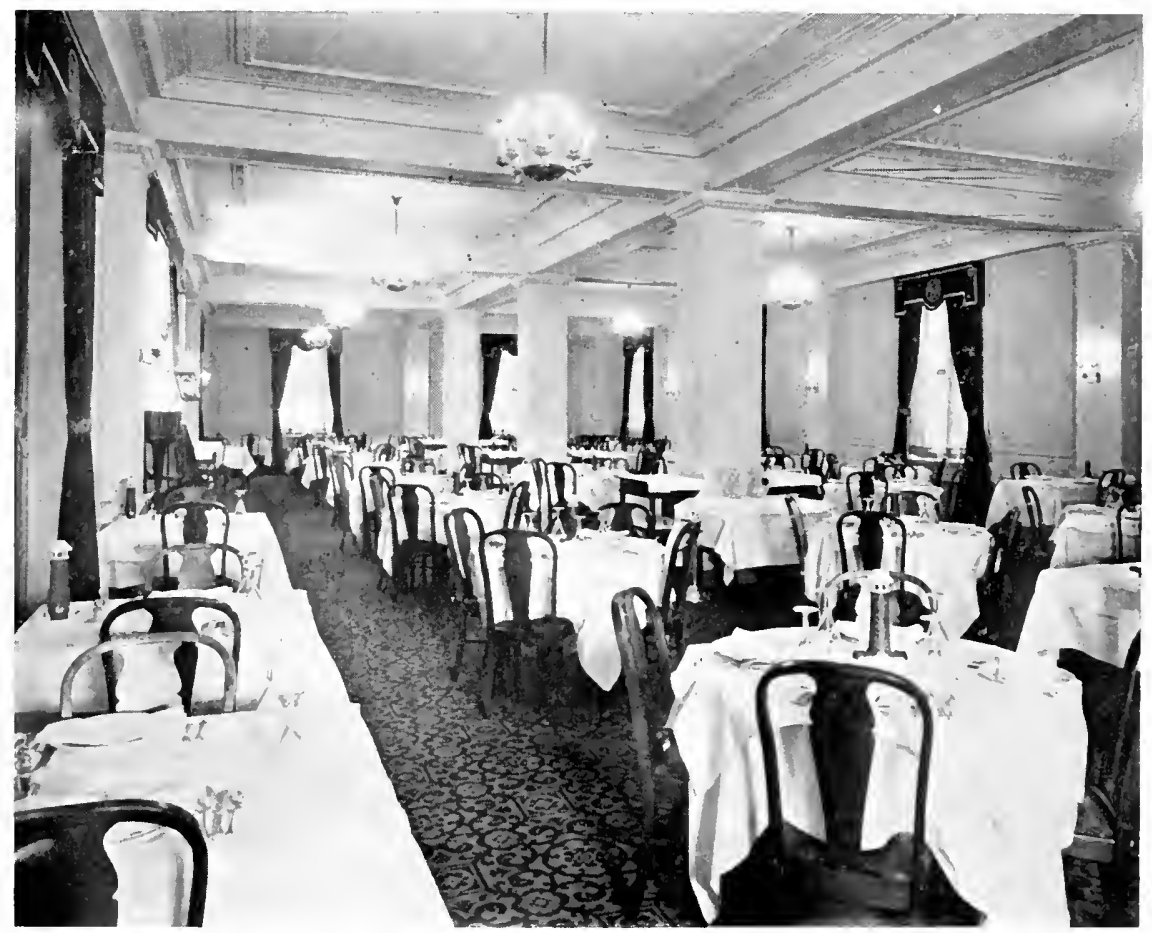

10 Mlinutes' Exposure, $f 32$.

Fig. 9 

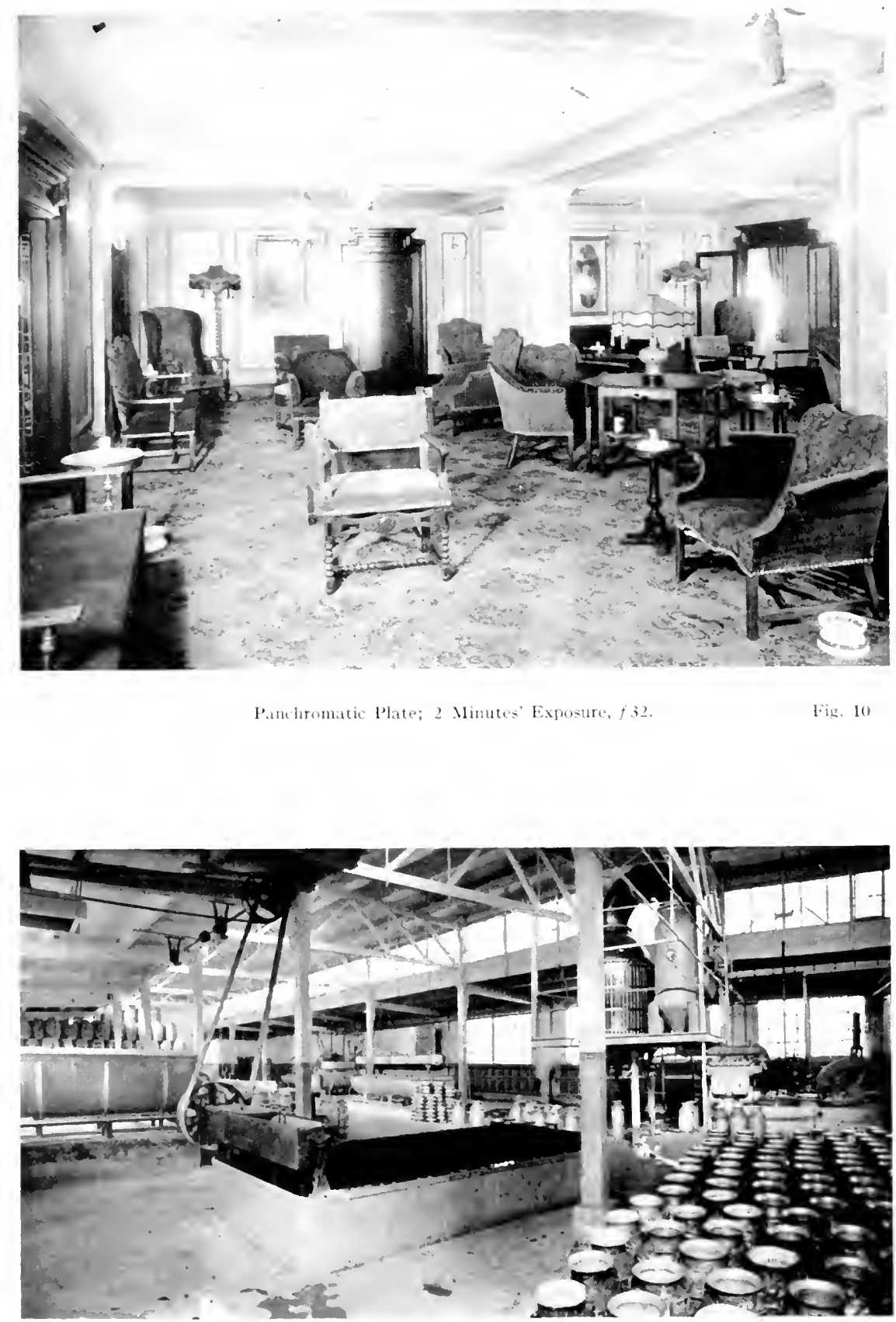


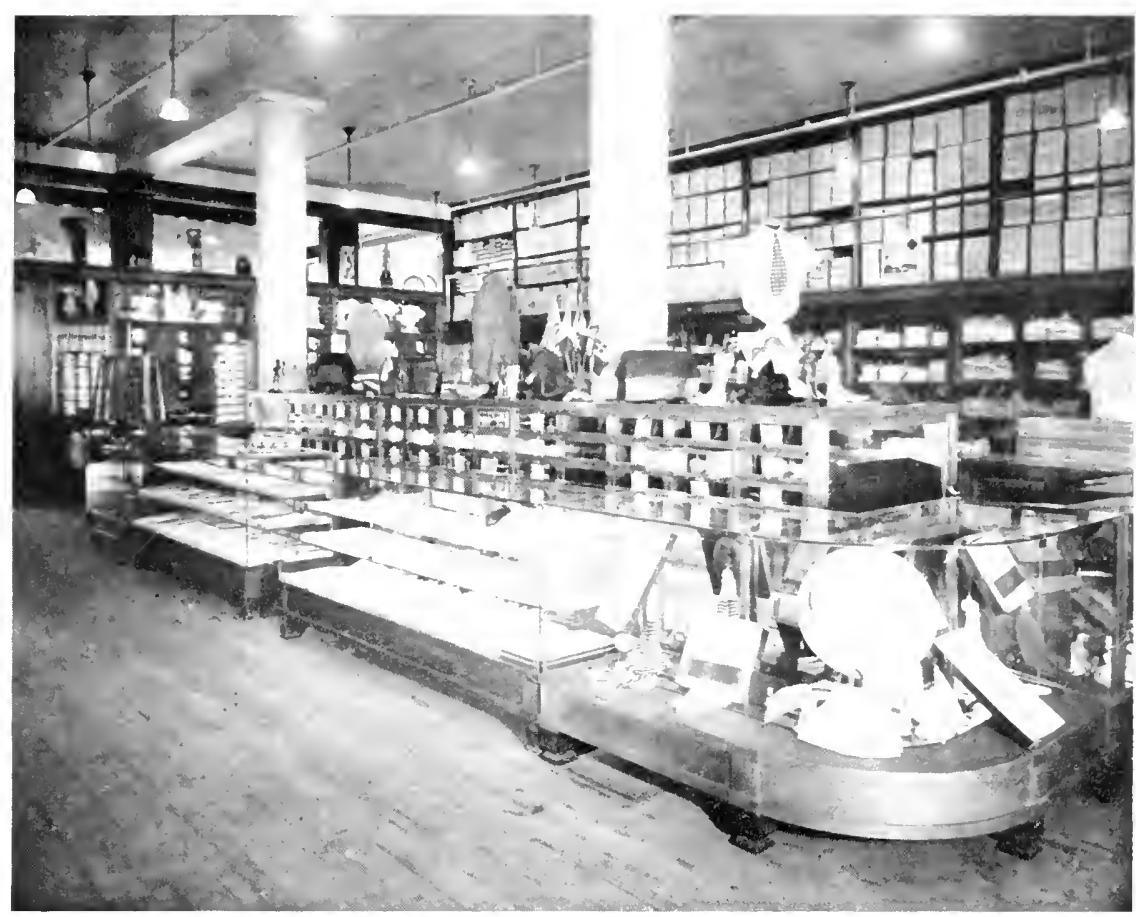

B. A 1. Series IV; Backed Standard Orthonon Plate;

Fig. 12

3 Minutes' Exposure, $f 32$.

and as smoke is generally of no consideration, the blow-lamp or flash are not objectionable.

A little point here may be of interest. If you are using a blow-lamp to make a picture with people included, it is best to start the lamp, that is, to blow the lamp before you take the cap off your camera or open the shutter. When the flash first starts, one is naturally inclined to jump a little, and starting the flare before opening up the lens accustoms the workmen to the strong light.

If it is necessary to make an open flash in a windy place, I cover my Hash pan, after loaling. with tissue paper, which prevents the powder from escaping. and does not interfere with the flash when it explorles.

When including life in a home picture, and smoke is particularly objectionable and electric lights possibly impractical, a good flash machine comes in handy, that is, such a machine as the Halldorson, or similar outfits whereby smoke is eliminated and perfect control of the light is had.

In photographing long corridors, which are nearly always dark at the far end and may have a spotted illumination, a succession of small flashes along the line, concealed from the camera itself, by working in doorways and behind columns, is a very nice way to get these. Electric lights may also be used to advantage by placing them behind the columns or in the doorways for short spaces of time during the exposure. 


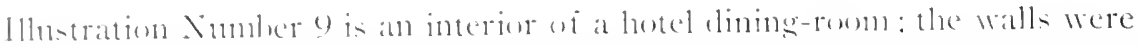

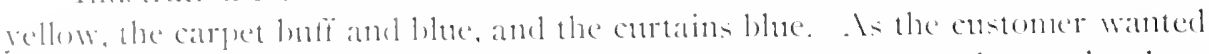
the color values preserved, the expesure was made on a panchromatic plate, meing daylight combing in at the windews, which was balanced up to avoid halatinn with two electric lanpe with diffusers attached. stationed on the camera

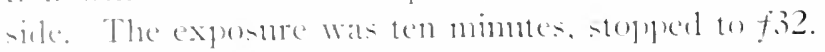

Nimbler 10 was matde alumost entirely with electric lantps. which were net mosed huring the expenture, and which gave the heary shatows under the chatre. This was made on a panchromatic plate: the time was two mimutes. stopled 41,32 .

Number 11 is the interior view of a milk condensory, which shows the effect of comblating strong light and at the same time eretting good detalil all bromgh the pieture. The exposure was about one minute, and portrat film mals used.

Number 12 is a photograph mate for a show case company of their installations. and electric lights were nsed entirely. The exposme was about three minntes, with a bansch \& Loml, Series IV lens, stopled to f32, and a backed standard (bohomon plate was weed.

lllnstration Nimber 13 is an interior made with electric lights with diffunce attached, pertrait film being used. and exposure was about five seconds.

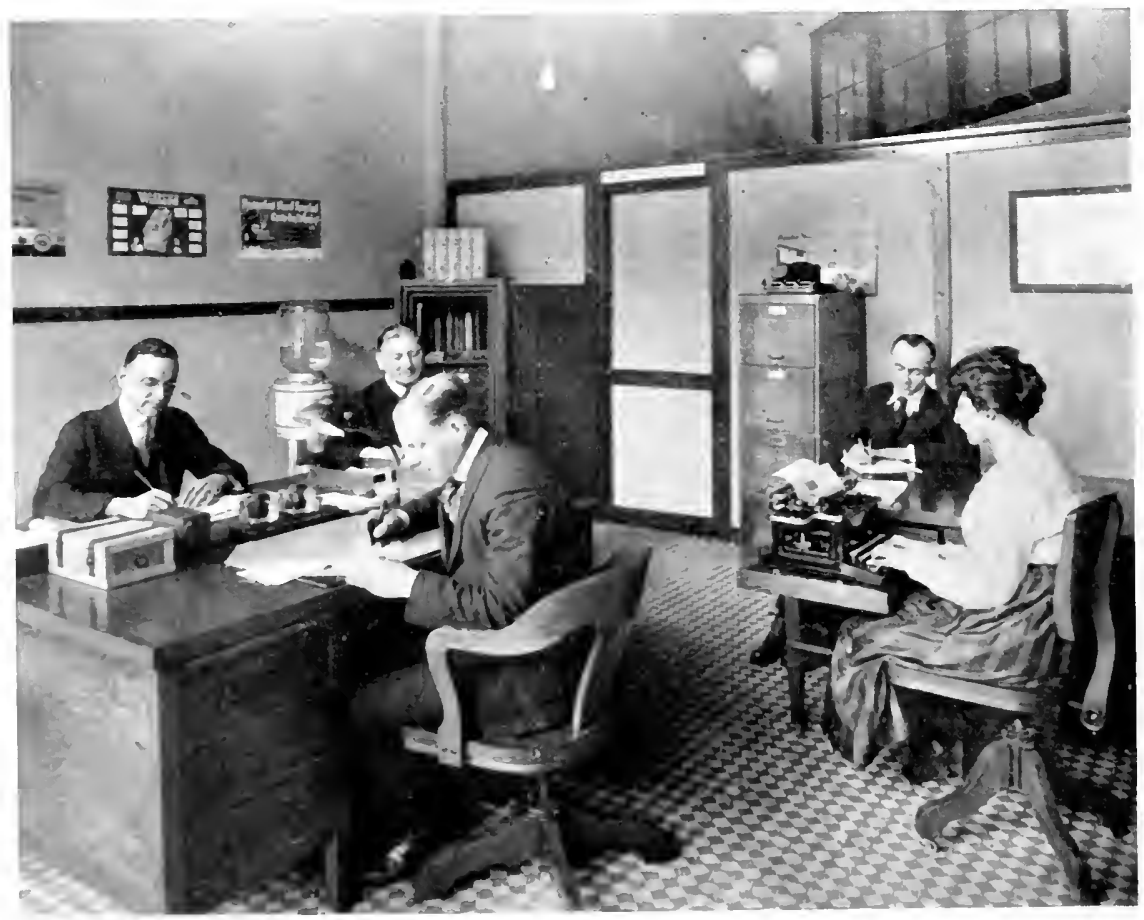




\section{CIIPTER VI}

\section{INOL I:T:}

B

INetere photography has proven itself very profitable to a number of concerns who have specialized in this line, but for sone reatson or other. it hats ahwas been surrounded hy considerable mystery in times gone by as to the methods they followed in tuming ont finished prints so fuickly.

The commercial photographer in a city of arerage size does mot mathy have enomgh call for this class of work to spend very much noney on erfuipment. For this reason, the bancuet camera, matle by the Folner \& sehwing Company, which is a very good and fine-looking instrument, is not a bad investment, as it may also be used for ontsile groups and similar work. It has one attachment which is exceetingly handy, and that is, the tilting front. This attachment comes in particularly good where the cancer is elevated off the floor, and, in using it, you to not, as it would seem, take in much more foregromul. The advantage ganed is that you equalize your focal plane from the back of the room to the front, get the heads more nearly the same size, and a sharp negative is olstaned of the people and tables with a larger diaphragm and. conseguently, less powider.

Is this point is better explained by demonstration, if you will try it out yourself, tilting the front of the cancera, and keeping the ground-glass perpenclicular, you will quickly see the alvantage of this tilting front board when you are raised off the ground, that is, when working with a tripod of seven, nine or twelve feet in length, or from a platform.

The cancras used by the specialists are nothing nore nor less than compo board and are of fixed focus-therehy diminating the necessity for bellows. with the tilting front the only movable part about it. That only has two movements, one for the seven- and one for the nine-foot tripod.

The lens generally used for banquet work is a Goerz Dagor series III. Number 6, that is, a 12-inch lens, and by working the tilting front and stopping its diaphragm to $f 16$, it cuts a 20 -inch plate very satisfactorily.

The bags used are either the Prosch, or those which they make themselves. and these latter are sometimes made to fire downward instead of upward as in the Prosch machine. This feature is rather an advantage in photographing in a room with a low ceiling, as it gives light at a higher point, thereby throwing the light downward instead of sidewise. These bags are also made to suspend from the ceiling, or balconies of the room, which does away with the necessity of carrying heary apparatus needed to hold them in position.

However, it is not a good idea for one to make his own bags unless he is an expert at the work, or his own flashlight powder either, for that matter, and 
persomally I arlvise against it, for, as is well known, it is a criminal offense to jeopardize the life of anyone, and an acedent might put one out of business for all time.

The plates which are poptularly used in comnection with banquet work are the English lmperials, Eastman portrait film and iraflex plates. After the exposture, the negative is developed, fixed, wasfied very little, hardened in formaldehycle, immerserl in alcohol to dry off superfluous water, and then dried quilily before an electric fan. Prints are then made, wigeled in the hrpo.

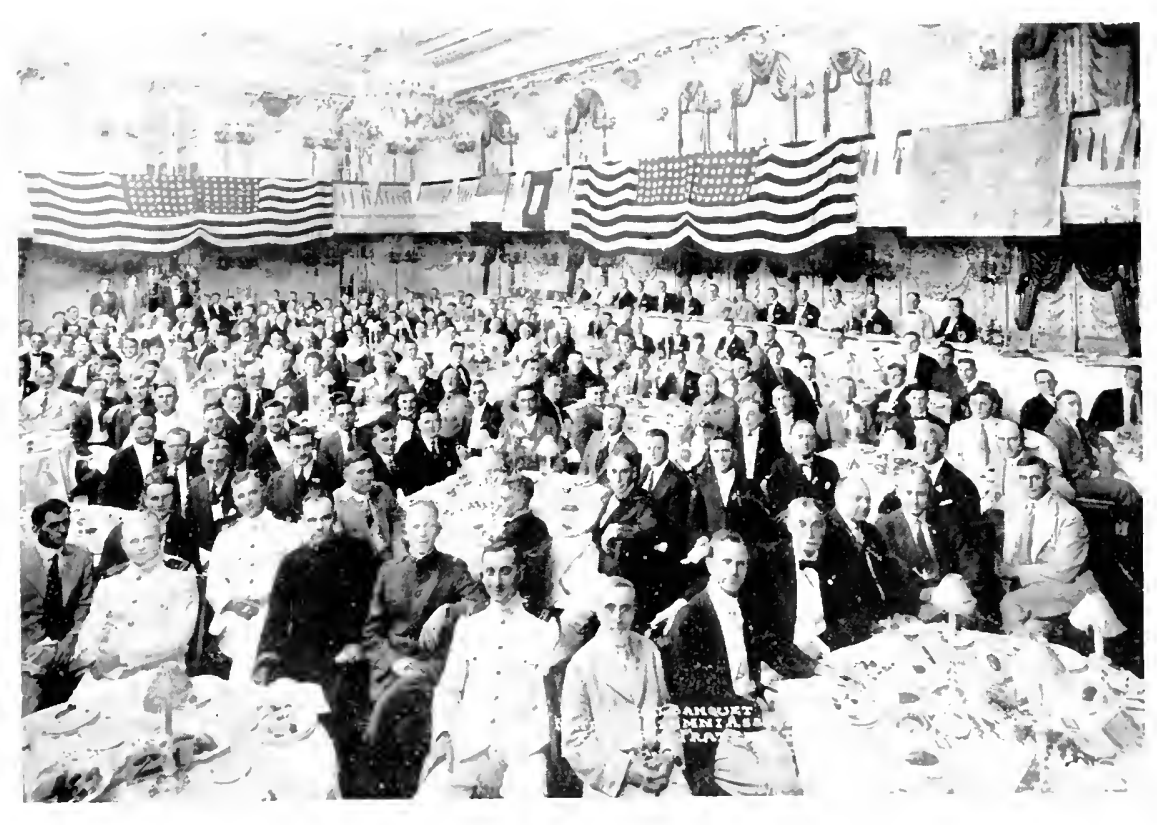

Kaufmann \& Fabry Co.

Fig. 14

twisted in the water, mounted on a card or slipperl in a folder and taken back to the banfuet hall. Orders and money are received at one time, receipt given and the finished fictures are then mailed within the next comple of days.

such a procedure, as is applarent, requires quite an organization. orelinarily. to be a sucess. and there have been several young fortunes made in the business, but the banducts which have proven the most protitable have been those where notables were present, in which case the pictures have sold like hot cakes. Also, such work is profitable if it is new in the community, but when repeated year after year with pratically the same crowd, it becomes an old story, and the reverse of profitable, for unless a large number of prints from each banquet negative are ordered, the immense amount of work entailed, and the keeping up of extensive equipment, cats up whatever prolit there might bave been.

The amount of powder used and number of bags are, of course, governed by the space to be covered and the color scheme of the room, dark walls recpuir- 


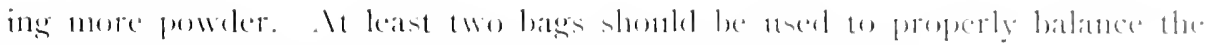
light, and from that mumber up to ton are nswally sulficient.

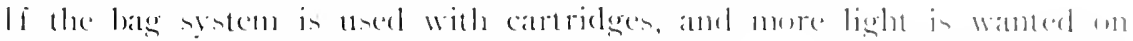

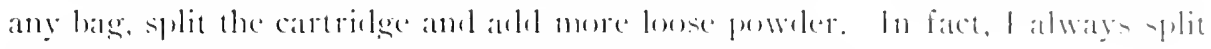
the cartridge, anyway, for what I think is a better effect.

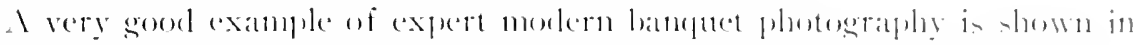

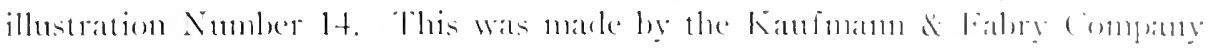
of (hicager) pinneers in the salme. 


\section{CIL.IFTER V'II}

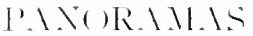

I Xarge offices. hanks, stores. factories, warehouses, and the like, especialiy if there is a promotion or adrertising campaign uncler way. you will be caller upen to malie pictures inclubling a view wiler than your willest angle lens. () fi course, a Cirkut camera is out of the question for most interiors. so it means the making of several negatives with a view camera and joining the prints together to make one continums picture.

llinstration Number 15 is the interior of a bank. considered a very beantiful buileling. the skylight and balconies of which were quite prominent features. Several photographers had tried to make the pieture with a wideangle lens. hut never satisfied the customer. The illustration, as you see it, is a three-plate panorama with absolutely no art work, and is joined together on the white lines, and when finished, the customer had but one complaint-the price. the hat heen spoiled by how prices.

You will notice that the picture was not joined in straight lines. which is, to my mind, a great advantage over the ofd method of printing all in one piece. for you cannot get around angles and posts in making a continuous print.

Is most jols of this kind refuire only one print for reproduction purposes. it is far better to put them up in pieces. The prints are lapped abont half an inch, and the extges. both underlapping and overlapping. are carefully sandfatered to a very hine edge. using santpaper manicure sticks which can be furchased at almost any drug store. After using several other means, I settled on these manicure sticks, as they are much easier to handle, and there is not so much danger of mutilating the print. The prints are then matched together and carefully trimmed.

To prevent buckling of the mount, just before mounting the prints. I paste on the reverse side of the mount a piece of heary wrapping paper just the size of the combined prints, and then quickly mount the prints themsches. A little careful watching and manipulation in the right direction during the drying process will result in the mount drying perfectly flat.

When dry a good folder tissue and cover paper. applied similar to the manner used by commercial artists, completes the job, and when put up in this style, will be found easy to deliver at a good price.

I am often asked what I do when the customer wants more prints. They hardly ever do in a job of this kind, but should more be needed, a copy can be mate and prints taken from the copy. Personally. I charge them enough for duplicates so that I can momnt them the same as the original and still have a profit. 


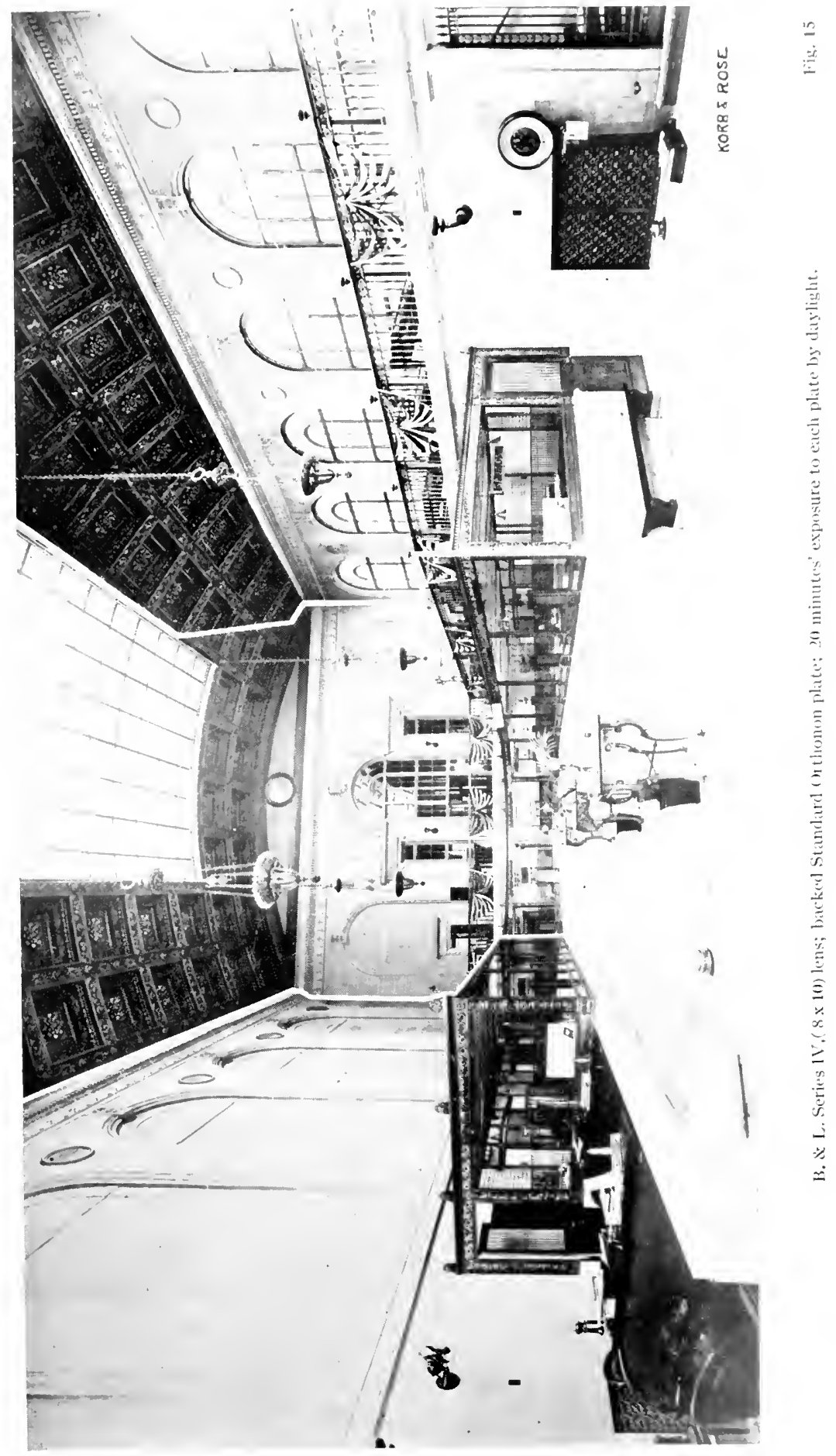




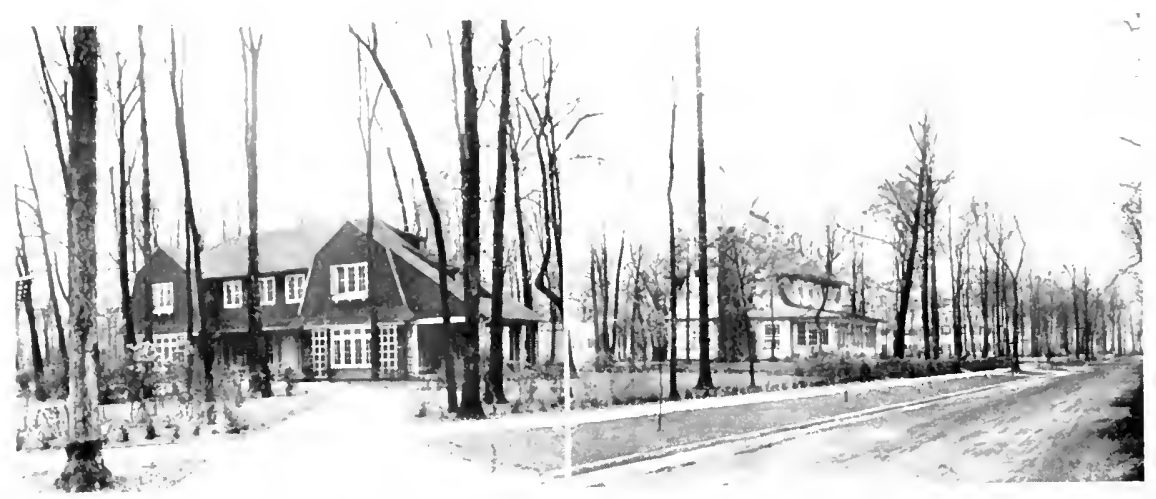

$8 \times 10$ Goerz Dagor lens; exposure, 3 seconds; $\mathbf{K}-2$ filter used on

Fig. 17

Standard Orthonon plate.

The exposure on the bank picture was abont 20 minntes to each plate. stopledel $f+5$, Batuch 8 Lomb series $11.8 \times 10$, on backed Standard Orthonon plattes, using daylight only.

Vou will notice no halation on the side windows or skylight, although strong light was coming in at all times. This is due to backed plates. proper exposure, and puick development in the dark-room.

Nimber 16 is a two-plate panorama of the interior of a phonograph and electrical fixture suphly store-no art work-with artificial lights only, and is joined on the white line.

The exposure was ten minutes to each plate, stopped $f 32$. Bansch \& Lomb series 11 . and the two Johnson Compact Ventlites used on the job were kept in motion during the entire exposure, which prevented any deep shadows. Baclied Standard Orthonon plates were used.

Number 17 is an out-door two-plate panorama and shows the possibilities there. Yon will notice the lines of the walks and roads are practically straight. and is, all in all, a very satisfactory job.

I might mention that this picture was nade on a hazy day in early spring. and from where I was standing, the end of the street was barely discernible. Bỵ putting a K-2 filter on my lens, using Standard (Orthonon plates, and exposing about 3 seconds to the plate, stopped to fot (Goerz 1)agor. Number $6.8 x$ 10), the result is that absolutely no haze is apparent.

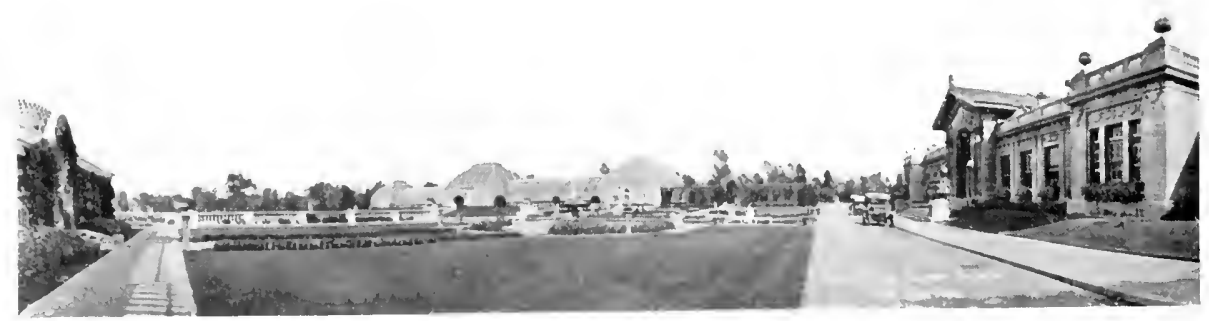




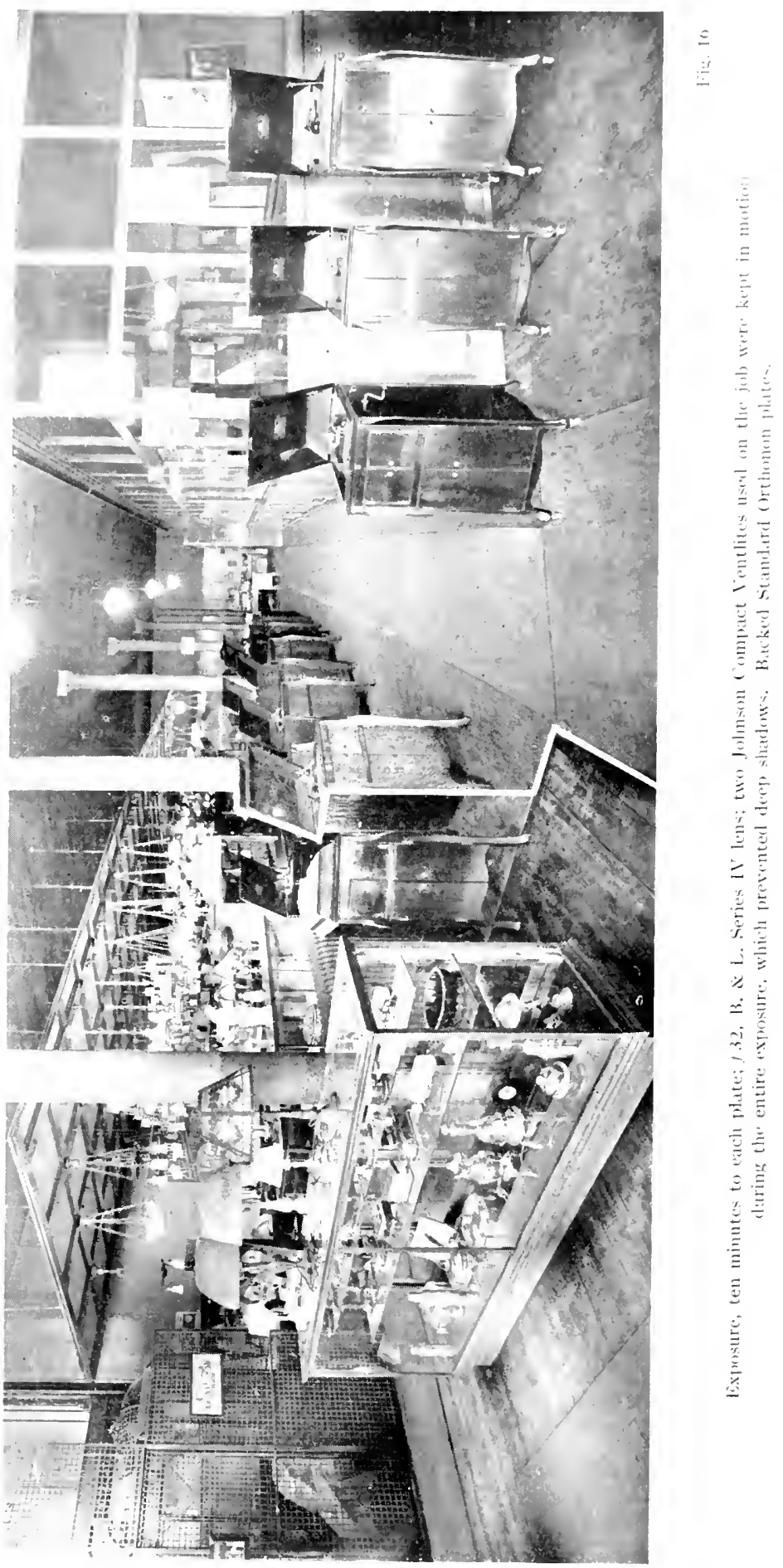


In making panoramas ontsicle with a vicw camera, it is advisable to stop the lens down considerably, eren thongh it may not seen necessary in covering your plate. Lnless this is done, you are liable to have mectual lighting of four plate: that is. your etges will be a trifle darlier than the center. which you womla probably never notice in a single print, but in a panorama will be noticeable at once. For this reason it is best to use a lens with very good covering power in connection with an ont-(loor panorama male with a view camera.

There is probably no linit to what you can do with a number of plates put together on an interior job. In fact. I knew of an Eastern murler case where the photographer photographed the whole room, ceiling, walls and floor, and put them together for the jury just as the room was.

lon can go right along in a straight line and malie five or six plates and put prints logether. This is a jol, I an often asked to execute. I have in mind one now I did of a lumber shed. While there was no perspective to the fintished pieture, it was just what the customer wanted, as it showed the shed much longer and larger than it really was.

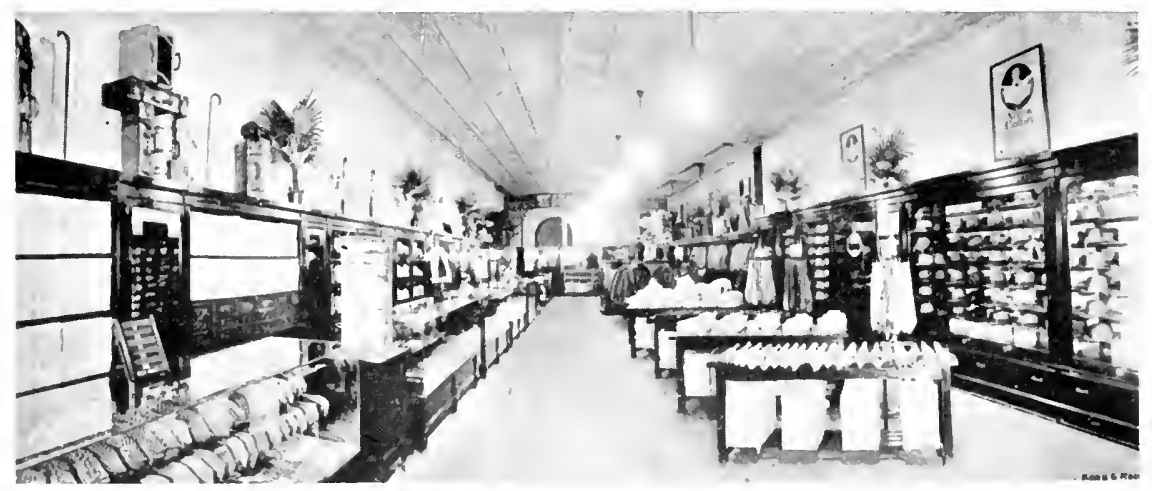

L. G. Rose

Fig. 18

llustration Number 18 is the interior of a men's furnishing shop, which was naturally rather cramped looking. By making two negatives, one on one side of the aisle, including all of the aisle, and the other from the opposite side, incluthing all of the aisle, when the two prints were joined together, the desired result of making the store look much larger and roomier was obtained-in other words, a canera lie. Some art work was necessary as, in making the joint straight down through the center, the tile in the floor did not match, and art work wats used to bring the tone of the floor ny cren.

I have also matle panoranas ontsile for landscaje architects where, in two panoramas of five plates each, I took in the whole 360 degrees.

$\Lambda$ word about placing the cancra. You have often been told that the lens harl to revolve right over the center of your tripod, which is right, but I often make them with the camera 15 or 20 feet away from the place where the first negative was made; one perhaps made on one sille of the room and the other 
100 feet away; in fact, there are condless possibilities. I little commonon semee and sone ingentity are all that is repuired. The ines on the gromenteglase.

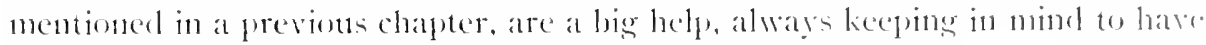
the nlatching places the sane size and with room for an inch laj of view. Another thing is to try to inclute the whole side of a roont, if prosibles on one plate and the end of a roon on another plate to avoid bends in ceiling beatus.

Fot will note the only bend in the bank panoranla is the side rail in the balcons. ( nn the two-plate panoranta, there is ne pereeptible benel.

In making panoranas of offices, including people, it is ahways advisable to work two canneras at the same tine. In this way you can liglut the entire office at one tine and the jol, is more quickly done and with less confusion. The two cameras can be set on a bard on top of the tripod, and the exposure should be equal. with at least an inch lap of riew. () course, gou should use lenses of equal focal length.

This work will be fotmel exceedingly interesting and is one of the quickent means of building a reputation. If you are at all clever. you can demand and get almost any price.

With reference to developing. the negatives should all be leveloped in one tray at one tine, or in a tank, to give absolutely expal printing quality, and. of course, the prints have to be made of e(pual depth to make a proper and unol)trusive match. When properly sandpapered and mounted, the joining places have to be pointed out to the customer, as they are hardly pereeptible. Another advantage derived by sandpapering is the fact that when they are set up to make cuts in photo-engraving shops, there is no shadow on the lap sirle.

Some people butt the prints, but that has always seened to me a rather clumsy methol, as the prints invariably pull apart and show the join.

While this method of making panoramas can be employed in almost any case. a Cirkut camera is a very good investment for many conmercial men, or portrait photographers, for that matter. especially in a locality where there are industrial plints, mining properties, real estate promotions, etc, and for large grouy) work, in view of the large print orders generally received, and which would be impractical moler the first method. However, each method has its own field, in my opinion. Illustration Number 19 is a very good example of ontside Cirkut work. 


\section{CH.IPTER VIII}

\section{M. \C 111 NERY}

\section{$\mathrm{T}$}

HIS is a line in commercial photography which takes the operator ont into the shops and manufacturing plants, and is one for which there is considerable call in mantfacturing centers. Is pictures of machinery are nearly alwas used for sales promotion work, and practically every machine has one or more competitors in the field, it is necessary to take them at their best - also for the operator to he able to pick up the good points quickly and with as few questions as possible. For this reason, unless he has a liking for machinery and a knowledge of mechanics, he is handicapled to a certain extent from the start. A knowledge of this sort also comes in rery handy in blocking.

Pictures of machinery are usually blocked, that is, with a pure white backgromul, and with this end in view, the shops usually have on hand backgrounds of sone kind, either dirty or otherwise, which can be stretched wp in back of the particular machine to be photographed.

Is to preparation, the modern commercial photographer does not rely so much on preparing machinery for photographing, as it is usually painted either a dark gray or blue-hlack these days, which photographs very well anyow, and exposure and development take up nany of those leficiencies.

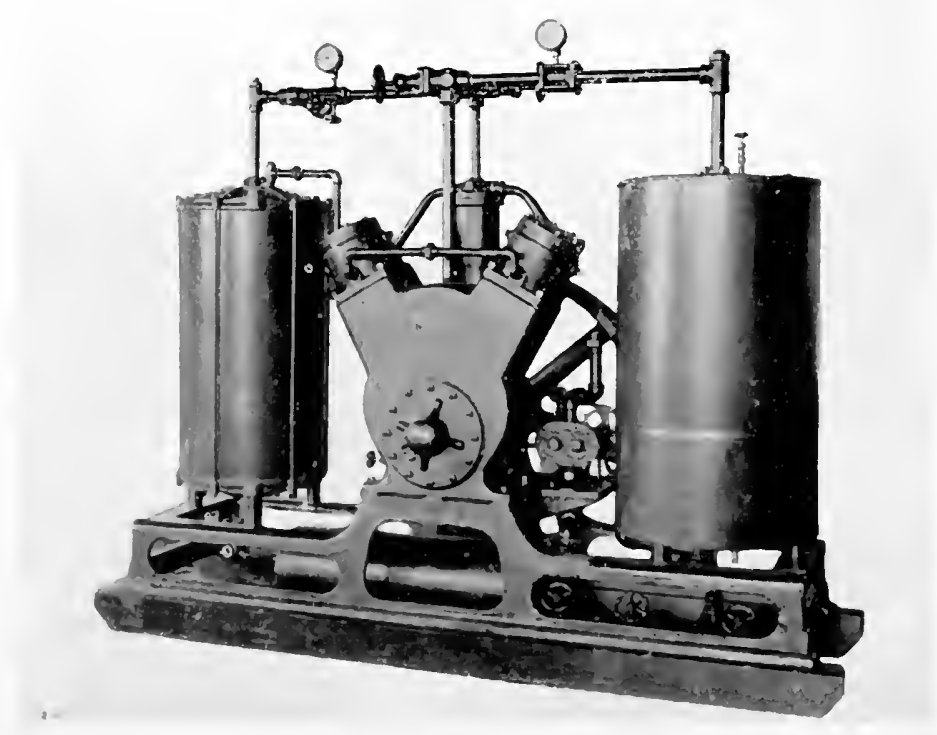




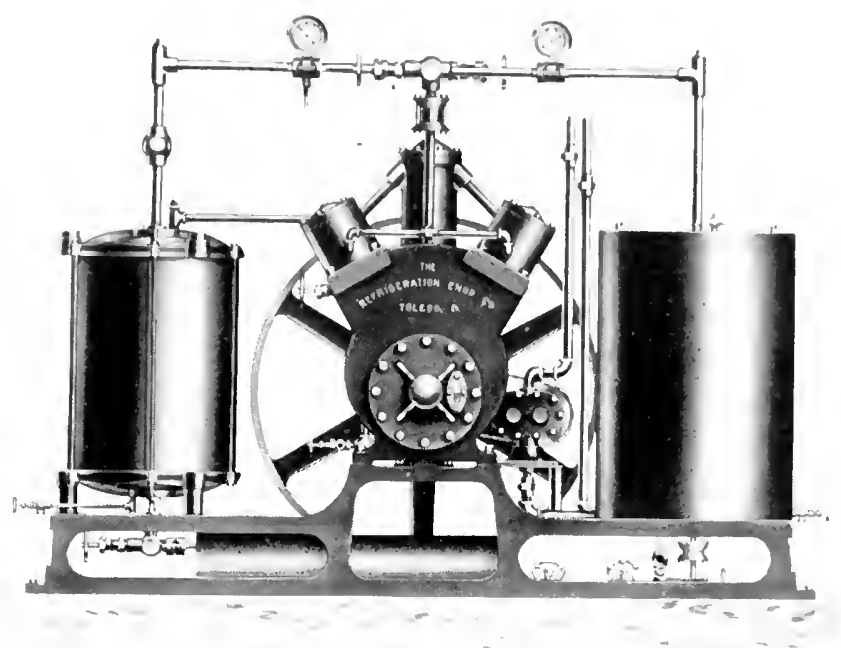

Fig. 20

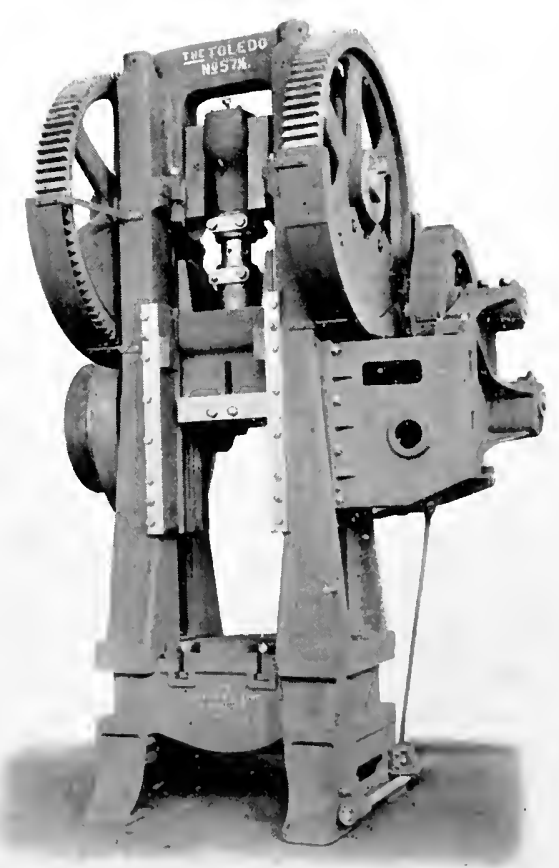

Fig. 21 
But, if you to have to prepare any thing, a color that photographs very well is what is known as battleship gray. This may be applied so as to come off quickly if gasoline or turpentine substitute are nsed in mixing. Practically the only time yon will have to prepare anything is in connection with some small parts, as the larger companies nstally make it a point to have their nachine painted before the photographer is called. If they do not have this done, work a little of the payment-for-time stutf, which will undoubtedly have the desired effect of having the job ready when you arrive on the secne of action.

If it is necessary, touch up the name plate, which should be displayed prominenty. This can he done with aluminum paint, chalk, or whiting, etc., just so it comes ont plainly in the photograph.

In my opinion. the one bent way to photograph machinery is with a blowlamp). I even nse it to help ont fairly good disylight, as there are nearly always gears. wheels or the like in the shadows. where a short blow will help detail. In using a blow-lamp for this purpose. the lamp should he moved at least six or eight feet during the exposure, that is, from side to side and up and down. so as to get light into all the crevices and shatows. Of course, a little longer on one side than on the other is good to give a slight relief.

In nsing blow-lanns, they give considerable trouble unless a few precantions are exereised. The blow-lanp, should be kept absolutely clean at all times, that is, clean off all of the deposit that forms around the burner, keep the powder passages clean, the alcohol pad in good shape, and by all means have a cover on it to extinguish the flame when the job is finshed.

With reference to the power, it is advisable to use a finc and a medium powder mixed together, as it seens to give a better restult than either fine or medium used separately. Shout an ounce of powdered almminum, such as used for bronzing, mixed in with the poweler. is also somewhat of a help, at it lecps the juwder from eretting dull.

Ill powder. should be taken from the lamp and the lamp reloaded after each exposme, as the moisture from your breath. blowing into the powder through the tube, has a tendency to calie the powder.

l suppose it is hardly necessary in this day and age to caution that it is not safe to use regular explosive flash powler in a blow-lamp. although it securs to happen occasionally, for it will surely ruin your blow-lamp for all times and will make business for the undertaker. Magnesium only should be used.

Occasionally, you will, of course, have to photograph with daylight alone, and at other times with electric light. The same as in commection with the blowlamp, when using electric light, the light should be moved about to get well into the shadows.

As for the plate, it should always be either on a double-coated plate or a filn, as one has a sreat range in tones, from the deep black to the white nickel.

With reference to the lens to use, this should be of long focus, and if it is at all possible to aroid it, a wide-angle lens should never be used.

The illustrations show various types of machine work. Number 20 being a retouched photograph. 


\section{CHAT'TR IX}

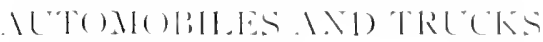

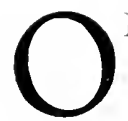

NE of the foremost industries in this comutry today, and one in the promotion of which photography is essential, is the manufacture of antomobiles and trucks. There is practically no town or city of reatsonabie size in which there is not a factory or an agency for the sale of one or more makes, or advertising concerns who specialize in automobile publicity, and by whom there is a great demand for photographs to be need in the assembling of their advertisements.

() f course, many of the automobile factories have their own photographers, but there are many times when they find it necessary to call upon ontsirle phortographers, and it is just as well to pick up this work in your own town ats to let it go to the larger cities.

In this line of work, which inclutes the photograpling of the parts for the parts book as well, there are a few points which it might be well to emphasize.

In photographing the passenger car there are many features, on some of which the designer has spent considerable time, to be brought out particularly strong, such as fenders, body, top. cushions, and ratiator hoods, and the popular position which brings these features out best, is shown in illustration No. 23. No particular attention was paid in this instance to the background, as it was eventually blocked out, but you will notice that effort was made to show all four wheels, a separation between the two front lamps and springs, and the top was pulled up taut.

The camera was quite low, not more than two and a half feet off the ground, and a lens of 28 -inch focus was used. This matter of the lens being low is really important, as it gives the car a more massive appearance, and an the same time showing all four wheels. Occasionally, a view will be wanted, however, a little more to the front, and it is then more necessary than ever that you use a long focus lens, or you will get a distortion which will show the front wheels much larger than the rear, something particularly to be aroided.

In photographing the interior of a car to make it look as large and roony as possible, you will, of course, have to use a wide-angle lens, unless two or three views are taken and put together on the order of an interior panorana.

While practically every bit of photography that is done on a passenger car goes into the hands of the commercial artist or retoucher, there are times when a natural or unretouched photograph is desired, or when little retouching is wanted. For this reason, in doing this class of work, it is quite essential that you know a few good locations around your town. By locations, I mean places where, at certain times of the day, the light is right and there is a good back- 


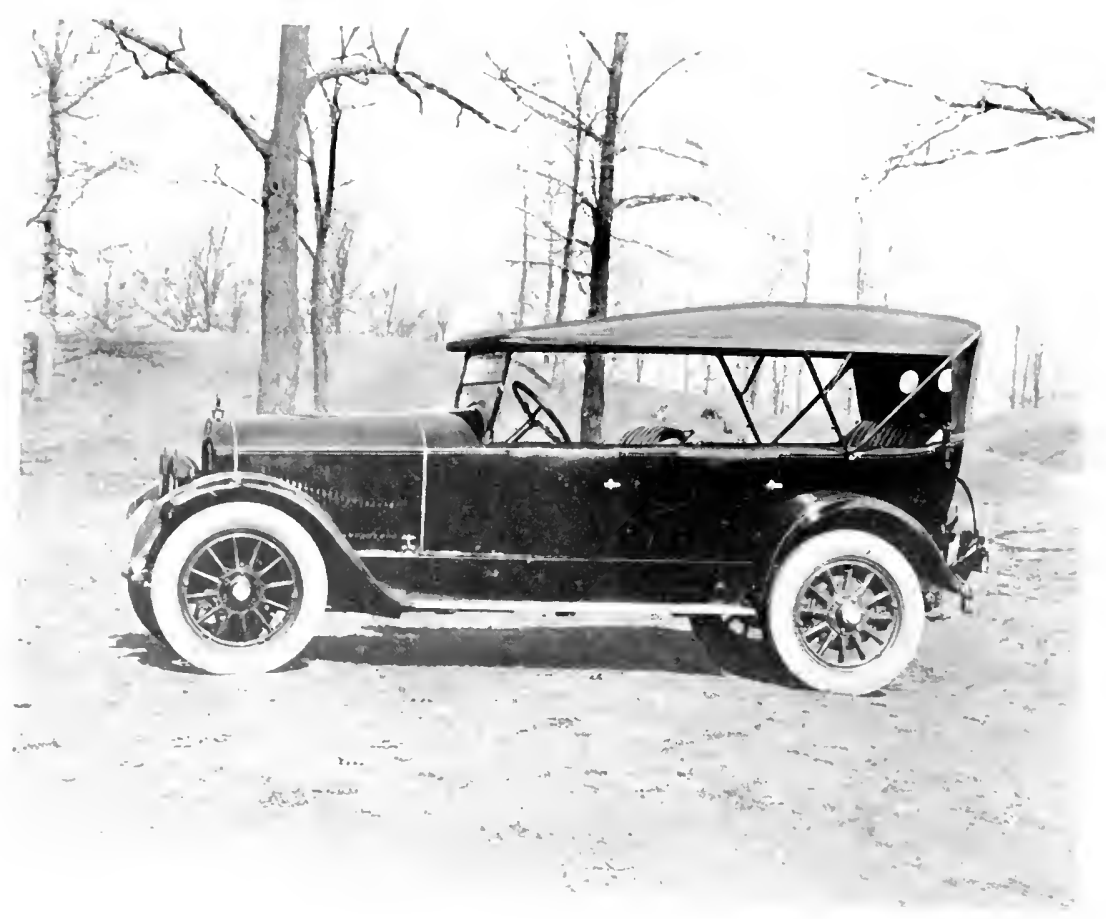

Fig. 23

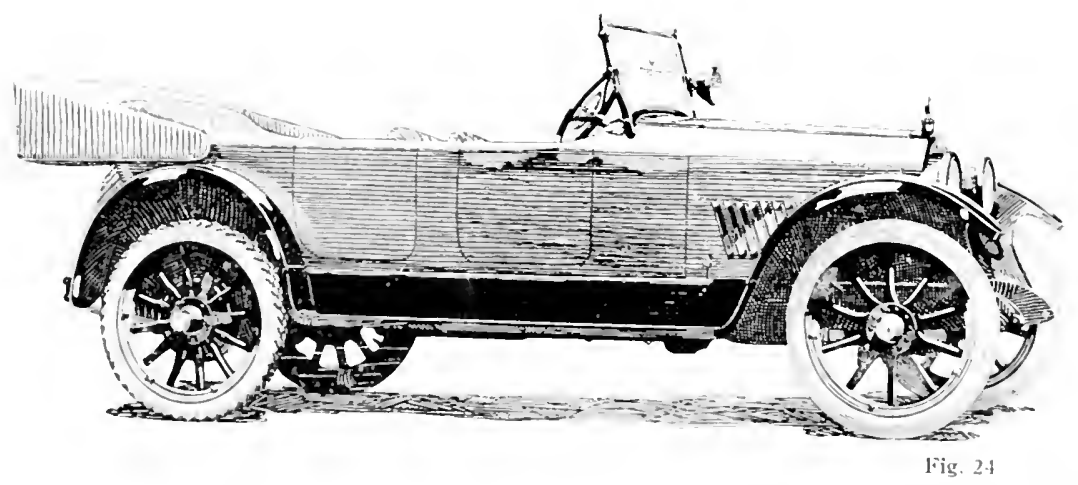




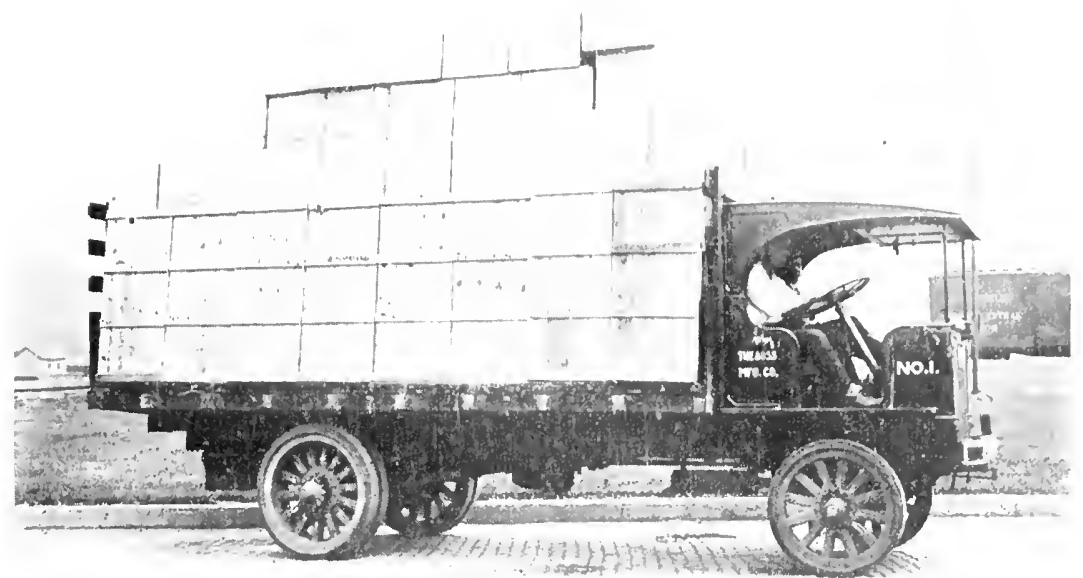

gromed. There is generally a park at hand, where there is an elevated roatway aroumel a ravine or lake, which makes a good spot for photographing atutomobiles, as you can get low enomgh to male a real good jol). There also hats to be considerable care exereiserl with the highly polished bodies as to what is reflected on them, and that is why I athocate going into the parks, at the reflections are then such as rarely resister on the negative. Whereas, if photographed in the streets, the structures opposite will undoulstedly show in the print.

Illustration No. 24 shows an effect often nsed in advertising passenger cars, as it reproluces well in the newspapers. This is obtained hy an artint. who goes over the original photograph, using waterporof india ink. It is then generally turned over to the photographer. who bleaches out the original photosraph with a solution such as gon will find under the chapter on "Printing," leaving the pen and ink drawing only: This kind of at job will conte up many. times in many different forms, but the general procerlure is the same.

With reference to trucks. their sate is promoted principally by the use of photographs, and form an exceedingly inportant part in the sales talk of truck agents. That is, the varions types of bodies on trucks already sold in the vicinity, and which are particularly suited to different industries, are photographed to show prospective customers in selecting the type for their use.

In this work, nearly a straight side view is best, as it shows the body, the main consideration, and, if possible, the truck should always be loaded-the 
bigger the loal, the better it will suit the dealer. for even though they always arlocate to their customests the melerloaling of a truck, they like to see a truck in a photograph loaked way heyout its capacity.

Illustration No. 25 shows a farored view of a truck with an ideal backgromul. It was mate on the river front and the load was thrown up into relief anginst the shy. It was sure some load. Such a background eliminates the necessity for blocking. Which some agents otherwise require, and which is a task for which they seldom are willing to pay the photographer adequately. A blocked photograph also does not have the atmosphere such as show by the illustration, but has the effect of being "staged" especially for the purpose.

It is important that the lettering of the mame on the side of the truck stand ont well, and it will be found a great help in many instances if a ray filter is nsed in making the separation of colors, that is, between the lettering and the color of the truck body. For this purpose, a panchromatic plate is necessary when reds are present, althongh ordinarily a $K-2$ filter used with a plate or film sensitive to yellow, will he sufficient. For general work, films especially are desirable, as the negative is usually surendered and sent to the factory. and there is no danger of breakage in mailing.

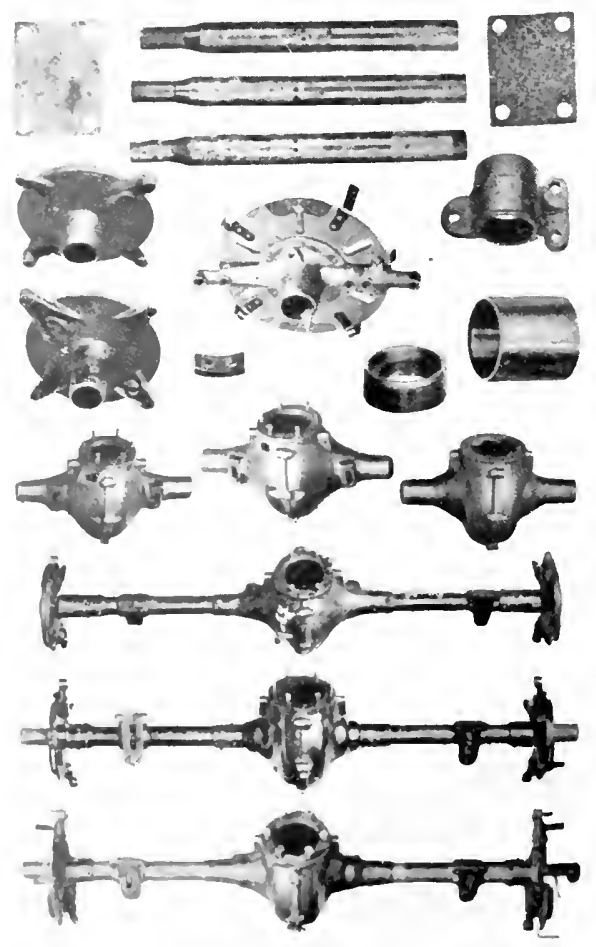




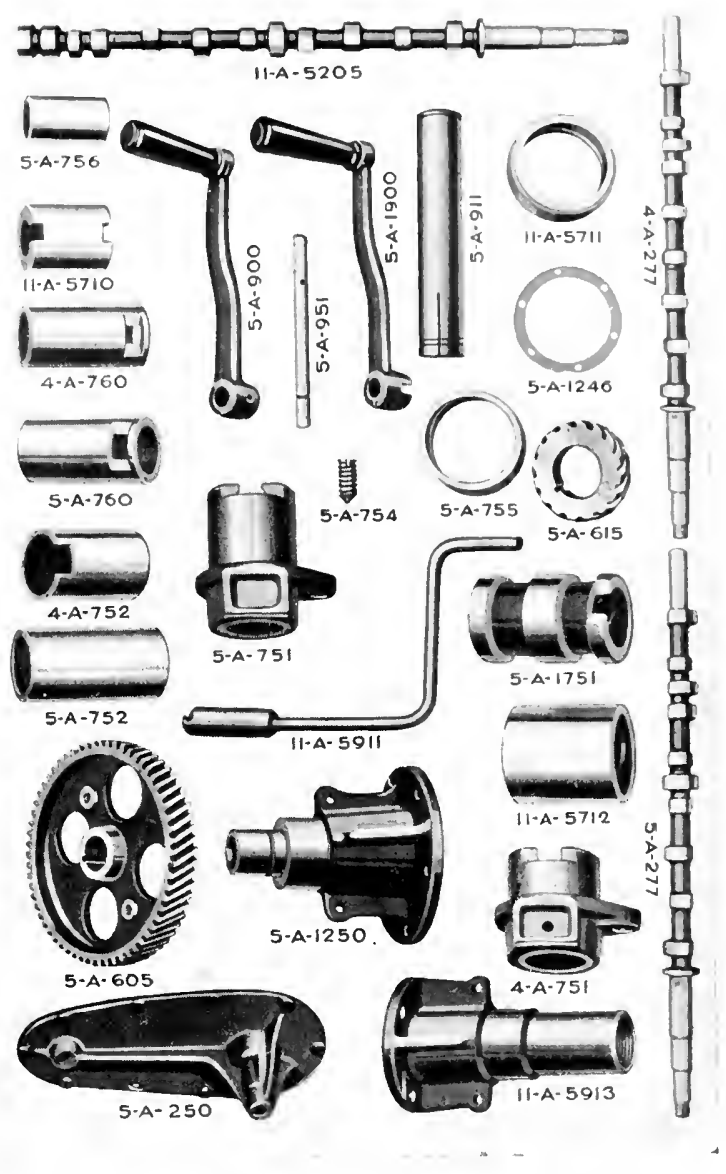

Fig. 27

The lens used should be of long focus.

Then, there is the parts book. This is gotten ont to accompany each new model, and it makes a very nice little job when it comes in. The parts range in size from the body all the way down to very fine serews and bolts, and with the exception of fenders, axles, and other comparatively large parts, it is nearly all vertical camera work. The parts of relatively the sane size are photographed in groups, that is, on the same negative, a representative of the factory usually doing the grouping and arranging the set-up, so that all the photographer really has to do is to focus the camera and make the exposure. The prints are then cut up and parts rearranged and mounted on cards accorling to their classification, $i$. $c$, electrical parts together, rear axle parts, transmission, etc., after which a second negative is made of the rearrangement, blocked, and new prints made for the photo-engraving retoucher. 
While the above procedure is rather expensive, it gives the finest result in the long rtul, and makes a very sitisfactory job, at the screws look like screws and all snull parts show up well and not like a nere speck on the page. Illustration No. 26 is an example of an muretouched print from a blocked second negative, and shows the advantage of this nethod. eren though the parts are ont of proportion to each other. llhustration No. 27 is a page of parts at funished by the commercial retoucher.

Inother methot is to take sonne one section. for instance, the transmission, and photograph it disassembled: that is, only transunission parts on that particular plate, although it has the disadvantage of showing line parts so small in proportion to the larger ones that it is difficult for the antomobile owner to distinguish them apart when orelering repairs. It is far cheaper. however, in view of the elinination of the second negative, and is nsed hy sone of the foremost antonohile manufacturess of the country.

Where it is necessary to get a top riew of the chassis alone. as it is rarely possible to photograph it from a point directly above, in hlock and tackle may be used to elevate the chassis against the side of a building. thereby permitting the photographing to be done with the camera in a horizontal position.

The particular points to watch in this work, especially shoukl the operator have to arrange the parts for the set-11p, is to see that every important and

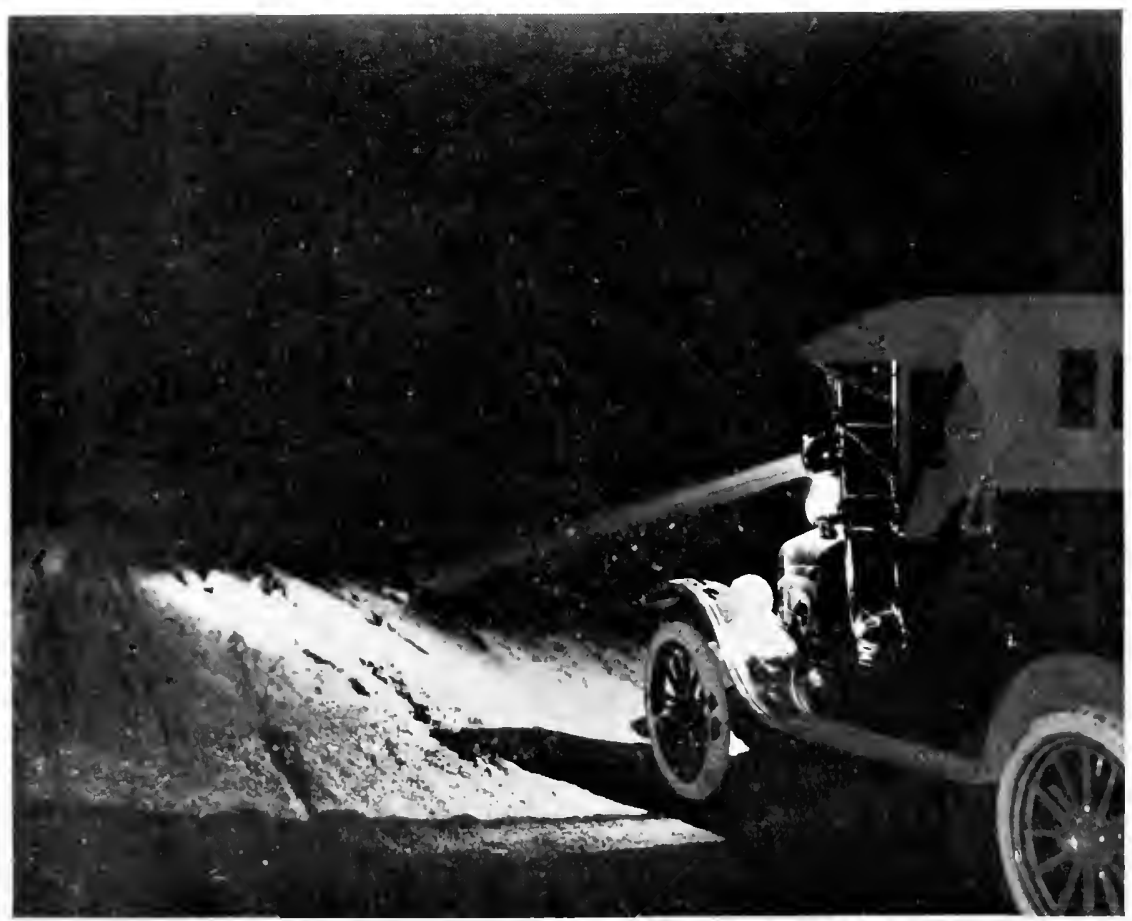




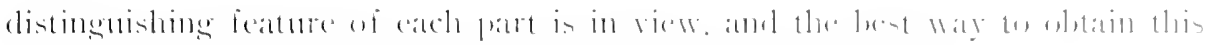

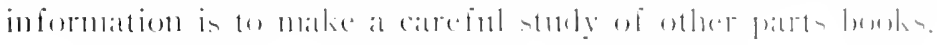

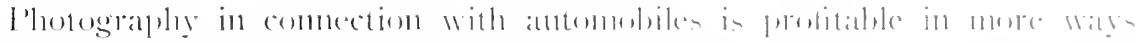

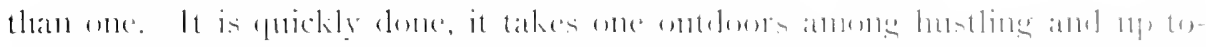

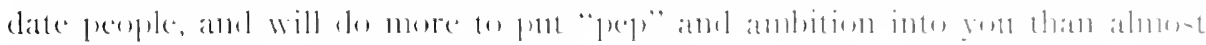

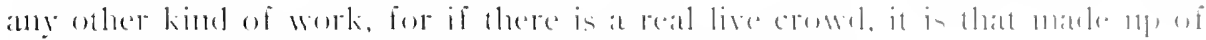

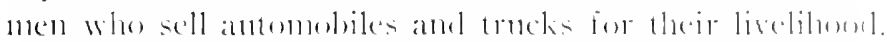

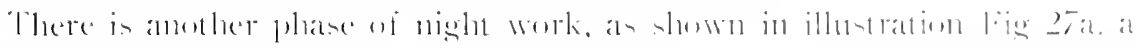

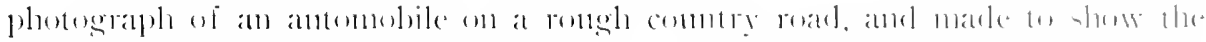

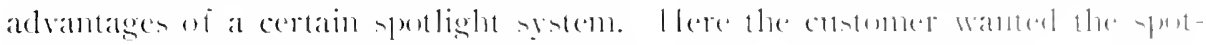
light without any faling and also a little detatil in the atummolute. Thin in a job that comes ale often in difierent forms.

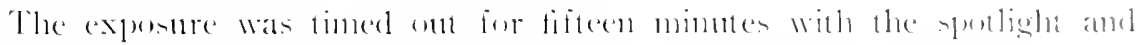

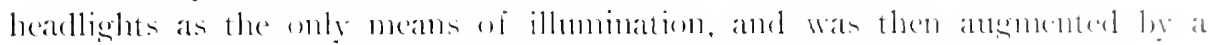

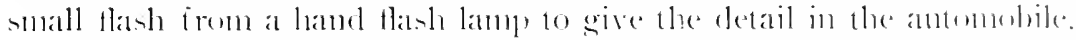

I peculiar thing about night work of this chatracter, including stred secones.

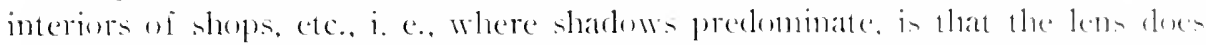
not necessatily have to be stopped down-it can be worlied wide epen and

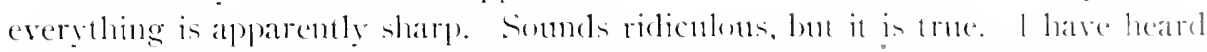
many explanations of this, hut, as they differ of wilely. will mu attemp lo lay down any reason. 


\section{CIIIPTER X

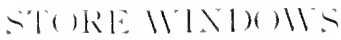

$\mathrm{T}$

HE photographing of store windows and all forms of that kind of work are. to nuy way of thinking, disagreealole. for it is a rare instance indeed, that, for the amome of time and labor involved, a proper compensation can le obtained. It times though, the work has to be done and many uperators seem to have consilerable tronble in getting good photographs of windows. The trouble is that store windows are generally located on busy streets. and if made at night one hats the street lamps to contend with, which give no end of tromble, the wind blows down your cantera, you get cold clear through to the bone in winter and swelter in the summer sum, you have to answer innumerable questions from passers-by. and all in all, it is anything but congenial emplowment. Then, if you charge what it is worth, a howl goes up). For this reation, many of the better class of commercial studios steer entirely clear of this line of work.

However, there are several ways to photograph windows successfully.

Yon can photograph them in the daytime with the sum directly on the window, which will kill, practically, any reflection, excepting. of course, in the case of a north window, or one which the sum does not reach, when it will be necessary for you to have a black screen in back of your camera to throw a black reflection. This screen may be made of dark canvas, and to be portalle. may be attached to sections of gas pipe. which are quickly and easily fut together. This may also be used at night to eliminate the reflections of lights opposite the window, and which may not be turned out during the exposure.

Some operators who work alone and camnot carry screens and other paraphernalia have a switch liey that will turn out the lights of windows along the street, such lights usually being controlled hy an outside switch box, but they camnot turn out the street lights, so it really comes down to one way of fhotographing some windows with any degree of suceess. which is to photosraph them at night and give time for the interior of the window, and then me a blow lamp to funsh mp for the ontsidle. handling it the same as you would a copy muler glass, that is, keep the light off you window. This means you will have to work your blow-lamp on each side of your window in such a position that the light will not reflect on the glass itself.

This method really gives a rery pleasing effect. There is only one drawback to it, and that is, the wimlow has to be absolutely clean, ats otherwise coery little streak and (lust mark shows up very plainly in the negative.

Another phase of this line of work is the making of night pictures ont-of- 


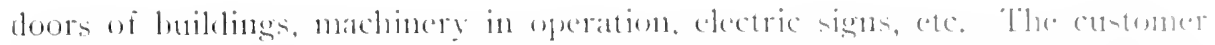
will tell you that he watnts the picture as it leoks at night, hut if gon gave him

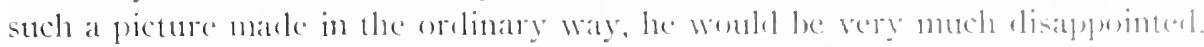
A very satisfactory way of foing steh a job is to set the camerat up in the early evening just before it gets dark, stop the lens down and make a short exposture. Ifter the lights are on, the balane of the expmsure may les given to show the illumination. This will give a fine might effect, lut it is another of those wating propositions which must be charged for, if one want to make a protit on his services.

In connection with window work there is another lind of work that in developing farrly rapidly, especially in jobhing conters. such an instance is where the mantifacture or jobler, in abling his custemers to make attrative window displays, has a sample wintow set-11] worked ont for them to gen by.

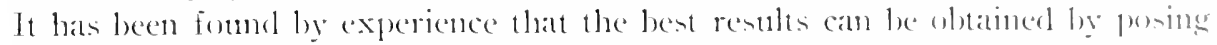
this dummy window in the studio, thus elminating reflections and other difficulties of ordinary window photography and obtaining a good lighting of the subject. This photograph is then sent ont by the jobber together with the necessary paraphernalia-cut-outs and goods-and is the guide for the retailer in making up his window.

Is the print orders are usmally of enormons size, this is becoming suite a field in photography, as several commercial photographers are specializing om it now, and it offers exceptional opportunities to those who like window trimming work.

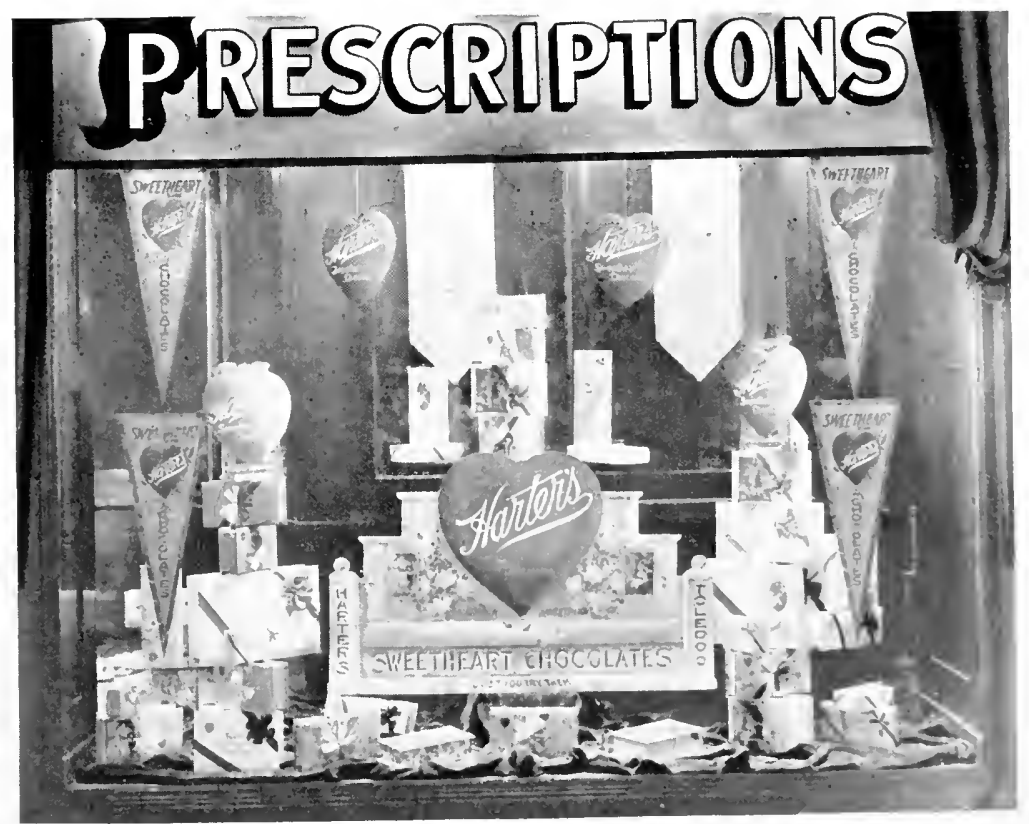




\section{CHIPTIR XI}

\section{Tll:}

I

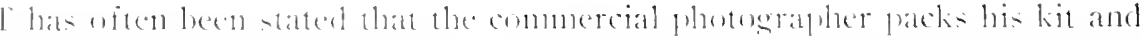

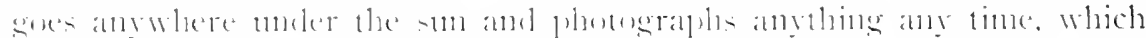

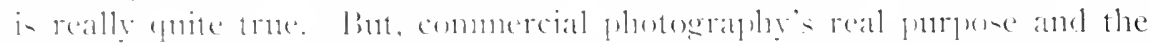

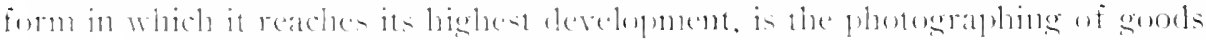

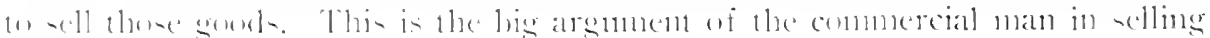
lis rerricen.

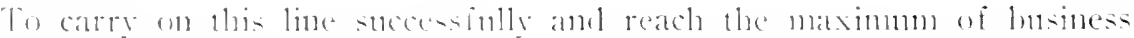

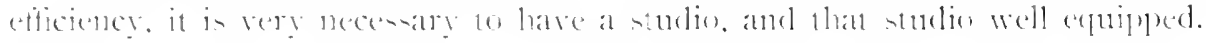

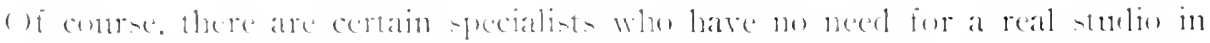

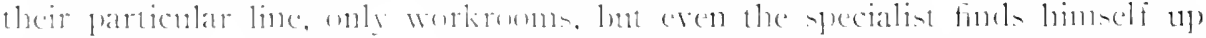

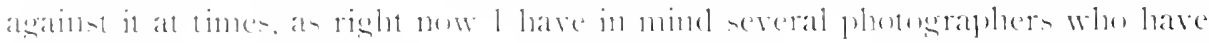

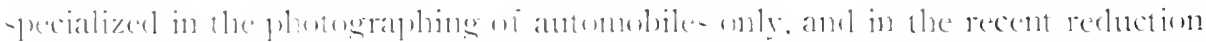

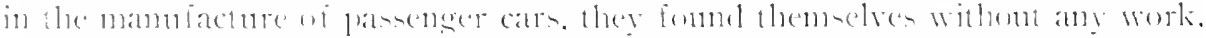

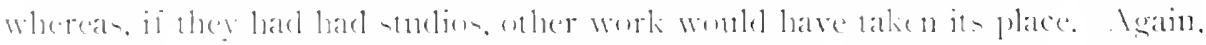

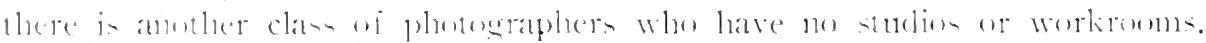

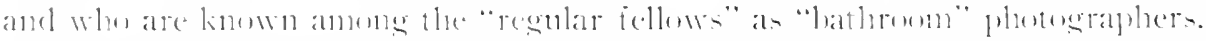

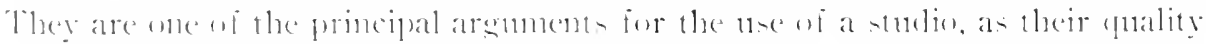

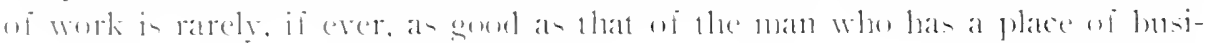

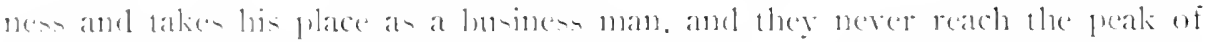

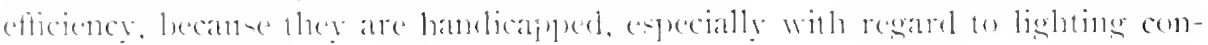
ditions at a rule.

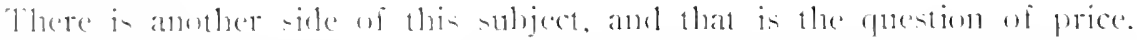

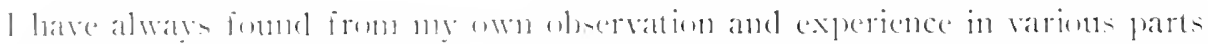
wi the combets, that the man with the entahlished place has more of a leverage for samel prices, which, after all, is what ereryone is after.

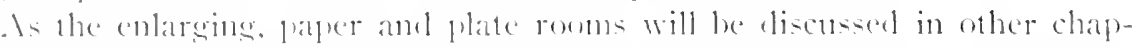
ters, I will take enp herein the operating rom only, and that, when weed for enemeral work.

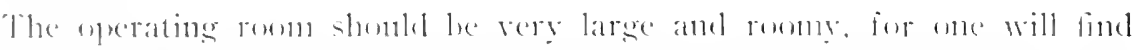

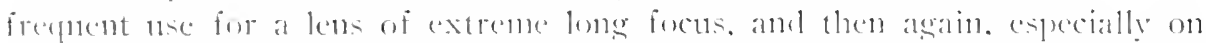

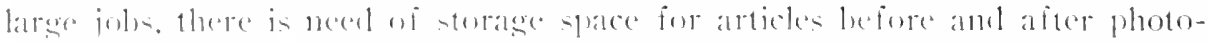

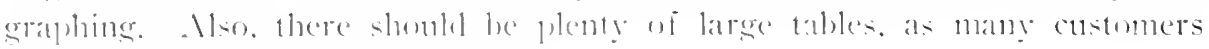
preter to make their omm lityouts.

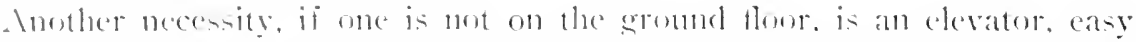
of acess, and opening comveniently into the operating room. This is more important than one would orelinarily think. as many customers will not send 


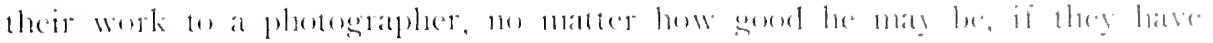
trouble esetting it lisere.

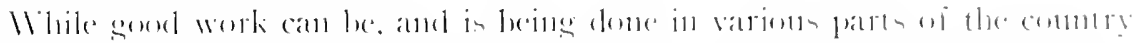

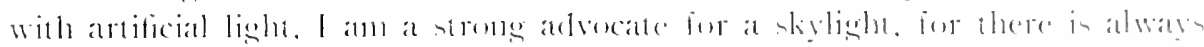

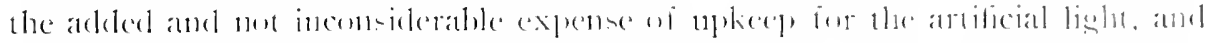

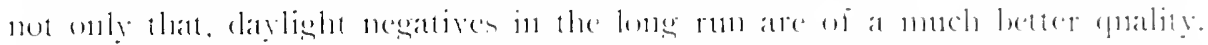

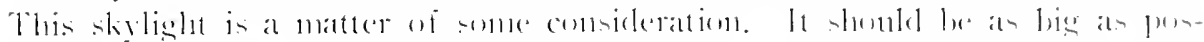

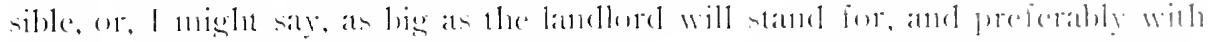

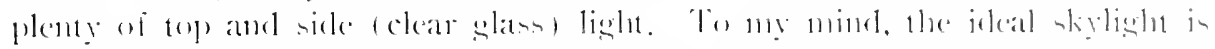

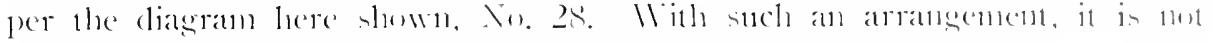

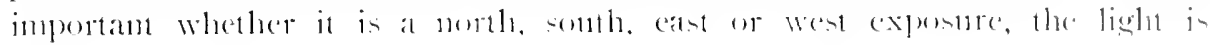

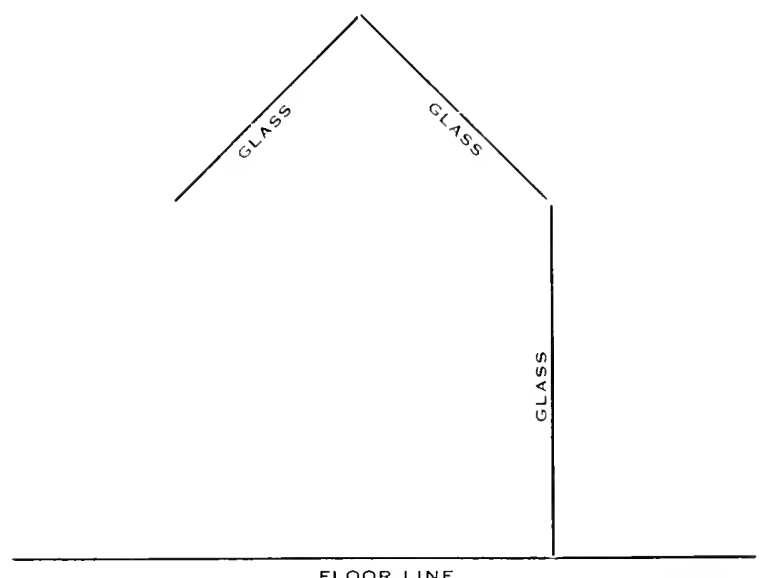

Fis. $2 s$

always good, althomels a month exposture gives the least trouble. In purtratit work, gou have always been told that a gromol-glass, a prisme glats. or some ribbed glas is really the best. l'osibly it is for portrature, but for comburercial work, a clear glats light will give the nicest and snappiest results, and it is quite estential a hate top light if one works a vertical cameral, as a sirle light alone will give consiglerable troulde in obtaining an even illumination.

Curtans for the skylight depend upon conditions, but for most places you will repuire a set of the opapte on roller vatiety, then a set of white diffusing curtains, and on the under side a set of black (muslin. for instance) curtains. these latter two sets on wire. The purpose of this imer, dark set of curtain is to cul reflections on shiny surfaces. Many times you will have reflections which can be killed instantly whthout cutting elown the volume of light by the movement of the proper curtain, especially when photographing a set-up on a vertical cantera. Is a supplenent to these curtains, head screens such as used by the portrait operator will be found extremely handy in cutting down or diffusing light locally.

No matter what your equipment is howerer, gou will neerl antificial lights of some kind or other, of the electric variety, proferably becante, nowadays. 


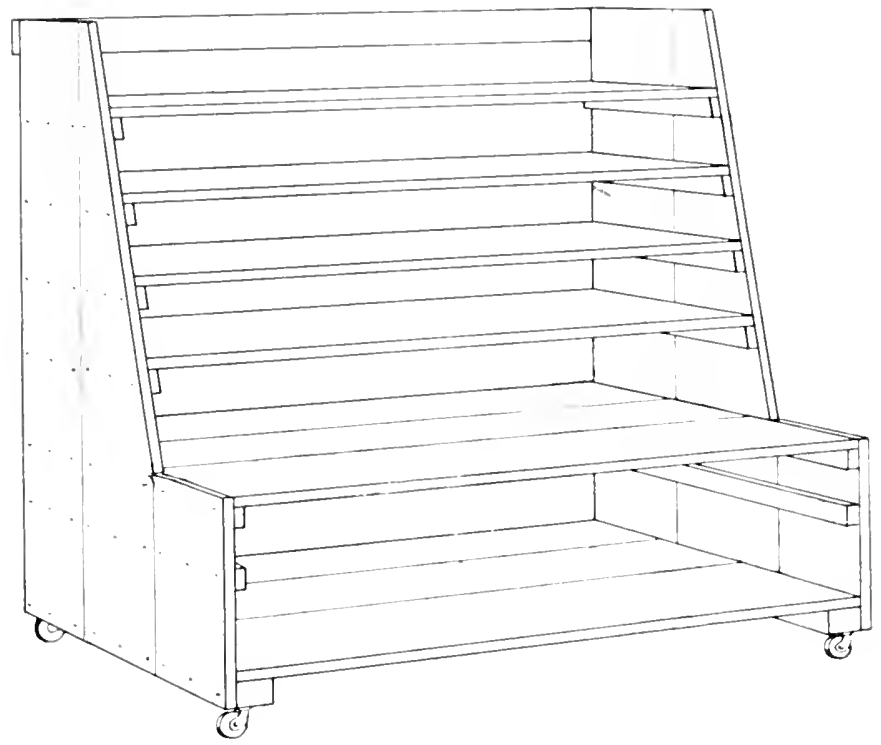

Fig. 29

speed is asential, and jols often conte in one day, with finished prints to be delivered the next, especially in caltalogue and magazine alvertising work, and the photographic work will have to be clone at night.

sone sturlios use the old-fashioned arc lights, sonte the Aristo, the Northcrn, Majestic, or Panchroma. These are all good, and practically the only lifference I can see is that some of them consume more current than others, and the initial cost.

Then, there is the cooper-Hewitt, often used to atument even dayliglet. when they ate attached to the crosibars of the skylight so that, as daylight wances, the tubes can be turned on. Some large plants, especially those doing in inmense volume of photo-engraving work, and rumning night and lay, use these conper-flewitt tubes exchusely for all photographic work, so ats to oldatu an eren run of negatives. flowever, these tubes have one disadrantage which can be overcome, and that is, in using color filters, one has to work sonewhat differently in view of the color of the light.

Ind. last hut not least, we hate the Mazcla or Nitrogen filled lublls, which can be nsed in so many different ways that it is almost impossible to enumerate them all.

They have several adrantages over the are lamps, in that they can be nsed in all sorts of positions; they consume less current, and are light and easy to move. They can le mate in the form of an artificial sliglight, or they can be used separately on stands. The light of the clear bull is a color correction of about the K-1 type by itself. Which is somewhat of an atvantage on certain work.

I have already taken w1 the matter of cancras and lenses in another 


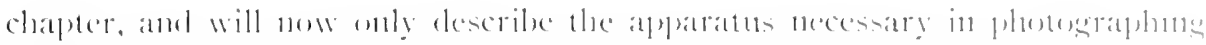

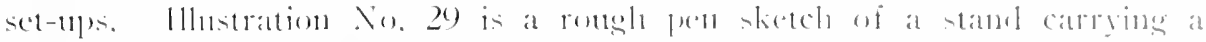

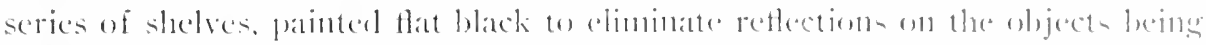

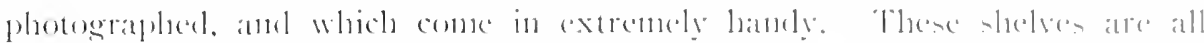

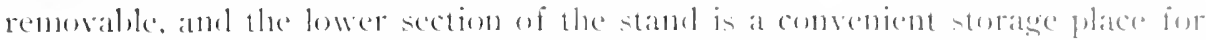

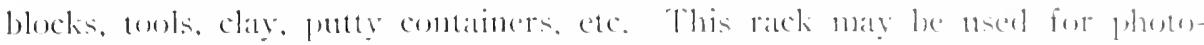

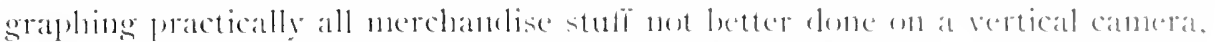
and illustration No. 30 is at geosl example of stach a set-11]).

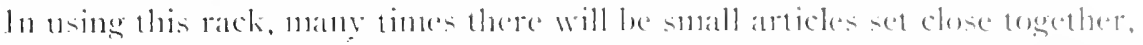

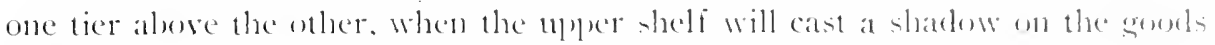
betow. In steh a case. the wooden shelves maty be replaced ly some of plate glass rery satisfactorily, and an exen lighting olstained.

While considerable work done in the studio is eventually blecked out. nevertheless you will need a good hatekround of some kind or othere and mow commercial places hase a backgroumd carrier with a black gromel on one side and a white gromme on the other. (of course. the best dark ground is of black felt, although the ordinary painted ground. even though it does not have the depth that felt possesses, does very well. For a white ground. it should be al

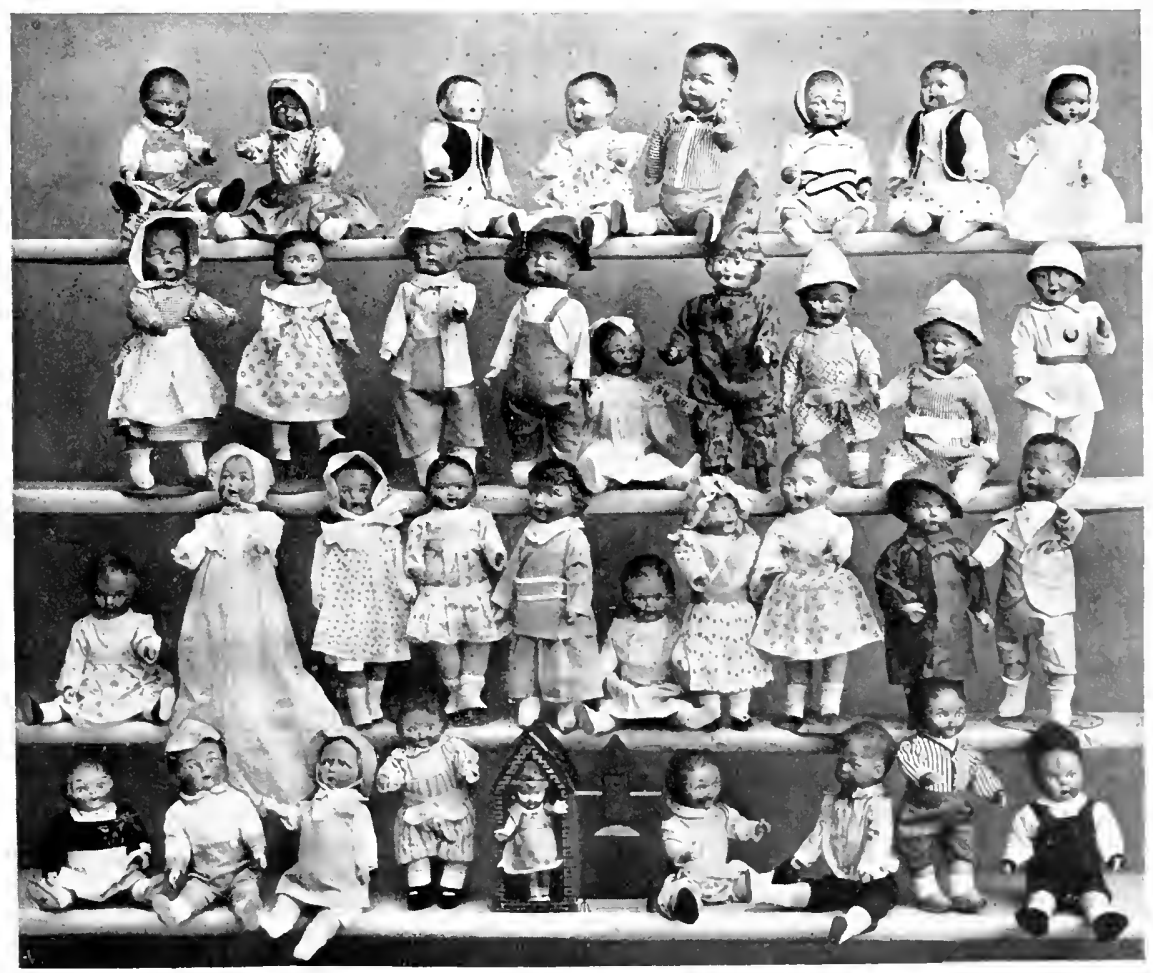


white that phetestaphe white. The lighthle-white and red-black gromels. which the pertatil man wes. and which, with color-blind plates, photograph

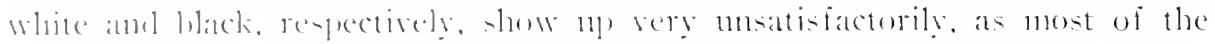

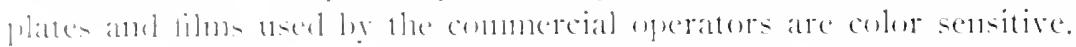

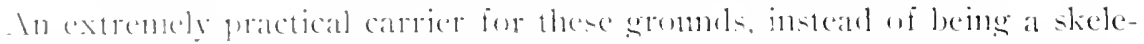

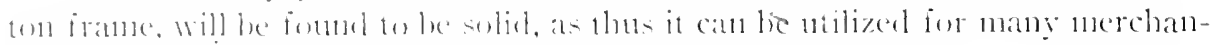

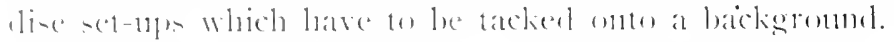

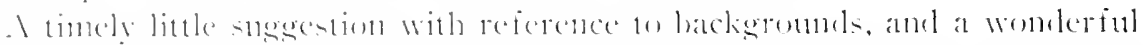

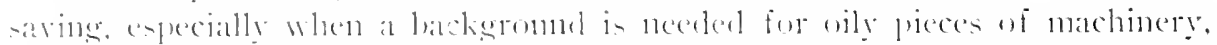

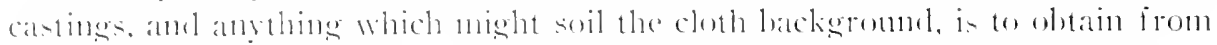

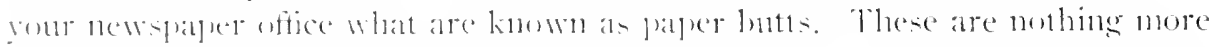

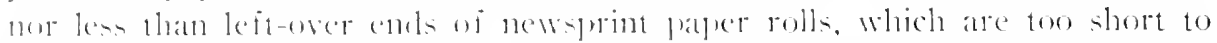

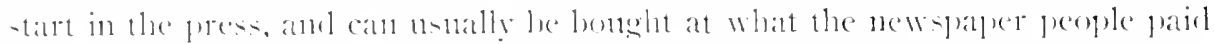

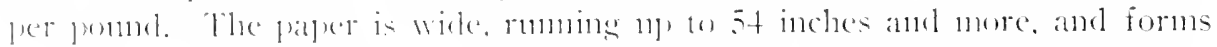

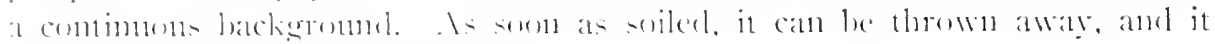

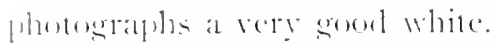

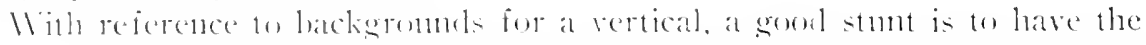
backerenumb. saly two of them. one hlack and the other a uentral tint, on shade

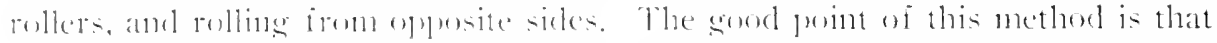

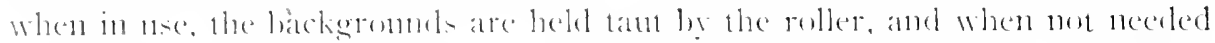

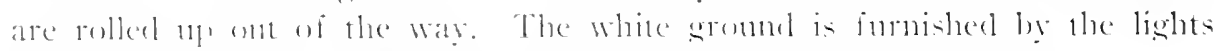

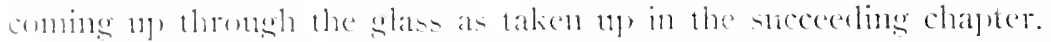

In maling set-ups where the artickes have to le primed to the backeromel.

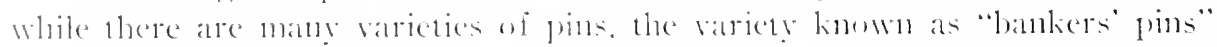

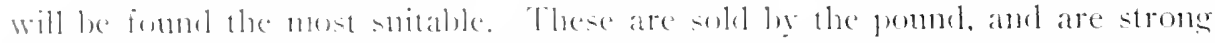

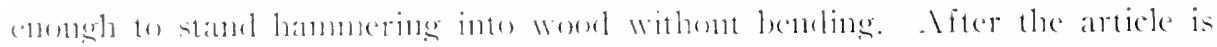
in platere the pins can le cut off close in with what are known as diagonal pin cutters, a toml you can buy all any hardwate sore for about a dollar and a quater. and which is werth its weight in wold to any commercial operator. In this wats, the neans of holding the atrticke in josition does not show in the

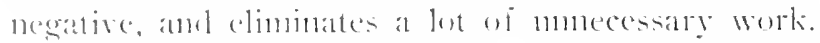

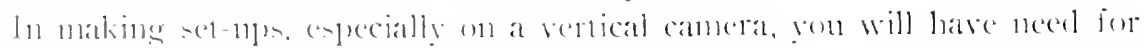

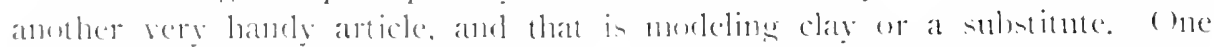

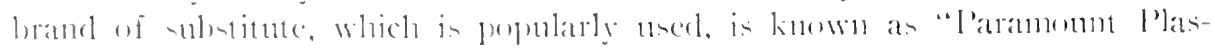

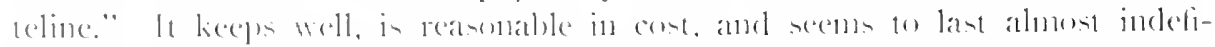

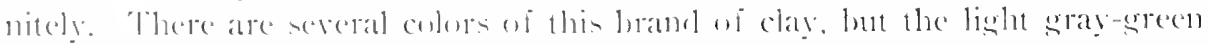

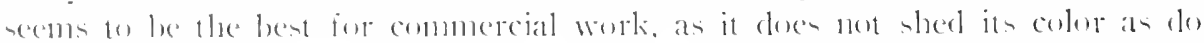

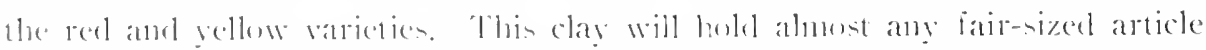

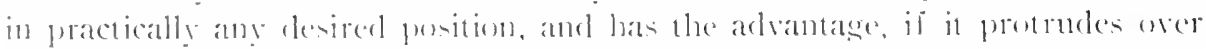

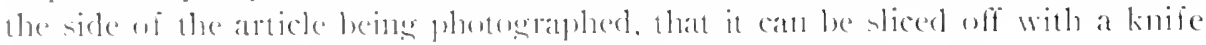

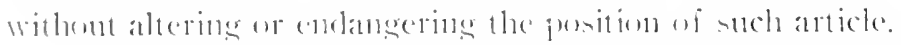

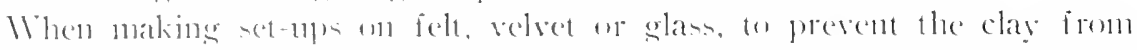

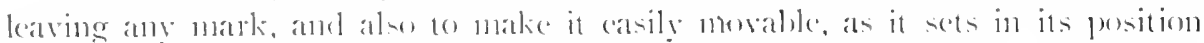

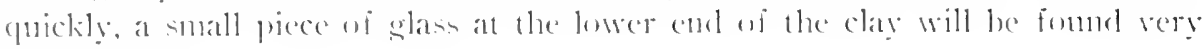
convenient. 


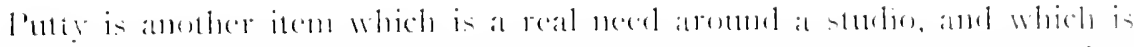

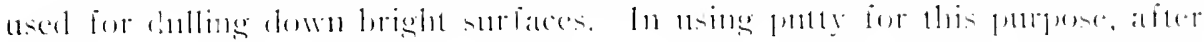

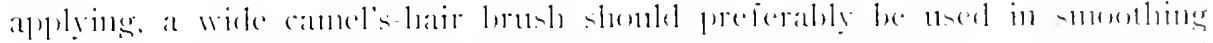

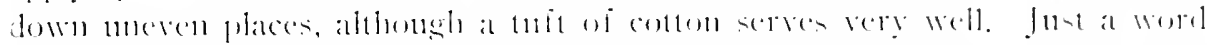

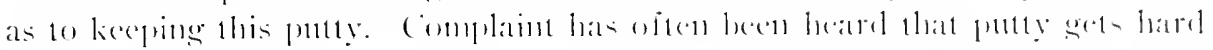

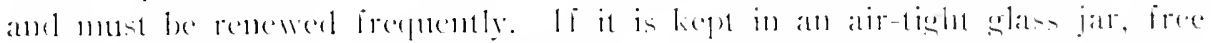

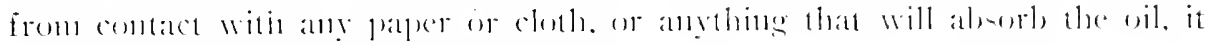
will kecp in equed comblition for momths.

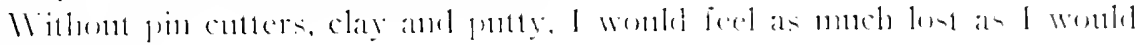
witholl il lows.

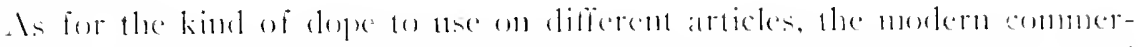

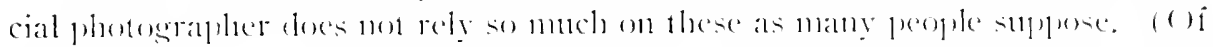

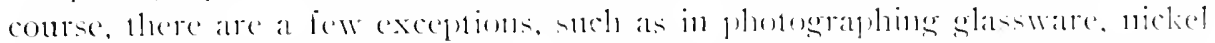

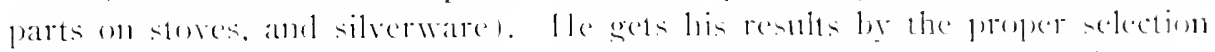

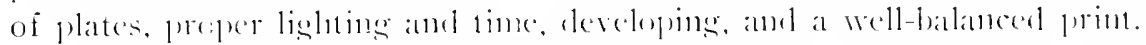

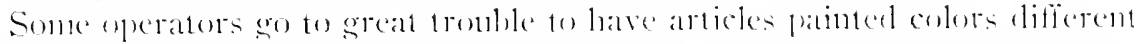
from what they ordinarily are, to malie them phestegraph, as they abll it.

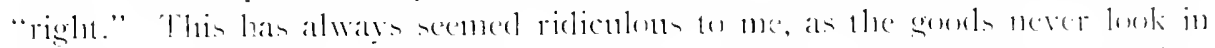

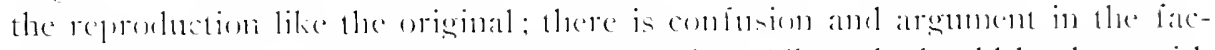
tory, and all in all, it is not the lest way to do. . Il work should le dene with the leatst trouble to the customer.

()f comse. there are certain ocasions when some dope helpse especially in toning down obtrusive high-lights and lightening ne dark corners. An excellent misture for this pulpose is what is known as retouch white and retomeh black, obtainable at artisss sapply stores, and used principally ly commerecial retouchers. When mixed in the rishe proportions for the particular job and diluted with water, they are easily applied with an air hrmsh, and any effect desired may be obtained casily and puickly. 


\section{CHAPTER XII}

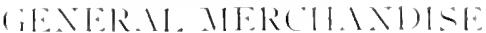

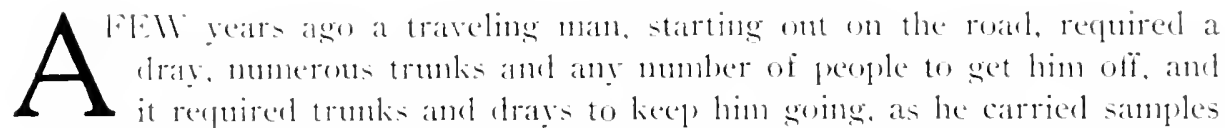
in some form of pratically ererything he solde If he carried any sort of a perishable line, stoh at candy. cigars, baked goods, etc. they had to be continually replenished from stock at headetuaters. which male a great many broken odd lots, and a large force of workers wats needed to lieep the samples in tip-top shape at all tines.

Nowadays. the sanke fellow. With the sane line, will go in to see a custoner. carrying only a portfolio, and in that port folio he will have photographs of his entire line, shown to nuch better atrantage than ever before-besides. he has not the heary trunks. nor the bother of carting them aromd, nor the necessity of renting a hotel room to show his samples.

of course, there are still sonc lines where they persist in carrying samples, but present conditions are rapilly hustling those few into the use of photogratphs.

You often hear the argument, "I can't sell my goods from photographs." An answer to that argument is the mailorer houses of Chicigo, who do millions of dollars" worth of business anmually-all from pictures.

Photographs for cuts for catalogues and for salesmen's books represent so many raried lines that all I can do in this instance is to pick out a few of them and explain the methods of procedure, for they rum all the way from cancly to merlical specinens.

If you want a real experience, just work for one of the large commercial sturlios, and in six months time I will guarantec you will have plotographed pratically ererything under the smu and lots of stuff that isnt under the sun. To my mind. medical specinens are about the worst I have encotntered-at least. they mate the most impression on me.

The latyout is one of the first things to be consilered in merchandise work. The standard merchandise print size, that is. for salesmen's samples, is generally $10 \times 12$, although some of them do use $8 \times 10$. this latter size ustally mate for the engraving houses.

In sromping articles for photographing on an $8 \times 10$. that is, for large lityouts to be reduced to $8 \times 10$. the proportions should be $16 \times 20,2+\times 30$, etc, whereas, those for $10 \times 12$ are $20 \times 24.30 \times 36.40 \times 48$, and so on. You can then gromp your articles within these lines, and you will know that they 


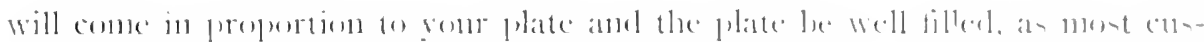

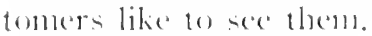

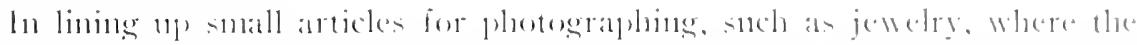

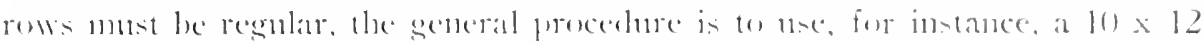

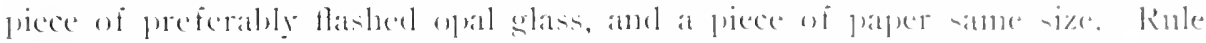

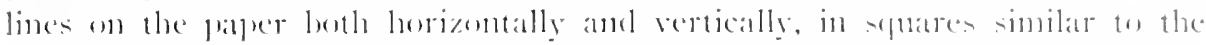

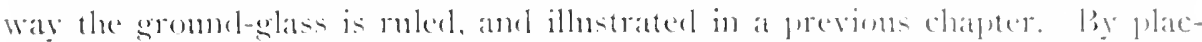

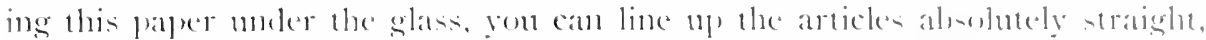

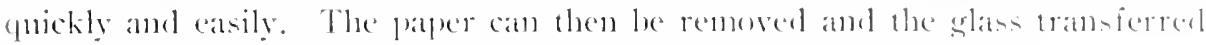
to the vertical canterat and in the photograph they will lowk right.

In excellent medium for holding articles such an rings and onher finte

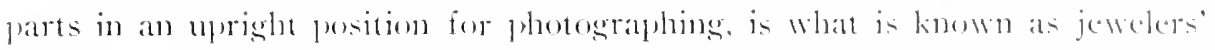
white wax, which photographs pure white and, as it is very tenateins, it takes a minute guantity to do the work.

1 good method wherely the size of the articles on a lage of merchandise may be determined by prosective enstomers, and especially where many are crowded onto one page. in to include in the picture a tape meatsure. ats illustrated in illustration No. 31. This tape measure should be rigid, that is, mounted on sonething which will hold it taut at all times. so that it can be

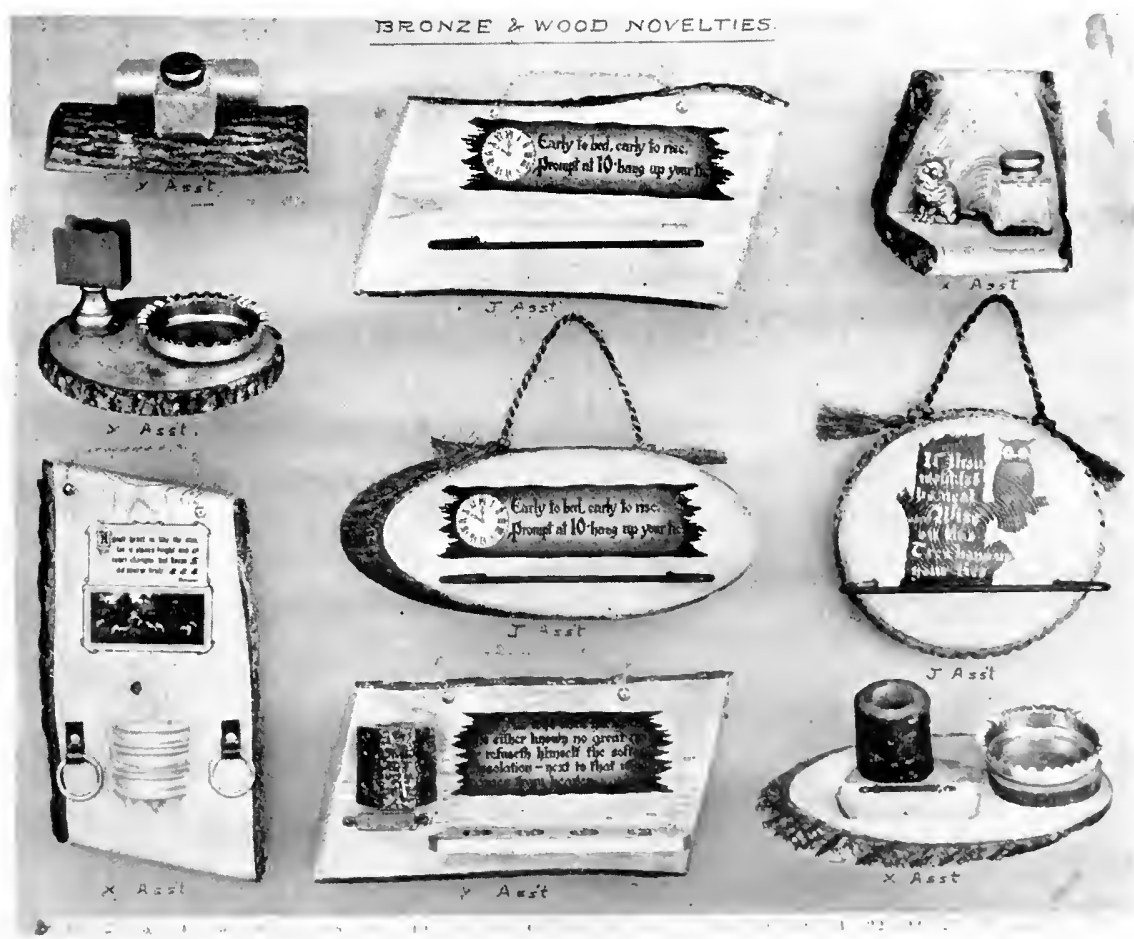



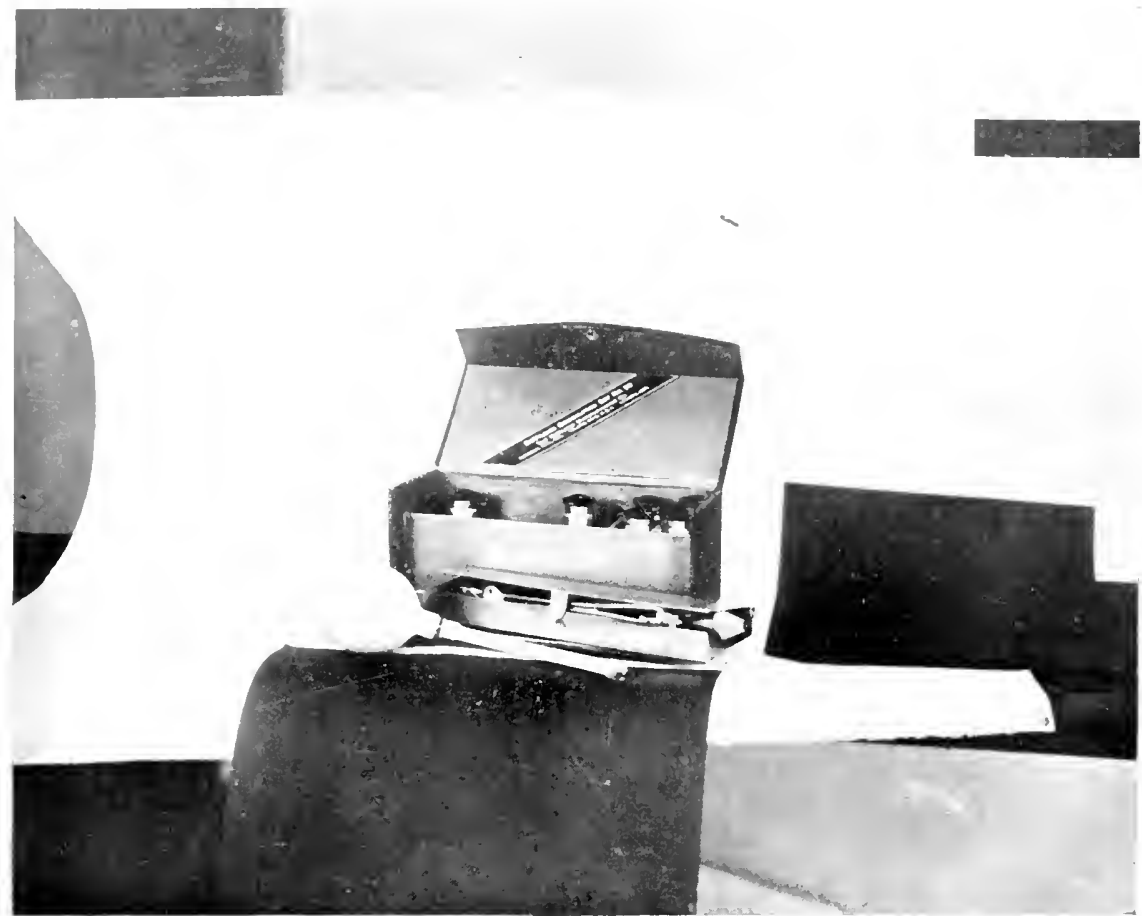

Fig. 32

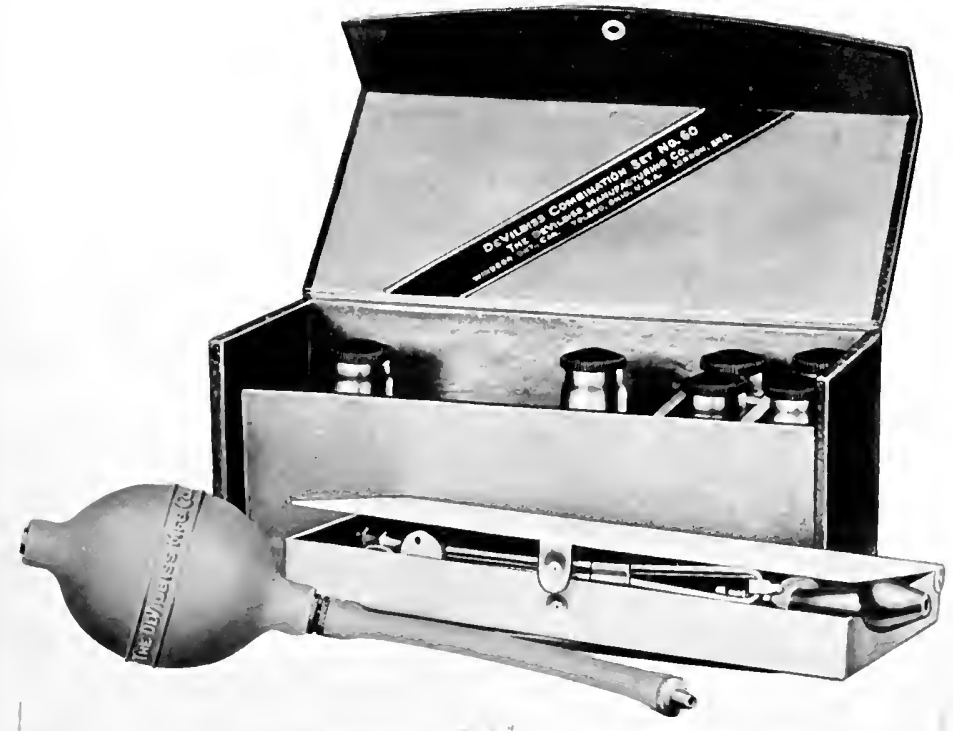




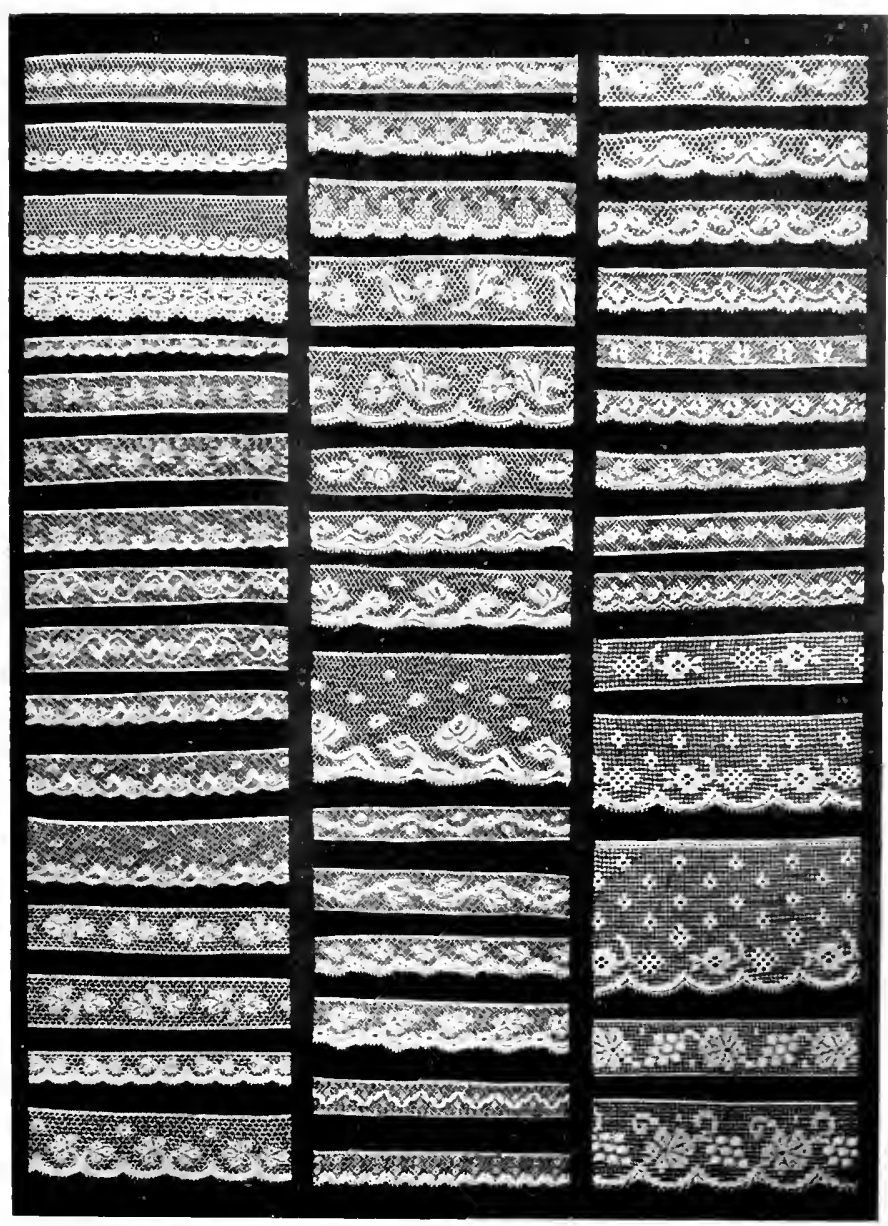

Fig. 3.4

placed in the same focal plane as the articles being photographerl, and should be of a color (preferably yellow) that will show up well against any background.

There are many articles, such as watches, clocks, certain jars of fruit, ete. which have a shiny surface at the edge, and which, if photographed sane size. even though a lens of long focus is used, look much larger than they really are. This has bothered commercial photographers for years. and I understand it finally took an outsider. an advertising man, to discover the cause of the difficulty: It is said to be an optical illusion. the shiny surface near the edge giving the effect of a much larger article. The way that has been evolved to get around this is to photograph an article of that kind. say foul-fifths or fivesixths size, that is, make an article that is ten inches high, eight or nine inches. 
and the article in the finished photograph will have the appearance of being the same size.

Another perplexing problem which arises in photographing commercial setnps is when a customer brings in something, for instance, a layout such as shown in illustration No. 32, which is about nine inches over all, and thinks, just because it is not as large as the plate. that it can be photographer the sane size direct on an $8 \times 10$. Is is apparent, the set-ni) is high and deep, and there is no lens on earth that will to a joh like that and get it sharp, with correct perspective, although many a poor fellow has tried it. The way such jobs are done is to make a 4 x 5 or $5 \times 7$ image and then enlarge 11 , and if the print order is big. make a copy and print from the copy. With your small inage, you get the increased depth, proper perspective, and the job is "right," being sharp at the points both nearest to and farthest from the camera. In the illustration, you will notice the black papers laid around underneath the set-up. These papers, which come wrapped around film, and which we used to have to buy, kill all white reflections and yet do not interfere in the blocking. Illustration No. 33 shows the completed job, some retouching having been done on the original photograph.

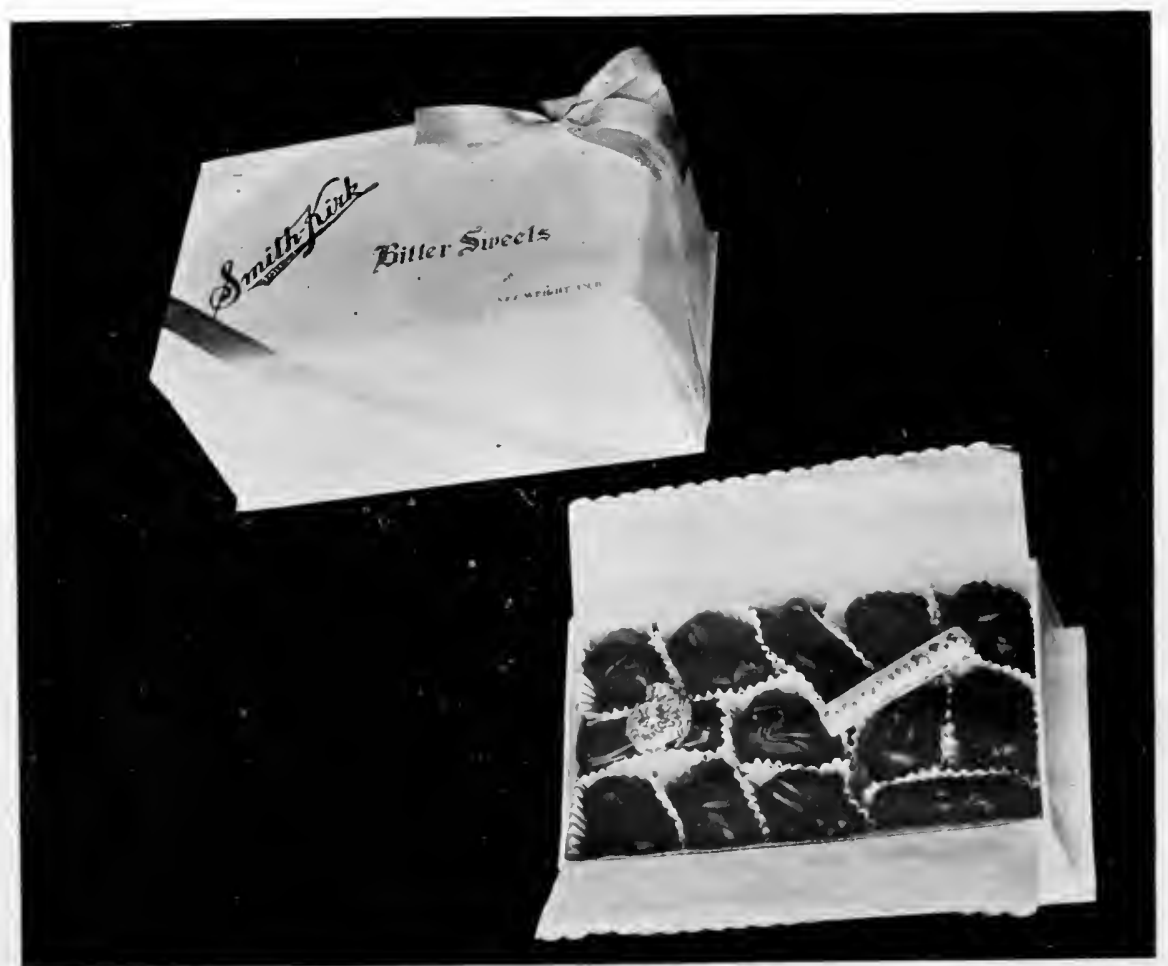




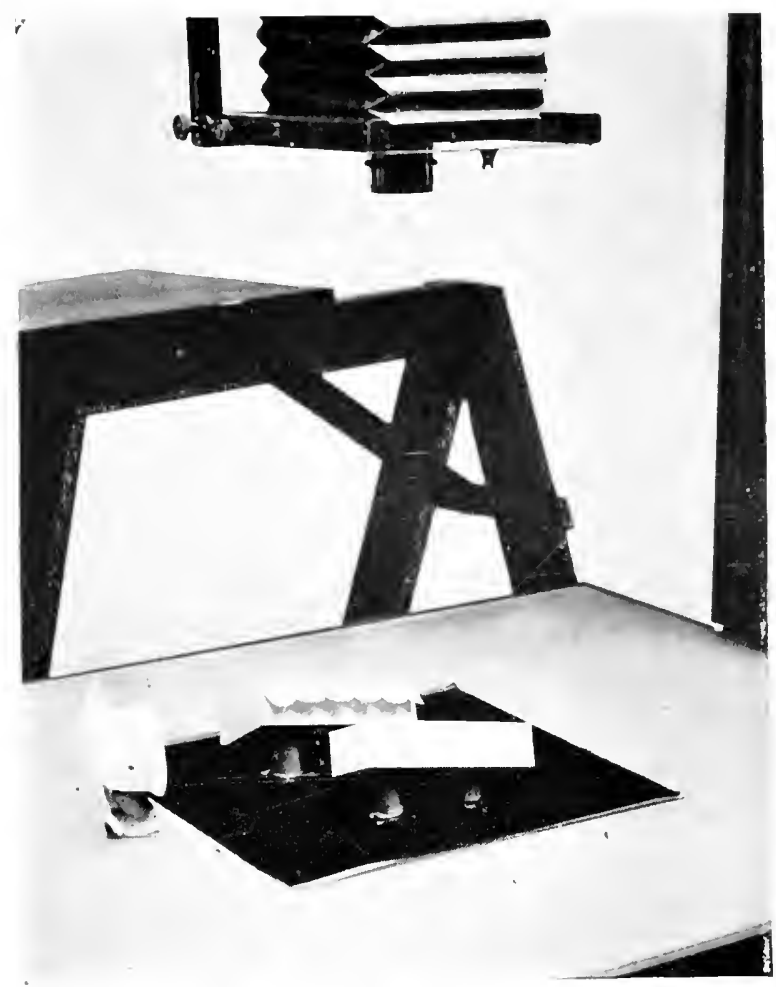

rig. 36

Laces and embroideries are another line which give considerable trouble. Illustration No. 34 is a set-rup of laces. The proposition is that the photograph has to show every little thread and design, as yards and yards are sold from these photographs. Laces and enbroideries are practically invariably photographed on a pure black ground, this particular lot being made on black velvet. A process film was used with pyro developer and the exposure was made by artificial side light. This side light gives nore relief to the threads of lace and to the raised design on embroideries.

It is in set-nps of this kind that the pins and pin cutter mentioned in the previous chapter come in especially handy.

A big help in making many set-nps is the vertical camera mentioned heretofore, and the results of some of this work are mystifying to many people, as the articles apparently have no means of support. Such a set-tup is shown in Illustration No. 35, while Illustration No. 36 reveals the manner in which it is obtained, by the use of clay on glass supporting the boxes. You will notice that the enstomer can see how deep the box is, its length and width. and how it is packed. It would be extremely difficult to get this set-up by any other method. A cup and sancer has been included in this illustration, to show the mamner of setting up these articles on a vertical camera. 
Illustration No. 37 is a set-mp of antomobile parts on a white backgromul. To do away with blocking, and at the sance tine get what you might call more of a relief effect and better light all around, as it does away with underncath shatows. electric lights are placed under the ground-glass at points denoted by crosses in Illustration No. 38, which is a photograph of the cancera with a set-up in place. The series of electric lights is placed aromel the lower edge of the compartment, and reflectors shate the bulbs in such a way that the light is thrown on the white floor of the lower compartment, and

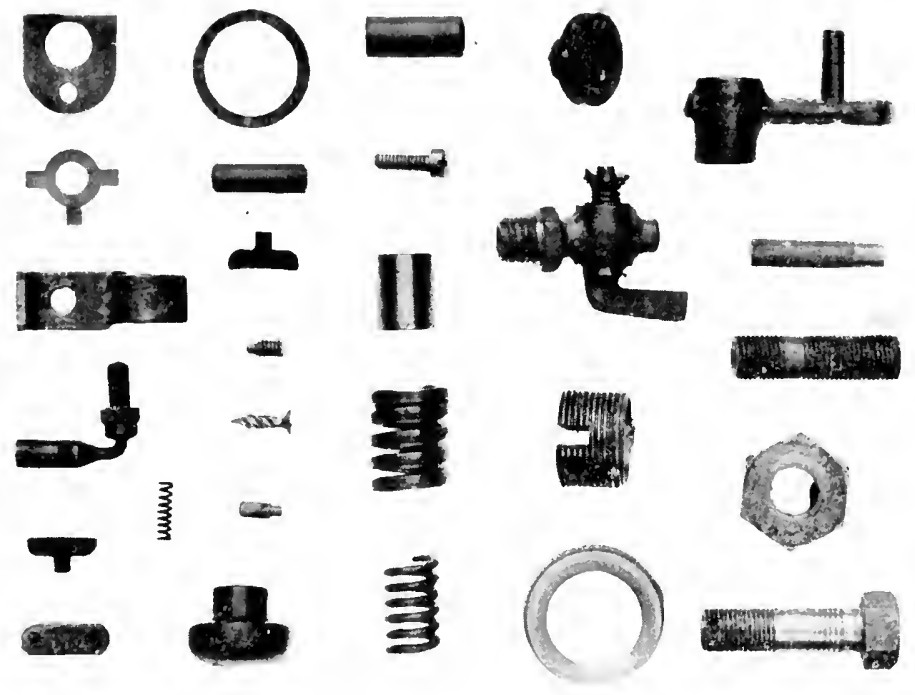

Fig. 37

which reflects 11p through the ground-glass. The lights are turned on for a short time, about 30 seconds in this particular case, when they are then switehed off and the exposture carried on as usual. The light passing up through the ground-glass gives more rom tness to the articles and an absolutely white background, providing you do not give too much exposure with the lights on ; overexposure, of course, flattening it down to a gray tone. This method is used in the larger studios a great deal, as it does away with a lot of work and blocking, and at the same time giving a much nicer effect. If you can afford it, an opal glass instearl of the ground-glass is exceedingly fine.

Of course, in a set-up of this kind, you are facing strong light, which absolutely puts the single-coated plate out of the ruming unless it is backed, for you woukl get halation galore. For this reason, film is exceptionally good, and if a plate is used, it should preferably be of the double-coated type, where the under emulsion is a slow one and the upper emulsion fast; such a plate being 


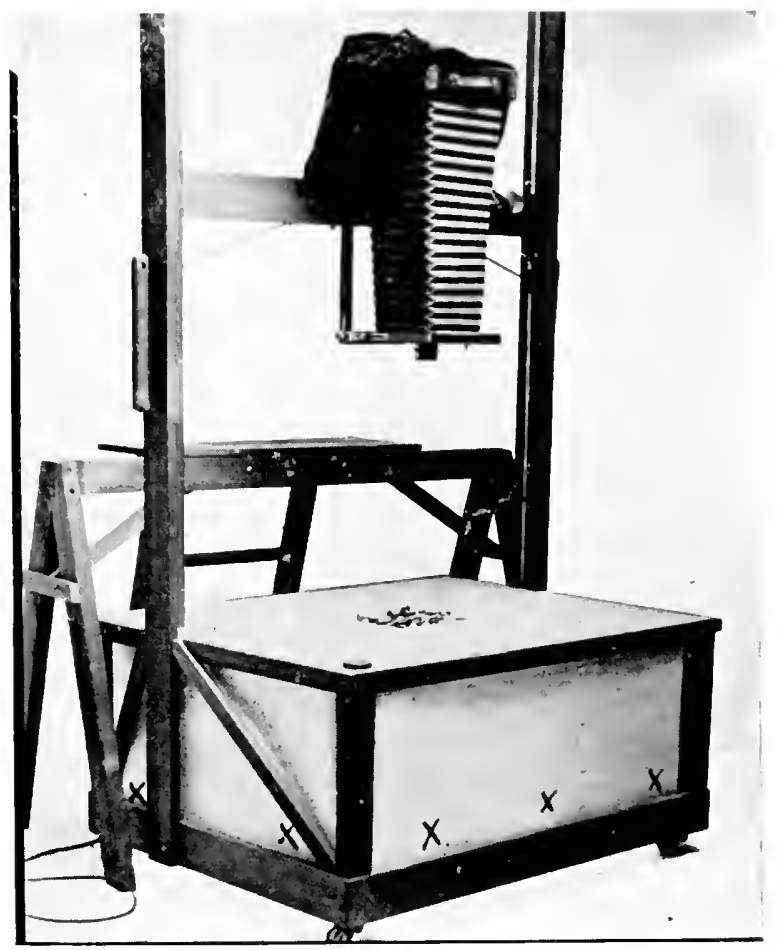

Fig. 38

the Seed Non-Halation, Cramer's Non-Halation, or the Hammer Aurora. The Wratten Panchromatic, being a backed plate, is ideal for this work.

Illustration No. 39 shows another type of set-up, being a combination of vertical and shelf set-ups. In this case, the customer wanted to show the peanuts full size, and yet wanted to show the large can, in which they were packed, on the same print. The peanuts in paper cups were photographed on the vertical camera, and the container on the shelf. As the exposures were all made on film, they were easily cut apart and all mounted on a $10 \times 12$ glass and then blocked out. 'This film is a wonderful help in such cases, and a big improvement over the days when you had to cut the glass; especially when nobody knew where the glass-cutter was, and perhaps the errand-boy had been practicing with it, with the result that a plate was spoiled.

In photographing any complicated mechanism which must be blocked or have a pure white background, and cannot be photographed on a rertical, for instance, a motorcycle, to save a lot of work, set it up on your platform about three or four feet away from a pure white background. Place an electric light on each side, in such a position that it shines directly on the background and not on the object being photographed. Give enough exposure so that the background will come white, in much the same way as when using the vertical camera, then cut off the electric lights and expose for the detail. 
Inother proposition that arises at times is in connection with making negatives for catalogne half-tones when the customer has all his pages mate

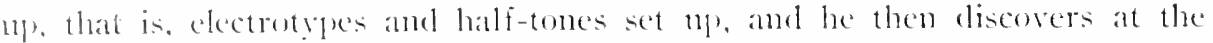
list minnte that an article is ont of style. Ont of stokk, or something has gone wrong necessitating a change in cut and a new photograph mate for substitution. The problem then put wy whe photograpiner is to photograph the substimted article so that it will exactly hit into the enpty space, which is really more difficult than it somuls, ats oftentimes the article, saly a box, is posed on a slant and tifted in different ways.

( )ne procerture on a job of this kind is to take tracing or tissue paper and make a tracing of the olel cont, or photogralph if you have it, and then make the new photograph to conform with this tracing, using the tracing paper aganst the gromel-glass of your cancera to follow it more exalety in focusing. Sone operators put a little castor oil or glycerine on the papere to malie it more transparent. This is a jol, that comes mp often in doing engraving house work, and nstually is a tomgh one, as it means putting the camera in exactly the same relation to the article as the othere operator hat it, and using the same focal length lens.

If one is perplexed at times to get a set-up that looks symetrical and at the same tine farrly comventional, and is at his wit's end for ideas, a little

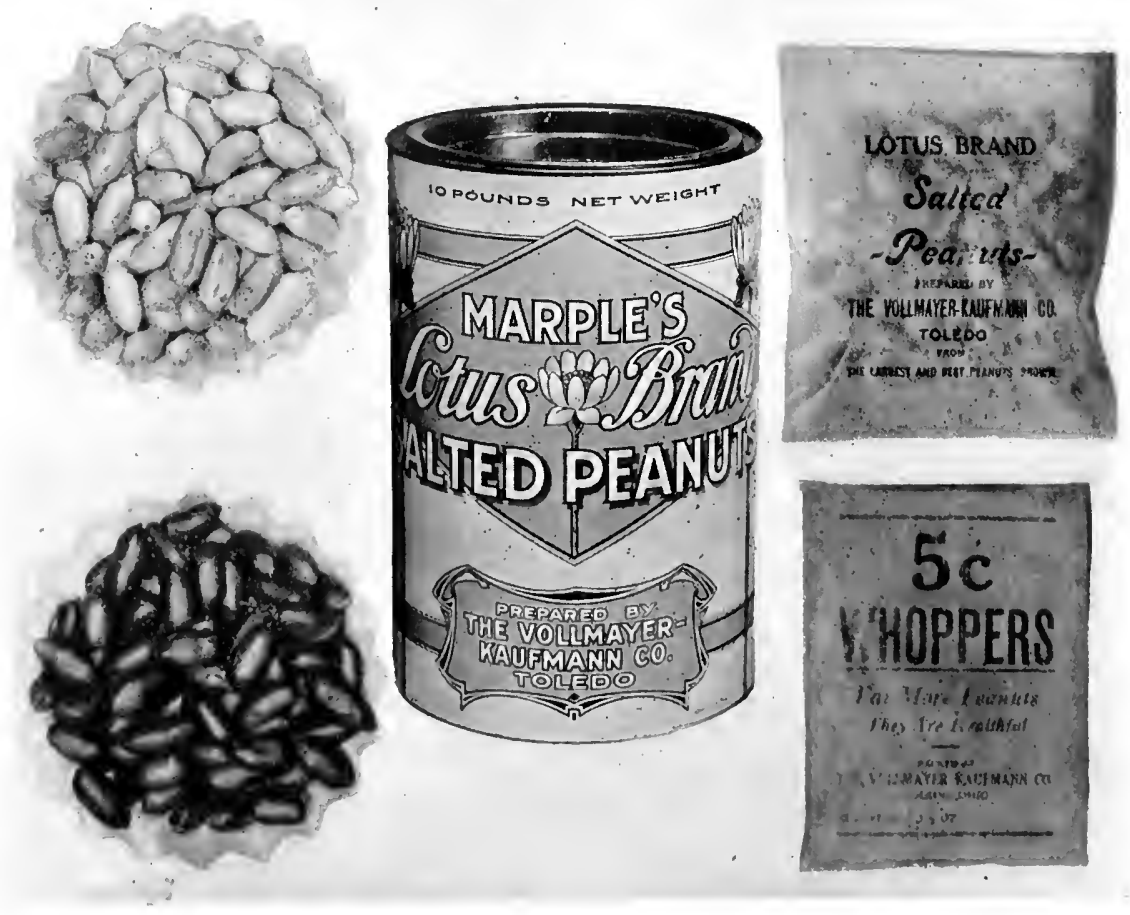




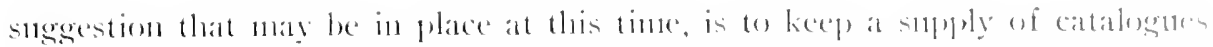
on hand eovering the various kinds of business that are in his vicinity and

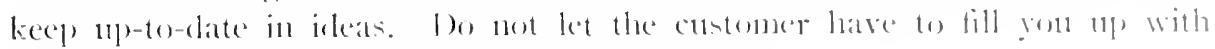
ideats. Give the restomer an illea now and then.

The kind of plates that will le used in the stuelio for merchandiace and catalogue nork is varied and ranges from process films or phates clear thromgh

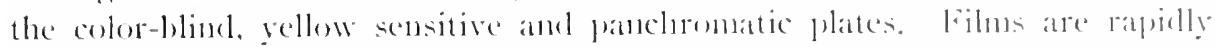
supplanting plates in the lareger share of this work exeepting with reforence to jobs repuring the panchronatic plates, in view of their non-halation dualities and the fact that they give better results and are easy to handle. store and ship. F'anchromatio plates are, of comrse, necessiry for a great deal wi work where reds must be given their correct color value.

The lens to be used in the sturlio should preferably le of farly long forens. although I have often used an extreme wide-angle lens in certain set-ups for adrertising concens who often get what they call "ideas."

On vertical cameras, of conrse, most of 11 s are linited to medium foncus lenses, in view of the necessity for working close to the set-11p. Mbout the tirst thing that strikes yon in wing a vertical, is that your lens is giving secmingly distorted inlages, and it will be fomd that the extrene corners will have to be tilted in slightly, that is, the center of your set-ny) is lower than your ontside edges, which will have to be pulled in, much the sane as in groupl work with the old style lens.

IV aste of Plates.-It is the habit of some oprerators to make an exposure, and then make another to see if they can better the first or make it a little bit different. To my mind, that is foolish waste. It not only wastes plates, lunt it destroys confidence in your own ability and always arouses a suspicion in a customer's mind that if you marle another you would get it still better. 1 know for a fact that it can be done away with, as many of the lig studios charge every plate to their operators and make then show a negative of some kind for every plate issued, and it makes good operators. They rarely, if ever, miss on an exposure, as they think instead of guess. Inother phase of this matter is that you have not got a lot of plates lying around on which no order can be obtained, and which are chargeable against the profit on a job. 


\title{
CHAPIER NIII
}

\author{
IURNTLRE
}

\section{$\mathrm{T}$}

IIE making of negatives of furniture and prints was one of the first branches of inclustrial work that called the photographer into use in helping to sell goods. Thirty to thirty-five years ago, some furniture mannfacturers were using photographs, and it is certainly interesting to talk to the old fellows and learn their trials and tribulations when working with slow and color blind plates. and to compare the results with those now obtaned with the modern color plates, ray filters and lighting methods. This work today is child's play to what it was fifteen to twenty years ago.

Nost furniture is photographed in the factories where it is made, nearly all of the larger plants and many of the smaller ones having a room for this purpose, which is nsually their display room, with a skylight and a plate changing room for the photographer, making the work comparatively simple. In fact, most operators consider it a poor day's work if they do not make eighty to ninety negatives, that is, in the general run of factory work. It is for this reason that photographers have the matter of low price to contend with, for some photographers have gotten the price down to 75 cents to $\$ 1$ for $8 \times 10$ negatives, and occasionally lower, they contending that the simple arrangement, the mannfacturer furnishing the cantera and by putting boys on to the work of doing any necessary preparing of furniture and making the exposures, allows them plenty of profit.

This is all to be very munch deplored, as are low prices in any line.

The general procedure in photographing in the factory, or in the studio for that matter, for a long run is about as follows: Lines are drawn just off the background and each piece brought w1 to those lines: the camera is practically never moved and the exposures go along one after the other and the only changes made are in plates, pieces of furniture and number on the signs. The manner of exposing for the signs, such as shown in illustration No. 40 , may he of interest. This is a fair average of factory photography. The lettering for such a photograph is set up in a frame alongsiule the piece and is exposed for a short time, say ten seconds. when it is covered with black velvet and expostre made for the furniture itself. The negative is then blocked for printing.

As for preparing furniture, that is a question which must he decided for the individual case. Certain manufacturers insist upon their stuff being photographer in the white or mnfinished state and positively will not stand for any dope of any kind. Others give it a sort of filling coat, which seems to bring out the gratin very nicely, and then again the photographer does his own pre- 


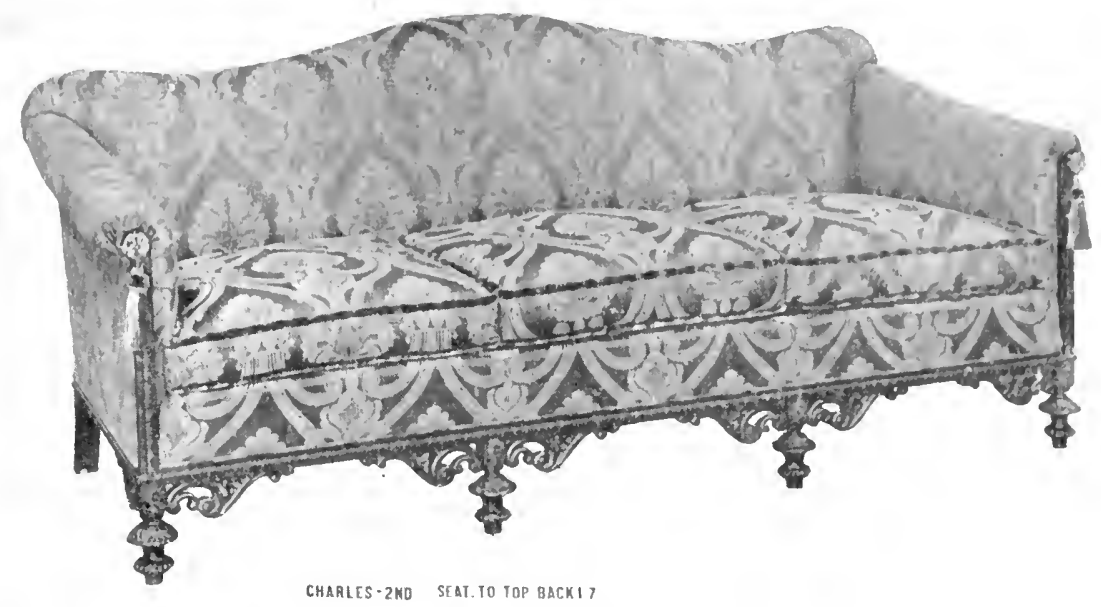

HO.6108D BETHITMARMS 71 183035H36

Fig. 40

paring, using a mixture of kerosene and gasoline, the gasoline being the ingredient that does the husiness and the kerosene keeping the gasoline from evaporating until the exposure is matle. Or, you can use gasoline and pariffine. What I consider the best of all is Cerlar ()il, but that is rather expensive.

However, it is in the photographing of finished furniture, which is highly polished as a rule, such as pianos, tables, ete. where considerable ingenuity is required in getting away from reflections and obtaining a satisfactory result.

There have been several methods recommenterl to eliminate white reflections, anong them what is known as tenting, that is, to stretch nuslin all around the piece and connecting it to the cannera, so that all the light is filtered through this muslin in reaching the furniture itself. That has several atrantages for some work, lut the disatvantages to my mind offect the advantages. That is, to begin with, it takes considerable time to put it up, unless frames are made for it, and it has to be taken down for every piece. Then, again, it throws white reflections on the artickes (unless darker muslin is used, when it takes longer for the light to filter through the tenting), which is highly detrimental to a piece of mahogany or rosewood. As speed is very essential, if one is going to compete with the price business, it comes down to a system of working with your open lighty putting the pieces against the light ground with dark reflectors in such a position that they will reflect upon the polished piece of furniture and make the illumination even. While it takes considerable time to get the reflectors in their proper positions, they will usually do for the whole rum of tops, and can be used in different positions for practically any style of furniture. 
In photographing furniture, the position of the cancrat is very important. That is, in most pieces, you must show all fonr legse give about a three-quarter view, show the gencral construction and design, such as muler shelves in tables, which neams that the camera must be worked fairly low. Where it is necessary to show sonte distinctive design in a table top and still show all four legs. the better conrse is to nse the camera fatrly low to get the legs right, tilt the top of the table forward, and nse your swingback to the limit. This is only one of many cases where an excessive swing is nsed to great alvantage in commercial photography.

The photograpling of furniture containing mirrors is also a problen that hats to be met. While in the general rum of factory work, the mirrors are nsually blocked out when photographing furniture for exhibition and other purposes, the mirror will have to be photographed to show as a mirror, which means you will have to tilt the mirror at such an angle that it will not reflect surromeling objects. or better still, a black, white or gray screen, according to the color of the furuiture. may be placed opposite the mirror to get the right result.

Is to the lenses-a lens for this line does not have to be one of highclass, although, of course. such a lens is preferable. Many of the commercial shops are using the old-tine lenses-in fact, you would be surprised if you knew how old some of them are and how cheap they can be picked up occasionally. I have a lens that I will wager is fifty years olle, if it is a day, and it is doing very creditable work on furniture and giving exeellent definition. It is a thirty-one inch focus Somerville. I do not suppose you can buy a new one today, and while it is clumsy to carry and slow. distortion of perspectice

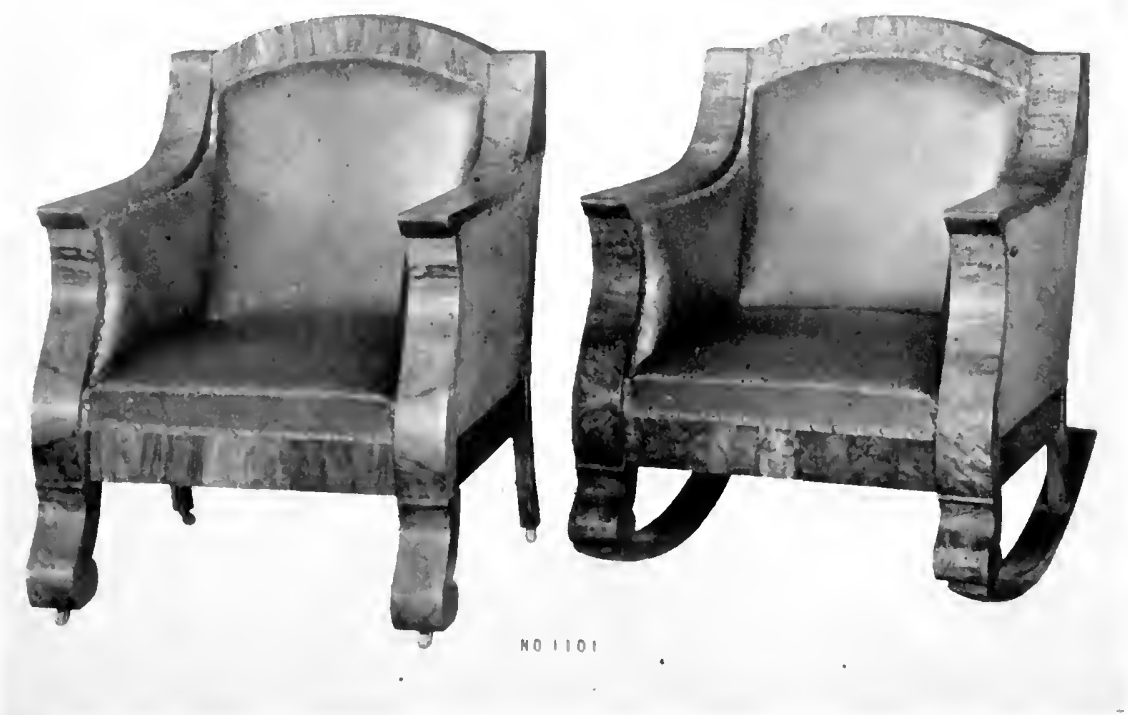



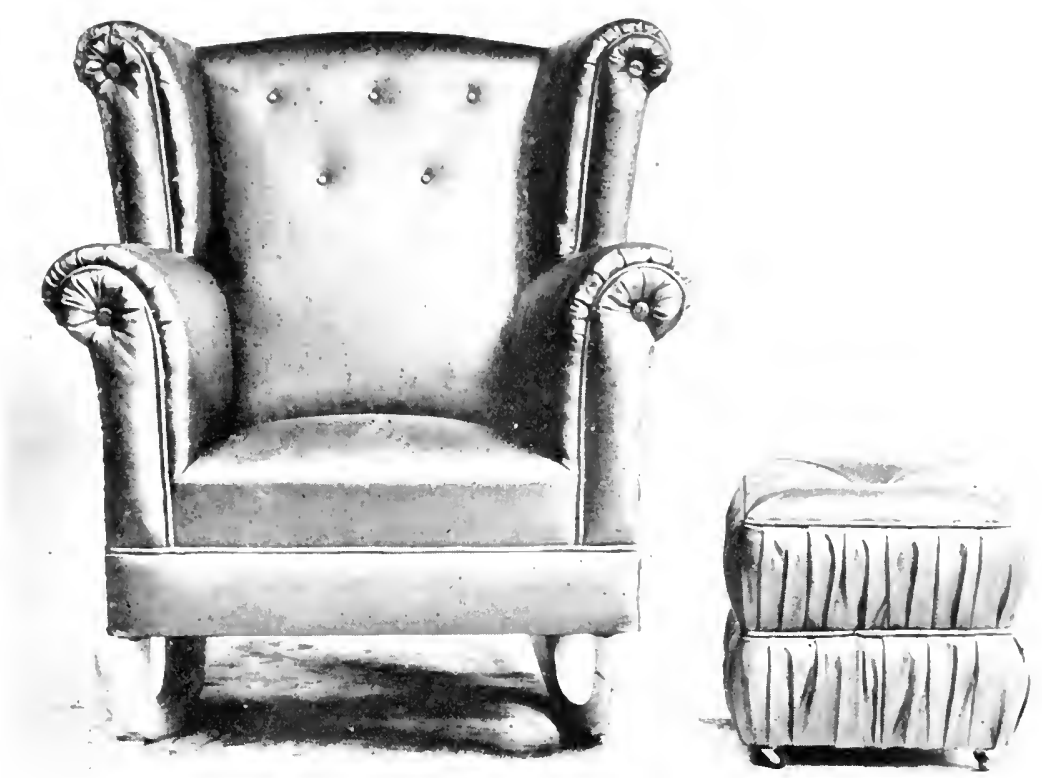

Fig. +2

is unknos'n to it. The main requirement of a lens for furniture is that it be of very long focus.

Panchromatic phates are a real necessity in photographing mahogany, rosewood, cherry and all red-toned woods and, used in connection with a deep screen, the results leave nothing to be desired. The filter you will use will depend upon the kind of wood. The $I$ and $F$ screens for reds, the $G$ on light woods to bring out the grain strongly, and the $K-3$ on panchromatic plates to give a normal correction.

The $K-2$ filter is used principally in connection with Conmereial Ortho film and gives wonderful results, as does the Commercial Ortho film also without a filter when used on prepared furniture or light woods.

Illustration No. 41 is a group of chairs made on Hammer Aurora plate with no color filter. No. +2 is a chair and stool made for advertising circulars, on Commercial Ortho film with K-2 filter.

Although the mamufactures' end of furniture photography is extremely cheap, there is one line which has proven profitable in localities inhabited by the wealthy, and where, naturally, the antique shops will be found. This is the photographing of fine, old furniture, and is really quite a field and can be worked in conjunction with the photographing of rare rugs, tapestries, bric-abrac and paintings. In this connection, the best of photographs have to be produced and the prices for this work are generally good. 


\section{CHAPTER XIV}

\section{STONES}

$\mathrm{I}$

LLLSTR.TTIOXS nsed for store catalognes formerly were made by the wool cut process, giving very sharp, clean lines, and an even appearance all throngh which, I think, is the cause of the requirement for so much preparation in the photographing of stores nowadays.

The stove, to my mind, does not look right prepared, and I an of the belice that the time is not far off when the mannfacturers will insist that the stove be photographed in its natural state. I do not mean just put the store up) and give it a "whack" in any old way, but I really think that if a stove is placed right, the proper lighting and exposure given, and good care exercised. that that photograph will look more natural and will sell more stoves to the average customer than one all (loped up to make it look like a Fifth Irenue display.

Nerertheless, most of the stove companies now require that their stoves be prepared before photographing. and a good dope for this purpose is made of lamp black of (lrop black that has been cut in alcobol, thimed down with water and applied with a soft brush. or with an air brush that will take heary mixtures. The nickel parts either should he puttied or painted up with zine ointment, and a great deal can be done with these parts by the proper preparation, that is, getting the coating, whether putty or the zinc ointment, on smoothly.

A real help in properly illuminating the stove is the tenting nentioned in the previous chapter, as the white muslin throws a light reflection into the dark creviees, and tones down the black surface.

In riew of the great range of contrast from the whites clear down into the black, the exposure given will have to be very full. and should be made on a double coated plate such as the Standard (orthonon or the Ilanmer Aurora, or a film with considerable body. which means the Commercial film or Commercial (Mrtho.

The lens, as in furniture, will have to be one of very long focus, especially for ranges, and the position of the cancra should be farly low to show the four lexs and also give a more massive appearance.

l'rices for stove negatives, including preparation. unlike that of furniture, are generally quite fair-in fact, I to not know of any kick one conld make in this connection, so it gives the plotographer time to fope the stove and still make money by this method.

Another way to photograph stoves. and a method frequently used by manufacturers, especially in the small towns where they do not want to go to the expense or inconvenience of sending their stoves to the specialist. or 


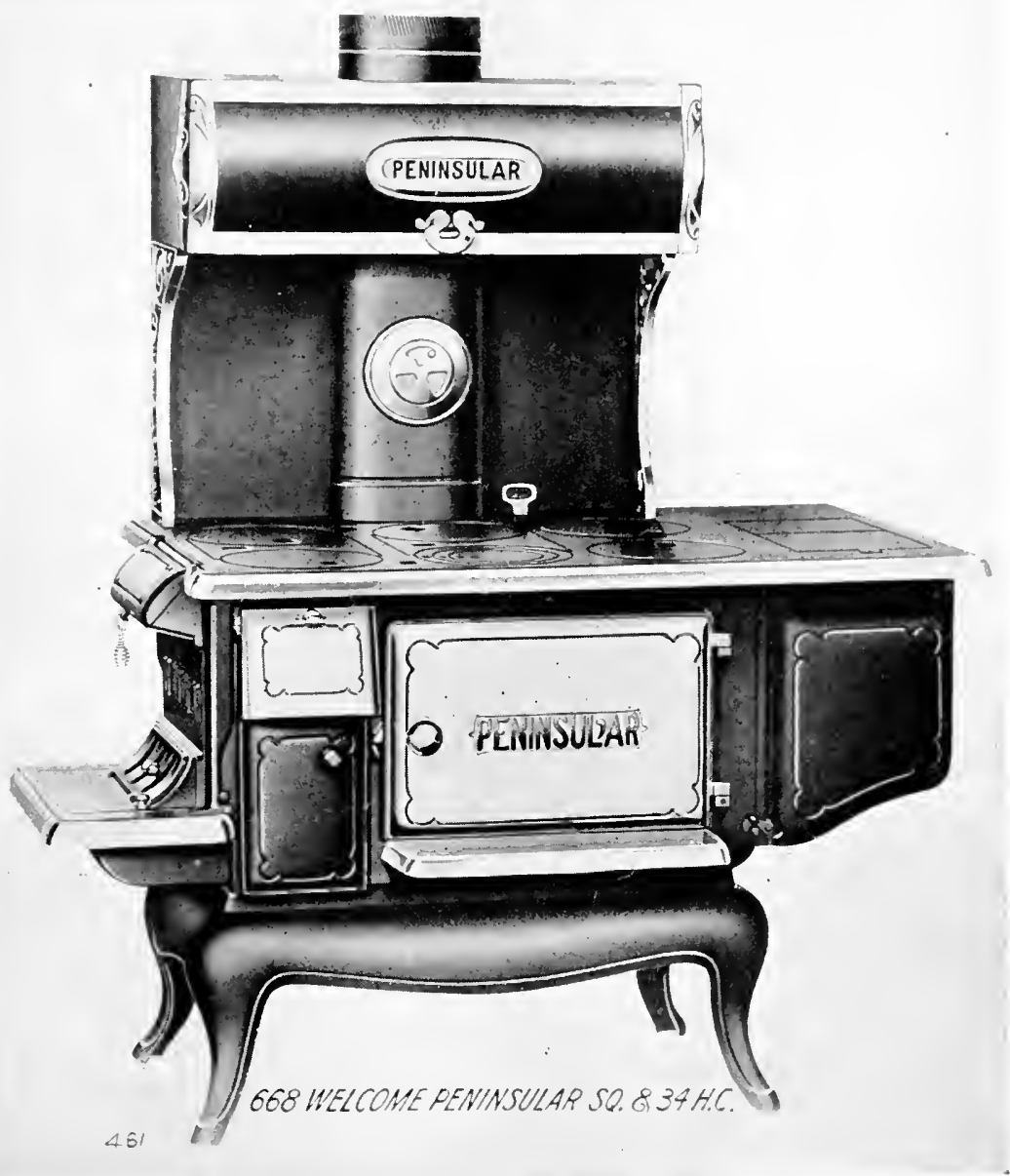

Fig. 43 


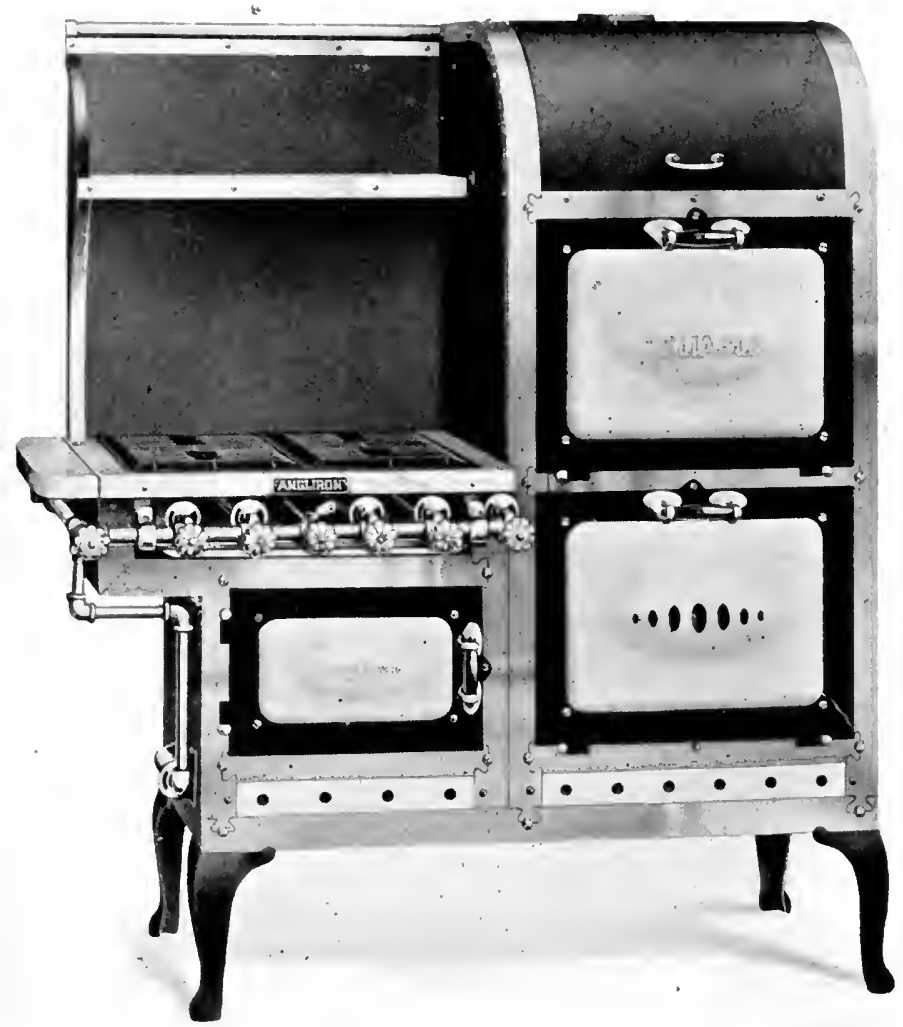

Fig. 44

bringing him from the city, or where no one is at hand to clo this preparatory work, is to make an $8 \times 10$ negative of the stove with ahmost any kind of a light, really paying little or no attention to this end, but getting the proper position. That negative is then blocked out and an enlargenent mate to $11 \times 14$ or $14 \times 17$ for retonching by the connuercial artists, employed by the photo engravers who are making up the catalogue. Should prints be wanted for traveling men's sample books, those retouched enlargenients can be copied and prints made from the copy negative.

Illustrations No. 43 and No. 44 show stoves that have been made by this means, and while an artificial appearance is given to the stove, some nuanufacturers seem to like it.

Illustration No. 45 is a plotograph of a stove that has been prepared, and No. 46 shows a stove, photographed with a living model, for advertising purposes. This latter line calls for a lens of good covering power and plenty of light, either daylight or artificial, but mostly daylight supplemented with some artificial light. It is a good field and one highly remunerative. 

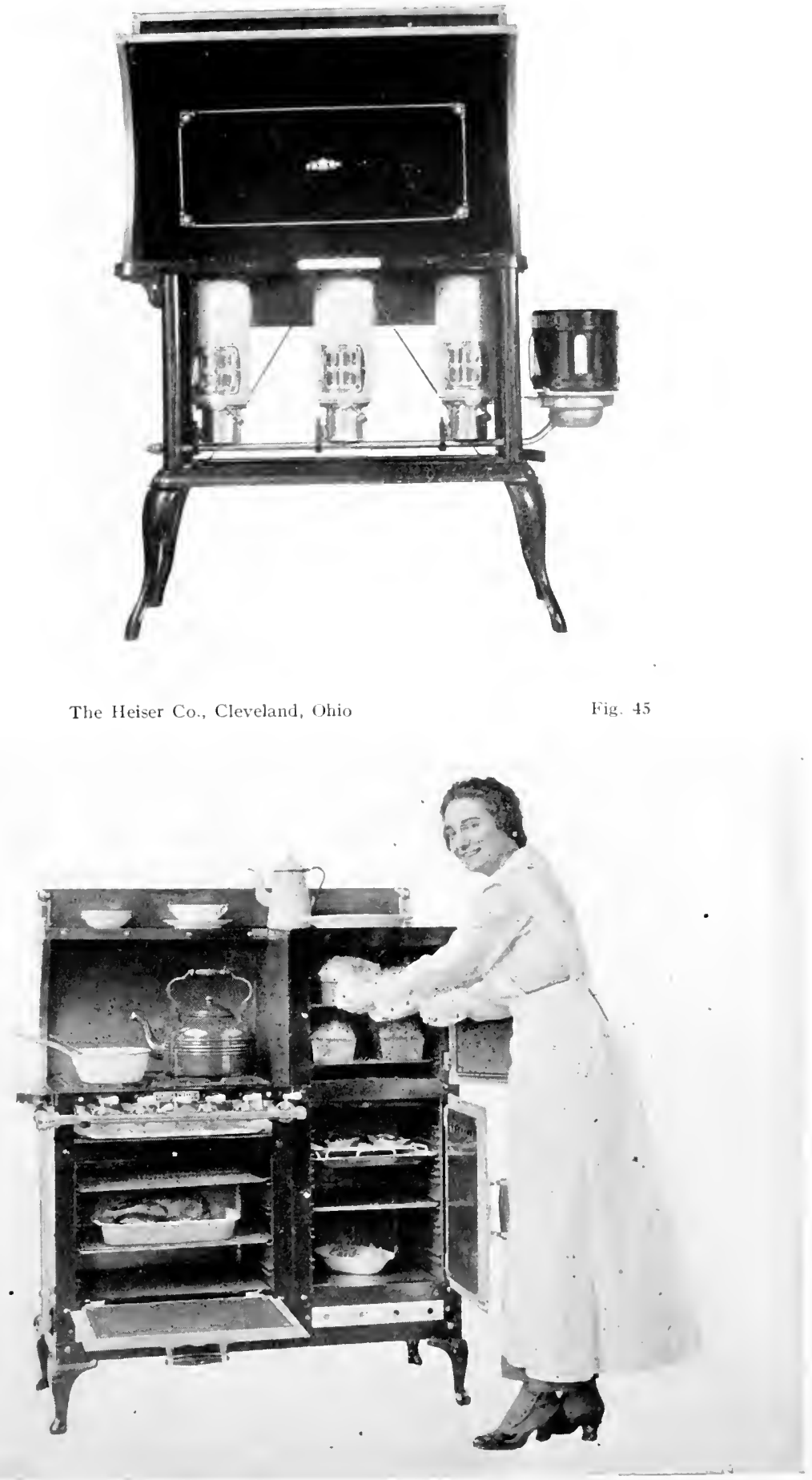


\title{
CHAPTER NI
}

\author{
MONLMENTS
}

$\mathrm{M}$

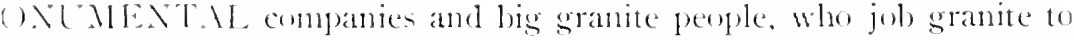
the monument factories. are consistent users of photographs-it is practically the only medium now ured to sell monuments, and while there are only about fifteen really large companies in the Lnited states who design and build nonuments and mansolemm, they have extensive sales forces and secure contract in every seetion of the country. Also, practically every large piece of work is photongaphed.

This is very nice work and for the most part is largely in the hands of a few photographers who specialize in monments only. One party I have in nind particularly, travels constantly all over the country, going to the various cemeteries and photographing any new or unusual designs which have been set in place since his last trip, and he uses these as stock negatives from which he sells prints to the monument people for use by their designers.

IIl of the large nanufacturers, who create their own designs, have about everything they produce photographed, and their salesmen carry all their samples in the form of photographs.

The proposition in photographing monuments is that the maker wants to show every detail in the granite, the lettering and design, and as the monnments are ustally set in place prior to being photographed, it is a matter of selection of the right time of day to bring these items ont well. A front side light is generally preferable, and if it is not possible to secure such a lighting as in the case of a monument set facing the north, the photographing had best be done on a day when the sky is overcast.

Another matter to consider is the backgromul, for it does not take much to detract from the seneral appearance of a monument. Illustration No. 7 shows a monument with numerous other small stones in the foreground and off to the side, which decidedly mars its attractiveness, although it is really at very fine stone and a good seller. A bromide enlargenent was made from this negative and the disfiguring stones were touched ont with a mixture of India ink, a minute quantity of white water color and burnt mulser, thinned down slightly with water. A little practice makes this work comparatively easy and the camouflaged stones make gool looking shrublery, as seen in illustration No. 48.

In cemetery work, there are a number of other details with which much care numst be used. First of all, dirt should be cleaned off the monument and high grass carefully pulled away. Then, again one frequently encounters cases where, in getting the proper view of a monmment with the cancra in a farry 
low position, there is another monument, possibly a little distance away ant generally a high shaft, or a smoke stack or other disfigmring elenent, showing over the top of the monment being photographed. One way to get away from this is to collect some branches, which workmen are constanty trimming from trees and bushes in the cemeteries, and have your assistant hold them up at little distance back from the monument so that they will hide the mulesirable feature, and keep the branches in motion while the exposure is on. This is very good camouflage and produces a much more desirable result than otherwise.

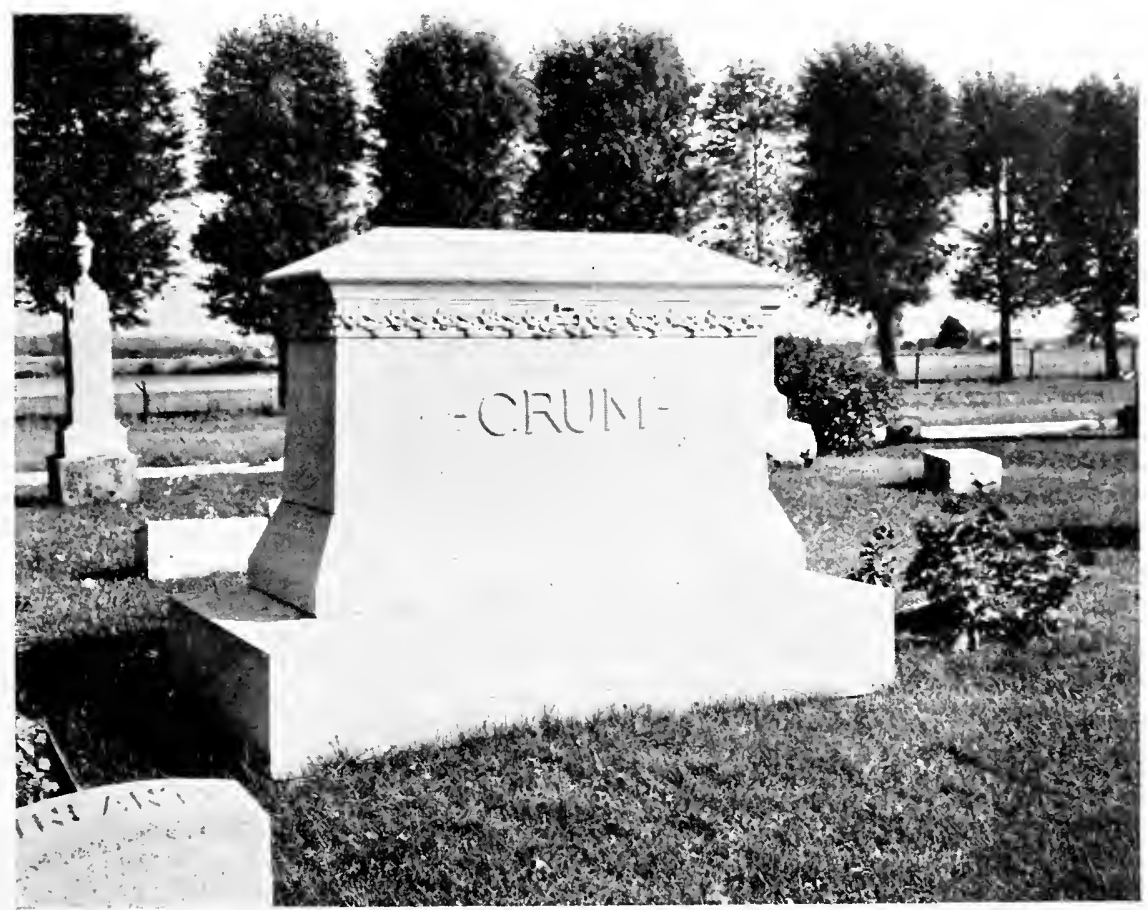

lig. 47

Some manufacturers are now having monments, excepting those which are too large to ship complete, such as mausoleums and memorials, and which have to be built on the site provided for them, photographed in the shop. Illustration No. 49 is a photograph made in this mamer. with a side light from a window, and gives an ideal effect such as desired by the designers. The lettering stands out prominently and the granite shows to advantage. Should the operator encounter reflections, as is often the case in photographing red or black marble, both in the shop and in the cemetery, a black screen can be carried along and used to kill these reflections, if placed in the proper position.

You will notice that this is an absolutely pure black background, and as 
much of this kime of work is done, the proposition is to do it quiclily and casily. () f course, it can he lug off with an etching linife, but this does not make a clean job. The method nsed to remove the filne, in this instance. was to ontline the momment which. by the way, shomld be photographed on a flate. With a sharp etching knife, that is. the film was cut through to the glass all around the nuonment. The film of the whole plate was then just wet through-just barely wet, when the negative was taken from the water, the smplus moisture dried off, placed on the retouching stand and the edge of the flum caught 11p by the etching kinfe and rolled off the glass, leaving only the

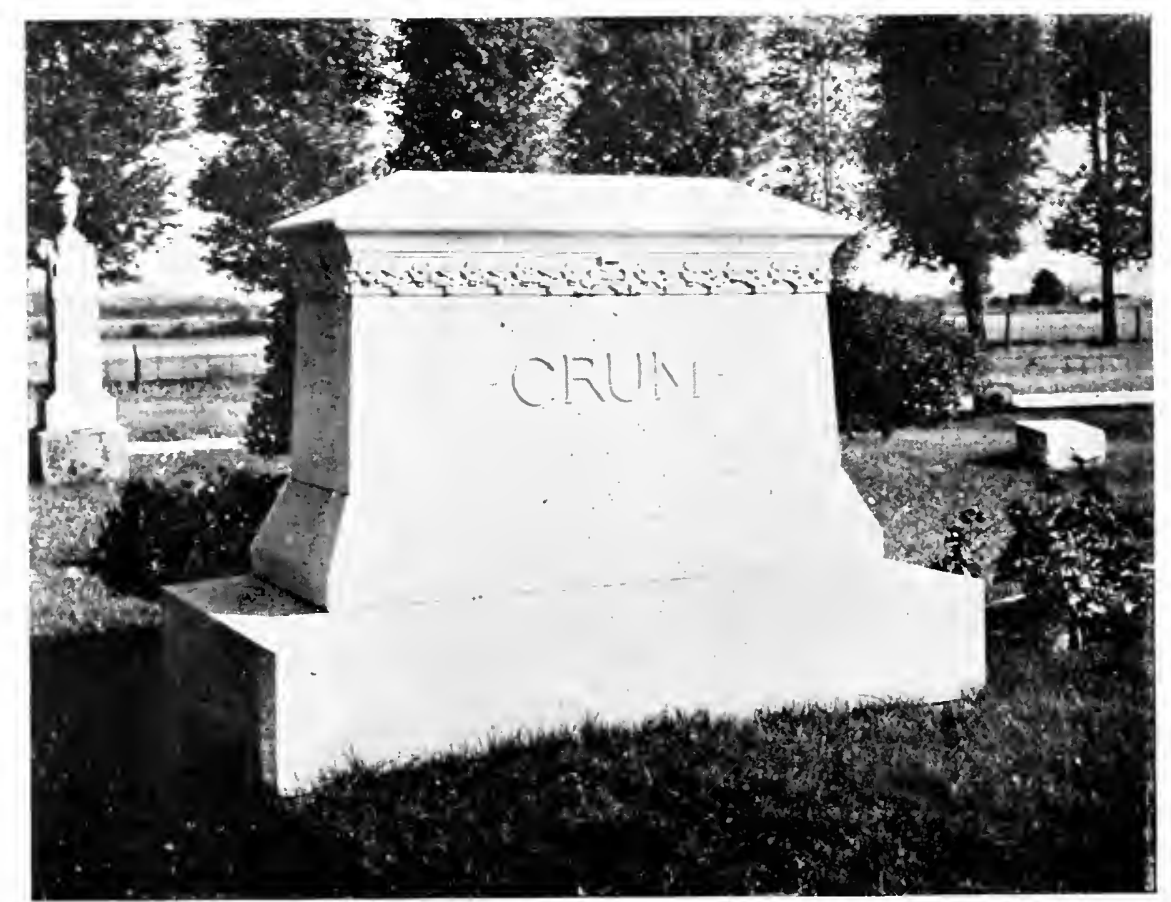

Fig. 48

image of the monument on the clean glass. With a little practice you will find it is not at all difficult.

Sometimes this film will not peel off readily. This is usually due to two things. The first is, probably the fixing bath was old and it elic not have enough acirl in it. The second may be that the film is too wet. It must be just wet througl and that is all.

The lens to be used does not always have to be of long focus, as a medium lens, say 12 to 14 inches, answers very nicely, but, of conrse, it has to be a lens of good covering power and the position of the camera must be low to give the appearance of massiveness. A favorite position is to show just a trifle of the end and all of the front. In photographing mansoleums, a long focus 
lens is far more preferable, hut it should alwatys be kept in mind that the monument people want them to show as impressive ats possible, as future sates depend upon these photographs, that is, showing the most for the money.

I good plate for this work, especially in the shop) where the bateground has to be skinned off, is the Standarel ()thonon or any double-coated plate, not necessarily color sensitive. For outside work, where gou hate to ger many niles sonctines and to photograph under all sorts of conditions, I do not think there is anything better than film used in connection with a yellow ray filter to give proper rendering of the foliage and background.

The size of the plate used is generally $8 \times 10$, although some prefer $11 \times 14$. The prints from the $8 \times 10$ negatives are then made on $11 \times 1+$ paper with a large white borker and backed with muslin.

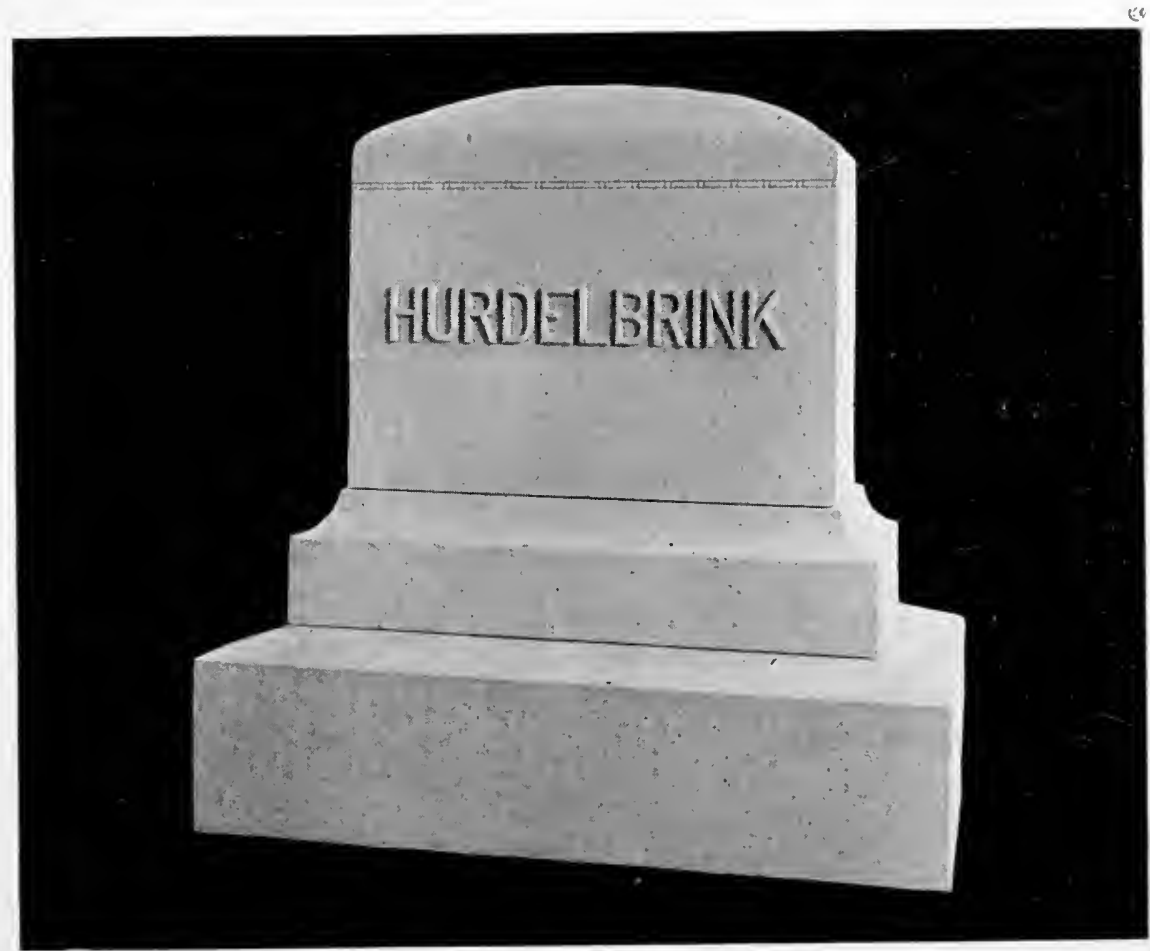




\section{CH.MPER NII}

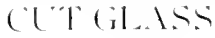

I N the past there has been more mystery surromeling the photographing of cut glass than possibly any other commodity, some people even paying fairly large sums of money to have others teach them how to do it. The difficulty has muloubtedly arisen through the fact that, while a piece of cut glass, in a good light. is a very beatutiful object to the eye, when photographed in a matural state, it is rery disappointing. This is probably due to the reflecting of one cut into another and the lesign on the back showing through, causing a confusion of lines.

Cut wlass can be divided roughly into three classes: deep cut, shallow cut and etched or engraved glats.

single pieces of deep or shallow cut can be handled very nicely in what is known as a shatow box with which we are all more or less familiar, and which consists of a square box open at two encls and lined with dart velvet, felt or Hammel. The object of the sharlow box is to cut down the reflections from one cut to another and also emables one to control the light locally. Many very pretty effects are gotten by placing the shawlow box against a light, or at piece of white cardboard, using reflected light, which produces a bate light or what wotald be known in portrature ats line lighting. 'This hack light. with just enough light in the front to give detail on the camerat side, makes a very satisfactory way of photographing one or two pieces without any preparation whatever. If there shonld be any trouble of the design from the back coming through, it may be sprayed very lightly with a solution of dextrine and condensed milk, steh as mentioned a little later.

llowever, this method cannot be employed in large set-ups such as are necessary when making photographs for salesmen's smmples or for catalogues, where the mannfacturer will want all pieces of a certain cut and design on one pase in showing his line, and the operator will have to nse a dope in working in the open light.

Some operators use nothing but blue analine lye sprayed on with an air brush, with just enough gum arabic solution to make it stick. Inother method used quite extensively is to spray on ordinary opaque with an air brush, covering the entire outside of a fiece. When the opante is dry, it is held over a jet of live steam to just slightly moisten the opargute and then powdered graphite or plumbago is dusted on, the surplus slaken off and. when dry, the piece is polished with a soft brush such as a shoe or clothes brush. It sounds like a mussy job, but when you have things working right and handy, it goes very quickly. In fact, it is work ustally performed by boys in the larger 


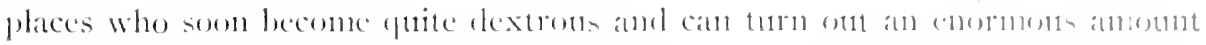
of glass in a short timle.

Illustration No. 50 is a good exanple of cuts-glats work prepared in this matllier.

While this method is often complaned of as giving a woulen or irom effect, it brings ont the design womderfully well and, ats cont glats is sedrl practically to dealers only by the use of these photograthe and they are acquainted with the article itself, the design is really the only part in which they are interested. This is quite an old dope, although it is still much macel.
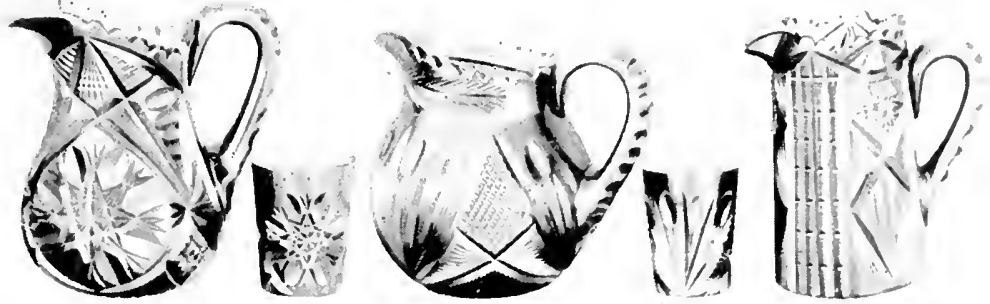

3036 sup 207

430 : Sue 20,
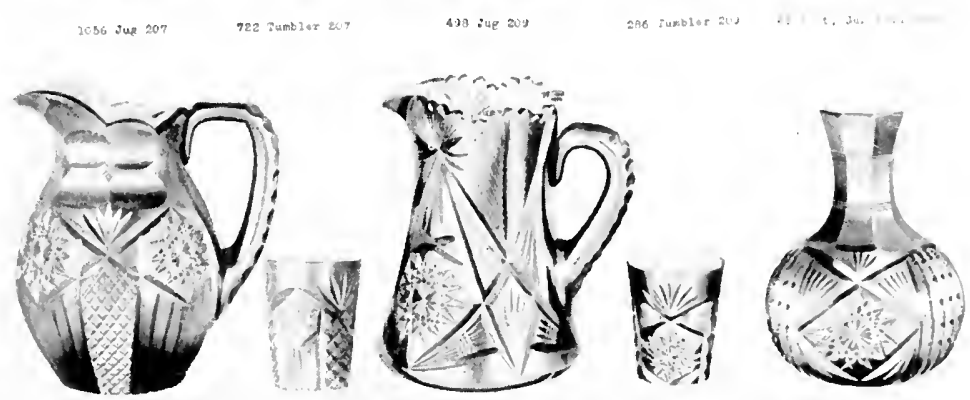

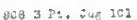

2 2aG Zumbler Br:211an

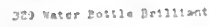

Fig. 50

one of its advantages being that the oparue is soluble in water and therefore easily remover, a big consideration when photographing a large quantity of glass.

Another dope is a water color paint which will photograph white, or nearly so, on which is dusted just enough graphite to give a slight sheen. This brings out the cut and gets away somewhat from the iron or wooden effect given by the opaque and yet has all its adrantages.

Still another method is to spray on a sizing of some kind or other and then apply aluminum bronze. This gives a fairly nice effect, although it is harder to get off after photographing and shows somewhat of a grain which is, to my mind, objectionable. 
(ne impurtant item, no matter what preparation is nsed, is to clean the cut glas after the photegraphic work is done. Nho it is well, when signing a contrate to photograph cut glats, to have a clanse inserted whereby you are releaterl from respromsibility in case of breakigge as, in preparing the glass,

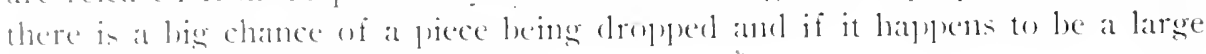
punch lowel, the protits are gune.

In matinge the set-mps for catalogne work, one should fambliarize oneself with the peritions gencerally used. for they are absolutely stanclarel and any
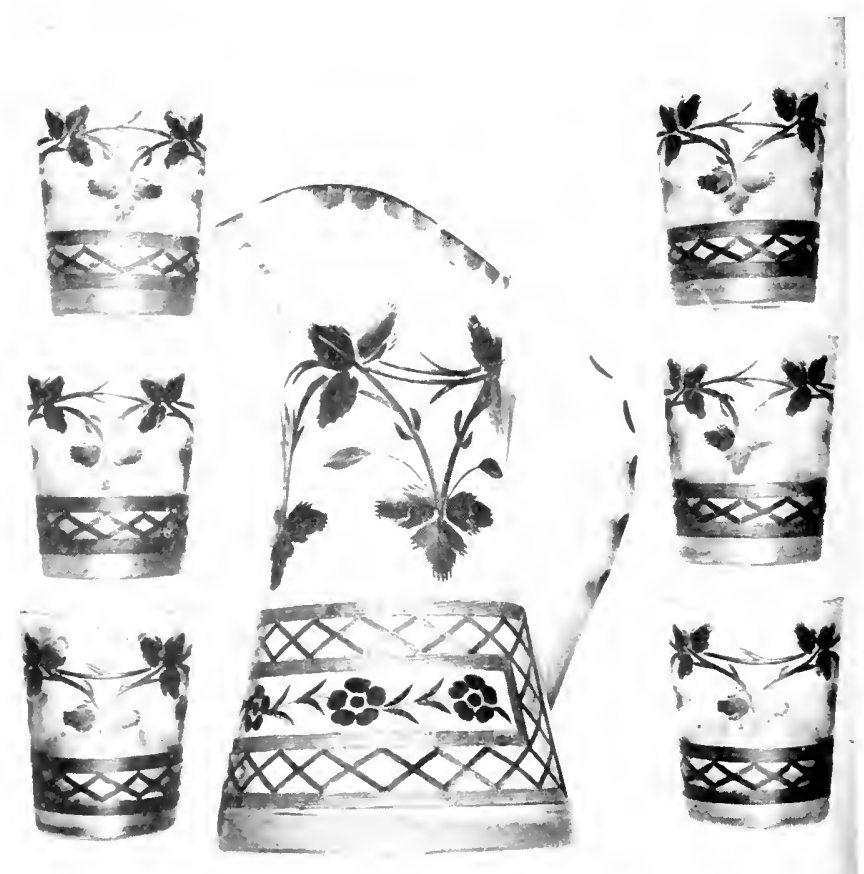

Fig. 51

variance from them is rarely tolerated. It is for this reason that a rertical camera is really a necessity, as it is quite impossible to get the standard positions in any other way.

Illustration No. 51 is a set-ul) of etched glass which was prepared as follow: :

Chronce yellow oil paint was carefully rubled into the etched design, being careful to get it in even and not too heary. Then. to eliminate the design on the opprosite sirle showing through. it was sprayed with a mixture of condensed milk and water. With just sufficient solution of dextrine to make it hold. When dry this has a light sheen. Some operators nse rouge mixed with vaseline to bring out the design, but I have found the rellow oil paint gives the better result. This set-up, was made on a rertical camera, while that shown in Illustration No. 52 was photographed on shelves. 

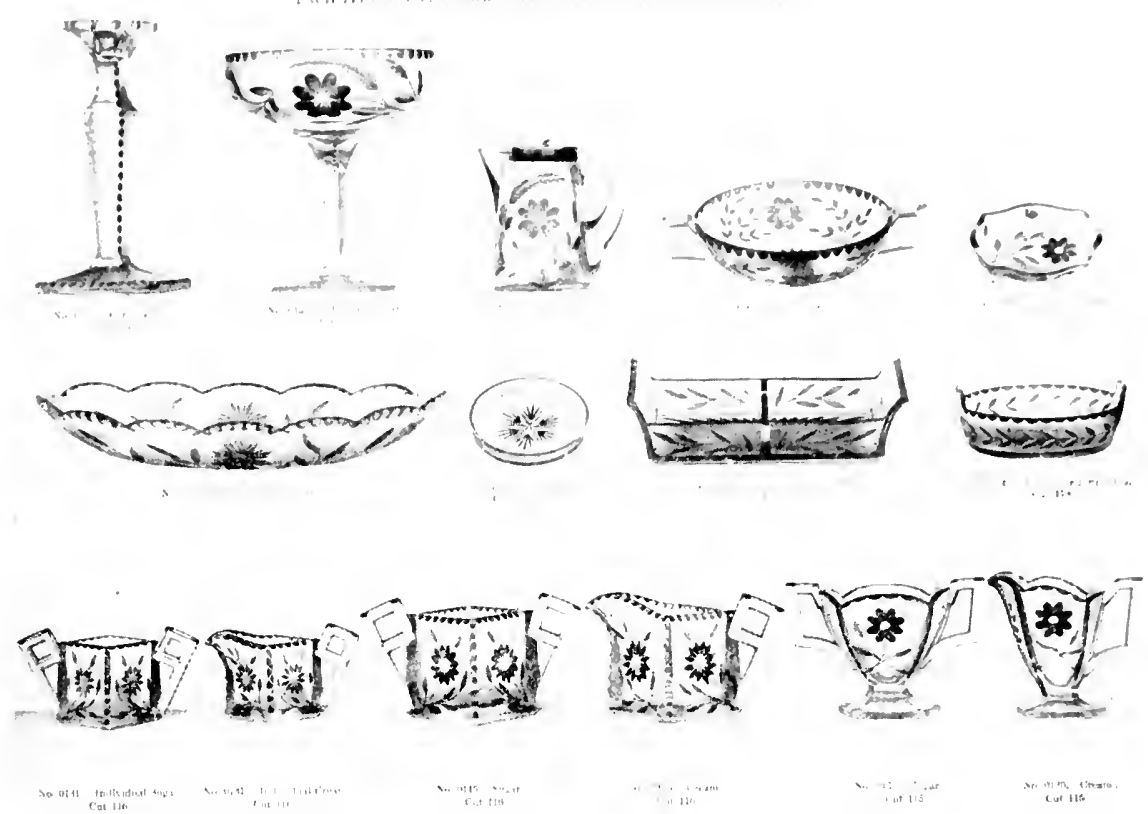

Fig. 52

Illustration No. 53 is a photograph of an atonizer, in which the custoner wanted to preserve the transparent effect as much as possible and at the sante time show the design wp well. This was accomplished by rubling the oil paint into the design, as before mentioned, and cutting down the reflections on the glass and toning down the design on the opposite sirle by the nse of a

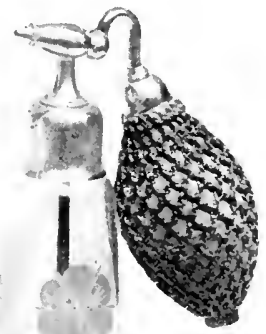
mixture of tripoli poweler (at fine polishing powder and lard oil of about the consistency of thick cream. This was applied with a piece of cotton and smoothed lown with a camel's hair brush and the result was most satisfactory.

It is not necessary to nse a color sensitive plate for all forms of cut glass, although it should be of the double-coated non-halation variety. A conmercial or conmercial ortho film is also at good selection.

When properly equipped and for a nice run of work, cut glass is easy, but when you are not so equipped, I do not know of anything that is any hater and reguires more tine and patience. 


\section{CHAPTER XVII}

\section{SILVER川ARE}

\section{$\mathrm{T}$}

HE photographing of silverware has the reputation of being somewhat difficult of accomplishment but, like cut glass, when one is properly equipped, it is really not so hard, and commercial shops in the East especially have a great deal of it to do.

Also one may pursuc a different course in photographing the single piece to be used for a newspaper cut than when photographing for traveling men's sample books or the manufacturers' catalogues.

Illustration No. $5 t$ is a photograph of a cup used for newspaper and magazine stuff. This was prepared first by rubbing common oily shoe polish into the lettering. After this was set, which was in a few minutes, it was puttied and then smoothed out with a camel's hair brush. The cup was then tented in with white muslin, two electric lights used on the ontside of the tenting supplying the illumination.

This method is all right for that kind of work and satisfactory for general purposes, but for real high-grade silverware, much preparation is hardly ever permissible, especially if the customer knows about it, and it should never be attempted without permission.

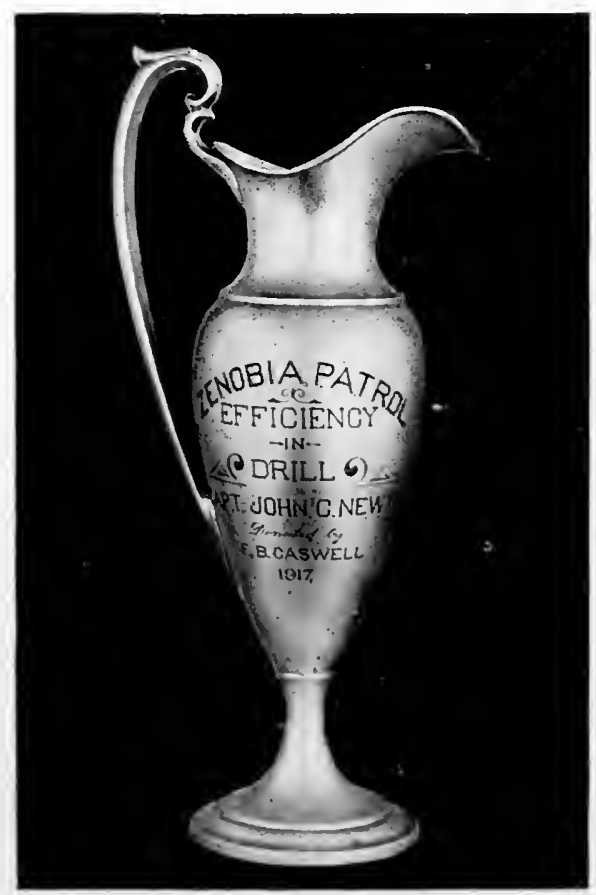




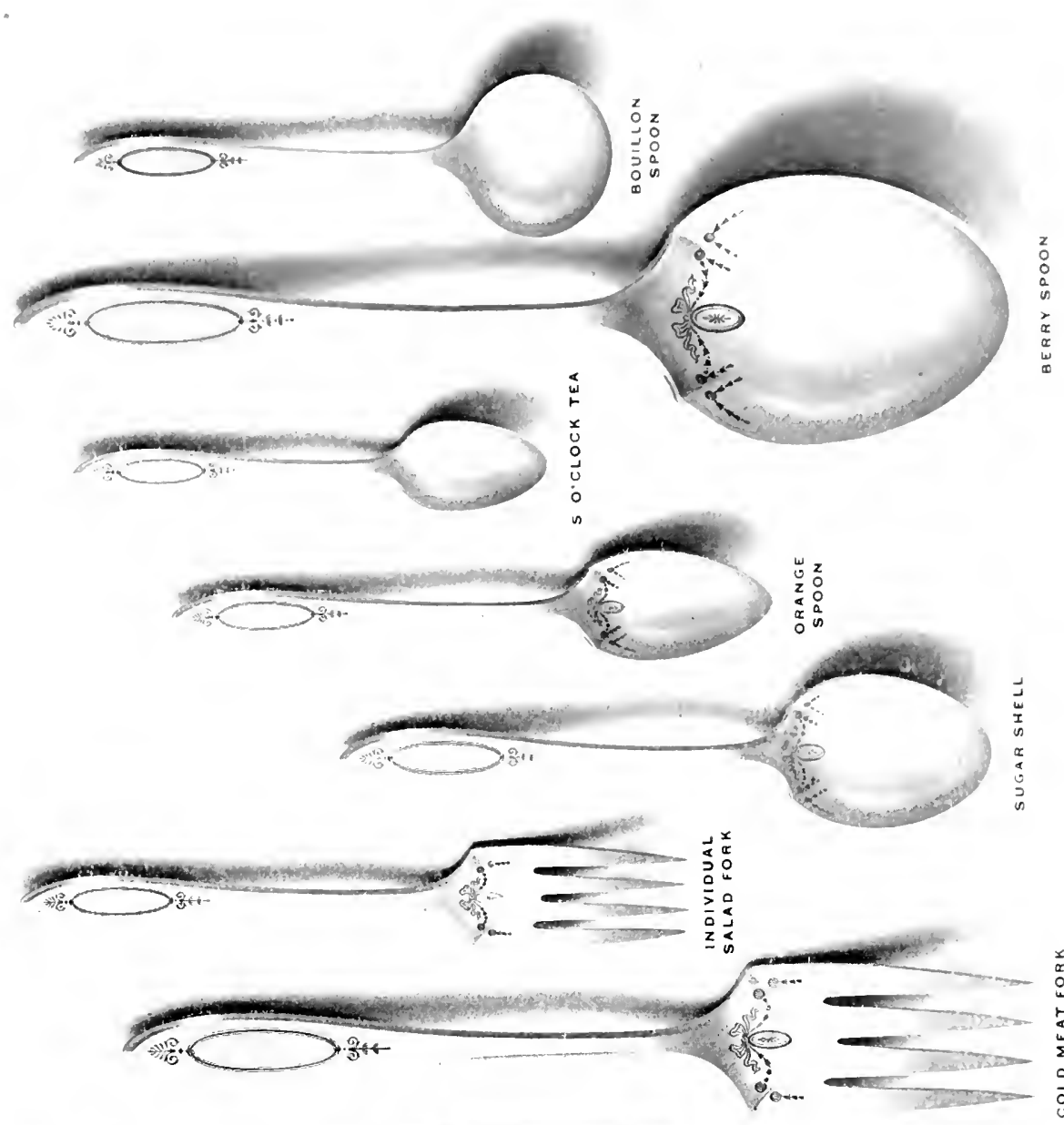

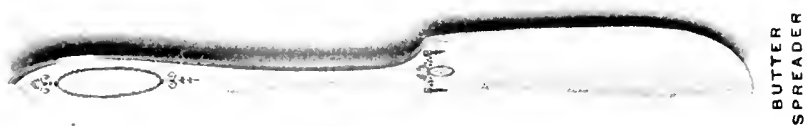
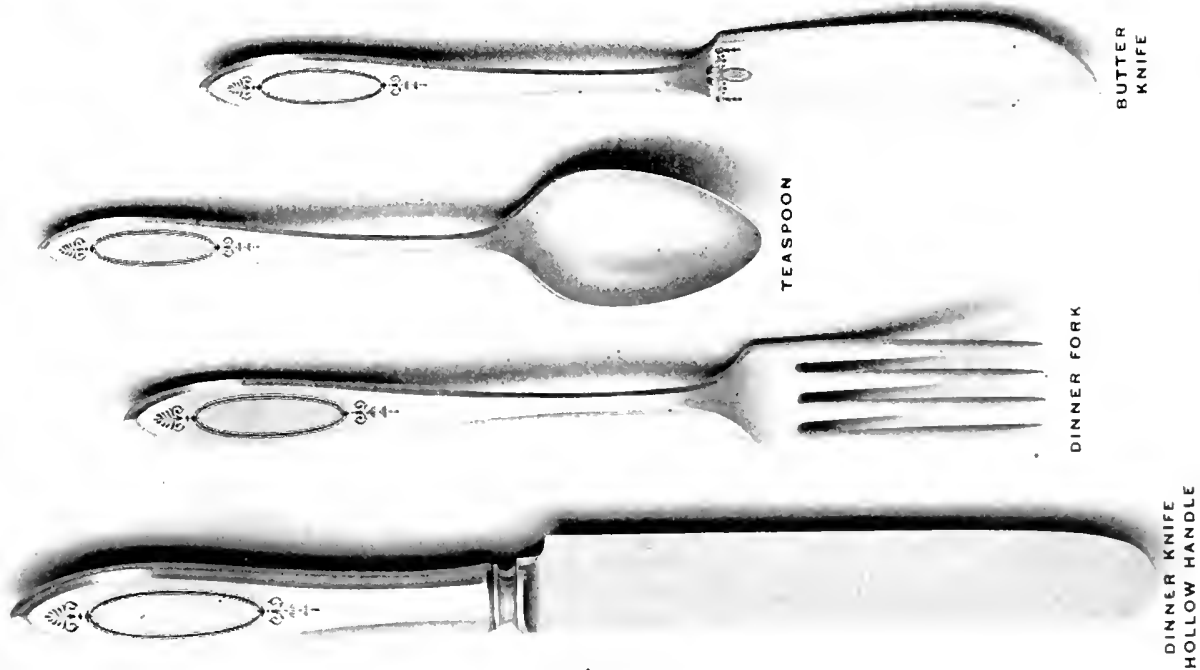
For this reason, the lighting will have to be handled much the same as in highly polished fuminure, using sereens locally, both to cut down the light and kill reflections, and as much of this work is done on the vertical cantera, a rather low side light, somewhat broken up by diffusers to bring the designs into relief, will be found the most satisfactory.

In photographs for the better chass of trate considerable inprortance is attiched to the backiground, the silver being set up on velects, tapestries and fine lace pieces, while, for catalogue work, the photograph is tumed over to the artist for retouching and he works in a sulable backeround to correspond with the rest of the catalogne before pasing it on to the engrater who makes the cut. Such a layout is shown in llhustration No. 55. As mentioned before. 110 dope is used on a set-up of this kind, as the artist wants natural reflections to guide him in his retouching. but there does not want to be more than one source of light showing in the photograph and that should come from the sunc direction at the artist's lettering shadows.

Ihustration No. 56 is an example of high-grate silverware photography to be used for traveling men's samples and also for dealers who are mable to carry a complete line to show to customers. This shows the possibilities of the line when handled in the right way and is really all in all a nice piece of work.

silverware mannfacturess are beginning to realize that real high-grade photographs will sell more goods and attract more attention and yet cost half the price of high-grade wash drawings, and is another instance of where commercial photography in its hest form is coming to the front.

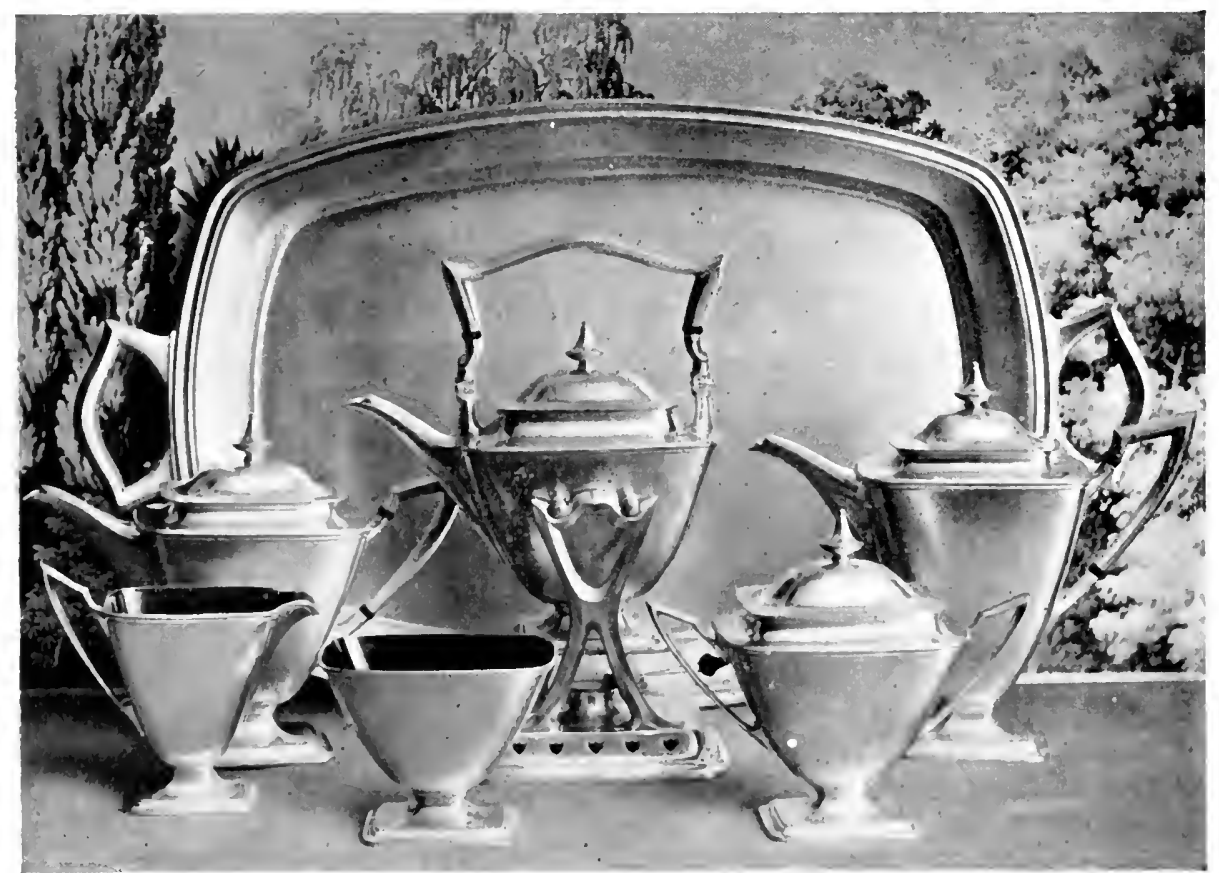

Courtesy" of J. J. Freeman Co, Toledo, Ohio. 


\section{CHAPTER XVIII}

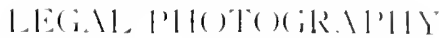

$\mathrm{L}^{\mathrm{E}}$

EG. 1 , photography is fascinating to many photografhers, especially those with an andytical turn of mind and it is exceedingly profitable when you can deliver the goods, which means, make photographs under any and all conditions and bring hone the results-not always results that look good to you, but results that will tell the story and win a case.

There are a number of high-class specialists in this line who have what I consider a nice business. The work calls for a great deal of technical knowledge ontside of photography and the real specialists are generally former law clerks or those who have had close affiliations with law offices, and who have a natural aptitule for photography and have become familiar with the requirements.

llowever, such a linowledge is not necessary when working under the direction of a lawyer or clam agent knowing his business, and while one is often called upon to perform a seemingly impossible stnut, it will generally be found that a way has been provided to obtain results. I have in mind a case where I was called upon to photograph the frepuency of alternating current of electricity. When the job was turned over to me I thought to myself, "yon cannot see electricity, how are you going to photograph it?" But I started out with the electrical engineer and found that thes already had an apparatus on hand, but required a nuan with a good linowledge of photography to operate it. There are very few jobs where one cannot pull out with results if a little headwork is used and by putting across three or four good ones, a reputation is established for making good. When a lawyer makes good, he charges and charges high, and there is no kick to what the photographer charges if he can help them make good.

This branch of photography takes several forms. There are the making of photographs for evidence, photographs for records, handwriting, fingerprints, accident cases and the photographing of special stunts like the one above mentioned, and of conditions of materials such as steel and other metals.

The lawyer or corporation employing a photographer will know whether the photographs they are making will be adnissible to court. Not all photographs are so admissible all the time, but that is a question concerning which there is a variance of opinion and requirements are different in different states, so I will not attempt to lay down any rules here.

Photographs of evidence to be used for eridence, must be absolutely clear and sharp and must be made to show the part or parts in exactly a 
natual way or light. This matter of light is somewhat important, as oftentimes an muthinking plotographer will go into a room, for instance, and bang away with a flash lanup and the result is anything but natural, posibly exasgerating the very details desired shown. Time and thought must be given to every joh.

Also, a carceful record must be kept and plates numbered to correspond therewith, of the lens nsed, diaphragn opening, exposture, time of day, month and rear, distance from objects, and name of the case. These should be liept whether you are asked to or not for your own protection, as it is very annoying to get on the stamd to ilentify those photographs later and be wable to tell the rate they were photographed or some other important information, and in these days of wise lawyers, especially on technical matters and patent ares, who may have a good knowledge of photography-or thinks he has(fuestions may be asked that will completely upset you, and if steh a thing happens, away goes your reputation as a legal photographer. Otherwise you are one step more forward towarl qualifying yourself as an expert. which means a good salary per.

The photographing of handwriting is not so difficult as might he supposed and is a branch in connection with which the photographer is the more often called upon. The general procedure is to photograph the original handwriting, being sure that the cancra is absolutely parallel with the copy board in all directions and giving the proper exposure-if neecsary, using a panchronatic plate. There are instances where a process plate can be used, but, in most cases, it is too contrasty for the fine shading of the lettering. The reason the camera should be absolutely plane with the copy is so that there will be no distortion, for, if the case gets the least bit conplicated, enlarget transparencies may be demanded for comparison with the original and forged writings and any distortion would not be tolerated, as may be imagined.

There is another branch of handwriting photography-the detection of erasure in, for instance, a check or a will. The procelure on a job of this kind is to make a direct enlargement of the place where the erasure is suspected, including enough of the surromuling paper to use it as a comparison.

It might be well to mention, before going any further, that there is consiclerable difference between a direct enlargement and an enlargenent from a negative. In making a direct enlargement, the texture of the paper, the shading, in fact, every minute detail, is enlarged correspondingly, while, if a negative sane size or a reluction negative is made, the texture. for instance, is lost to a more or less degree, accorting to the reduction, and you cannot enlarge something you have not got on the negative.

If a chemical has been used to eradicate the original bandwriting, the substituted wording can generally be detected by the difference in the shades of ink used when enlarged lirectly.

This is where a noving picture lens, of a focus of say two inches. comes in very handy, for you will have bellows enough on an ordinary studio camera to make an eight, ten or twenty times entargement direct. 
The photographing of finger prints is sometines rather disangecalde, ats yon will be called ajom to photograph them in almost inacessible places. Finger prints on light surfaces are more readily plotographed by dusting on a little fincly powelered lanmp-black or sraphite and then carefully blowing off the surplus powder. If on a black surface, it means they will have to be whitenerl. One way to do this is to dust on a little powetered calomel. This will bleach them out fairly white, and with a rather contrasty plate wood results can generally be obtatined.

Most railroals, strect car and other public utilities corjorations, which are

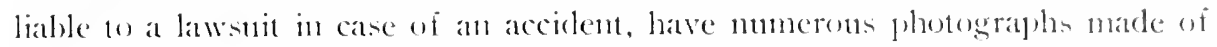
the scene of an accident directly after it oecurs, so that they can reconstruct the place and put things back to normal, and when the time comes for a suit, they will have an accurate record of the conditions at the time of the accilent. This photograply is gencrally lone under the supervision of a clain agent and usually simply means following his instructions and the making of good clear photographs. Nll plates should be numbered and accurate account kept of the distance from point photographed to the camera, time of day, etc. This is really profitable work, for it is quickly done and they do not care what you charge if they can rely on you and have confidence in your getting restults, but they certainly do not want to bother with a fellow who is the least bit hesitant about his results, as oftentimes photographs cannot be remarle.

There is considerable litigation connected with conditions of metals, such as used in bridges, boilers, engines, etc., which have gone bad. This is as a rule in the sphere of the metallurgist and he will be the proper man to direct the making of the photographs. It is usually a case of direct enlargement up to thirty and forty diameters and in special cases 250 to 500 diameters enlargement, although this latter is a high magnification and is, of conrse, done on a photo-micrographic outfit.

Then, there is the photographing of old documents, such as records of inventions, old deeds, and the like. This is always better clone on a panchromatic or yellow sensitive plate with a G filter of the Wratten series, and by the use of this combination, you can get the paper to photograph nearly pure white, thus darkening up the ink enough to make it photograph black, which is about all there is to a job of that kind.

The type of lens to use on legal work is important. It should always be an anastigmat-the more free from astigmatism the better. Some photographers, who make a specialty of legal work, have their lens tested by the Bureau of Standards, at Washington, D. C., which, I believe, charges only a nominal fee for the work and tells the true condition of the lens.

The kind of plate to use will be governed by the work and conditions, but generally speaking, a slow plate, such as the Hammer Slow, Seed 23 and Cramer Slow, is to be preferred to the more speedy makes. As mentioned herein, Panchromatic plates will be found very satisfactory for copies, but the general rule of it is to use as slow a plate as the job will stand, as results will be far more brilliant and clear. 


\title{
CHAPTER XIX
}

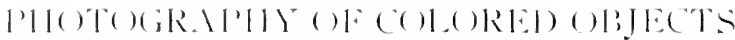

F

) a great deat of the modern commercial, technical and scientific photography, color sensitive plates and filters are practically a necessity-in fact, it might be said that they are anecessity. While it is true, old tine plotographers got really remarkable results without plates sensitive to red and the deeper greens, the modern photographer will get far better results much more quickly:

It is a known fact that all dry plates are sensitive to red to a more or less degree and by giving a prolonged exposure, sometines rumning into days, it was possible to get a sort of negative and, by skill ful printing, dodging, staining, etc. a fairly nice print was obtained. But, all that for the past. Today, the commercial operator gets negatives with any desired correction or separation, gets them quickly, and he has the satisfaction of knowing they will be right and of knowing it in advance of his exposure.

If yon are loing work for photo-engravers. lithographers, commercial artists, ete. you will oftentimes have what are known as separation negatives to make, that is, where one or more colors are completely eliminated, but the most of the work will be correction, which is rendering the colors in proper tone in monochrome.

There have been so many very good articles and books written on this subject, and it has been the topic of so many demonstrations and so nuth discussion, that it is not in the sphere of this limited article to go into the theory

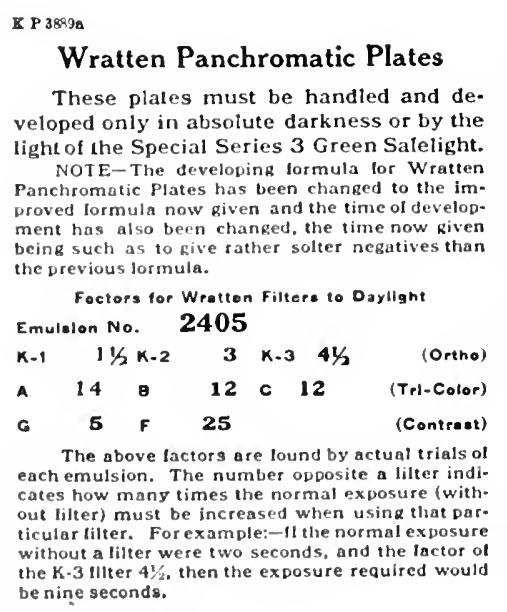

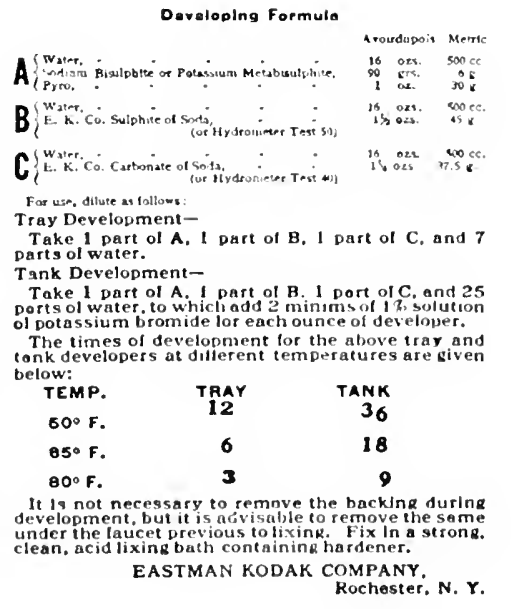

17 ig 57 
of it. I will discuss it from the practical side and try to overeone sente of the little difficulties that are net with from time te tinfe.

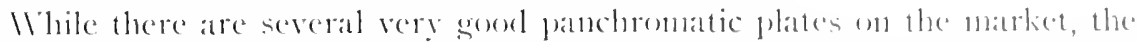

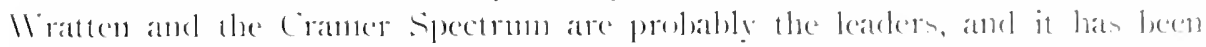

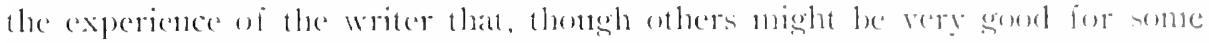
purposes, they are not the all-arrumel plates that the two just mentioned are, and it nerer pays an ase anything but the best.

The Wraten is a backed plate and gives mont excellent results moller any and all conditions. The ome drawback we panchromatic plates, luwerer, is that

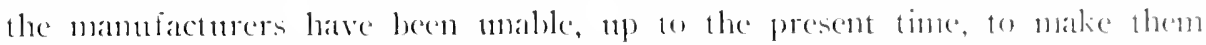
absolutely mifom in speed for all filters. for this reasm, with every lox of

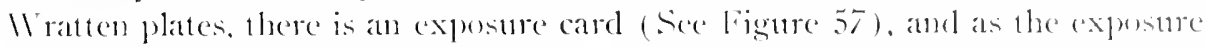
figures change with different cmulsions, before making any expesture, e epecially with reds, it is well to comsth the card accompanying the plates for that patrticular contsion being used. I find that many operators paty absolutely no attention to these cards. That part is impertant if you are going to "bring home the bacon" and eliminate waste.

When to nse a panchromatic plate and filters will be governed ly the result it is desired to obtain. They should be used for studio work such as pianos and furniture finished in red, merchandise set-ups for catalogute work containing reds or deep greens and for photo-engraving color work.

When photographs are to be hand colored, panchromatic plates are more of a necessity than ever to give the proper color correction.

()utside of the studio you will need them on all cases where a correct color rendering is wanted, and inany times a light yellow filter will be used with a rellow sensitive film or plate to climinate the blue haze-especially is this true in mountain scenery and seascapes, snow work and in making pictures from high buildings and what are commonly called birdseye views.

There is a tendency among some workers to overdo ontside correction, that is, to use too deep a filter. While it possibly is right to correct your blue sky down to a gray, nevertheless, there are very few customers who really like a dark sky, even if it has clouds in it, and we must remember that we are not selling the sky as yet.

The kind of filter to use and its position either before the lens or in back of it, or in between, is somewhat of an important matter. You should always use the filters made for the plates being used, that is, do not use Cramer filters on Wratten plates, and sice a'crsa, and expect to get real results. I have worked in studios that used home-made filters and they seemed to work all right, but I have never felt really safe as I would with regular filters.

Many of the shops use gelatine filters for studio work, which are placed in a slot in between the front and rear combination of the lens. When they are so placed, it is easy to change the filters on a run of plates and does away with changing the focus after the filter is on, which is quite a good point and they are somewhat cheaper than filters put in optically plane glass, but the filter used on the front of the lens seems to be the most popular. 
If yon are gome to photograph all-comers, you will need the complete set of commercial filters, but if you are just cloing a certain line of ontside work, you will only need the correction filters-the yellow sertes.

() f the 11 ratten series of filters. the $\mathrm{kl}$ will be used mostly for a very light correction inside and fast exposures ontside and is a good filter to nse with a yellow sensitive film or plate.

The K2, which is somewhat deeper, and with mazda or nitrogen lamps on copies, will give practically a true correction, is possibly the filter more nsed than any other of the 11 ratten series.

The K3 is said to give an absolutely true rendering of colors in monochrome, but, for ontside work, it is a little too deep.

The "( $"$ " filter is a contrast filter and should never be used on correction work. as it is too contrasty and therefore alnost kills the yellow-makes the rellow photograph white-and, with a fairly light yellow, kills it completely.

The "F" or red filter is the other contrast filter which absolutely kills most red-makes it photograph white.

The ".,$"$ "l," and "C" filters are what are known as tri-colors. The average conmercial photographer has but very little use for the "l?" and "C" filters. as they are used practically only in separation work. that is, "l?" kills the green and "( " kills the bluc.

The ". I" is used a great deal in red separation and correction work.

Ittached is a chart of the Mratten filters and Cramer filters.

\section{CONTRAST FILTER CHART}

To photograph dark

SC.IRI.ET RED :

DEEP RED :

MIGLNTI IND

P'CRPLE:

YELLOW:

YELLOW GREEX: Ordinary plate (Seed 23 or 26X)

Bueisn Greex: Wratten Panchromatic plate and red "A" filter.

BLUE :

Several Colors TOGETHER

Wratten Panchromatic plate and red "l" filier.
To photograph light

Wratten Panchromatic plate and red "A" filter.

Wratten Panchromatic plate and red "F" filter.

Wratten Panchromatic plate and red "F" filter.

Wratten P'anchromatic or Ortlochromatic plate and yellow "G," filter.

Orthochromat ic plate and yellow "G" filter.

Wratten lanchromatic plate and green " 3 " filter.

Ordinary plate (Seed 23 or $26 \mathrm{X}$ )

Are given perfectly correct rendering when photographed with the Wratten Panchromatic Plate and $\mathrm{K} 3$ Filter. 


\section{CRAMER'S CONTRAST FILTER CHART}

\section{Color}

To Photograpli Red as Black

To Photograph Orange as Black

To Photograph Yellow as Black

To Photograph Yellow-Cireen as Black

To Photograph Cireen as Black

To Photograph Bhue-(ireen as Black

To Photograph Blue as Black

To Photograph Violet as Black

To Photograph Red as White

To Photograph Orange as White

To Photograph Yellow as White

To Photograph Yellow-Creen as White

To Photograph Creen as White

To Photograph Blue-Green as White

To Photograph Blue as White

To Photograph Violet as White

\begin{tabular}{cl} 
Filter & \multicolumn{1}{c}{ Plate } \\
G & Iso \\
B & Iso \\
B) & Ordinary \\
B & Ordinary \\
BR & Spectrum \\
OR & Trichromatic \\
$O$ & Iso \\
O & Iso \\
DR & Spectrmm \\
BR & Trichromatic \\
OR & Iso \\
O & Iso \\
O & Iso \\
G & Iso \\
B & Ordinary \\
B & Ordinary
\end{tabular}
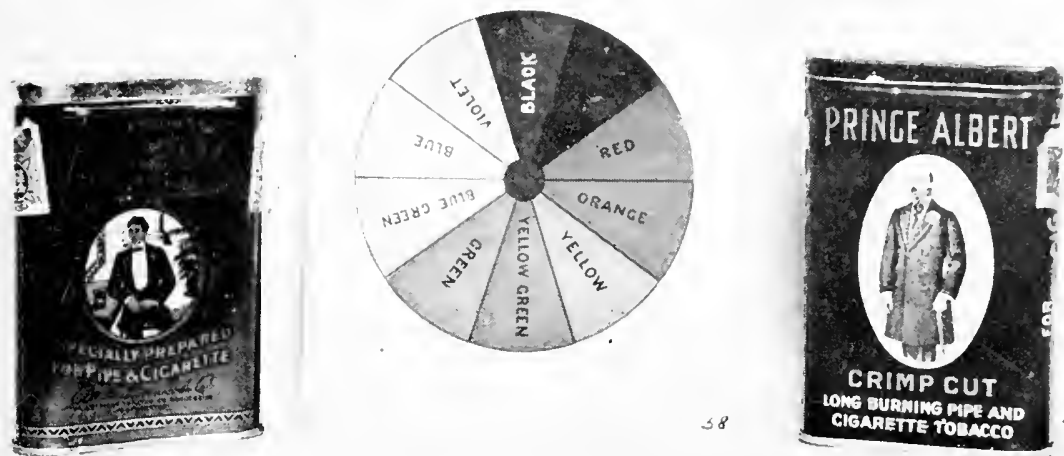

Fig. 58
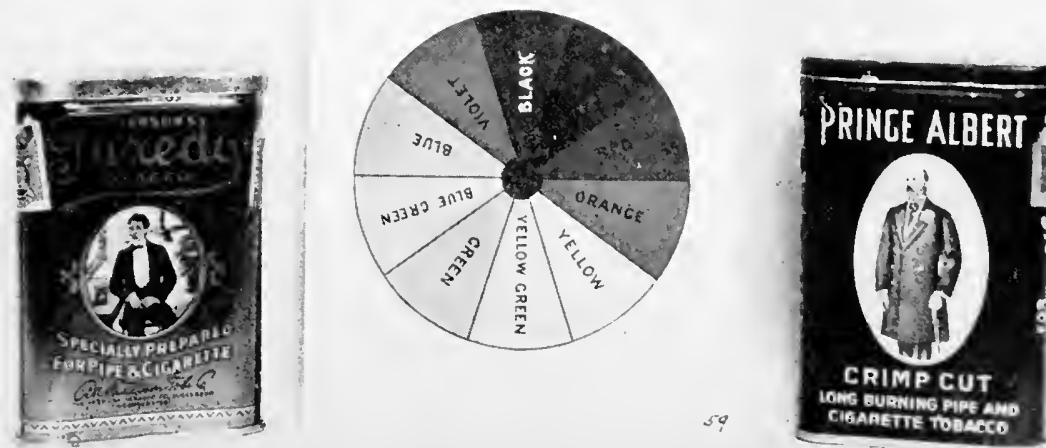

Fig. 59 

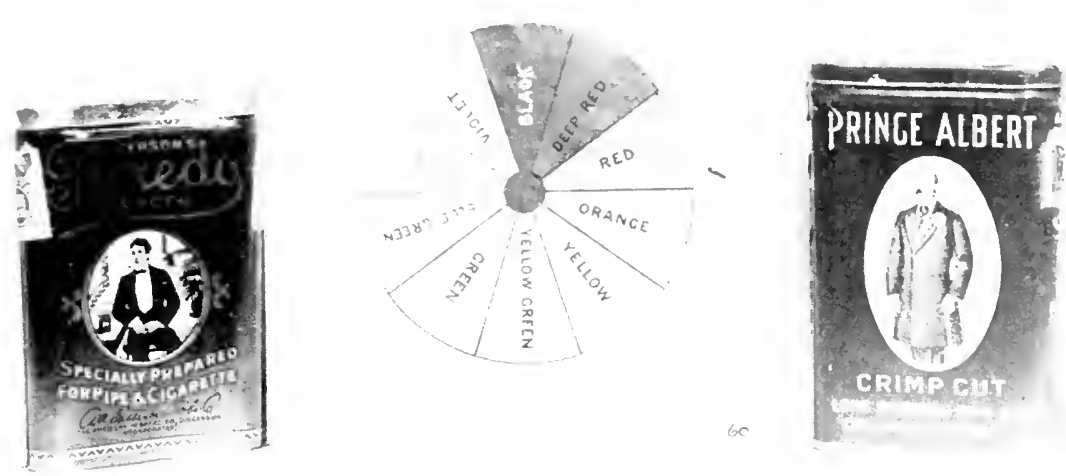

Fig. 60
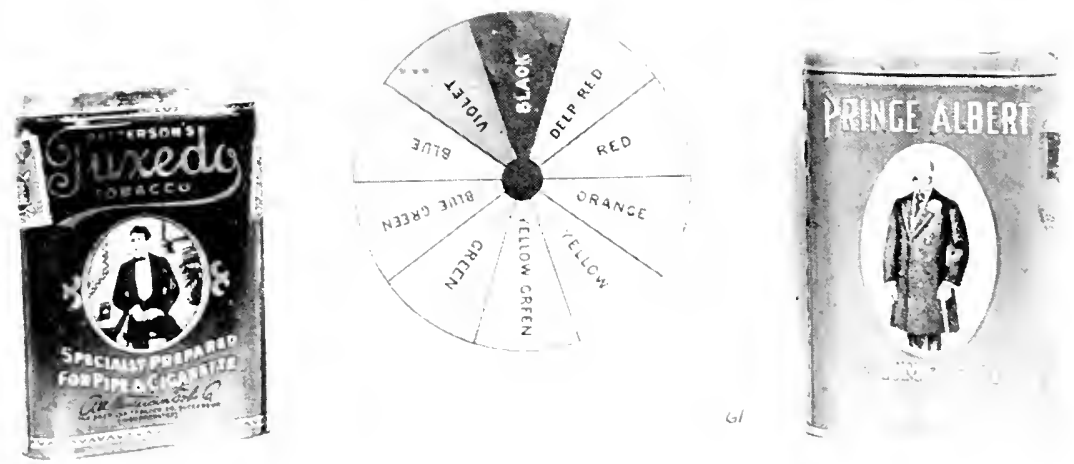

Fig. 61
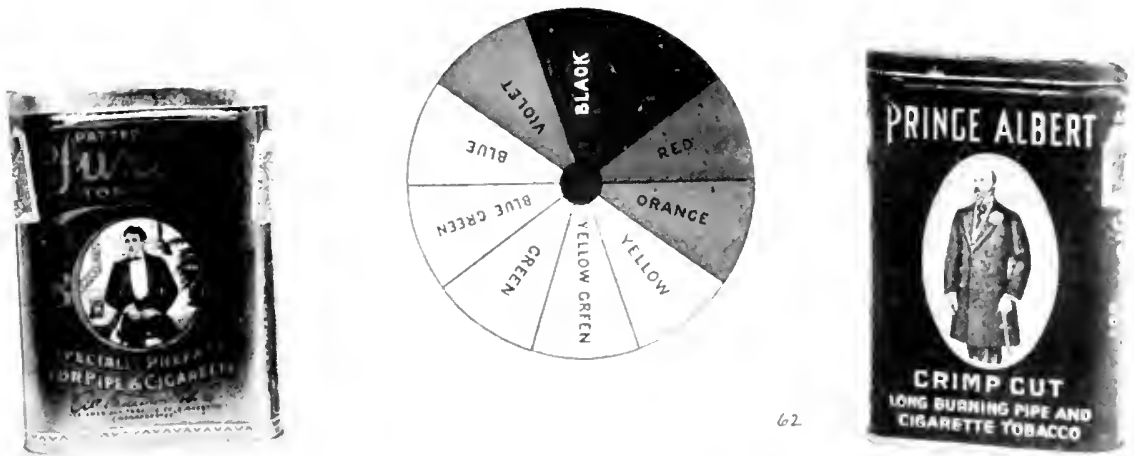

Fig. 62 
Many operators hesitate to use panchromatic plates on accomnt of the tronble in developing them. In shops where they have atumonatic tinners it is fairly smooth saling, hut otherwise it is a bit more molandy, ats the plates atre sensitive to all colors and the only really safe light is no light at all. The ll ratten (E. K. (o.) and (ramer people both furnish a fatrly safe light which is of a deep green, and while, when first turned on you think there is no light at all, owing to the faintuess of the light, after you are in the dark-room at little gon begin to wonder if someone did not leave the dener open.

For myself, I develop all panchromatic plates in absolute darkness, depending upon time and temperature alone and wheh l. of conrse, think is the best way. Ilowever, there are many different contrivances to use in this connection. About as good a way as any is to have a double tray or a tiglat fitting cover for the tray. After the plate is immersed in the developer, put the cover on, turn on the ordinary dark-room red light, take note of the time, turn ont the light and proceed with what you think is alout the proper tine. Then, turn on the light, check up the time, and at the end of the proper period, stop the development.

In the large photo-engraving color plants, where they use panchromatic plates all the time, they have timers which are nothing more or less than alarm clocks which can be set for three or four minutes and are very handy.

The time to develop panchromatic plates also changes with different emulsions, but I find that most operators settle on a certain time ascertained by experience, and which will fit their formula. I develop them from four to four and one-half minutes, using pyro developer with a little more water than the Wratten formula calls for-otherwise exactly like the formula.

The Wratten plate is a backed plate and consequently will have to be rocked all the time in the developer or the backing will settle on the plate and cause streaks, and the backing should be washed off before the plate is put into the fixing bath or it will soon get the fixing bath too dirty for regular use.

Panchromatic plates all have more or less of a black edge around them which, under ordinary circmustances, would be taken for old plates, so there is no need to worry if you see a black edge around them, but you have to allow for that and cannot figure on using up to the limit of the size of the plate. These plates also come wrapped in black paper and, in the case of backed panchromatics, come packed face to face. In opening panchromatic plates and taking the black paper off of a pair of plates, that black paper should be thrown away and not wrapped around the remaining plate or you will have a streak across your negative, which will mean a make-over.

Figure 58 is a photograph of two cans for popular brands of tobacco and a Wratten color chart. This exposure was made on commercial filn, $1 \frac{1}{2}$ minutes exposure, $f 32$. The red can is here shown black and you have practically no values in red, yellow-green and green, but blue-green, blue and violet are light. In other words, it is a color blind film.

Figure 59 is the same set-up made with commercial ortho film. K2 filter, same stop, eight minutes exposure. We are still short on the reds, but have a 
good correction in the yellow, yellow-green, blue-green, blue and violet. You will notice from this that this particular film is not sensitive to red to any marked degree, but is very good for set-ups where there are no greens or deep reds. The multiplying factor for commercial ortho film and $K 2$ filter is about fifteen times, that is, behind a 12 filter commercial ortho fim requires fifteen times as much exposure as it does with no filter, which is the only drawback I can see to this film.

Figure 60 is the same set-up made with Wratten panchromatic plate, no filter, the same stop, exposure 30 seconds.

As can be seen from the chart, we have a fairly good separation even with no filter. The deep red in the Prince Albert can is still short, but, nevertheless, shows the advantage of this plate even without a filter, in that it can be used naty times for interiors and set-ups in the studio without a filter and yet get fairly good separation without prolonged exposure.

Figure 61 is made on a Mratten plate. K3 filter, sime stop. exposure four minutes. This gives what the commercial photographer would call full correction.

ligure 62 is made with the "l,", the green filter, exposure five minutes, same stop. The Tuxedo can with that exposure is still a little dark, but by a prolonged exposure, it conld be made light.

For those who wish to go into this subject deeper, for the theory, 1 can recommend the following books:

"The Photography of Colored Objects." by Dr. C. E. Kenneth Mees.

"Color l'lates and Filters for Commercial Photography." Eastman Kodak Company.

"Dry Plates and Filters for Trichromatic Work." G. Cramer Dry Plate Co.

"The Photographing of Color Contrasts," (i. Cramer Dry Plate Co. 


\title{
CHAPTER XX
}

\author{
COPYAT
}

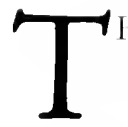

HE making of good copies is considered by many to be the most difficult branch of commercial photography and forms a large portion of the work, yet it is the custom, in some studios, to turn the copsing over to apprentice boys and cheap help. This means, as a general rule, that the copies are stuck up in a careless manner, no real attention paid to exposure, lighting, and other important details with consequent indifferent results.

Good copies are hard to obtain and the best operator, apparatus and materials possible should be employed. The reason is that no matter how much latitude the plate or film may have, the exposure has to be absolutely correctnot a little over nor a little under, but correct. This is necessary if you are going to preserve the gradations in the copy print that are found in the original.

While it is true that, with the four degrees of contrast in paper, one may obtain a print from almost any negative, it will not be a true copy in every sense of the word if the exposure of the copy negative is "off." That, of course, applies to good originals.

There are many occasions, such as in copying old documents, pictures that are soiled or naturally a little flat, when it is desirable to add a little contrast and, at other times, equally desirable to get a little softer result, but the copies the commercial photographer is the more often called upon to make are those where a true copy, both as to contrast and gradations, are wanted.

The kind of light to use in making copies is somewhat important. In shops where copies are a major portion of the work, it is the custom to copy entirely by artificial light in some form or other and is by far the best and easiest method to pursue. With daylight, the conditions are constantly changing every hour and every day and you will be troubled by reflections, so it resolves itself right down to artificial light for real results. Some operators use arc lamps, one placed on each side of the copy board, and which are all right with the exception that they take considerable current, thus entailing too much expense. Others use mercury tubes placed upright, one on each side of the board, and while the first cost is considerable, the amount of current consumed is negligible.

Illustration, No. 63, shows an apparatus which is very handy for lighting small copies. It can either be worked with incandescent gas mantles or electric bulbs, and gives good results, while clear bulbs of the Mazda or Nitrogen type of 500,750 or 1,000 watts, on stands on each side of the camera, make a very effective way of handling various sizes of copy. 


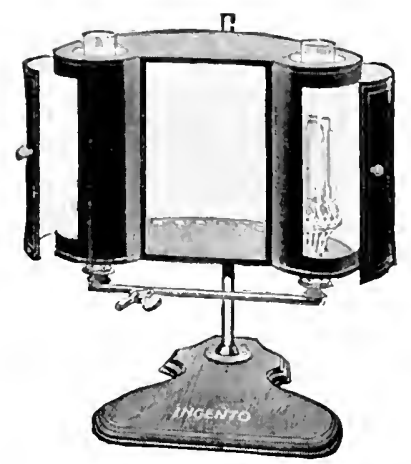

Fig. 63

Illustration, No, 64, represents a type found in some studios and known as a "circle light." This is exceptionally convenient, as the light is all around the copy-a lig factor in copying drawings or other copy that is patched, as there are no shadows from the lights and absolutely even illumination is obtained casily.

However, if one uses daylight for copying, it is always well to have a black screen directly in back of the camera, if possible, to do away with reflections. This applies more particularly to copy such as oil paintings or copy placed mnder glass. Some operators, in copying oil paintings by daylight in musemms and art galleries, where they have mostly top light, place a black screen directly in front of the painting to be copied with an opening just large enough to accommodate the lens. In that way, reflections are cut flown to a minimum.

If artificial light is used in copying, in the ways mentioned hereinbefore, there will be little trouble with grain, but if there is trouble despite the artificial light, it can always be eliminated, even in the worst cases, hy copying under glass and making, for instance, a half reduction of the original and then, for the finished print, enlarge it up.

The kind of plates to use will be governed, of course, a good deal by the original to be copied. For instance, a black and white line copy shonld be photographed on a process plate or film and should neaer be photographed on a single coated plate without hacking, as halation is just as had here and destroys just

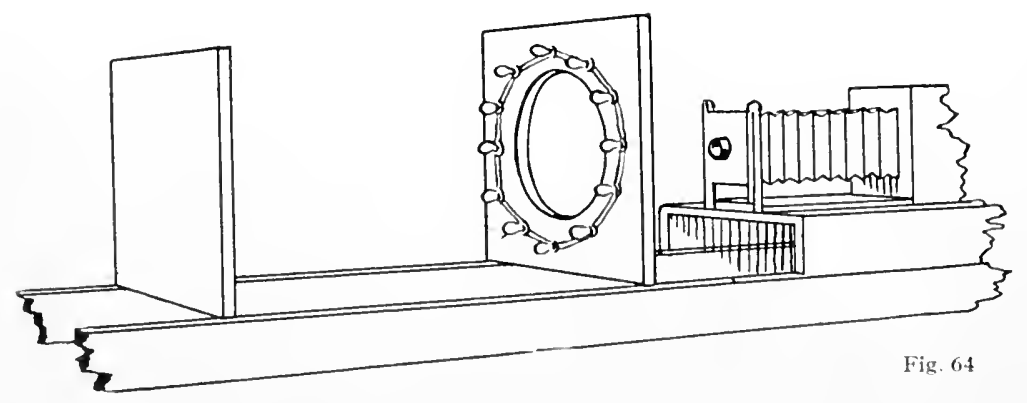




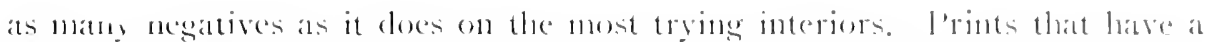
good many dark and mintlle tones and rery little white can be conferd on at single-coated plate, but they would be better on a filur or at dothble-conted plate.

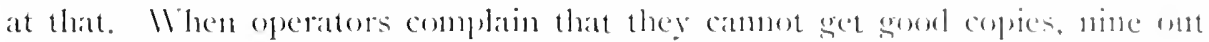
of ten tines that is the reason. They are getting halation, only it is at litte different form from that to which they have been aceustomed.

It is the habit of sonte to the at domble-coated plate like the stamelard Orthomon on pratically all copies. That is wong for the best results. While the standard Orthomon plate is a little bit harder in contrats. for instance, than a portrait film, it is a little soft working in contrast for most copies. I commercial or Commercial ortho film, Cramer's Medimu Iso or llammer's medim speed of plates will give better results but, of comse, as above mentioned, if gon use single-coated plates they shothl always be backed, whereas, with a filn this is not necessary.

The lens to use should preferably be an anatigmat of good make, although a rectilinear will do very well when stopped down.

I suppose it is hardly necessary to mention here that the copy hoard. lens and ground-glass should all be exactly parallel.

There are several things that cause trouble in copring. 1 will take up a few of them and give a few points in that connection.

The first is sepia prints. I sepia print, copied in the orelinary way, is a disappointment. For really good results, use a panchromatic plate with a red contrast filter and, while that increases your time a lot, the results leave nothing to be desired.

With blue prints, which the commercial photographer is often requested by architects, engineers, ete., to photograph for reproduction, the best results are obtained by using a red contrast filter and a panchromatic plate. However.

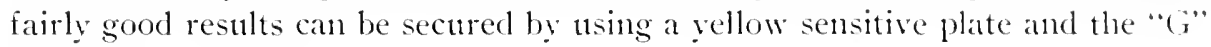
yellow contrast filter.

Then, again, you will get pencil sketches on rough paper. They can best be handled under glass, using a process plate or filn and a very light filter such as the $K 1$ of the Wratten series.

There is another job of copying occasionally coning wy, and that is copying from a book, the paper stock of which is known as India paper, very thin, and where the printing on the opposite side of the page shows through. By putting a piece of black paper in back of it and photographing with a process plate or film, giving just the right exposure, you can lose the print on the other side.

Still another job often enconntered is where it is necessary to patch originals for copies and, at the same time, return the original in good condition and without the patch. A little stunt comes in handy here, and that is, to use rubber cement-just the common tube variety used in mending auto or bicycle tires. Rub it lightly on the patch, as well as on the surface where the patch is to be placed, letting it dry down some, then put the patch in position and roll it down. When through copying lift off the patch and if some of the cement clings to the original, it can be cleaned off with gasoline or benzine. 


\section{CHAPTER XXI}

\section{EメI.IRUプ}

$\mathrm{T}$

11E commercial studio is called mon to make enlargements, oftentimes in quantitien, wherein the quality has to be abse reproach and yet speed is a factor. Therefore, the best expipment obtainable and conveniently arranged, is a mighty gend investment.

Here, as in copying, different lighting systems nay be employed, but an are lamp with condensors is by lar the speediest equipment we now have. Inst how speety this is depends upon the power of the lamp. There are some in une so speedy that you can make an enlargement on carbon green developing paper in 10 to 15 seconds. Those of you who have used carbon green paper know what that means, hut it is not generally necessary to have as speedy an ontfit ats that.

Figure 65 shows an are lanp with reflecting cone-an arrangement in use a good deal, as it is farry fast and allows the use of $11 \times 1+$ negatives, as well as $8 \times 10$ and smaller, without the expense of large condensers.

Figure 60 represents an ontfit that is coming to the front pretty lively, and that is the Cooper Hewitt mereury tube (M). This ontfit is very good, indeed, for $8 \times 10$ and under, and is quite speedy and very economical on current. In enlarging from $11 \times 14$ negatives though, the if type of tube, that is, two vertical tubes side by side, must be used as the 11 type does not cover larger than $8 \times 10$.

The Mazda lamps and multi-mirror reflectors are also nsed. but for most commercial work they are really too stow.

With any of these lighting systems, it is far preferable to have the light on the ontside of the dark-room, for it is then easier to have a light-tight outfit. Especially is this an urgent need when making large negatives from small trimsparencies.

I have often noticed photographers working with a make-shift lighting apparatus for their enlarging. I amps covered up with oil cloth, cloths, cardboard, ete. This is not only dangerous, hut extremely eletrimental to the quality of the finished product, extraneous light hitting the paper during exposure.

Figure 67 shows a very handy and convenient enlarging camera-the revolving back F. \& S. enlarging camera. This revolving back feature is really quite a saving in time, as it enables one to put the paper on to the board or into a frame and then turn the image to fit it. I think that is the one big feature that recomments this apparatus.

If you are in a buikling where there is vibration and are making fairly big 


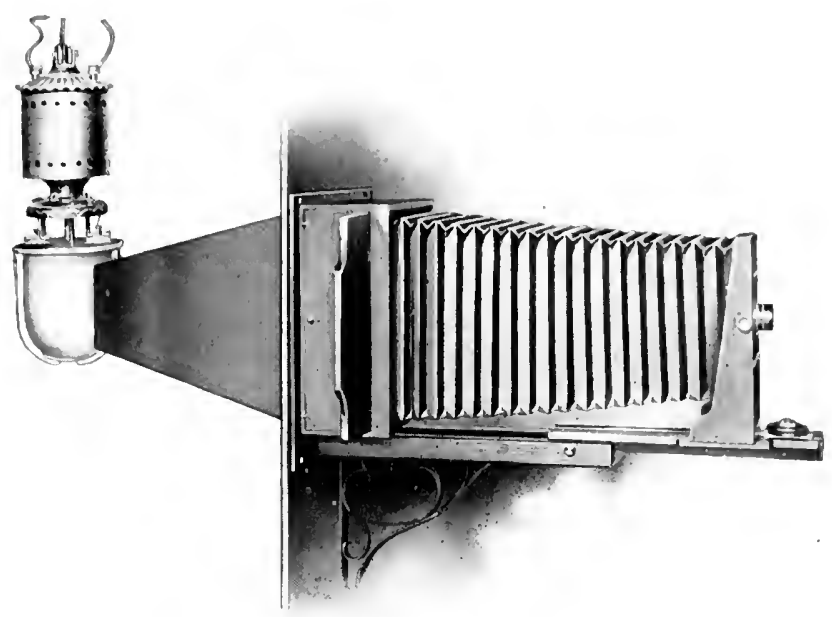

Fing 6.5

enlargements, you will notice a considerable improvenent if the entire enlarging outfit is constructed on a heavy frame-work and the whole suspended from the ceiling by springs. This vibration is one of the greatest difficultics photographers have to overcome, especially those in downtown buildings which also house printing plants and other concerns operating big presses, as the vibration of the building makes it practically impossible to get sharp, clear-cut enlargements. The expense in this connection, which is very nominal, will be easily offset by the improvement in quality of work and the elimination of waste.

In certain of the large studios, where a lot of enlargements are made-and speedy - they use a large printing frame mounted on hinges to hold the paper during exposure, and the lens safety cap is generally on a hinge also, but, for the ordinary place, the large easel, with roon for extensions in both directions, does very well, but be sure to have plenty of room, as a $40 \times 60$ enlargenent is nothing unusual for the commercial man. Just a little point here. Sometimes, in cramped quarters, it is practically impossible to develop $40 \times 60$ and similar sizes of enlargements in trays. They can be developed directly on the board after exposure, or they can be developed on tables or on the floor, of course, using oil cloth underneath, and soaking them up first with water, then applying the developer followed by a short stop. This method effects a big saving in developer as it can be swabbed on with a piece of cotton, althoingh the enlargement must be timed just right so as not to develop too rapidly.

The kind of paper to use varies, of course, with local demands, but the average commercial studio is making enlargements for reproduction, when the xx.P.M.C., No. 4 (glossy) is considerably used while the P.AI.C., No. 5 (matte surface) makes a very nice paper for photo-retonchers and artists to work upon. These two papers are probably the most used, but Monox also is in demand as 


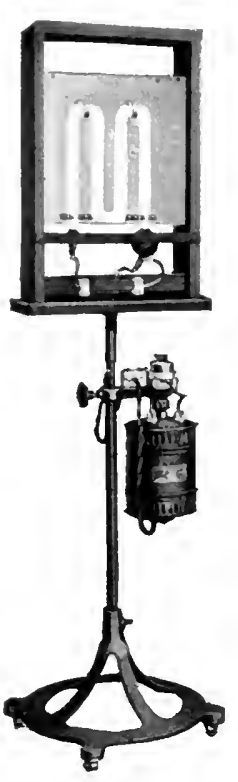

lig. 60

are also the cularging Chloride papers such as Cyko enlarging and Artura Carbon Black.

The making of good bromicle enlargenents is really an art by itself. Several years ago I came on to a man who was really a genius in this line and who showed me its possibilities. 1 think the one best tip that can be given on enlarging is not to over-expose, keeping in mind that, with bromide paper, the image cloes not appear as rapilly as with chloride paper and the result of over-exposure is a poor gray and greenish black, one of the complaints we have heard of hronlides for years. but with the proper exposure and developed to the linit, you will get brilliancy and nice blacks, with plenty of control.

Just a word about negatives. Negatives for enlargement should be not too dense, but rather brilliant, or a little snappy, but not contrasty. If they are copy negatives, still more care must be used. For instance, a negative that would make a good print on Izo llard Medium, the chances are, will make a good enlarsement.

Is to developers. Amidol developer. to my mind, is really the one best developer for commercial enlarging, as it gives better blacks and cleaner whites. I never cared to use a metol or metolhrdrochinone developer for enlargements.

These modern metol substitutes give some nice enlargements, especially Frerlol, when cliluted.

I have gotten excellent results from Firedol moder the following formulat.

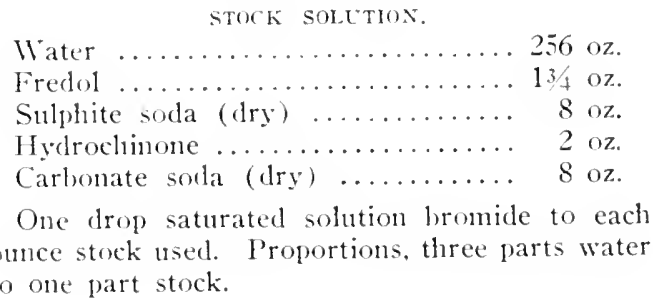

To the above formula I add a few more drops of saturated solution of bromide than called for and it certainly gives heautiful enlargements on P.M.C. paper and Royal Promide, but the image should not appear for $1 \frac{1}{2}$ to 2 minutes for really good enlargements and development should be carried to the limit.

A discouraging factor in working certain brands of paper in the summer time is that of blisters. There are so many causes for blisters and they have been described in other places, that I an only going to touch upon one point that I know has helped quite a few people, and that is to use as a preservative metabisulphite or bisulphite in the fixing bath.

There are times when you are asked to mount big enlargenents. There seems to be no mounting hoard large enough, so these enlargements are often 


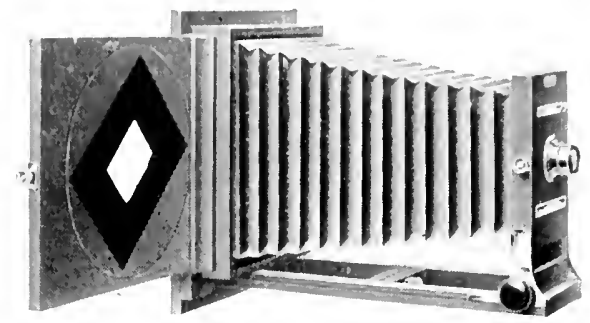

Fig. 67

mounted directly on to compoboard or beaver board, which solves the problem very nicely-it is not heary, yet it holds its shape.

At other tines, you are asked to monnt them on cloth on what are known as stretchers for artists. The correct procedure on a job of this kind is to tack muslin on to the stretcher, beginning at the middle of either end and the midde of either side and then work towards the corners until it is absolutely sumoth and taut in all directions. When this is done, take a sponge fairly wet and quickly wet the cloth, rubbing it in both directions and get it wet evenly. Let it dry a little, then apply your paste, and then the pasted enlargenent, bringing both in contact ly rubbing with a sponge or piece of cotton. If this is done as above, the enlargement will neither buckle nor cockle. 


\section{CHAPTER XXH}

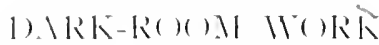

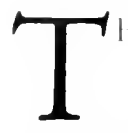

Ili developing and manipulation of negatives for commercial work is far different from that rerpured for portrait work and therefore cannot le handled in the same mamner. Commerebal customers demand detail, snap and brilliancy in pronts-the portrait man is looking for softness and with most of them, lack of detail.

While it is true that we do not make a business of selling negatives and it is really the print that we sell, nevertheless, the better the negative the easier it is to nualie a dandy print. (Iften an operator will say "()h, well, I can get a print off of thatt"-possibly it can be done. but it takes time, wastes paper and all in all, it is poor business. If the operator will use a little brains in making his exposure, a little care in developing, there is very little excuse for a poor negative.

First of all, a good dark-room is a real necessity. While one can work in cramped, crowded, umventilated yuarters-and the commercial man frequently has to do this under certain conditions while on the road-the sudio darkroom should be arranged conveniently, and above all, be well ventilated if the hest efforts of the dark-room man are to be called forth. Such a darti-room, with ventilating system, is shown in Figure 68, a pen sketch. You will notice the small grating at the lower left hand corner, which is the inlet for air, with an outlet at the upper part. which is nothing more nor less than a large galvanized iron tube bent over to prevent the light shooting back into the darkroom. An electric fan of about the 16 -inch size is set in front of this tube, which draws the old air out through the tube and the fresh air coming in through the light-locked inlet down near the floor. Of conrse. care must be used in placing these two so that the comrse of the draft will not be over one's hearl while working at the sinks, or an everlasting cold would be the result.

There should be no other inlet or ontlet open in the dark-room when the fan is on, except the floor ventilator-otherwise this system will not be effective, and the floor ventilator should be just a little bit smaller than the outlet.

It has been the writer's good fortune to have been engaged, several times. on experiments for large companies in ventilating big dark-rooms, and this is one system that really works. There are numeroms others that work sometimes.

Another important item shown in this sketeh is the indirect lighting system. This is an eaves trough, such as can be purchased at any timers. with four electric bulbs, two red and two white, throwing the light up against the ceiling. With the red lights turned on, it makes a mighty nice room to work in, of course, having the side wall red lights for developing, while the white lights can be switched on and the red off. Where more than one man is working in a 


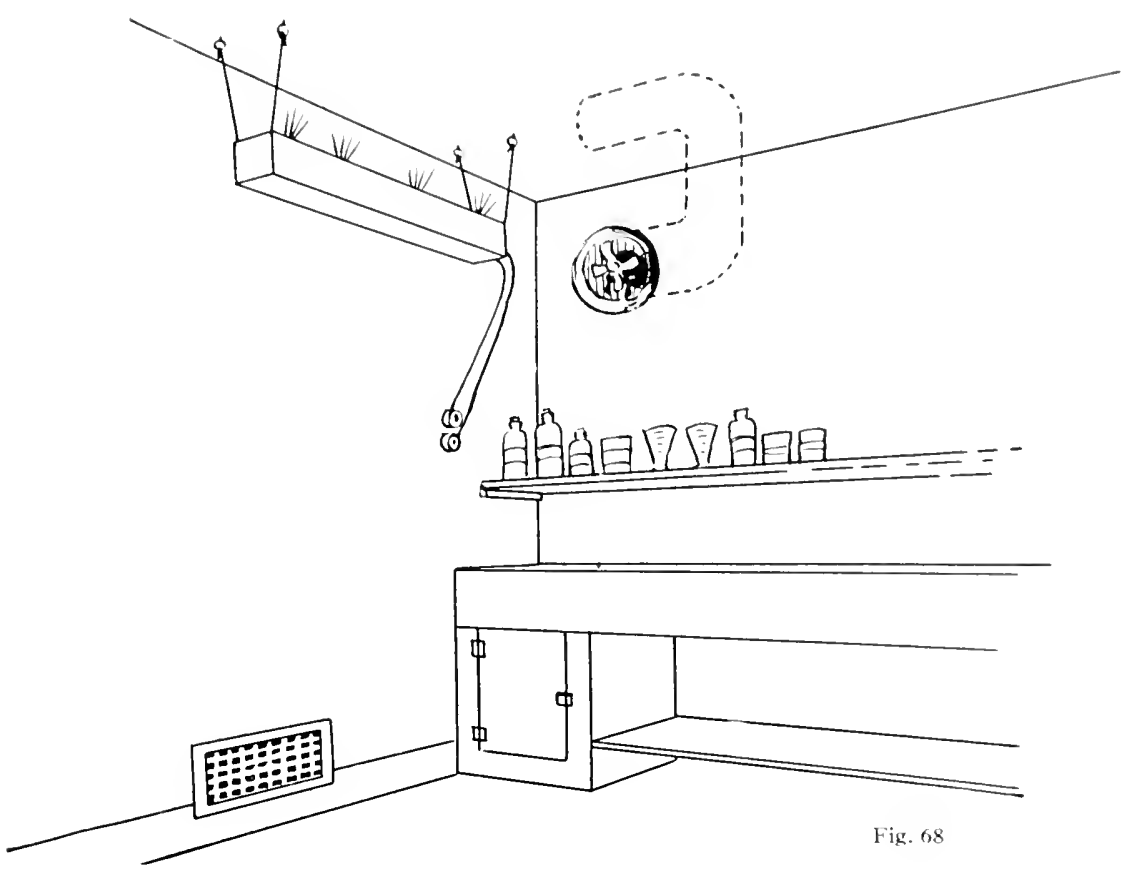

dark-room, it is good custom for the foreman only to have the master key that will turn on the white lights and which will prevent many a catastrophe. Also, under such conditions, abont one of the best arrangenents is the S-shaped entrance to a dark-room. However, these have to be carefully planned or they are the source of many a poor negative. While light does not travel around corners, it reflects around them, and I have been in dark-rooms, using a similar entrance, which I knew were not safe. It least two turns should be made, but three is better.

We have long been accustomed to seeing the inside of a dark-room painted black, which is unnecessary. Many of the modern and np-to-date dark-rooms are painted red or orange, which, with the indirect lighting srstem mentioned, makes a very effective combination. Another really good stunt, especially in dark-rooms constantly in use and where there are possibilities of hypo and water being spilled on the floor, is to use a floor oil on the floor, applying it with a mop every few months, as it absolutely prevents dust and hypo from flying around.

A very important part of the equipment of a dark-room is the sink or sinks. I believe I have worked, in my time, with practically every kind of sink I have ever heard of and I like the wooden sink best of all. There are porcelain, cement, slate, soapstone, lead lined sinks, and wooden sinks lined with paraffine or marine glue, but, as above mentioned, you have trouble with all of them, and the plain Lonisiana cypress sink, California redwood, or even white pine, with absolutely no paint on them, give the best results in the long run, with less trouble and expense. Of course, they should not be allowed to dry out. 
As the commercial man is generaily working for some special result and nearly alwats has to control development to a certain extent. I think pro is In far the lest developer for all-romnci commercial photography. While there are operaters who get rery nice results with different coal-tar developers, they are generally those who are working on some one line all the time. have their exposure right down to a nicety and their lighting always muler inll control. but, for the average commercial man. who is meethe any and all conditions. I believe you will find more of them using pro than almost any other developer

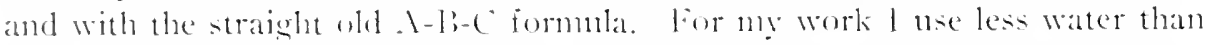
the fromula calls for. lut 1 believe I time longer than most operators monder the same conditions, and thus arrive at abont the sime result. Is to the atrisability of using tank development, it is very good for long runs of negatives. such as furniture, stoves and similar lines, hut for the average studio work. development seens best handled by tray. Likewise. most panchromatics are developed in tray, excepting those for long runs.

Many people believe that if they hat some one formula, the liey to success would be theirs. Such is mot the case. It is experience with a little hrains, mostly brains, that really helps to make success in developing. and to know gonr product and balanee your chenicals to suit it, taking into consideration font water conditions. I have made negatives in varions parts of the comntry under any and all comblitions and have used practically nothing else but pyro developer, almost identical with the formula published, rarying my amonint of carbonate and suphite to meet locil conditions.

For a stock solution of developer. I have used the following for a mumber of years on different oceasions and like it very much:

\begin{tabular}{|c|c|}
\hline & 90 \\
\hline $\mathrm{E}$ & 1 \\
\hline ch & $t$ \\
\hline$\cdot$ & $t$ \\
\hline$(1) r$ & $\begin{array}{r}49 \\
20\end{array}$ \\
\hline 16 & 3 \\
\hline otasl & \\
\hline
\end{tabular}

For tank, dilute with 42 gallons of water: 20 minute development at 65 .

For tray, dilute 1 to 12 or more, according to speed wanted.

In a tank this bath will last two weeks. After one week, add one-half quantity of abore stock.

PROCFSS DEYELOIER.

No. 1.

Hylrochinone ............. 1 oz.

Potassium metalisulphite ....... 1 oz.

Bromicte potash ............. $1 \mathrm{oz}$

Water ..................

So. 2

Canstic potash ............ 2 oz.

IVater ..................... to oz.

Lse equal parts. Shake well hefore using and rock tray in both directions during development.

There are times when gon will need intensification or reduction, sonretimes both on the same plate. The kind of reducer to use will be governed somewhat 
by the lind of negative you have. If your negative is harsh in the high-lights, but farrly good in the sharlows, a reducer like the following will be inst alout what you will want and is known among the eommercial photograpluers as "high-lighte" reducer"

No. 1-Saturated solution of Potassium Permanganate.

No. 2-Sulphuric Acid, C.P.

Take about one dram of No. 1 and six or seven drops of No. 2, to ten to twelve onnces of water and you have a pretty nice reducer for that kind of a negative. To use it, the plate should be thoroughly washed first and it is always well to try the redueer on the extrene edge first to get the speed of it on that particular plate. It can be used locally or all over. The way most of the workers use this redueer is to immerse the negative in it, rocking the tray a few times, take the negative out and immediately transfer it to a traty of running water, sousing it up and down a few times. If not reduced enough, repeat, if it is not going fast enough, adel more of your stock, and if it is going too fast, put more water in it. After the negative is reduced enough, it should be put in the hypo bath. The idea of using the rumning water is to remove the reducer as quickly as possible, as it oxidizes rapidly and will stain the negative if not washed off quickly. ()f course, the reduction can be done locally by aplplying the reducer with a piece of cotton.

This reducer is used probably more than any other formula and it does not reduce the shadows to any perceptible degree and is a mighty nice, quick and clean working reducer.

Sometimes, under certain conditions, a yellow stain will appear when using this reducer, but by placing it back in the hypo, it should disappear. If not, a weak solution of oxalic acid will remove it.

If by some accident you have developed your negative too much all over, or possibly you may purposely have done it, the negative can be reduced very nicely by what is known as Farmer's reducer, which reduces all over. $\mathrm{Of}$ course, your shadows being thinner, reduce faster than the high-lights. This reducer is made by making (No. 1) a saturated solution of Potassium Ferricyanide (keep in a dark bottle, as light affects it) and (No. 2) a saturated solution of hypo. Use about a dram of No. 1 and a dram of No. 2 with four to eight ounces of water, according to the speed you want. Immerse negative all over, or it can be handled locally the same as the other. After the negative is reduced enough, it should be washed under a tap and placed in the fixing bath for a while.

For intensifying, the following is one of the most satisfactory and extensively used formulie. It is a very old formula and has been used practically as long as dry plates have been on the market.

$11 / 4 \mathrm{oz}$. Potassium Iodide.

$12 \mathrm{oz}$. Water.

To this add saturated solution of bichloride of mercury until it will not take up any more. As you add the bichloride of mercury to the iodide solution, it will turn red, a sort of salmon color and will almost immediately clear up. 
Keep on adding the saturated solution of bichloride of mercury until it stays red, or in other words clears up very slowly. When it does clear up, add enough water to bring it up to 20 ounces and add 1 ounce of hypo crystals. This intensifier can be applied locally or all over and has the advantage of putting a little color into your negative and can be used repeatedly until exhausted. Of course, your negative should be washed thoroughly before using. If you want to take the intensification out, all that is needed is to soak the negative in water and then put it into the fixing bath and it will be removed.

Another method of negative intensification. especially for a stronger result, is to use mercury and ammonia. That is, to bleach your washed negative out in a saturated solution of bichloride of mercury, wash and then immerse in a solution of ammonia, about half an onnce of ammonia to 20 onnces of water. This is a very strong intensifier and is very seldom used except for line copies and the like.

If a less strong intensification is desired, it can be bleached ont and then blackened with a solution of sulphite of soda.

Oceasionally there are negatives where the high-lights are too strong or harsh and yet the shaldows need intensification. In such a case, one way to accomplish this is a follows: Bleach out with a saturated solution of bichloride of mercury and then, after washing thoroughly, touch the spots that are too harsh with a very weak solution of plain hypo on a piece of cotton and they will be reduced, hut the hypo must be very weak, as its action is quite fast. After the high-lights have been reduced sufficiently, the bleached negative can be blackened to its original state by one of many methods. It can be placed in a weak solution of sulphite of soda, sulphide of soda, or ammonia, according to the amount of density that is wanted.

With a little intelligent practice, almost any kind of result can be accomplished. In fact, I do not think there is any limit to what can be done to a negative in the hands of a clever workman. A ground-glass, with a light under it, placed in a horizontal position to light negatives during intensification and reduction, is very helpful and makes a very convenient arrangement.

Again, there are times when but one small portion of a negative either has to be intensified or reduced, and especially in the case of reduction, the reducer is apt to get on to another portion of the negative where it is not wanted. One way to get around that is to proceed as follows: Take a clean blotter and dry your negative (or a clean towel will do the same thing) and then apply your reducer with a piece of cotton, pulled out to a fine point, in the center of the spot that is to be reduced. The reducer does not spread so rapidly on a plate that has been blotted or dried off and is thus more easily controlled. Some operators use an ear syringe, applying a strong intensifier or reducer with a thin film of water running over the plate at the same time. The thin stream of water going over the plate keeps the reducer or intensifier from causing a little ring around the spot being reduced.

Hot weather brings on its share of trouble, especially with double-coated plates, where the emulsion will become quite soft despite ice in the washing 
water, ete. There is also some tromble with films, they being eoated on both sides. One way to remedy this is the method used by the pioneer dry plate workers in the old days, when plates were always soft. As the negative eones from the tray or tank after developing, rinse it off as ustal and then inmerse in about a 5 per cent solution of elurone alum for a second or so, transfer immediately to the fixing bath and then, muless your fixing hath is terribly old or very warm, your negatives or films will be ahnost hard enough to skatte on.

Then, in the winter tine, especially when using tanks or large trays of developer, there is difficulty in holding up the temperature. There is an electric iron on the market used for heating shaving water and the like, which is a very convenient attachment to have, as it will raise the temperature to any desired point with little trouble and one is very well repaid by such an investment.

The drying of negatives is also very important, if their quality is to be preserved. It is the habit of some dark-room men to dry their negatives in the dark-room. A far better plan, to ny mind, is to have a place on the outsile of the dark-room that is up off the floor and away from dirt, and the possibility of dirt flying on to them and away from the dampness of the dark-room.

Where several operators use the same dark-room and the same plate holders, especially when several different kinds of plates and films are employed, there is always the possibility of a plate holder lying around and nobody knows whether a panchromatic, Orthonon double-coated, or single-coated, or what kind of a plate is in the holder. A convenient way is to mark the holders with a grease pencil, such as is used to write on glass, specifying the kind of plate or film in the particular holder. Many of the large studios require their operators to return all unused plates or films to the proper boxes every night, which is a good plan, and if this method is employed liability of a mix-up is avoided.

In using pyro for developer, we all get our fungers stained, and many young fellows, going out among the ladies, and those of us who labor in "high brow" studios, have to remove the stain from our fingers. There are several methods of doing this. If the stain is not very bad and it has not been on very long. by immersing the fingers in the permanganate of potash reducer mentioned above, and seeing that the nails get plenty of it on, washing then a little bit, and then dipping them in the fixing bath a few moments, the stain will come off. If that does not work, wet your hands thoroughly with warm water to get them softened up, and apply a saturated solution of potassium permanganate to all of the stained parts; wash them a little, and then bleach them out in a saturated solution of potassium metabisulphite. This will remove fairly obstinate pyro stains.

If the stains still stay with you, proceed to put more saturated solution of potassium permanganate on the finger nails, immerse in a mixture made of two or three drams of hydrochloric acid (Muriatic) and about eight ounces of water, to which is added four or five crystals of hypo.

This makes a kind of emulsion or soapy looking substance, but will remove the stains from your hands. I suppose if you left them in long enough, it would remove the hands too, as it is a little hard on the hands. 


\section{CHAPTER XXIII}

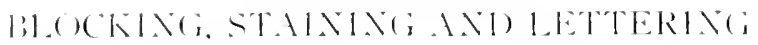

I

Thas long heen the custom, with the large portion of negatives made for commercial work, to block these negatives, that is, paint ont or opaque then so as to render the backerromed pure white in the finished print, but the tendency now, in high-class stullios, is to do awaly with blocking as much as posible.

Ilowerer. blocking of negatives will be in demand for some time to come, and there are many photographers who have considerable difficulty in doing this work. The principal trouble has been possibly that they dicl not have the proper equipment. For success in blocking. it is quite necessary to have a good ruling pen, a transparent triangle and an irregular curve and a good lettering pen, all of which articles can be bought muler these names at almost any artist's supply store, and a few good brushes, which most photographers senerally have on hand, anyhow.

A worl about this ruling pen-a cheap ruling pen is an abonination-therefore, the best that you can find will be foumel the cheapest in the long rum. Keep, it clean at all times, and occasionally aprly a drop of good oil to the set screw on the sicle. A little care will be amply rewarded. A good brand of pen for lettering is Gillott's, No. 303.

A satisfactory opatue, to buy it ready prepared, is expensive, but probalbly it also is the cheajest in the end, for I notice a good many of the large commercial studios buy their opatue prepared. There are several goof brands on the marliet, Victor, Alvord's and Eastman's being possibly the best. If you prefer to make your own opaque, the following is a good formula.

Procure a small jar of Indian Red (ground in water) - Heath and Milligan's is good. To the Indian Red, first add a little water and after thoronghly stirring, add a little dextrine solution, which is made by taking about two ounces of powered dextrine (obtainable at a drug store) and heating it in a double boiler with eight to ten ounces of water, until it is thoroughly dissolved. When dissolved, add a few drops of oil of cloves, carbolic acid or any similar preservative, and store away in a tightly corked bottle. Ard enough of this solution of dextrine to the Indian Red to make it spread nicely. Try it ont on a piece of glass with a brush and if it does not spread well, add a tablespoonful of common table syrup, such as Karo. With a litte experimenting, back and forth, you can get this opaque very smooth and as it dries very quieliy, is a really good oparpue, although it does not keep quite ats well as the prepared opaque. 
Another opantue used considerably on films is mate as follows: To drop' black (gromel in Japan (lrier) add turpentine until it is tle proper consistency This makes a somewhat more expensive oparpue than the first formula, but because of the absence of water, is the much more satisfactory oparfue for the films, as the films will not cockle.

Still another formula which is much used by particular and careful workmen on small things, especially those who apply oparpue on the negative with a brush, is to take Windsor \& Newton's oil color lamphlack and dilute with turpentine and apply directly on the negative with a brush, as this kind of opanue boes not flow very freely from a ruling pen.

About the next requisite in this work is a good blocking stand. There are several different kinds used by the commercial workers. Some seem to prefer the horizontal type which is nothing more, ustally, than a big plate box with a sheet of ground-glass set over the top) with an electric light in the bottom of the box. The negative is put on this ground-glass and blocked in a horizontal position. Those who use a brush exclusively seem to prefer this position, as more light is thrown onto the negative from the workers' side.

Others use a nearly upright stand, with electric light in the back and which, to me, is far the better position. A good light for either type of stand is a 75 or 100-watt blue bulb placed back of a sheet of flashed opal glass and gives really ideal condlitions.

To proceed to block a plate negative, go around the outline of the object with the ruling pen for the straight sides, using the transparent triangle, and

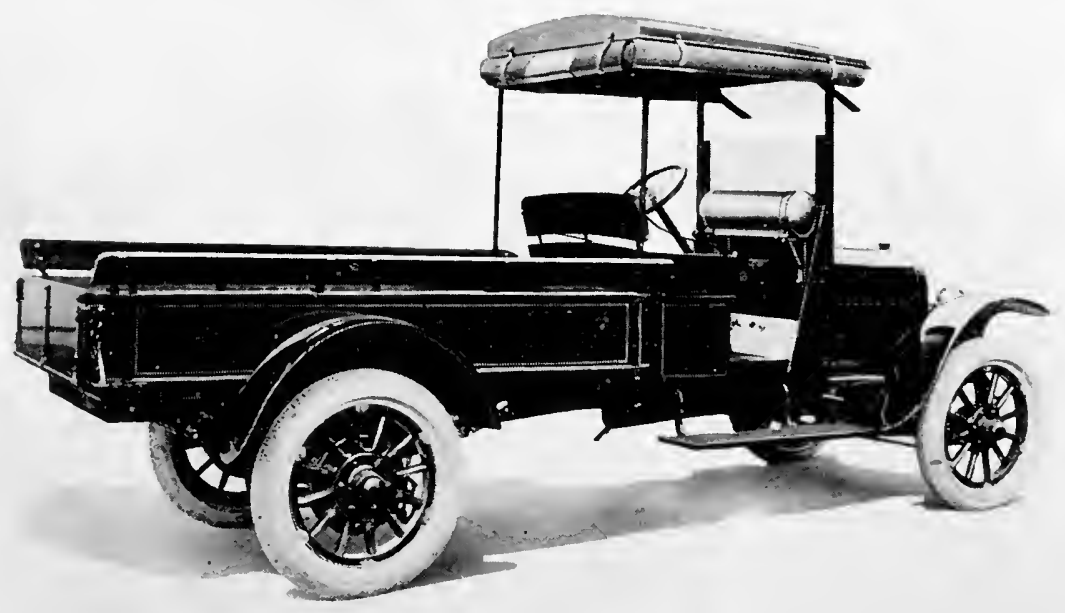

Fig. 69 
for the curved spaces the irregular curve, while, for intricate places, nse either a pen or a sllall brush.

Solnds eatos, and I think really is easy and I cannot understand why some people have such hard times doing this, as it ordinarily is a kidls job. After the ontline is completed, fill in the rest of the plate, using a heavier brush. some shops fill in an inch or two of the negative with opatue and then use postenfice paper masks for the rest of it. hut as the mask gets torn off and somebuly possibly has to make a new one abont every time an order is printed, it rould seem cheaper to opanue clear to the elge in the first place.

Opaquing film presents a few diffeulties. anong which are cockling of the film and slipping and sliding of the film on the blecking stand. The way to overeone these is to hind your fibm negative on to a sheet of clear slass, same size, and then proceed ats with a plate, and elininate the cockling, as mentioned ahore, by using turpentine insteat of water in the opraptue.

When the opatule crawls and refuses to go on eventy-catused ustally by grease on the negative, this can be overcome hy rubbing the place with a cloth or piece of cotton moistened with saliva or alcohol.

lllustration No. 69 is a blocked job of a motor truck. The point I wish to bring ont by this illustration is the blocking of the groment of which this is a good example. and which wa done by simply following the shatow of the truck on the groumi.

STIINING

No matter how careful the operator may be in making the original negative and probably has done all he conld in intensifying and reclucing, there will be cases of negatives that are too thin in some one place or maybe sereral small places. This is something that frequently occurs and creates quite a little trouble in the printing-room. The time to correct it is on the negative before it goes to the printing-room and is usually done by what is known as staining, which, in this case, means to apply a stain of some kind or other to the weak portion of the negative. A good stain to use is what is known as V'clox water colors. These can he purchased at any photo supply store and are used or linarily for coloring anatenr prints. The two colors most used by commercial photographers for staining are brilliant red and light yellow. There is another color nsed considerably, known as turkey red. a dye obtainable at the drug stores. The brilliant and turkey reds are nsed to hold back extra thin places and the light yellow to hold hack the medium places.

The method of applying these colors is to make a weak solution of the desired color and then moisten that portion of the regative to which the stain is to be applied with a little saliva. Then go over it with the color on a brush, and as soon as the color is applied all over, blot it off with a clean, dry blotter, and, if more density of color is neederl, apply another coat. It is hetter to use several applications of a weak color than one application of a strong color, as you have more control.

While it would seem that the red would be too strong, that is. make the 


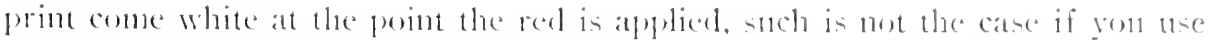
the colors mentioned, that is, brilliant or turkey real.

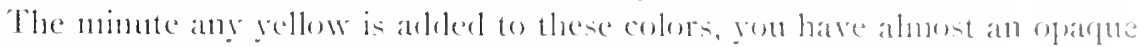
color as far as printing quality is concerned.

This staminge is really a womelerful help and is a very old stumt, uned for years anong the old-tinte connulercial photographers and is still muth used. It, like alany other stunts in photography. resuires a little practice and dexterity in making the application.

If you get on tow nutuch coloring, the neative can be fut batek in the wathing box and the color emirely wathed out, if the brands of colors mentioned are userl.

\section{LETTERING}

lnsertion of titles and letering on negatives is a necessity in commercial work. Amost every print delivered in merchandise work for traveling men's sample books will be numbered or lettered to a more or less degree. There are many different ways of putting this lettering on. If on a white ground, it can be scratched in reverse through the opaque with a sharp point. I good point for this kind of work is what is known as an engraver's needle. However, there is considerable trouble, at times, in preventing this lettering from be-
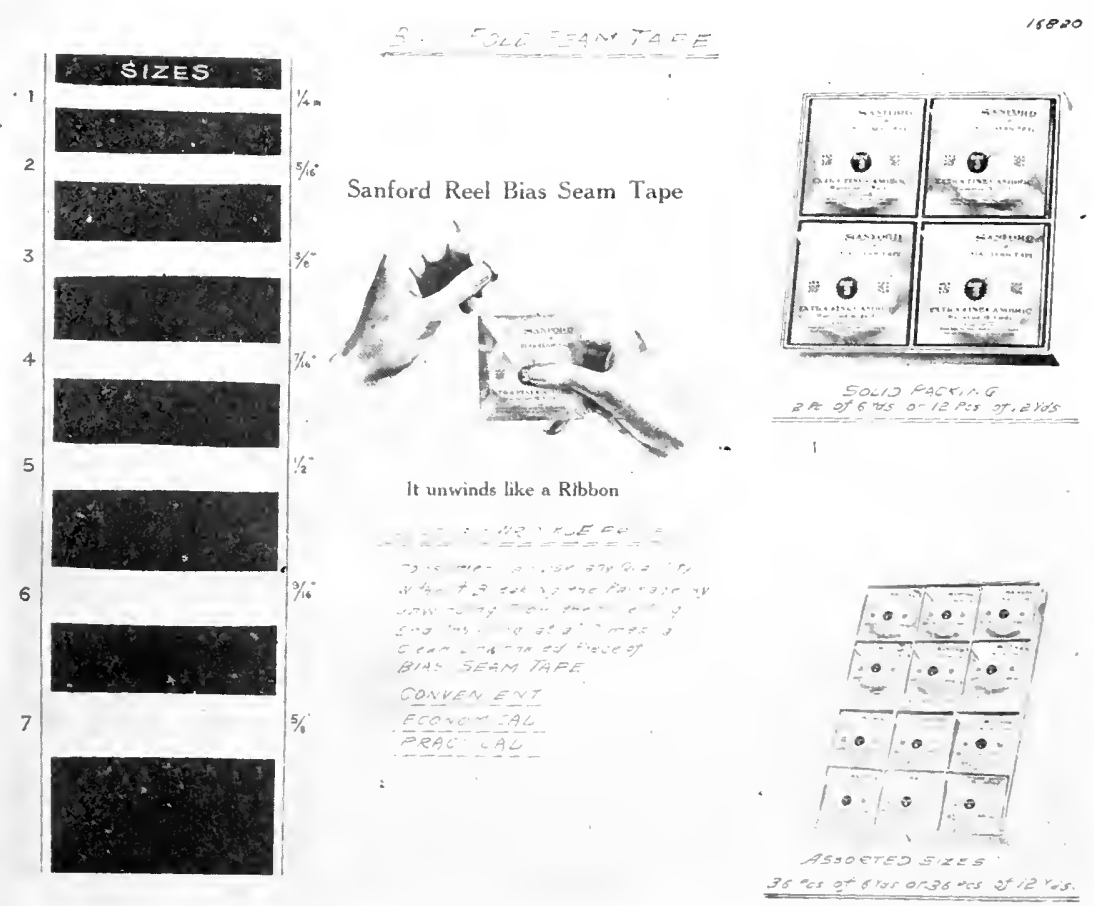
WHICH is WHICH?

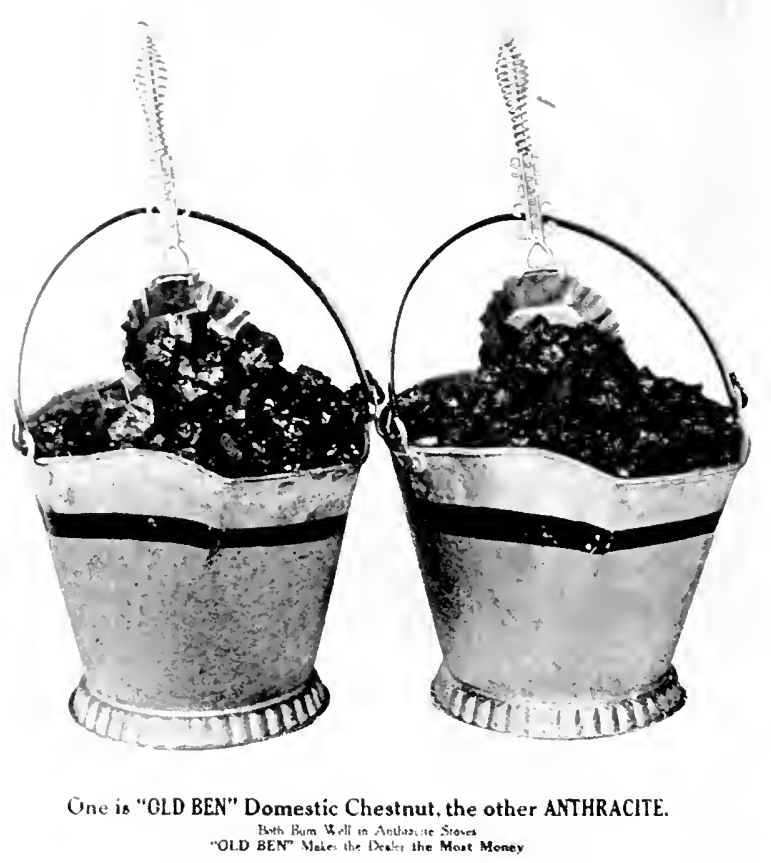

Fig. 71

coming ragged. A far better method is to put it in with a hot point, which. in the simplest form, consists of a $1-16$ inch machinist's drill, with the shank end filed off and driven into a piece of wood for a handle, and the drill end ground down to a fine point. Heat this point up hot and letter on the negative. Yon will be surprised how easy it is. The hot point, in its more elaborate form, is heated with electricity, alcohol or gas, much the same as the old wood-burning outfits so popular a few years ago.

Figure No. 70 is an example of hot point lettering.

Figure No. 71 is an example of inserted printing on an opaque ground. The wat this was done was to have a printer set the titles up and make a press proof on a pure white paper. This printing was then photographed with a process film developed with contrasty developer. The film was then cut up and the lettering inserted on the negative. The method of inserting these film strips on the negative is at follows:

Cit up pieces of blotter just a little larger than the titles you wish to insert. Dip the blotter in water and pull it right ont and place on the negative where the title is to go on. Go around the edge of the blotter with an etching linife, cutting through the film. Allow the blotter to stay in place for a minute, remove, and then with the etching knife, catch up the edge of the film and pull 


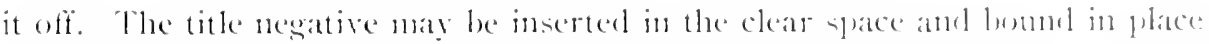
with biating strjes. This makes a rery neat and satisfactury jobl).

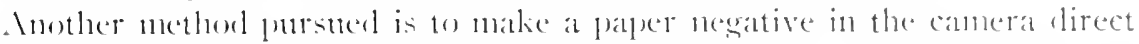

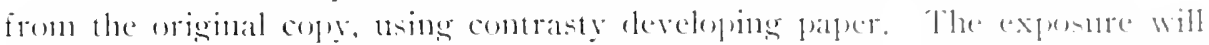

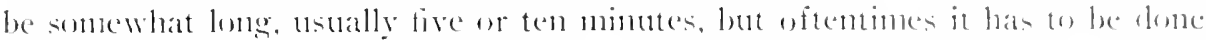
that way. This paper negative, after it is developed, fixed, wathed and dried.

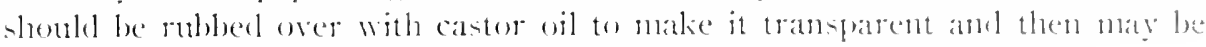
inserted on the nexative the same as the filme strips mentioned aluese.

Titles may also be double printed in, that is. make the title newative the same as mentioned above hy either the film or paper method amd attach them to a mask eovering the whole plate. Then, by first printing the proture taking the negative sut and replacing it with the mask with the titlen in, making a second expostre and developing un, your title will be in. This takes rather bonger to accomplish, but malies a neat jol).

The simplest and the best way when gou have long titles or descriptive matter is to have a printer set up type using a light face, and print the insoriptions exacty where required on a piece of fihn support, thing a printing ink used for printing on cellubid and then bronzing it to give greater deshity. This is the method used by the payer makers to title sample prints. of entrese the printed title and the negative are placed face to face and printed an one time. In enlarging, the printing will show much better than at if done hy hand.

Inserting titles on black grounds is far easier. They can be lettered in directly on to the negative, using India ink and a pen, lettering in reverse, or you can use opalue, which is really better. If you have trouble in lettering reverse, procure some film support from your stockhouse, the same size as the negative you wish to title and letter on it. Then reverse and attach it to your negative and print through the two of them.

1 lot of attention should be given to titles, as they are important, if you wish to help the customer sell his goods, as many an otherwise excellent photograph is spoiled in appearance by untidy lettering. 


\title{
(HAPER XXIV
}

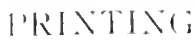

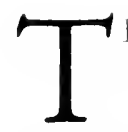

11E printing-roum of a commercial stuclio is by far the most important part of the entire outfit-important in that it is the department from which comses the finisher product for the customer and is considered he many of the leaters as the most profitable department of the business, and, for that reason, should le thoroughly and properly equiphed with sood rentilattion and the bes pessilde afplaratus, as well as latel out compeniently for heary work.

There hats been, from the tine the photostaphic business first started, more or less friction hetween the operating and printing degatuments. the operator blaming the printer for not turning ont goosl prints and the printer blaming the operator for not semeling in good negatives, all of which should be done allay with, as it is up to all concerneal to help in turning out the best possible prints and make money for yourself. if you are in business or make money for your employer if gon are working for others. and which cannot be accomplished if there is continual dissension.

The main consideration in the printing-room is the printing machine. There are about as many different kinels of printing machines as there are stulios. Fach and every commereial photosratpher having his some one idea as to the best printing machine: alout the only quality asreed on by all of them being that there numb he absolute control of the light. Faking and dodging must be easy and fairly fast and absolute contact must be had. Mbout as good a machine as there is now on the market is the Folmer $\mathbb{d}$ schwing professional printer, Figure No. 72. most commercial photographers using the No. 2, although as above mentioned, many make their own machines.

Just a word about the lind of prints wanted in the commercial line. l'ortrait photographers prints are considered good when they tend just a little bit towarl the olive. warm hrowns and some of them make a lot of sepias. A commereial print, to reproduce well and to natch up with commereial prints from other parts of the comntry which the customer may have should never be ereen or olive, lut a pure black and white, what some of you may eall a coli blue-black, and should have detail all through, be snappy and hrilliant. but not harsh or contrasty, and, for most cases, will be wanted on glossy paper. The reason so mueh commereial stuff is on slossy papee is that a glossy print shows more detail and when it is wanted for reproduction purposes, there is no liability of pieking up the grain of the paper.

But, of late gears, many of the commercial studios. especially those malsing prints for salesmen's sample bowks, are using more and more papers like lzo E. double-weight and other semi-matt and semi-gloss palpers, as they do away 


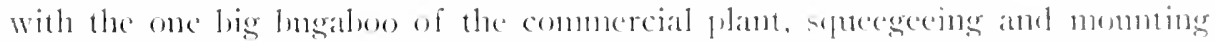
on musilin.

For outsile work, many of the better stmelios today are using sepia prints with tinted in borders, very much the same as the high-garde pertrat men are using-also. there is a great deal of carbon green leing used for prints froms negatives of ont-door secenery.

It is just as well to get awaly from glosey prints where others are pertmissible and yon can (b) it at a prolit, for it makes the work turned ont from your studio more distinctive than where everything is dome on gloss paper.

The commercial printer of a few years ago, using printing-ent paper, hat

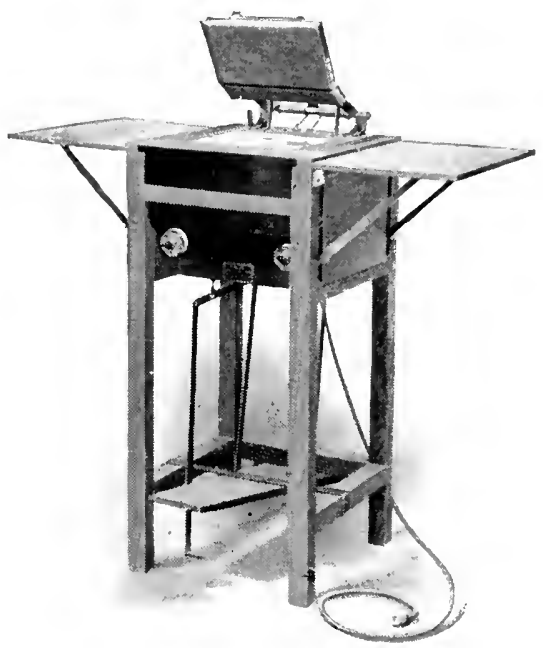

Fig. 72

but one speed, to which he had to bring all of his negatives. Today, we have many speeds and contrasts and surfaces. In fact, there is practically no limit to what can be done. We have the four different contrasts of Izo pajer line, for instance, soft, hard, hard medium and hard X, as well as Argo. Cylo and the Haloid Industro, all of which have their particular adaptability and their individual peculiarities make them very desirable in obtaining the best results from any and all negatives. However, in making a print from a negative, keep towards the soft end as much as possible, as it is there that you get the long scale of tones and better gradations all through the print, one of the points that distinguishes a good workman from a poor one.

There are many stunts used ly good printers to pull themselves out of tight places at various times. I will describe two that are more commonly used than any others in printing undertimed and uneven negatives, for no matter how careful the operator may have been and how much has been done on a negative in staining and blocking, negatives will find their way to the printing-room which are far from good and are shy in quality. Negatives, such as of interiors where there is furmiture, dark wall paper, etc., will hatve detail, but in the print will show a little too dark. One way to correct that is 
to take a printing frame and buikd it we, say, threse inches with cardboard. smilar to slown in Figure No. 73. Cover it with rignetting tissue. cepia or onjom skin fraper, flace bour nexative in the frame and hold it up to the light

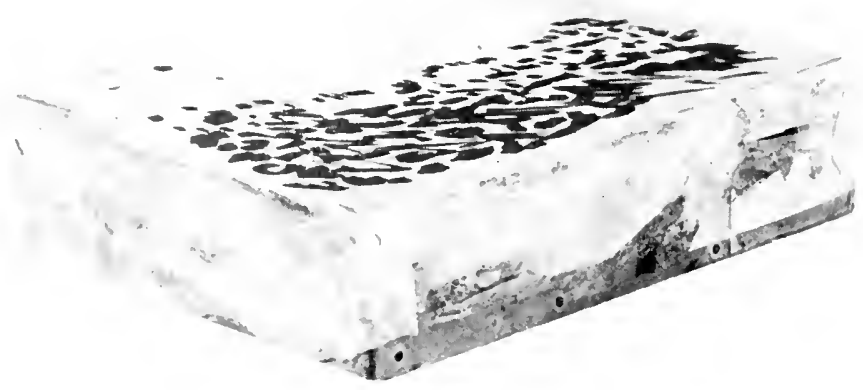

Fig. 73

and dauls opatue on in splotehes here and there oser the thin places. It does not refune much practice and you will be surprised what an improvensent it makes, but, of course, the france must le kept moving before the light during the exposure (this being one of the advantages over a printing machine) as one gets more diffusion.

()easionally an operator will go out on a jol and bring back a negative horribly undertined through lack of sufficient artificial light. Illustration No. Tt is a print from such a newative. It first sight it looks as though there is absolutely no hope, but there is. One way is to make a very thin transparency from that negative and bind it in contact on the glass side, which means that your thin place in your negative is being covered by a thin deposit in the sharlows of your transparency and your high-lights are not being obstructed by the transparency. Of course, it does not make as nice a print as the negative wonld if fully timed, but it will "save the bacon" many times, and is an old stunt which has been used for years. Illustration No. 75 is a print from the combinerl negative and transparency.

The washing of prints is quite a proposition in the large studio. where prints are turned out by the thousands, as there has never been a real satisfactory washing machine put on the market that woukd wash large size prints. that is, prints from $8 \times 10$ on 11 . Shout as good an arrangement as I know of is illustrated in No. 76, which is a pen sketch of a washing tank used by one of the largest studios. These boxes work practically autonatically in that, as soon as one side is filled, the weight of the water turns it over and the water rums out that sille, while the other is being filled from the fancet. The 

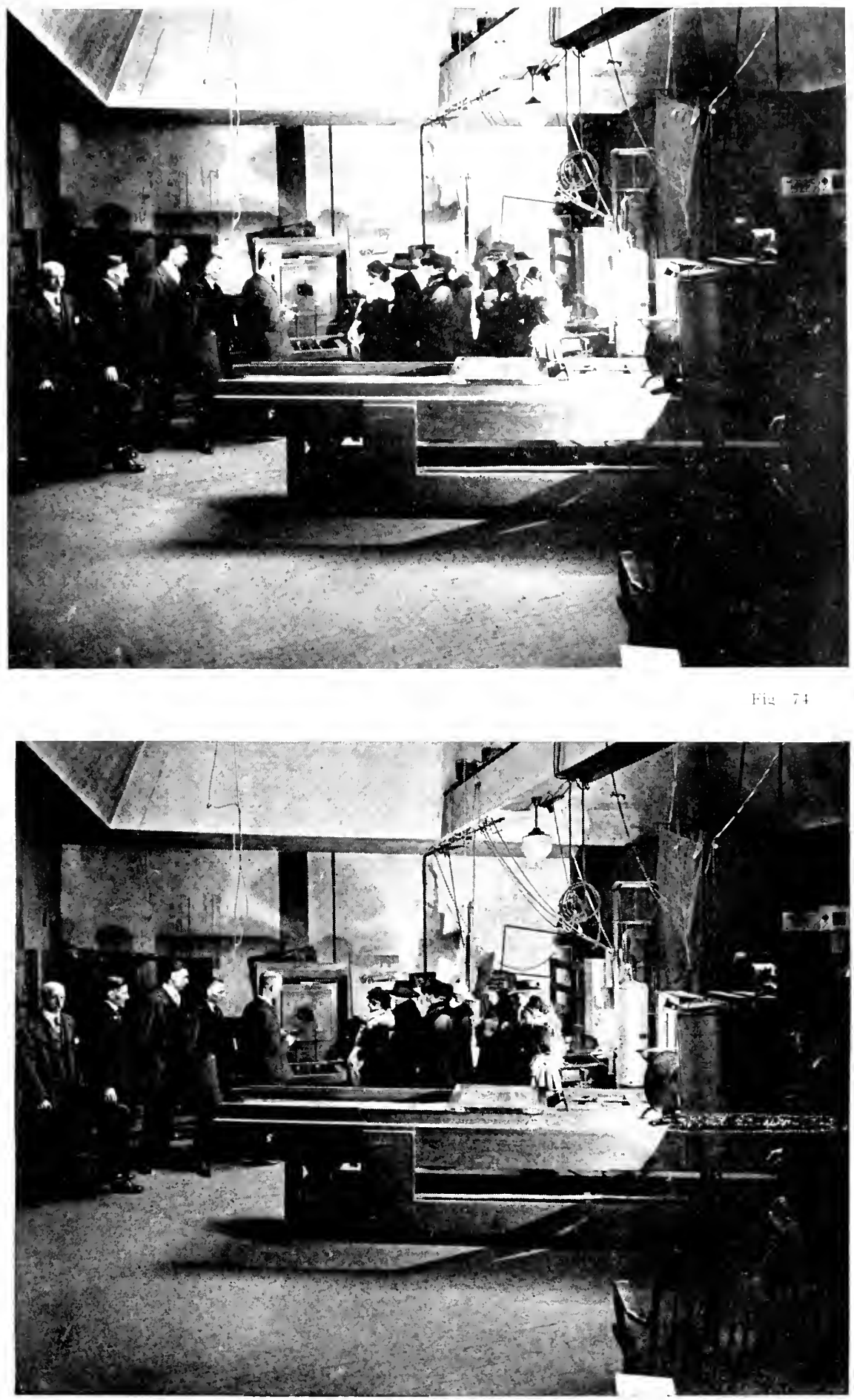
-tudio mentioned has fifteen to twenty in a battery. with one boy to change the prints from tank to tank, and is as practical a way to handle a large ammunt of gool size prints ats I know of although the washing of prints by hand and changing from one traty to ancther. as used by the majority of the stulios. after all has been said and done, is alout the only satisfactory mamer of thoronghly washing any kinul of a print.

The dring of prints is another proposition that worries namy of 11 . sturlios doing a lot of arlvertising mork, where speed is essential, have to turn ont prints in a hurry. ()ne way to do this quickly from ferrotype tins is by a drving callinet such as illustrated in pen stetch No. 7T. This cabinet is generall mate of woos with slots to holl the tins with the prints on them in an mpright position. with an air space hetween. so that the air can pass right through from the bottom. There is a gats flame molerneath the calbinet with

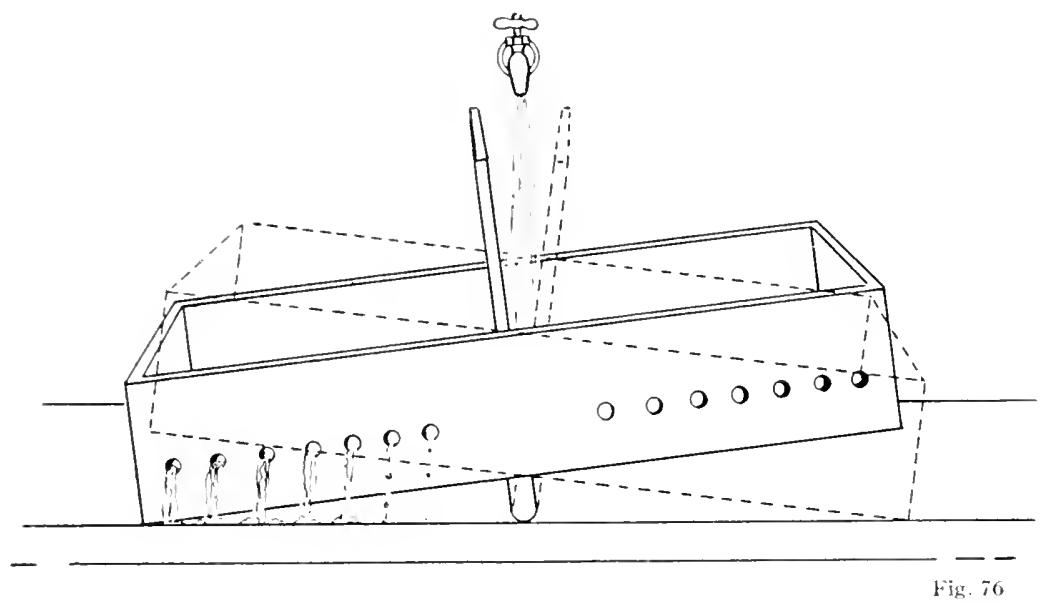

an clectric fan at the top, pulling the heated air from the was flame right straight up through the cabinet past the prints. Prints will dry in a cabinet of this lind in frve or six minutes under nomal conditions. I would not recommend this system for prints with muslin backing thongh, for to prevent then from sticking and to get the proper gloss, the prints shonld dry more slowly.

The kind of ferrotye tins and the care of them is a matter for much consideration. Nhust every day someone asks me- what do you put on your ferrotype tins." 'lins when they are new do not need anything on them and I firmly believe that if they always had good care and the prints were properly hardened before going on to them, the tins would not have to lave any thing on them. It is only when tins get scratched and dirty and prints lave stuck on them that you need a remedy. What to put on tins is governed by circmmstinces.

If you are delivering prints to commercial artists or to people for coloring. (11 you are coloring the prints yourself. you certainly do not want to put paraffune and gasoline on thent. Lint, if you are delivering prints to customers 
for salesmen's sample books, paraffinc and gatsoline is all right, although it should be used sparingly at all times and the tins should be forlisherl to the linit-the more they are polished, the better.

The real theory of it is that no more paraffine should be put on the tin than just enough to fill the seratches.

If delivering prints for commercial artists, wash the tins with warm soajy water, but do not rinse them very much and apply the print dircetly. Then, when the artist applies saliva to the print to make his color stick, he will have dissolved off what little soap there was on the print.

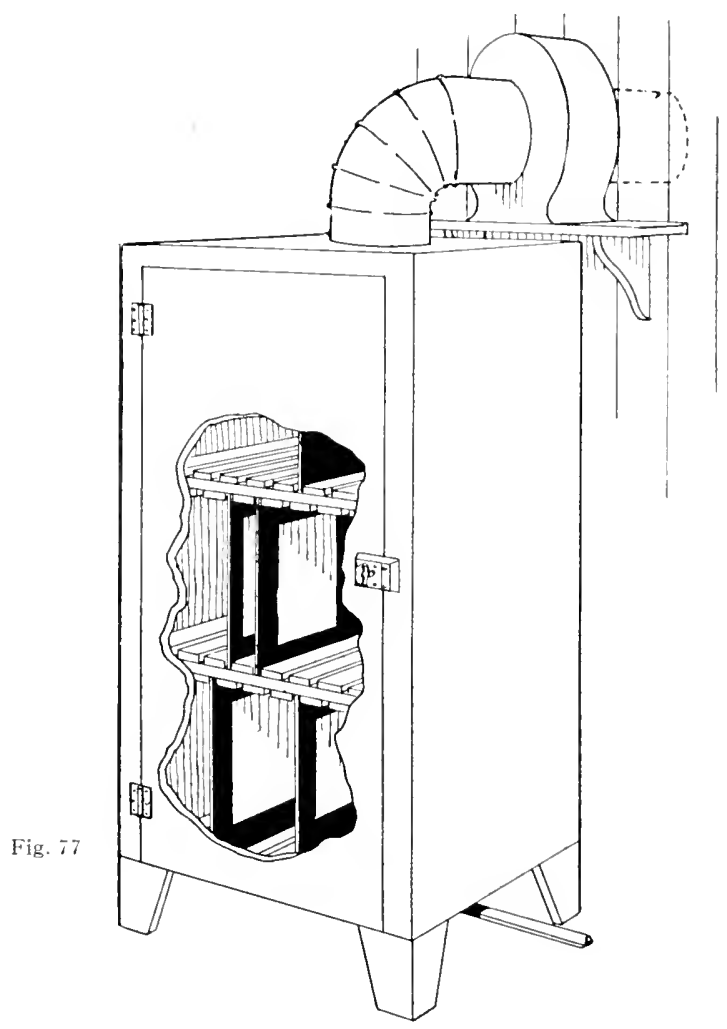

Paraffine and gasoline should never be applied to a tin while the tin is still wet. The tin should be rubbed dry and be free from paste for the best results.

Of late years there have come into use, for squeegeeing purposes, heary sheets of celluloid, which have their advantages and disadvantages. The advantages are that you have practically no trouble from prints sticking, you can put twice as many prints on, as the sheets can be used on both sides, and they are easier to wash. But the disadrantages are that they are so easily scratched and are so mwieldy in handling and difficult to set up that, taking it all in all, tins still have the preference. 
Sonne of the old tine shops use plate-glass polished. While plate-glass gives a very high ghos and absolute contact, it is more easily broken and unless prints are hardened to the linit and the glats well polished, the prints are always stre 60 stick.

Ifew proints alout the care of tins. When tins are first benght, to last a long time, the comers shonkl be slightly rommed with a pair of timner's shears and then filed off smooth. The hacks of the tins should be finished with asphaltmon varnish. which nakes them water-prosef on the back and does away with one difictulty- renting of the backs of the tins, and huring all operations

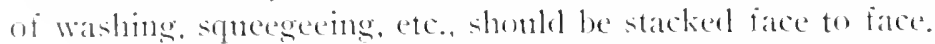

The tims shomlel never be allowed to stand with water drops on them, and if not need innuediately after washing. shombl be thoromghly dried. It will be found that musch of the sticking of prints to the tins is cansed by these dried teare (lons)

If one would unclertake to figure up the waste in paper, nustin and lime,

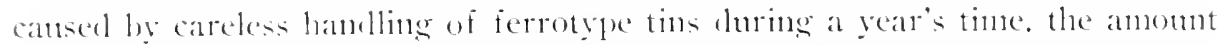
woukl stageer him, and I think, give him canse for serious thought on the matter.

The application of muslin and hinges to prints is another item that bothers sone photographers. In studios where employees time is a matter of consideration, this operation is generally done in a machine-like way, but the principle is the same in smaller places. The procelure is about as follows:

The prints are separated in the water in lots for guick handling and are put in place on the tins (the tins first being rinsed), together with the hinges. which have been well soaked in water beforehand. The tims are then passed along for squeegeeing-a wringer will be found a big tiuse satrer-althongh mam prefer the velvet rubber squeegee. I little idea here to prevent tearing of the hinge is to cover the entire tin with a piece of oil cloth and squeegee throngh the oil cloth. The tins are then stacked up on edge to let the surplus water dram off, although rumning them through blotters keeps the tins in better condition.

The prints are then pasted-not just here and there in spots, but evenly all over. A good thin paste is better than a watery paste. Nie have all had trotbles with paste, that is, when we wanted it, it never wats made, or else it was sour, watery or something wrong or it ran out toward the end of a large jol), so that it has resolved itself down with the majority of us, to using a prepared paste powder, and eliminating considerable trouble.

After the pasting operation, the muslin is laid on and brought out smooth in all directions by the hands. But one should be careful to see that the muslin is in contact all over, and the muslin should, by all means, be kept clean. The grade of muslin to use is usually governed by the class of work. There is no advantage, however, in wsing an extra good grade, nor is it economy to use a real cheap kind. There are many backing cloths on the market now, made especially for this work, but they are generally of a lrab or light tan in color. which is the only draw-back I can see.

Hinges can be bought from any printer or paper supply store cut to size, 
although some people still use bateking paper for hinges. The grate of patpere should be of a heary bond or ledger payer and printers watally have large quantities of left orer ends which can le purchased for a trifle.

The proper method of arving prints with mustin on them is to lay them absolutely flat, for the lest results, although most commercial shops now dry them on elge, time being the governing factor. There is no real salfe methonl 1 know for rapielly drying prints with nuslin backing.

l'roperly equipued and with a trained crew. one tremendous lot of prints can be put on tins with muslin and hinges in a short space of tine. but if everything is not arranged conveniently and there is not enough help, it is a tedions jol.

Many prints are wanted these days in sepiat. (Of course, there is a variety of formula for sepias, hut the oll, straight hypo alum is still about the most reliable for getting results casily and conveniently.

The tone of the print is good and the bath can be nsed hot or cold.

Another thing used in the printing-room a great deal is a cutting bleach. There will be many enlargements and occasionally prints with dark edges or portions of an edge which should be eliminated, background that tint through, etc., which can be bleached out with the following formula: To one dram of saturated solution of potassium cyanide (be sure to mark the bottle "deadly poison"), add two ounces of water. "To this add abont 25 to 30 drops of iodine solution, such as obtainable from the drug store and you have a very fast and effective cutting bleach which, when applied to your print, will bleach out to a pure white any portion it touches. This was mentioned in one of the previous chapters in connection with bleaching out a photograph under a drawing.

Prints, with a gloss surface, often show abrasion marks, which many find troublesome to remove. A piece of cotton dampened with alcohol and rubbed on a cake of Bon Ami, such as used in cleaning windows, and then applied to the print, will quickly and easily remove such marks without, in any way, damaging the print.

When wanted for salesmen's sample books, especially when without hinges, the prints shonld have the corners rounded. There are several machines on the market for this purpose, any one of which will be found a good investment for a studio turning out large quantities of prints and the appearance of the print is greatly improved, there being no conners to become broken and ragged. 


\section{CHAPTER XXV}

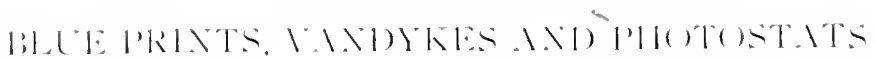

$\mathrm{M}$

IXY photosmaluers, who are comnected with industrial plants, engineering and arclitect's offices, have charge of the bhe printing department; also many commereial photographers make large numbers of lolue prints from dry plate negatives, while the larger connulercial studios doing merchandise set-ups and catalogue work for ont-of-town customers use the blue print for customers proofs.

There are several reasoms why this latter is done. Should the proof fall anong unscrupulous people. it camnot be used for reproduction purposes, as the blue print will not reproduce by the half-tone process to any degree of satisfaction. Inother reason is that the blue print is cheaper, and, with many custonners, such as furniture manufacturess, manufacturers of stoves, statuary, picture frantes, ete. where the goods are known, but only new designs want to be shown, blue prints fill the wants very nicely.

While the average commercial photographer looks upon blue prints as a nuisance, they are really the source of a great deal of profit when handled right and in quantities.

Lilue print paper, as purchatied in the open matket, connes in three degrees of speed-slow, medium and iast-also comes in several grades of quality as to palper stock that it is coated on. If you are making blue prints from drating room tracings on a continuous blue printing machine, you will need either the fast or medium speed. If naking blue prints in a printing frame out in the sun, a slow or medium speed is far preferable. The medium speed paper is also used in printing from dry plate negatives.

Illustration $\mathrm{No}$. IS is a continuons printer, washer and dryer and is one of several different kinds on the market, and this machine has the paper fed to it in continuous rolls and is printed, washed and dried and rolled up on the other end. It makes a very good outfit for studios doing production work.

like print paper, at its best, does not keep very long, deteriorating very rapielly in a damp or light place. It should always be kept in a dark and dry place. For those who prefer to coat their own paper the following is a formula that gives very nice results:

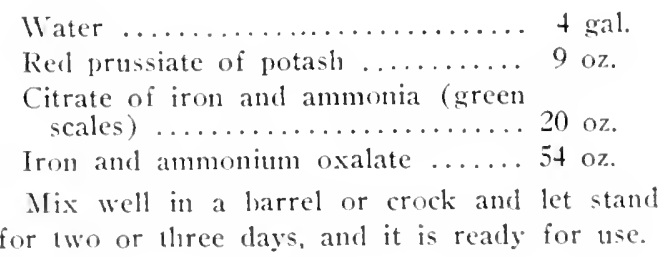




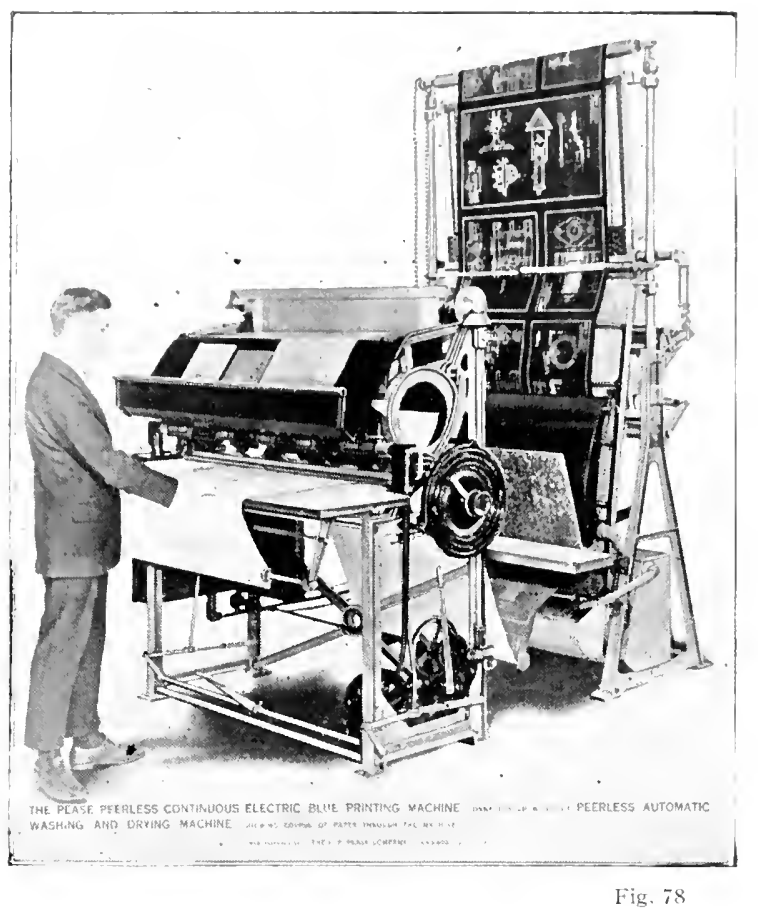

There are several different ways of printing blue print paper. You can print it in the sun, with arc lamps, or with Cooper Hewitt tubes. They are all satisfactory as far as I know, although the arc lamps are probably the speediest for all around work. The Cooper Hewitt tube people make an unusually large tube especially adapted for blue printing.

Professional blue printers always treat their prints with a solution of bichromate of potash to give a better blue-it also makes it more permanent. The method of applying this solution is about as follows: Enough solution of bichromate of potash is added to the washing water to make it a fairly deep yellow color and the prints are inmersed in this. It has rather a bleaching action, so, therefore, many printers do what they term "burn 'em up"-that is, print then several degrees stronger than ordinarily before immersing in the bichromate. Other printers, especially those printing from dry plate negatives. dip their over-exposed prints directly from the printing frame into a strong solution of bichromate of potash, and then wash the print thoroughly. Either way gives satisfactory results. Illustration No. 79 is a coating machine for those who coat their own paper.

VAN DYKES

In printing from paper negatives and for making paper negatives from tracings, Tan Dyke paper is used. This is known under several other names, such as black line process, brown print, and Maduro paper. While this process 
is somewhat similar to blue print, it differs in that it must be fixed in a weak solution of hypo, or some fixing agent of a like nature.

Commercial photographers also use this paper for nuaking prints from line negatives. copies of letters. etc, as it has no emulsion on it and it can be folded up and creased without injury, and as this paper is also very thin in certain grades, it is not so bulky as regular photographic paper.

This paper can be bought ready coated or you can coat your own, in which casc, the following is a very good formula:

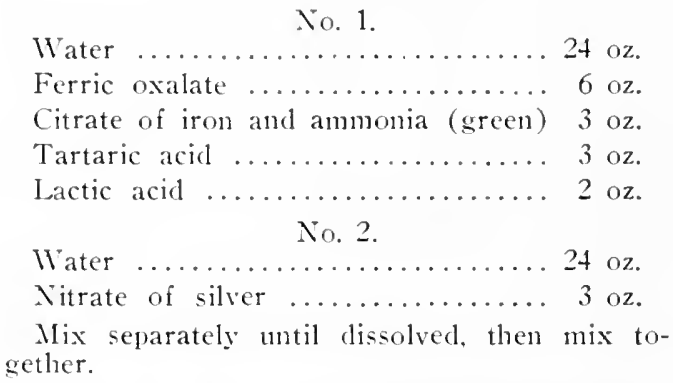

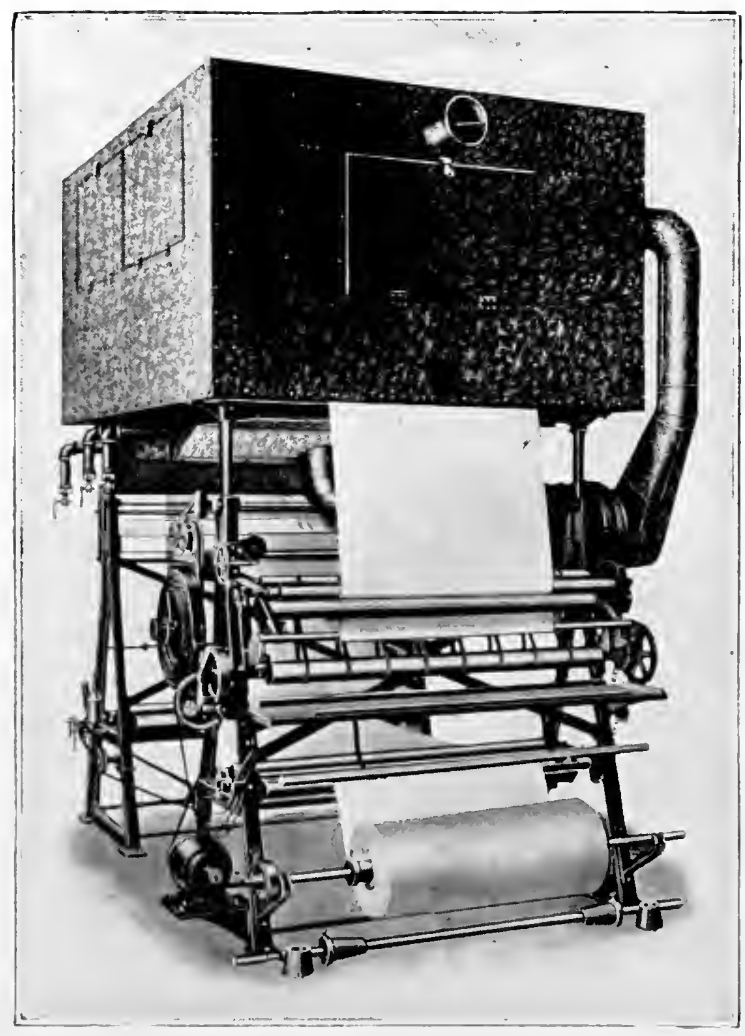

Coating Machine

Fig. is 

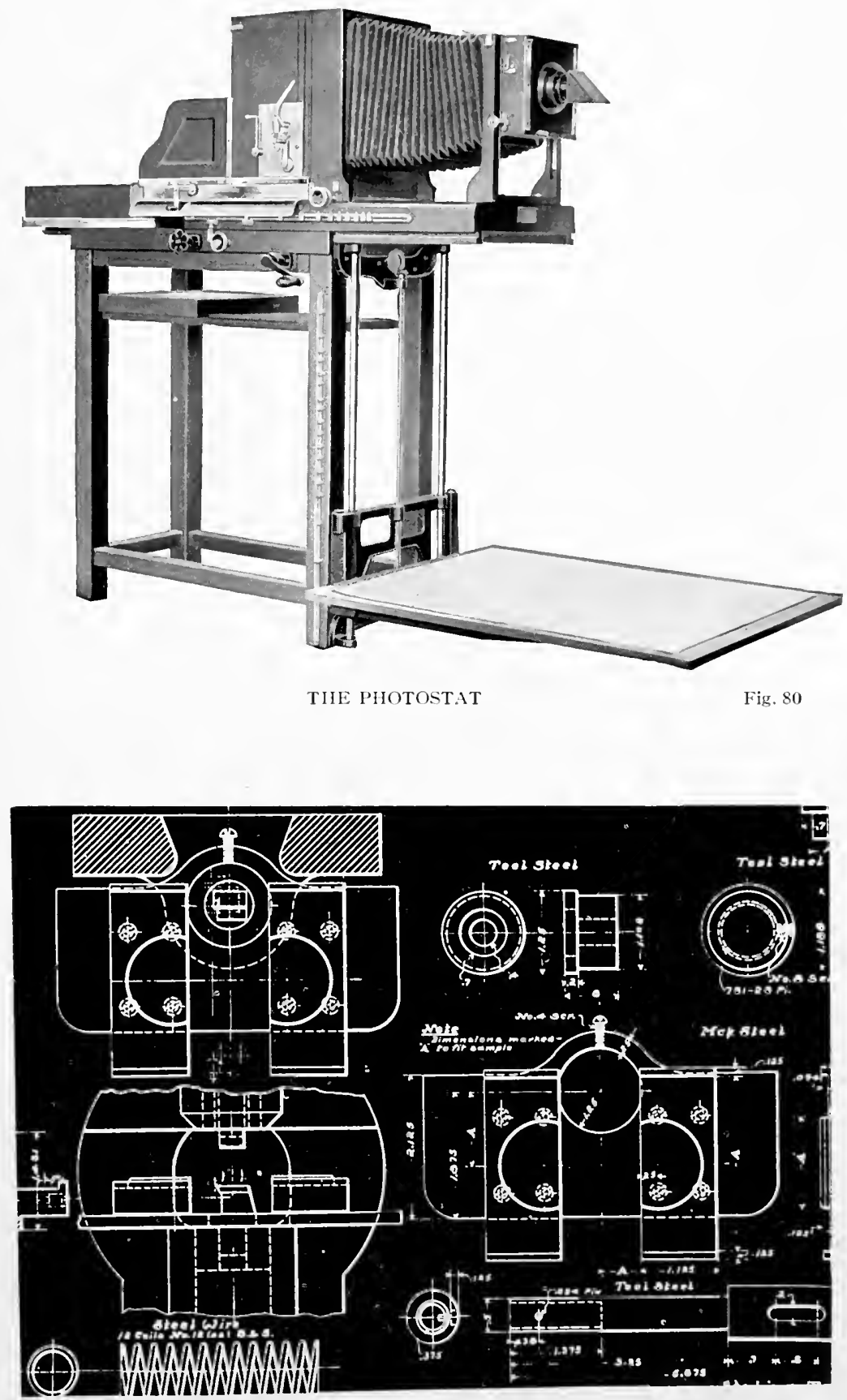
In latrge mannfaturing plants, there is another mathine that is found in nearly all the photographic departments and that is the plootostat-sece illustration $\mathrm{No.80}$.

This maldine is uncel to copy drawings, blue prints, letcres checks, pages from bowks, designs-in fact, there is searcely any limit to its soope. The

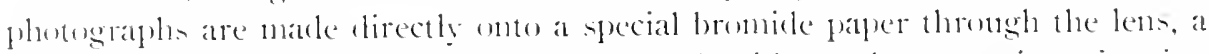
prisms. therely making thent reat right, and without the necensily of gong through the disual negative and print process. The colors in a l'hestontat print are revereed, the black coming white, and white, black. Lllustration No. \&l is of a l'hotentat copy of a tracing. If the original colors are desired, a second copy is marle from the first Photostat print.

This machine is made in varions sizes to fit almost all kinds of work and rerputes very little skill to operate.

The lighting equipment for a machine of this kind is generally of the Cooper llewitt type, one type on each side of a horizontal copy board.

The copyloard is nurlied off with rectangles, which are given numbers to correspond with the length in inches, and there are corresponding numbers on the leg of the nuachine and on the Cantera lied to which the machine is set, so as to mechanically give the correct focus. The machine is also equipued with aljoaratus for developing and fixing the photographs, so that ath of the work is done right in the machine itself, exeept for the washing and drying of the photogratphs.

In some places the l'hotostats are equipped with a light. tight convegur. which shouts the photographs from the nuchine through a specially arranged opening into a dark room, where the developing and fixing can be handled with somewhat greater rapidity.

When maps or drawings are larger than the regular coplonards, they can be copied just the same. Ender these circumstances, the subject is humg on a wall or a sereen at the sicle of the machine, and the prism turned at right angles wo its regular position, en as to cover the subject which is to be photographed.

()casionally, blue prints are made directly from the Photostat prints. When blue prints or lan bykes are to be nade in this way. better defintion is obtaned if the prism is remorect, and the subjects to he conied humg on the wall and regular negative print nate directly on the brommle paper. This necative print is then re-developed, the same as the sepia process in printingthat is, bleacherl ont with ferricyande and bromide and blackened with snlphide. 


\section{CHATER XNII}

IRINTS . IN) ( )

\section{$\mathrm{A}^{\mathrm{u}}$}

I0 NG a certain class of enstonters there is an increasing demand for colored photographs, especially is this true with such lines as bicycles. juvenile automolites, dishes, uotions, candies, soda fountain supplies. toys, ganles, etc.

It is a wonderful help to a salesman to have photographs of his line. It is still more of a help to have that line in its real colors. Commercial photographers have been consicherably bothered, for a number of years, to get this work done satisfactorily, cheaply and with a fair degree of speed.

In times past, for the above reason, undoubtedly, there have heen only a few commercial photographers throughout the combry who have done this work. Now, there are several in almost every large city. It is a profitible line of the business, attracts attention and creates new business wherever shown. There is nothing so really difficult about it, merely practice and patience.

For a line of goods to be colored, the negatives should be correctly nade, that is, they should be made for color correction, and, in sone cases, separation. Of course, the pioneers in this color gane relied alnost entirely on faking their negatives, but nowadays, the men who are nuking a real success of colored photographs are using filters and panchronatic plates, when there is very little trouble in getting the goods to look right and, in consequence, the colors right. This is really important, this making of the negatives, for mules they are correctly made, there is trouble from the start.

Of course, there are times when even with panchronatic plates and filters, staining and all manner of faking will have to be resorted to, but this should be avoided as much as possible, as custoners are very particular as to the colors, many articles being known by the colors, and a little off shade in the color. caused by an off shade in the print, is recognized instantly by the custoner and by the trade buying the goods, and ereates a suspicion in their ninds.

Figure 82 is a straight print from negative that was made for coloring. You will notice the candy hearts, in the upper right hand conner, are very nearly white in the high-lights, with the shadows a light gray. These are the old familiar red cimnamon hearts you used to eat in your childhood days. You will also notice, in the candy beans, the light yellow and red beans are practically white with gray shadows.

About the first requisite in a print needed for coloring is that there should be absolutely 110 color to it. By color, I nean green or olive tint, nor should they be a blue black-they should be black and white, but not too dark, nor 

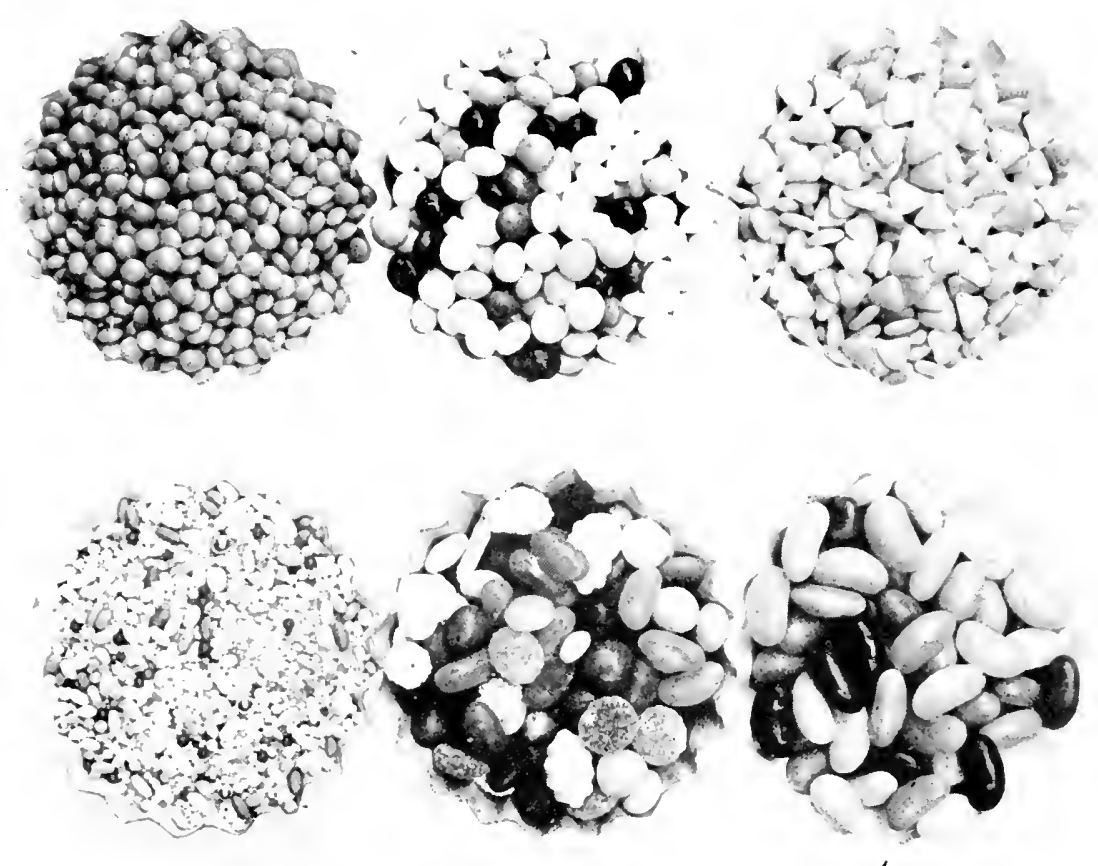

Fig. 82

quite as dark as you wonld eary them in case of prints not to be colored. They should be developed fully, but not over-developed.

Another point about the printing is, there should not be tou much alum in the fixing bath to get the best results, and for easy coloring. the prints do not Want to be hardened to excess, nor should they be fixed in an old fixing bath that has any tendency to scum or sediment.

If they are gloss prints, there should be no paraffine on the tins, as this sonnetimes causes crawling colors. If the prints to be colored are toned sepia, the scmu should be removed from the print before it is dried, after coming from the sepia batl.

The colors and application thereof is where the real stunt cones in and trouble commences.

There has been a great deal of wondering and mustery in times past as to what these colors were and where obtained. The colors that are the more easily obtaned and give far results in suall lots of coloring are what atre known as Japanese or le exox Transparent Water Colors, obtamable at any stock house, and another and far cheaper way is to necommon household dyes, such as the Diamond byes in the colors desired. In fatet, practically any sharle can be gotten from the three prinary colors of red, vellow and bitue.

() f course, there are many different wass of preparing these colors, but, generally speaking, the simplest way is the best, dissolve in wam water, making a strong solution for stock colors. 


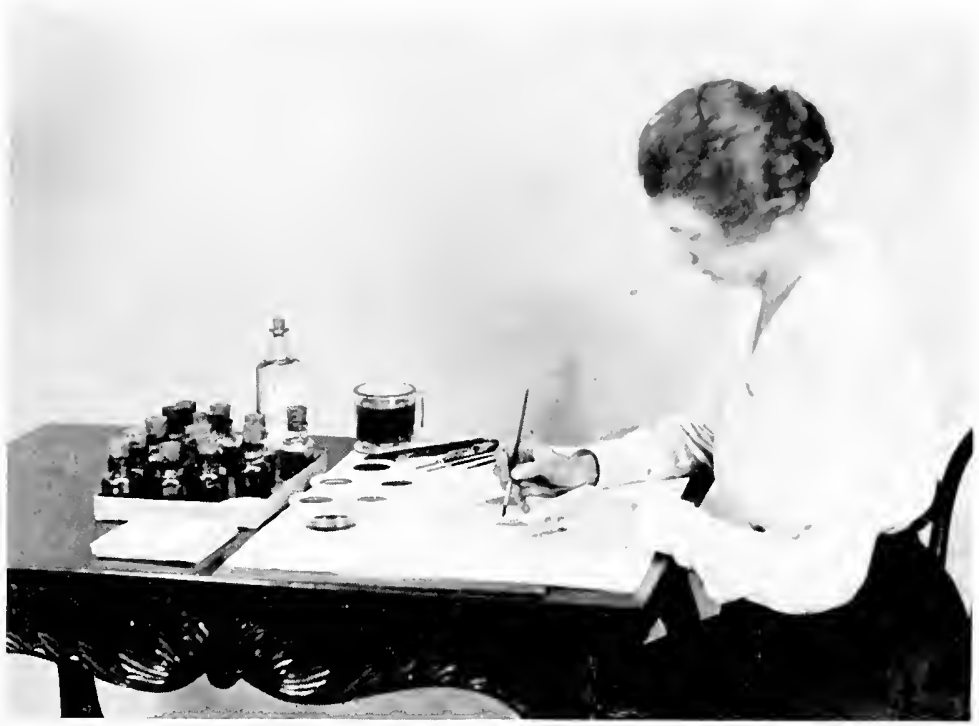

Fig. 83

A knowledge of colors and combination of colors is a great help. To sone people it seems to come very easy and other people never do seem to learn. However, it is hardly necessary to go into a combination of colors to make others in these pages, as that has been taken up by other people more extensively, and in a more comprehensive way, than is possible for me.

Figure 83 represents a colorist at work and gives a general idea as to a colorist's layout. This lay-out generally consists of about the following articles: Several sable brushes, ranging from sizes for fine lettering to the heavy body brush for large washes. A quill point lettering pen, a ruling pen and a large lettering pen of the ball point type, which will not scratch the film of the print. Several bottles, about a dozen, for concentrated colors; an eye dropper for transferring colors from the bottles to the small dishes; a half clozen or so of small dishes of the butter dish type, in which to mix various shades desired; a pile of small blotters of the lintless variety and several pieces of clean cheesecloth, together with rulers, triangle, curve, a bottle of ammonia and a real sharp etching knife, which comes in extremely handy at times.

To start in to color a print, about the first thing to do is to moisten the place with saliva, applied with a small piece of the cheesecloth-absorbent cotton leaves a lint that hinders a proper application of color. You will find, in different books on coloring, all kinds of medium mentioned for this purposegood old saliva or "spit" cuts the film and any grease on the print better than anything I have heard of. The next step is to take your brush, charged with the color, which should be applied smoothly and evenly to the part where it is wanted only and as soon as it is on a second or so, blot with a clean. dry blotter. One application only should be required, and the shade of color applied should be such as to show right over a black and white print or sepia print. Several 
applications of color to one spot should be avoided. as the detail in the print is soon covered up.

In lolending, this will be found much casicr to accomplish if but a small guantity of color is carried on the lrush at one time, althongl a smoother job will restult if the color is sradually toned down with water.

As to whether it is better to color over a sepia print or a black and white print, there are cases where a sepia print is possibly better. but for the general rum of work, a great deal more speed will be made by training oneseli to color over a black and white print, keeping in mind that your resultant color should come right over a black print. While a sepia print is wamer and easier to color over, such a print is not always arailable and another thing. it takes time to make sepia prints and some smlujects positively will not color satisfactorily orer a sepia print, while, with hlack and white, almost everything can be colored without difficulty, kecping in mind that a light wash is much better than a heavy wasly of color.

If necesary to remove a color after it is on a print, a little ammonia, applied with a brush and then blotted with a blotter, with several repetitions, will remove most of it, but this should not be relied npon, especially in the heavier colors.

() ne of the prime requisites for a snccessful and speedy colorist is neatness and order, as there is nothing quite so inexcusible as a sloppy set of prints-also nothing will disgust a customer more than to see a print on which the colors have run over into places where they should not be and to be presented with a print with a soiled and discolored back.

( ) ne of the big disadvantages to coloring on glossy prints, backed with muslin, has been that there was so much coloring on a print, that the moisture. in applying the colors, caused considerable cockling. I wat to get around that is to set the colors after the coloring operation is applied and then squeegee them. I solution that will set the colors has been somewhat difficult of attainment. Shuost any mile acid, such as citric, acetic, tartaric, tannic, etc., will set some of the colors, but to set all the colors has been the trouble. A 5 per cent solution of phosphotungstic acid will do the trick if it is applice correctly.

The print, after it is colored and dried, is immersed in the 5 per cent solution, heing sure first that the tray is absolutely clean. Just as soon as the print is limp, put it directly on to the ferrotype tin-lo not slide the print in this operation-squeegee, apply your hinge, paste and muslin. The print should not he left in the acid for any length of time nor should they be washed after going into the acid.

The acid does not seem to hurt the prints to any extent so far as I have been able to ascertain, as I have had prints set in this namer exposed in bright sunlight for over a year with no apparent fading of the colors or print.

A great cleal of coloring now is done on other papers beside glossy paper, such as the $\backslash z 0$ E. Transparent oil colors can be used as well as aniline in that connection and many beattiful effects can be worked out casily, to the profit of the plotographer as well as the customer. 


\section{(HATER XXVII}

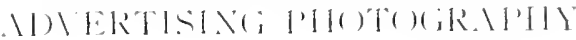

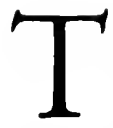

11l: making of photographs for alvertisements is at once the most fascinating and can be made the most renunerative branch of contmercial photography. It is fascinating in that you are helping to create a denand for a product-you are coming into contact with the pulse of the workl-commerce.

Many fortunes have been made almost over night ly means of arlvertising in the past. Today, many standard products owe their success alnost entirely to advertising. I'hotography is playing its part in the making of ads.

It is remunerative, because, if you create an idlea, make the pictures to get that iclea across, you are entitled to all you have the nerve to ask for, and there is no fixed price on brains.

The commercial photographer is especially fitted for this line of work, as he already has an acquaintance with business men who advertise. He is in on the ground floor with the manufacturer with his new nodels of different goods and appliances. He has, in other words, an inside track to what is coming. He has a knowledge of photography and the tricks and stunts necessary for this work. He should get it. Tut, I am sorry to say, few of then do, as the photographs that seen to grab the big money are photographs made, oftentimes. by amatenrs. However, there is a new school of photographers coming wp who are going after this business, and they are going to get it.

Conditions are really coming to such a point that the advertising pages of the leading magazines are more interesting. or equally as interesting, as the reading pages, due, to a great extent, to the quality of the advertisements inserted, and, while it is true that many drawings and paintings are still nsed, there is nothing that will tell your story like a photograph, and actrertisers are beginning to realize this fully.

Even the cover pages of a number of the magazines of late have been made from photographs, and it is, indeed, a tribute to the progress of photog. raphy, lut why shotnld this not be the case for, in the hands of the slitled photographer, the camera can be made to do almost anything.

Advertising managers and advertising agencies want photographs. They would take all of them they cotnld get, but they want quality; they want something with a story, something that will ronnd out their argument for the goods, something with a punch and up to the minute, and they want it when they want it, which does not mean next week, but today, for an idea is an old story in a week or a month. 
Dhout the simplest rule I know of. in making photographs for ackertisements, is to get the picture so that it tells a story so that "he who rums may reatl." In other words, it must tell the story at a glance and tell it strongly so as to make an inpression.

In this line of work you will come in contact with the atvertising agencies. or the advertising manager of the concern itself. There are two methods open for procedure. (One is to work up their ideas, and the other. and by far the best way, that is, where the money is, is to fumish the idea yourself, work it up yourself, and turn it over to them with a catch phrase or an idea for the printer! copy.

Arvertising agencies generally have one or two artists on their staff who spend all or practically all of their time working up advertisements, which are nearly always started from a photograph, or photography plays some part in the "make-up" one way or another. In other words, photography is an essential in the alvertising world.

For instance. Figures 84.85 and 86 are copies of page ads taken from an issue of the Saturday liaening Post.

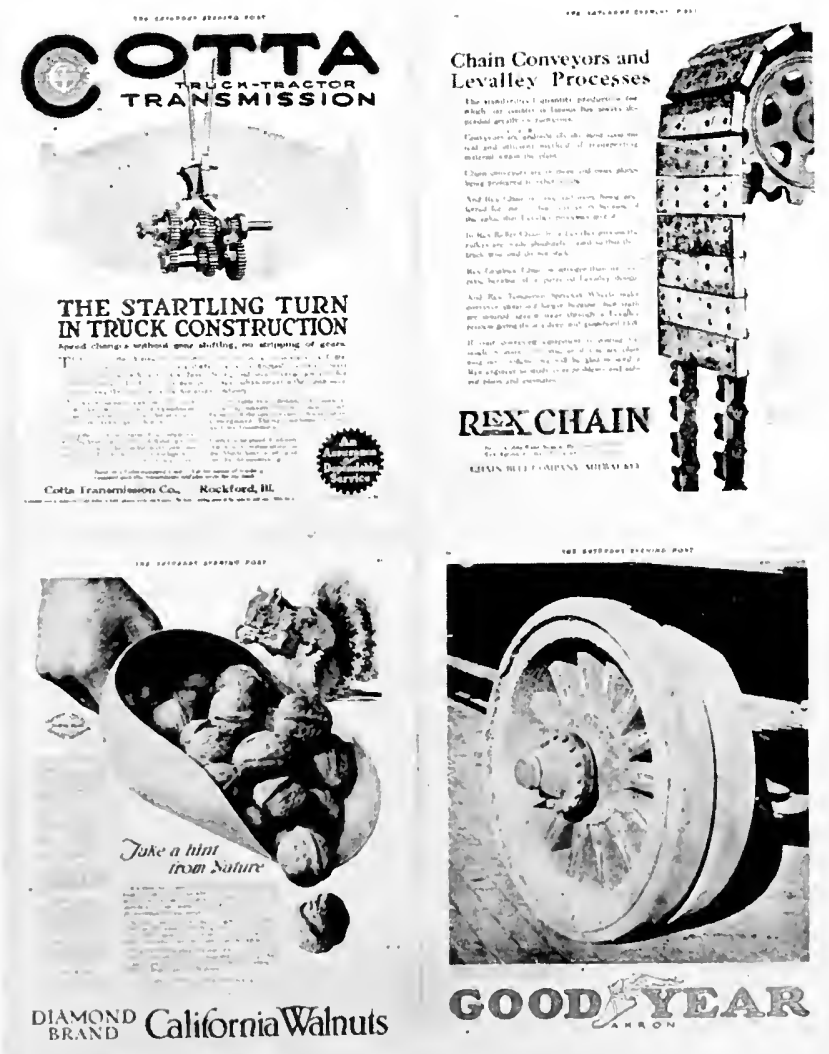



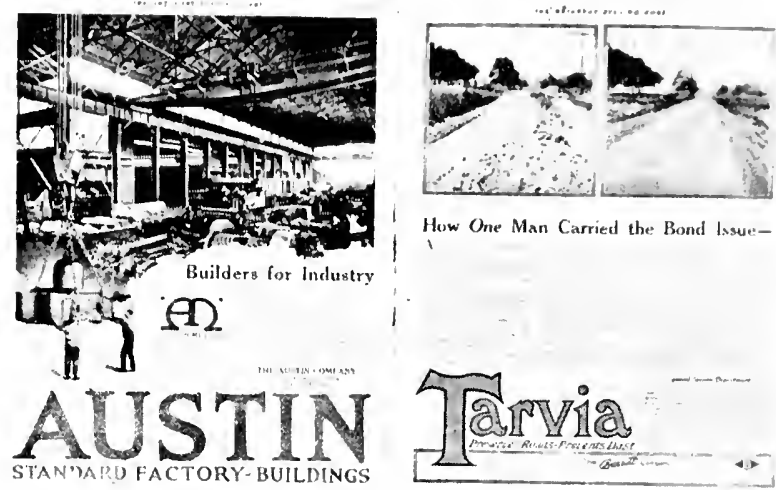

How One Man Carried the Bond Issue,
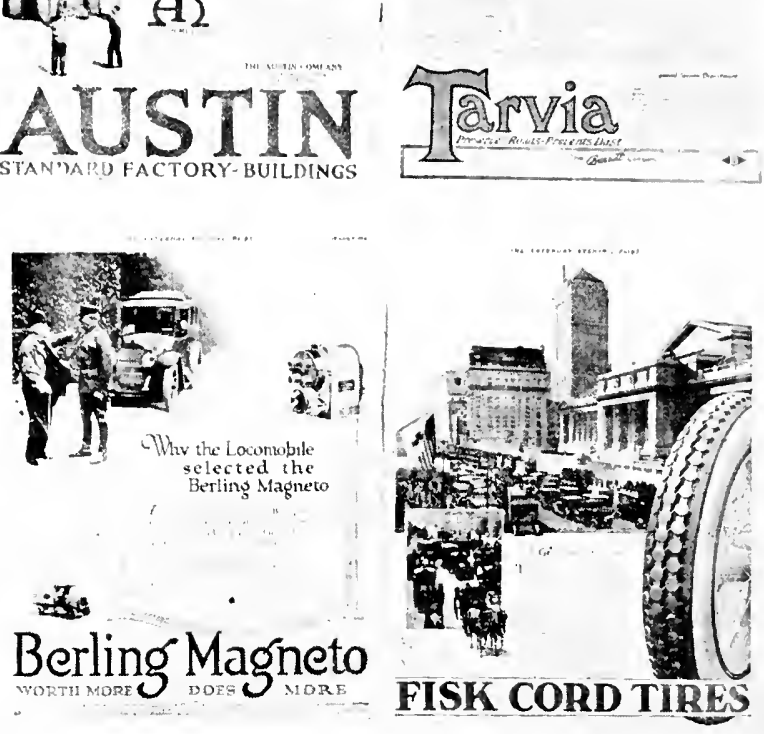

Fig. 85

The one of the Cotta Transmission is partly photograph and partly drawing, the phantom effect is obtained by working over a photograph and is the type generally handled by a commercial artist. The chain conveyor is a straight photograph, the Goodrich tire ad is nothing more than a close-up photograph, made with a good strong side light, with the camera practically on the ground. The nut page is a wonderful example of photography, and, as one would say in advertising circles, "it should knock them dead," but this just goes to show that this photographic work is nothing beyond any photographer. One needs nothing elaborate in the line of equipment-nothing but what the ordinary photographer has.

Figure 85 shows a collection of ads made up from what are generally known as stock negatives. The one of General Pershing is a news photo used in an effective way. The Fislie Cord Tire ad is a combination of an old photograph, a modern photograph and a copy of a drawing, 'and makes a spectacular ad with some art work.

The Tarvia ad is nothing more than two photographs, evidently made 

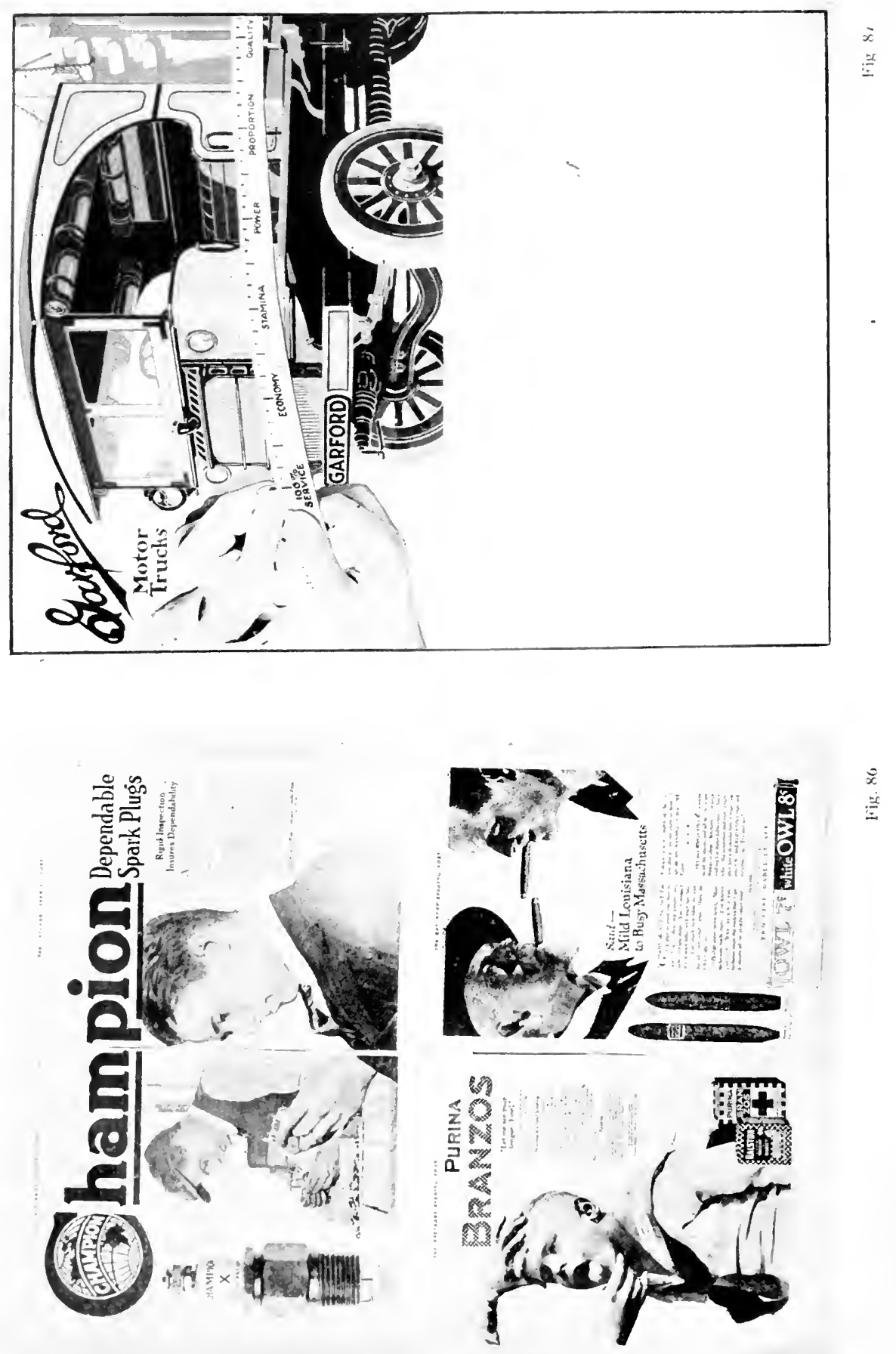


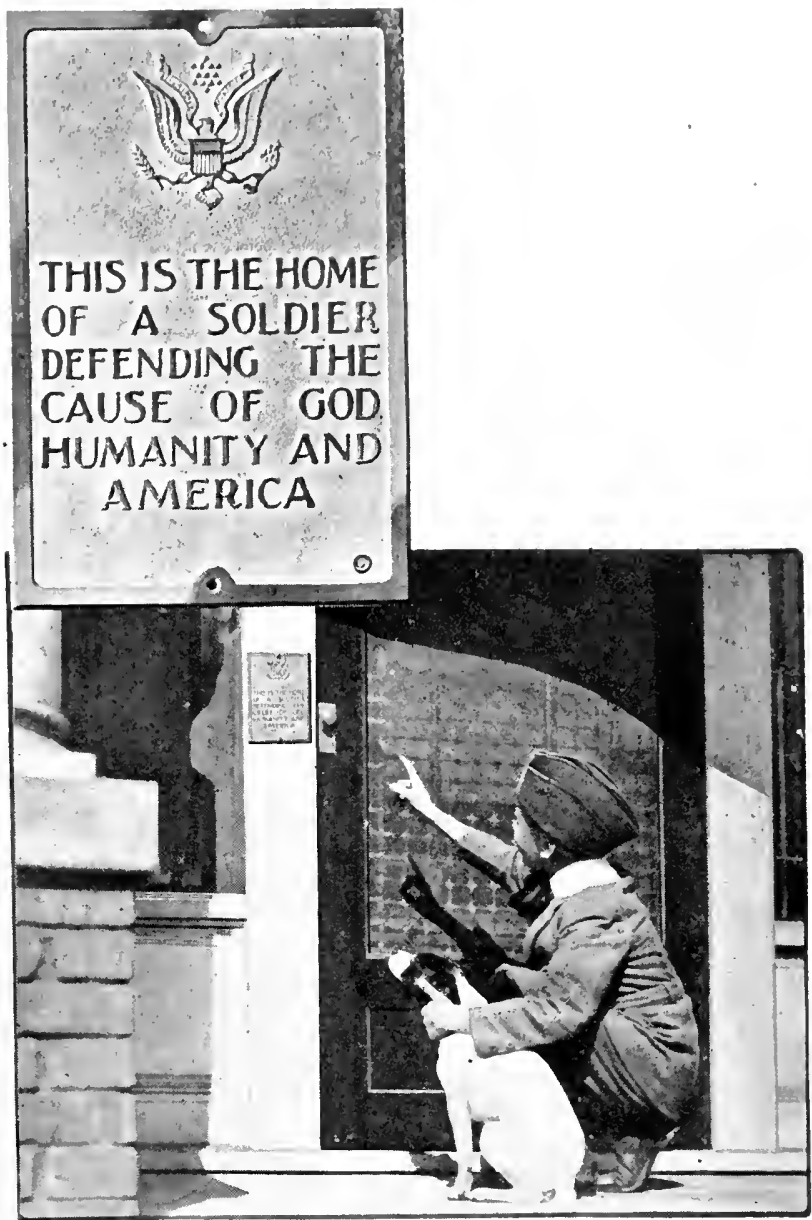

Fig. 88

with a Kodak, and yet drives home the slogan that "nothing will tell your story like a photograph," as does the Mustin ad.

The Champion Spark Plug ad represents what is known as model stuff, in that it is here that the selection of models and the handling of these models in posing and directing them plays an important part. The plug itself is practically an unretouched photograph.

The Owl cigar ad demonstrates what are known as light effects, which. together with the characters selected, are what makes its success, and these ads have attracted attention all over the country. The cereal ad is a straight photograph.

Figure 87 illustrates a type of ad which one is the more frequently called upon by the advertising agencies to execute. This particular ad is comprised 
of a photograph of bands, a tape measure, which hats been retouched. and the retouched photograph of a truck.

Figure 88 is a purely photographic atvertisement: that is, it is a combination of two photographs with some art work on the tablet and has an appeal to it that mate it a suceess.

Figure 89 is an ablertisement for a trate foumal and shows the construction of an ablertisenent of this kind. The arms were photographed separately, as well as the truck. The truck was photographed with an extreme wide-angle tens, very close to the front. with the cancra right on the ground. The factory picture for the background is a light print, made from a line negative, all of which only goes to show the possibilities of this work.

In making many ads, you will have to use live models. The eternal feminine attracts a lot of attention, and to get morlets for this work is not easy, as a rule. Nlmost any woman will tell you. or she thinks herself that she would make a model, but such is seldom the case. One that photographs well. with a pleasing personality. is hard to find. They must also have a certain

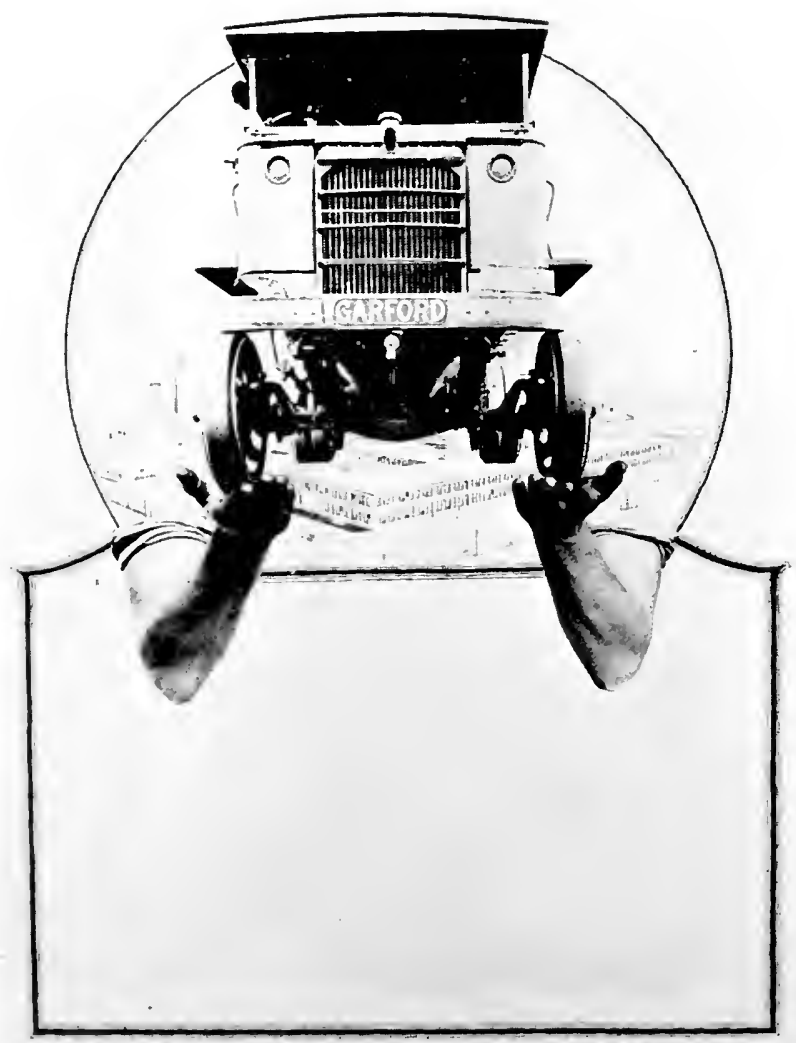

Fig. 89 
amount of drandatic ability to assume a pesition or pose gratedully and furickly,

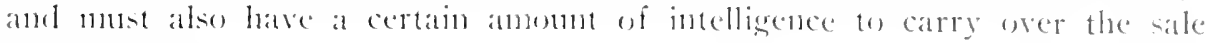
themsiches.

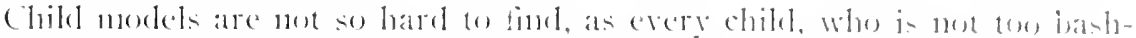
ful, when worked with a little while, makes a tambly morlel. Morlele for char-

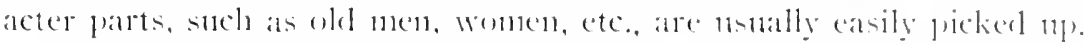

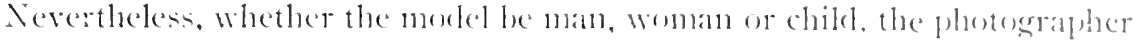
should get a release for services. This releate is necessary lefore gen call sell

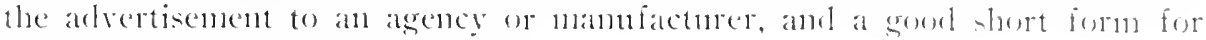
this purpose is about as follows:

()atte..................

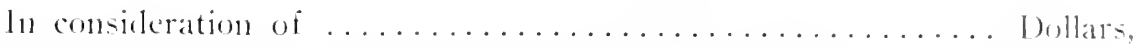
the recejpt of which I herely acknowledge, I herehy sell and asign to

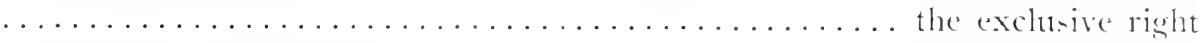
to copy and reproduce the

in ang namner whatsoever, and to secure copyrights for all such reproductions.

signature $\ldots \ldots \ldots \ldots \ldots \ldots \ldots \ldots$

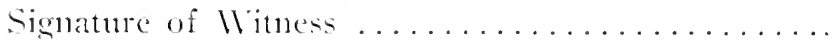

This next form, although more lengthy, is explicit and covers all tetails:

For and in consideration of the sum of

Dollars, receipt of which is herely acknowledged, I.

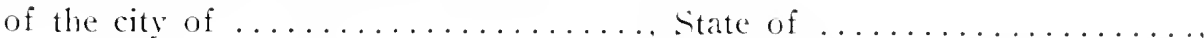

his successors or assigns, has the right, and the right is hereby given him. to copyright all pictures he has produced of nyself, in any and all poses, as model, and I do further agree to permit the said ................. his successors or assigns, to use, or he may cause to be used, all such pictures for commercial and art purposes, withont further compensation to me.

Witness my hand and seal this ......... day of .......... nineteen hundred and ................

Mitness :

There have been many law snits, some ruming into thousands of dollars, over the use of photographs in ads, so, to protect yourself, as well as your customer, by all means get a release, no matter how mimportant it may seem. Friends of today may be enemies tonorrow, especially where noney nay be involved.

The advertising photograph field is minlinited, and is the greatest field in photography today, I believe, for a man who has ideas. He must have irleas. "pep" and ability, and with these there is no linit to what can be accomplished. 


\title{
CH.MTEK NAIH
}

\author{
lRices
}

$\mathrm{T}$

111: prices bou get for gon work determine your potit. ()ne of the drawbacks in times past, in eommereial photography, and, in fact. the comblition still exists. is that of loa prices. This condition of low prices may he attributed possibly to some such incilent as this. The mannfactrer will go to a photographer, who ha- been used to making photographs in dozen lots of portraits. and ask bin for a price on orders of. say a hundred prints from a negative. The photographer gets excited, immediately builds a conple of homses or flats and a few other air castles with the money he is going to make, then gets sared for fear he might lose the job and down goes the prices, but a precelent has been established for like price cutting all down the line.

Another reason for low prices has been a lack of knowlerge of costs. I cost knowlerge or sistem of some sort is highly essential to every commercial photographer. Ile is lealing with business men who know their costs and why should the photographer not know his:

Hence, in making your prices, do not forget to take into consicleration the depreciation of your equipment, which can be determined by the amomt of work you can do with that equipment before it is morn out, when there should be sufficient funds on hand to replace $i t$.

Your insurance, both on your business and your own person, should be paid out of the business and reckoned in your prices.

Were the amount of money you have invested in your business invested in something else you would expect a return. Therefore, ligure it in.

I know you will think that is old stuff, but sometimes we all forget it in making prices, and the men who are making a sucess of commercial photography torlay are men who get a price-and a goos price. They are men who deliver good work. They know it is good and they demand a living priceone at which they can make a profit after properly figuring their costs.

Those who are getting low prices are generally working night and day. have no new equipment. cammot give proper time to get quality, and they are all in all horrible examples of low prices. This is not only in one city, but it is true all over the commtry. If you are doing quality work, by all means get a living price: in fact, more than a living price. If you are not doing quality work, raise your standard. It will pay.

This question of prices is deeper than just making a living. If you are delivering ruality work and getting a good price, your customer has more respect for you, you have nore respect for yourself, and it is much easier for 


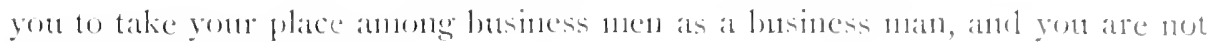
ashamed of gour calling.

()ne of the thorns in the commercial mants siele is the purchasing atgent. lle will semel ont offers for bids to all the commereial photengraphers in his section, and what some of them do to these prices is a shande. There secens to be always sonke one whe will cut the prices. () ne of the lest ways to get aroumel this is to well arlvertise the fact that gou positively will not cut prices. rather, will mot compete for such business, as it would mecessarily cont ruality as well. If the concern calling for prices wants quality. Ion will have no

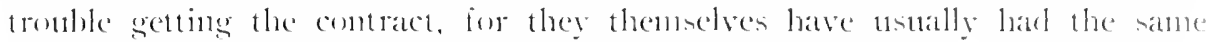
experience. They found ont years ago that, for the same article, deliverefl in the same manner as their connetitor, it is folly to cut prices. They know why. They have hat cost accomentants on their varions items and linow that to cut prices they lose money.

Competition is another thing that scares some commercial men into low prices. It is becoming the custom, in the larger firms of photographers, to nuantain a real price for their work, and, if the customer insists upon a lower price, to send him to the fellow that makes the gonels at a lower figure, lecaune they have found out that, if he gets enough of that work, he is bound to go out of business, and that it is the quickest and surest way of climinating a clueap competitor.

There is still another sile to this price husiness. That is the man who uses his home for his studio, has no rent to pay, works his whole family if he has one, cuts prices munercifully and then thinks he is making noney. Naybe he does for a while, but in time he cuts quality. possibly not intentionally, but he does, for such a man generally has plenty of work, he has no time for outside interests and never takes his place in the husiness world. He never knows his brother photographers, and is a bad actor from start to finish. What could he not do and what conld he not make by maintaining a goorl scale of prices? If he is a good worknan, as many of them are. he conld make money and make it easy, because of that very small overhearl. He could specialize on some one branch and get top-notch prices. Is his ontfit is generally a one-man affair, he could get very close to his customers, for he both makes and lelivers. and conld give real service if he would only stop and think. But, I an sorry to say, very few of then clo. with the result that the whole profession suffers.

Business concerns, really worth while, are commencing to find out that such an outfit seldom does give them real service. ITe has no really new ideas. nor has he the equipment and organization to give real bona fide service. so that part is gradually taking care of itself.

For a scale of prices, it is hard to lay down any that will fit all places and conditions. The following prices are average-averaged from studios both large and small, and are only meant to serve as a guide:

1. For photographs in the studio; that is, negatives made in the studio. the prices are as follows:

(Including objects, posters, etc.) 
$5 \times 7 . \$ 2.25 ; 8 \times 10, \$ 2.5 ; 10 \times 12, \$ 3.50 ; 11 \times 14 . \$ 4.50 ; 14 \times 17, \$ 6.00 ;$ $16 \times 20, \$ 7.00$.

()f course, there are many photographers who specialize and gret much more in cases steh as photographing cut glass. stoves and work on which there is mucle preparation, when at least 50 cents more a negative is charged, but, on the other hamel, there are some who nuke $\& \times 10$ negatives for 50 cents to 75 cents. 1 know it somuls ridiculous; however, it is a fact. Isain, there are some who get unlelievably ligh prices for one nesative and one print, with possibly no more work than the first fellow, hut quality and brans, with a grood dose of common sense mixed in, spells the difference.

2. For black and white copies, the average price runs alout as follows:

$5 \times 7 . \$ 1.75 ; 8 \times 10, \$ 2.25 ; 10 \times 12, \$ 2.75 ; 11 \times 1+. \$ 3.25 ; 1+\times 17 . \$ 5.00 ;$ $16 \times 20, \$ 0.50$.

Where color plates and filters are used, from 25 to 50 per cent. more should be alded. It is the custom in some shops to give a disomut on puantity nexatives of copies where all are in the same focus, of approximately 10 per cent. which is really quite right.

3. For negatives matle outside of the sturlio, the prices rum about as follows: $8 \times 10$. First negative mate within a limit of one mile from the studio, \$t.00. Idditional negatives male at same location and on same trip. $\$ 3.00$ each. liegond one mile limit, add 50 cents for each arlditional mile to cost of first negative in the mile zone. Extra negatives, same location and trip, \$3.00. For $11 \times 1+$ size, \$1,00, with additional negatives at \$5.00.

In connection with outsicle negatives, there is a question that comes up) which is harrel to settle. I customer will want you to go ont of town to be sone two or three days. How much will you charge? There are many different ways of detemining this. Some photographers insist upon a guarantec of $\$ 25$ to $\$ 50$ worth of work a day. (Others make the eustomer pay the expenses from time they leave stulio to time of return. It depends upon the customer. If for a railroad company, I believe transportation and per diem basis is good, together with a negative charge for each negative, while with other companies it is jossibly just as well to get a guarantee of so much work and paying own expenses ontsile of railroad fare.

Igain, another matter often coming up is when you go on a job and the customer will lecep you wating, sometimes for two or three hours. I time charge of not less than $\$ 1.50$ per homr should be marle. The plumber, the electrician, as well as the lentist and many others do it, why should not the photographer?

t. Circuit panoramas are mate on a basis of 10 cents per square inch of film exposed within the three-mile limit. For work beyond the three-mile limit, adel 50 cents for each additional mile traveled from the studio. A minimum charge of $\$ 15.00$ should be mate for any circuit panorama.

5. Multiple plate or film panoramus. I straight charge of $\$ 5.00$ for $8 x$ 10 negatives is a good gange for this work. In other worls, a two-plate panorama wotld be $\$ 10.00$, a threeplate $\$ 15.00$, and so on. 


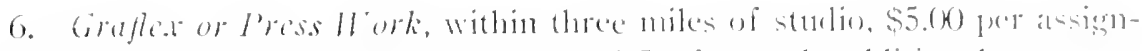
ment, including two or there exposures; $\$ 1.50$ for cated atditional expresure mate alt solne tinke and plikes.

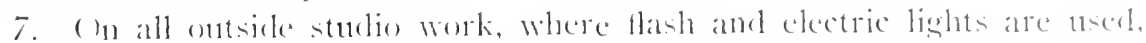
there shoukd be and extrat charge, which rans about ats follows:

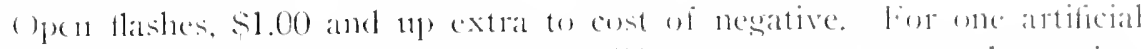

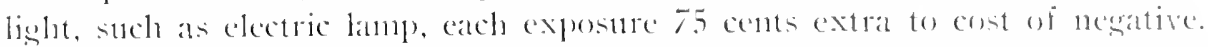

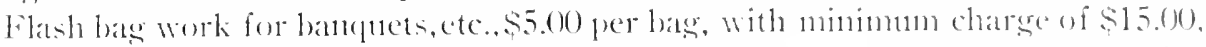
which includes cost of making s $x 10$ nexative. For $11 \times 14$. $\$ 4.00$ extrat. Five bag work or oxer, no extra charge for $11 \times 1+$ or $12 \times 20$.

The surrendering of negatives, or letting the custonser have the negatives, has ahways been a little point of contention between many commercial photographers and their custonters. This should never arise, as the negatives should always remain with the photographer who has made them and will do so, if the invoices rendered with the finished work read so much for one photos raph, with so much for additional prints, and not so much for the negative and so much for the print. To make it short, if you libl the customers for negatives. they belong to the customer, but if you bill prints, the negatives belong to you. That is a very important point and will save much controversy. for then you can make an additional price for surrendering the negative, if this is insisted upon, and such a price generally rums about 50 pere cent. of the charge made for the first print.

Quantity print orders should never affect the exposure charge and quantity negatives should not reduce the price of prints per negative. There is also no logical reason why prints from a furniture nesative should sell at a different price than that charged for prints from, say, an automobile newative.

Negatives should not be mate at a loss, or at no profit just to obtain the print orter.

8. Price for prints is as follows:

\begin{tabular}{|c|c|c|c|}
\hline \multirow[t]{6}{*}{$8 \times 10^{\prime}$} & 1 to 11 & $\$ 0.35$ & $\$ 0.40$ \\
\hline & $12+025$ & .30 & .35 \\
\hline & 26 to 50 & .28 & .3 .3 \\
\hline & 51 to 100 & .25 & .30 \\
\hline & 101 to 500 & .23 & .28 \\
\hline & 500 to 1.000 & .20 & .25 \\
\hline \multirow[t]{3}{*}{$10 \times 12$} & 1 to 11 & .45 & .60 \\
\hline & 12 to 25 & .43 & .50 \\
\hline & Larger quant & es corre & spondingly decreasing. \\
\hline \multirow[t]{3}{*}{$11 \times 14$} & 1 to 11 & $\$ 0.60$ & $\$ 0.70$ \\
\hline & 25 to 50 & .55 & .60 \\
\hline & Larger quant & es corro & spondingly decreasing. \\
\hline $14 \times 17$ & 1 to 11 & $\$ 1.00$ & $20 \%$ more is \\
\hline $6 \times 20$ & 1 to 11 & 1.25 & \\
\hline
\end{tabular}

Plitin. Backed \& Hinged.

$\$ 0.35 \quad \$ 0.40$

.35

$28-.33$

.30

$20 \quad .25$

$45-60$

$43 \quad .50$ 
Sepia prints 25 per cent. alditional, and these quotations refer to prints orderel at the same tince from same negative.

\section{ENLARGEMENTS}

The making of enlargements in the commercial shop has of ten been thought a loss. The possibilities are that when a loss. it was catsed by incompetent help, as the quality of commereial cnlargements motst be good, and good enlargements sonetines take consilerable paper to get right. especially in color separation. Where every tone must be preserved. Commercial shops doing a large anount of various-sized enlargements generally set nuon a price per square inch, and it runs from $\$ 0.008(+5 \mathrm{c}$ ) to $1 \mathrm{c}$. per square inch, with 25 per cent. additional for sepiat, also additional for mounting on muslin and stretelere of 25

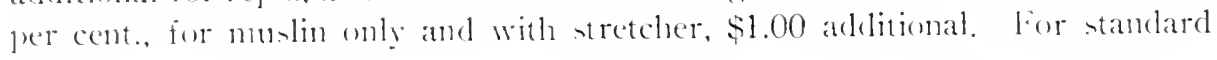
sizes:

\begin{tabular}{|c|c|c|}
\hline$\therefore \times 10$ mnturounted & $\$ 0.65$ & Mlominted so.s. \\
\hline $10 \times 12$ & .85 & 1.10 \\
\hline $11 \times 14$ & 1.20 & 1.50 \\
\hline $1+\times 17$ & 1.90 & 2.40 \\
\hline $16 \times 20$ & 2.60 & 3.10 \\
\hline
\end{tabular}

Sepia. 25 per cent. arlitional.

9. Iantern slides form a branch which commercial photographers. in certain sections of the comntry. have a great deal of and prices are very low in many cases. The following is a price list from one studio:

Seventy-five cents for single slide, negative furnished: if not, malie negative charge same as marle for copies. For quantities from same newative. 50 cents. Coloring slides, 75 cents per hour.

10. Nodel work, in connection with advertising. reytures considerable skill and oftentines the use of a number of plates. Some of them charge $\$ 3.00$ for each negative, but, among the better class of fellows, it is now the custom to charge at least $\$ 5.00$ for each position. including model charge and guaranteeing a negative without a move.

11. Bhe prints run from 5 to 10 cents for $8 \times 10$, accorling to quantity. Photostat prints from 20 to 50 cents, according to quantity.

12. Solar bromide from 15 to 20 cents, according to quantities.

13. Titles for negatives-type composition cost plus 20 per cent. Typewritten, 75 cents for first neagtive. 25 cents each for adlitional titles on sane order.

14. Coloring. The prices run from 5 cents to $\$ 1.25$, in addition to cost of the print, governed by the amome of coloring, size and quantity of prints from each negative.

15. l'ostcards and enclosures for letters. Negatives, $\$ 1.25$ cach.

$\begin{array}{lc}1 \text { to } 50 & \$ 0.10 \\ 51 \text { to } 200 & .08 \\ 200 \text { to } 500 & .05 \\ 1,000 & \$ 35.00 \text { per thousand } \\ 2.000 & 30.00 \text { per thousand }\end{array}$

Note.-The prices in this chapter are tentative and based on thase prevailing on May 1, 1920. 


\section{CHATER NAIX}

\section{HOLLITNG HLSINES}

B ULDOLNG and holding business, or getting and holding a patronage or following of customers, is something in which we are all vitally interested, and our efforts along that line determine whether we are a drifter or a success. Statistics prove that a man in business cannot stand still, he is either going forward or drifting backwards. None of us wants to saty he is drifting backwards, so we are intensely interested in how to push forward.

The commercial photographer cones mostly in contact with business men. Therefore, the methods enployed by the portrait photographer in kealing with what night be termed family matters, are totally unfited in establishing a commercial business. In meeting business men, we must be acquainted with business methods, and everything that is consilered somul in general business methods is equally applicable to a commercial photographic place of business.

Big business men ate finding out more and more every day that strength of character, integrity and all that goes with it, such as truth and honesty, are the foumlation of goot business, so we, as commereial photographers, must be prepared along those lines.

The business man, to get new business, uses advertising. personal solicitation, personal letters and his own personal contact with people. Now. let ns analyze that system of getting business as applied to the commercial photographer. To my mind, personal soliciting is the one best way to obtain business for the commercial studio. Advertising works very nicely for accumulative effect, but I know of very few of the large commercial photographers who use newspaper advertising to any great extent. It seems to not reach the people they want to interest.

A man in this business, in the course of a year, meets a good many people both in and out of business. The more people he meets out of business the more he will eventually meet in business, so it can be considered a mighty good thing to belong to several good chus if the opportunity arises. I know from personal experience that it helps.

Of course, everyone cannot have a good personality, but personality plays a great part in the success or non-success of most businesses. If the operator employed is of pleasing personality, he is more liable to be called upon again than the operator who has an eternal grouch, although the grouch may have the best of the other fellow on ability.

Another effective way of helping to build a business is by sending out special appeals, or letters. you might say, to a select mailing list once a month. 
Xow this mat take several forms. I know of one large company which does sonnewhat of a national business, and which takes for one nuonth all of the piano mannfacturers within a working ratlins of their studio, sending each one a very small photegraph of insert size, very leamifully mate, of a piano. This particular print 1 have in mind was a glossy, double weight print of a liano, with a rigneted base, accompanied ly at clever form of letter, which letter, together with an actual example of piano photography, going to piano mannfaturers, mate quite a hit. The same thing was carried on throngh sereral other lines, but, of course, such a procedure could only be posssible in a studio able to cover a large territory. The man in the smaller city will have to hit something in a hapy medium and send it ont once a month.

1 know from ny ownexperience that this is a rery effective way of bringing attention to yourself and arousing interest. But it must be followed up by quality work and service, for, no natter how clever yon are in adfertising and soliciting, if you fall town on quality or your service, which means promising delivery and linowing a few things about the customers wants, all your alvertising and building efforts go for naught.

(Ouality of work has a great deal to do in building business. I know of many fair-sized studios whose managers think it is economy to employ mediocre operators, kicl printers and sleepre delivery boys, and wonder why a paying huniness is not done. It is becoming lnown through the business world that the best men you can hire are the cheapest in the long run. (heap labor means generally poor labor, poor results and Waste, a tremendous item in these days of efficiency.

While we are on this worl quality, I know, from observation, that the best of apparatus, plates, lenses, paper and chemicals, ete, help in building business. Yany of your customers in the commercial line are nen who know a great deal about photography, either directly or indirectly. Some of them have their own photographic departments for general work, as in the case of lithographers, photo-engravers, roto-gravures, engineers, architects and adrertising people. They all nse photographs and have more or less knowledge of photograply. If you have good aplaratus in your place of business, they will know it, you know it, and if you know it and they know it, they have double confidence in you and you have in yourself, which is building business.

To go back to that worel "service." It is one of the n110st-abused worls in the entire English language. Service means to help somebody. If a customer comes into your place or calls you to see him, and he is a little undecided as to just what he wants, if you are acquanted with sales plans, jobling methods and general merchandising and advertising methods; in fact, with the use of photographs, as every commercial photographer should be, you can be of great assistance in telling this man what he wants, and the chances are that you will increase your oreler many times. Not only that, that customer will think many times later on of what you have lone for him.

I have in mind a man now who jobbed an article that was known practically all over the comntry. He had done some advertising and I had solicited 
him several times to the photographs. He hat always tohl ne that, as his line was known alf over, he did not see any use for photographs. But I thought I knew better and was only wating for a favorable opportenity to bring my views before him in the right way, which cante at little later when he wanted to get ont a small printed leaflet to accompany his commodity and which necessitated complete photographs of his line. Then I showed him where, by distributing photographs to his jobbers for their traveling salesmen to take out with them on their trips, along with their other photographs, if it diel nothing more than remind the retailer that the line was still on the marliet, it woukl do some good. He reluctantly placed a small order. I know he thomght he was stung, but when be was complinented by the jobbers on his new move and received requests for more photographs to completely equip their entire sales forees, accompanied by orders for his goods beyond his wildest dreams, he fairly swamped me with work and is a big booster for photographs toclay.

That is what I mean when 1 say service. When you show a man where he can sell more goods by the use of photographs, you are helping that man as well as helping yourself, which is service, and when you give service you are building business.

Another way service comes in is promising and delivering orders. I was in a commercial studio not long ago when a customer came in and was told by a photographer, "Mr. X, your prints are not ready. I was sick and will have to give them to you tomorrow." I know the custoner was disgruntled. and I know if he gets half a chance he will not go back there again. This happened several times during my brief visit. A business man's word is considered one of his best assets. We are dealing with business men in commercial photography, so, therefore, not keeping promises is one of the surest ways to tear down a business.

Still another word as to this term "service." Service, to my mind, does not always mean delivering a print to a man in five minutes, even if he wants it, for, as stated above, service means helping people to help themselves. If you give a man something that may only help him temporarily and comes back eventually as a boomerang-that is not service. No print made and delivered in five minutes will give permanent service, except possibly to an engraving house, and is eventually a boomerang to you. If properly explained, it is usually the case that more time can be obtained on a job to the ultimate satisfaction of all concerned.

Again, I have often turned down orders from people I knew could not use photographs effectively. Unless you can see some real nse for them, it is better to discourage their use. I know of a concern, which hat an extensive line of photographs made, which were not the right kind and did not prove any help to them, with the result that they became soured on the whole photograph business, and no one has been able to interest them since.

Now, as to soliciting. Personal soliciting is by far the best way of building business. I know from experience that it is mighty tough, and in looking back over the time I was solicitor for a commercial studio in a large city, I 
remember now that it was one of the toughest and nost discouraging times of my life. It is the most gruelling experience one can have, and again, when you know how and business comes good, it beats baseball, war and everything else for excitement and exhilaration. I have never felt so good in my life as I have after closing a good-sized order, and I have never felt so bad as to be walked out of an office in front of all the clerks, practically "kicked out," becanse I did not yet know ny business and cond not interest the man.

Now, for a few points as to successful soliciting. If you get in to a man, I do not care who he is or how busy, and you have something that will help him, he is going to "stop, look and listen." He has no time these days to fool with time-wasters, so the first thing is to have something that will interest him, and which, if he huss, will help him. To take a concrete example. Ne will say a man is a manufacturing confectioner. He has from twelve to fifteen and more salesmen on the road selling a very perishable commodity, which necessitates a corps of people to keep up the samples and which means the breaking of boxes of goods at a great expense, especially when the particular goods hapjens to be jobbed for some other manufacturer. Even with the greatest of care, the salesman will often find, long before completing his trip, that his samples are in poor shaye, or, in case of chocolates, he cannot carry them in hot weather. Niso, his complete line of hoxes cannot be shown as it would be impossible to carry them. You know all this before you go to see a man, and, in soing in to see him, you have something to interest him if you have a portfolio of colored photographs of candy. It interests him-why? First, because it is his own line, and, sccond, you have something that will help him-help him how? By saving him from three to four humbed dollars a month, if he has twelve to fifteen salesmen, in samples alone. Not only that, the salesman can show the complete line to the customer at all tines, and the salesman has no heary sample cases to hinder him in catching a train. Furthermore, almost anyone likes to look at colored photographs of goods he knows, whether he expects to buy or not.

The foregoing is good salesmanship. Nine times out of ten gou will land him if you proceed along that conse-have something that will interest and help him and save him money. This example is equally applicable to any concern which has salesmen on the road, whether the commodity be trucks, plows, cash registers, dresses; in fact, any firm that employs salesmen is a prospect for photographs if handled property.

As for the kind of solicitor to have. I have seen youngsters just out of high school make good, while I have seen old-time photographers fall flat. It resolves itself down to the same thing hereinbefore mentioned-what applies to other lines of business will apply to commercial photography. Good, clean appearing, interested men, who might nuke good selling other lines, will undoubtedly help your business if backed by service.

A while back I mentioned that it would be well to join clubs, ete. When you come in contact with those people-talk photographs. You will have an opportunity from time to time without appearing to talk shop. Know the 
interesting things going on in photography and you will have interested listeners. Moving pictures form an excellent ofrening, and, during the recent war, there were nany excecelingly interesting developments photesgraphically, and ability to talk on these developments intelligently could not help but attract

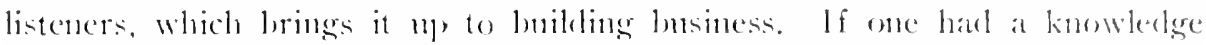
of color separation and correction, such as was ased by the ateroplatue photographers in the ware and conld explain those things clearly and simply, it is building business, for it is attracting others to your knowlerlge of your own line. In other words, be alive, progressive and keep up with the tines, not only in photography, but on general husiness. Read np-to-date magazines. I) not let the other fellow have anything on yon. Keep everlastingly at it-ro what you know you ought to do, and your efforts will surely bring suceces. 


\section{INDEX}

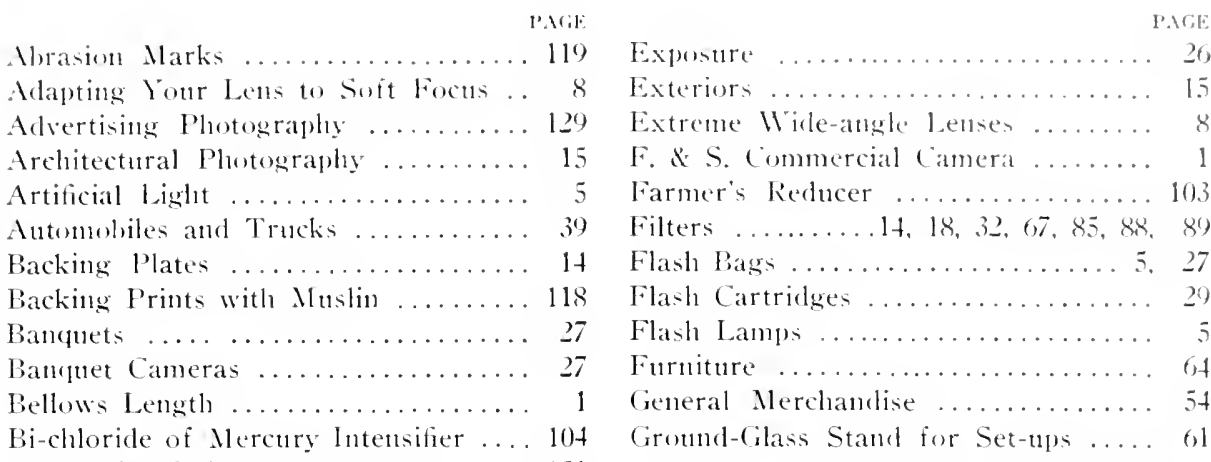

Black Line Prints ............... 121

Bleached Prints .................. 119

Blocking-out ................ 70, 106

Blocking, Staining and Lettering .... 106

Blocking Stand ................. 107

Blow Lamps ............. 5, 23, 47

Blue Prints, Vandykes and Photostats 120

Puilding Business ............... 141

Camera Cases .................. 3

Carbon Lamps ................. 5

Cirkut Cameras .............. 32, 35

Coating Paper for Vandykes ....... 122

Coloring Prints .................. 125

Composite Photography ...17, 18, 19.

20, 24, 31, 32, 33, 3t, 131, 134

Contrast Filter Chart, Cramer's .... 89

Contrast Filter Chart, Wratten ..... 88

Cooper Hewitt Lights ...... 50, 90, 98

Copying ....................... 5, 93

Copying Oil Paintings ............ 94

Copying Printed Matter .......... 95

Cramer's Contrast Filter Chart ...... 89

Cramer Spectrum Plates ........ 12, 87

Cut Films .................. 11, 15

Cut Glass .................... 76

Dark-room Work ............... 100

Developers ................. 98, 102

Developing Large Plates ........... 97

Drying Muslin Backed Prints ...... 119

Drying Negatives ............... 105

Drying Prints ................. 116

Enlarging ................ 96, 140

Enlarging Cameras .............. 96

Equipment $\ldots \ldots \ldots \ldots \ldots \ldots \ldots \ldots, 3$

Grouping Articles for Photographing. 42. 4.3, 51, 54

Halation ...................... 22

Harkening Negatives .............. 105

Hinges for Prints ............... 118

Hot Point Lettering ............. 110

Improving Uneven Negatives ....... 113

Inserting Titles ................ 109

Intensifying Negatives ........... 103

Interiors ................... 22

lodide of Mercury Intensifier ....... 103

Johnson Compact Ventlites .... 5, 23, 32

Lace Photography ............... 57

Legal Photography .............. 83

Lenses ..................... 7

Lens Flanges ................. 8

Lettering .................... 109

Lighting Dark-rooms ............. 100

Lighting for Copies ........... 93, 94

Long Focus Lenses ............. 7

Machinery ................... 36

Maduro Paper ................... 121

Making Blue Print Paper .......... 120

Making Composite Photographs ..... 30

Making Set-ups ............... 52

Making Vandyke Paper ........... 121

Mazda Lamps .................. 5. 95

Models, Releases for ............ 135

Monuments .................. 72

Mounting on Cloth or Muslin ...... 99

Night Photography .............. 45

Non-halation Plates ............... 11

Opaques ...................... 106

Over-development ............... 103 
Panoramas . .............. 30

Paper for Printing ............. 113

Paper Negatives ............... 111

Payment for Banepuet Photographs ... 28

Photugraphic Stands ........... 51

Photugraphing Etched Giass . . . . . . T

Photegraphing Finger P'rints ...... 85

Photographing llandwriting ....... 84

Photengaphing Jewelry ......... 55

Photographing Mirrors ........... (s)

Photugraphing of (olored Olijects ... 8f)

Photegraphing Old bocuments . . . . . 85

Photographing Parts ........ 42, 43, (6)

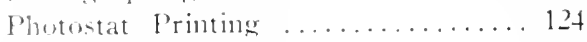

Plan for sky-lisht ............ to

Plates and libms ................ 11

P'laten for Colored Objucts ........ 12

Prepariner Cut Cias ............ 70

Prepariner Ferrotype Tins ......... 110

Pregaring Machinery to Plonograph . 36

Preparing Domments for Photographing ................ 72

Preparing Silverware for Photographing .................. \& 8

Preparing Titles .............. 111

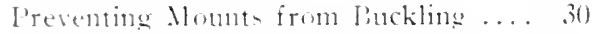

Pricen ..................... 1.30

Printing .................. 112

Printing Machines ............. 112

Printing Oper-timed Negatives ..... 114

I'rints and coloringr
Kerncers for Negatives ........... 103

Kelease Blanks for Models ......... 135

liemoting Stains on Fingers ........ 105

kuled Grommel-glass ............ 16

shelies, Photographic ........... $\$ 1$

Shelves. live ot .......... 51. \$2

Silverware ................ 80

Sinks ...................... 101

Sky-light, Prrangement of ........ 49

Skyncraper Camera ............ 2

Sift Focus lenses ............ 8

Speed Cameras ....................

Speed Plates ................. 12

Srpuetgeeing Prints ............ 117

staining ................... 108

Store 110 indows ............... 46

Stoves .................68

Studio, The ............... 48

Tape Measure in I'hotograph ..... 55

Testing Lenses ............... 85

Tripuls ................. 5

2 Trombles in Copying ............. 95

Lsing the flow lamp . . . . . . . . . 38

Ventilating l)ark-rums . . . . . . . . 101

Vertical Camera ............. 4. 59. 61

Vibration, Correcting ........... 97

Vicw Cameras .............. ?

Washing Print . ............. 114

Viaste of Plates............. 63

11 ratten Contrast Filter Chart ...... 83

Mratten Plates ............. 12, s5

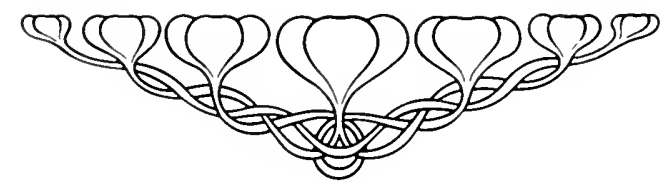


ADVERTISEMENTS 


\section{COMMERCIAL LENSES}

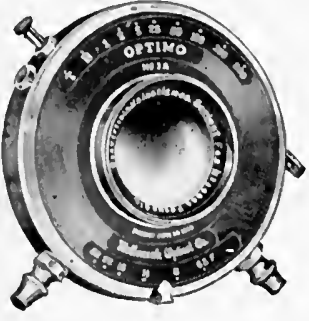

\section{VELOSTIGMAT}

Series I F:6.3

Triple convertible anastigmat, ideal for allround commercial use. Single elements may be used alone when stopped down so affording three focal lengths.

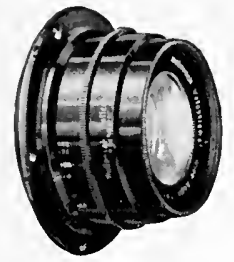

WIDE ANGLE VELOSTIGMAT Series III F:9.5

Anastigmat wide-angle lens, angle of ninety degrees, unusual speed of F:9.5. An indispensable lens in conmercial work

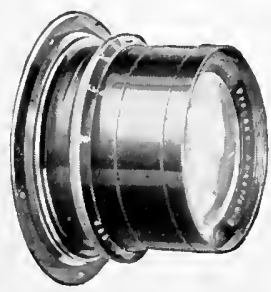

PROCESS LENS

Designed primarily for photo-engravers use, therefore of extreme correction and ideal for copying tracings, blue-prints, etc. Well adapted for use on banquet cameras.

\section{$=$ OF GOOD SPEED AND FINE DEFINITION}

\section{(2)}

THE most important requirement of a lens for commercial use is the quality of definition it renders. For this reason we have exercised the greatest care in computing the formulae of

\section{Wollensak Velostigmats}

The result is a quality line of speedy anastigmats capable of producing brilliant negatives of sparkling definition.

By specializing in the manufacture of photographic lenses, we have developed a complete line of products covering the needs of commercial, professional and amateur photographers.

Only a few of our lenses are here illustrated. Let us send our free, illustrated catalog, describing the complete line.

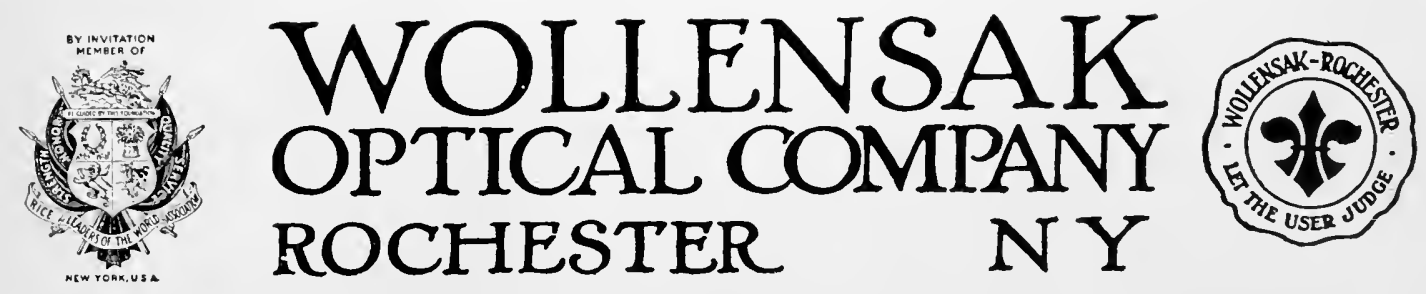




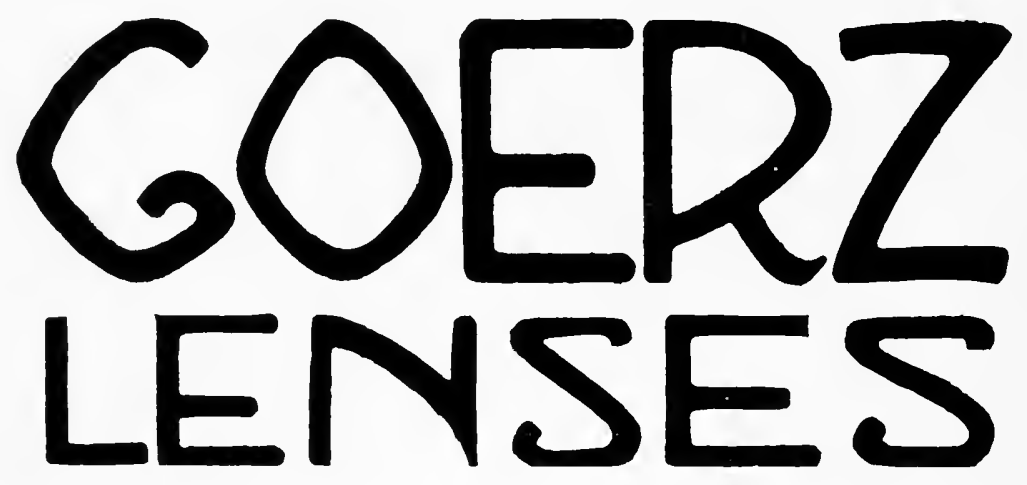

HE lens is the most important part (1) of the commercial photographer's equipment. Upon it depends much of his success. For over twenty-five years, GOERZ LENSES have enabled progressive commercial photographers to meet the most exacting requirements. GOERZ LENSES have made good. The famous GOERZ DAGOR F:6.8, the well-known GOERZ CELOR F:4.5-F:5.5 and now the popular convertible GOERZ DOGMAR F:4.5 are lenses that produce results. See your dealer to-day or write us direct. It will pay you to investigate now.

\section{C.P. Goerz American Optical Company}

319 East 34th Street. New York City 


\section{KOMPAKT -VENTLITES}

THE KOMPAKT-VENTLITE is at

1 once the most compact, the lightest and the most efficient reflector for photographic purposes. It is the result of very extensive experimenting, practical tests and actual use for several years.

In producing the Kompakt-Ventlite Outfits a very careful balance has been arrived at between what is essential, practical and scientifically correct, as against what was faddish, freakish and impractical, with the result that we have an outfit that is ideal for all phases of photography.

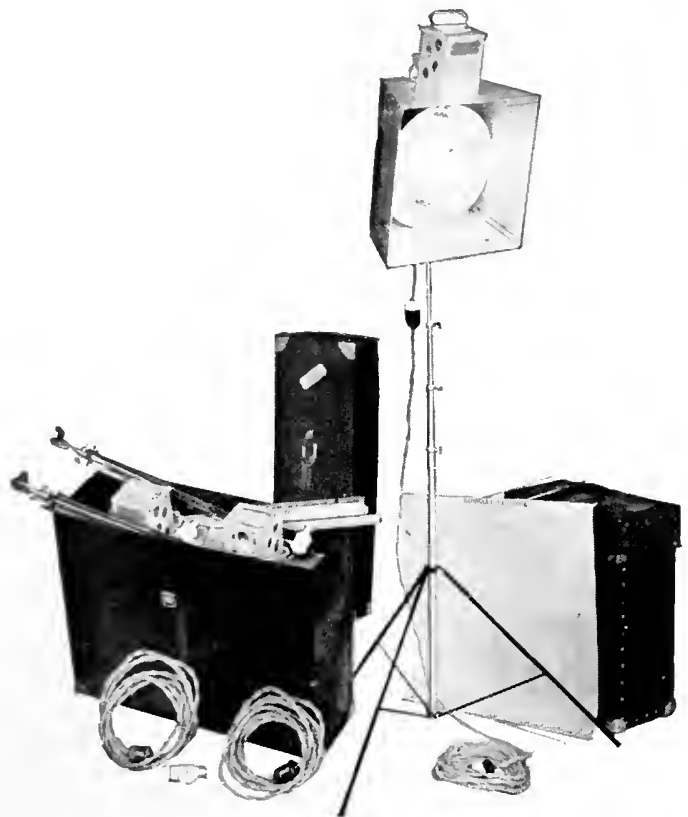

Double Kompakt Ventlite Outfit in Case.

Total weight only $26 \mathrm{lbs}$.

The VENTLITE-SKILITE, illustrated on this page, is, as the name implies, a veritable artificial-light skylight, and is manufactured with the same care and consideration as regards to photographic requirements as the Kompakt-Ventlites. With these you become independent of daylight, and you can make all sittings when wanted.

YOUR DEALER SELLS THEM.

Get descriptive circular from him.

Manufactured by

\section{JOHNSON VENTLITE COMPANY}

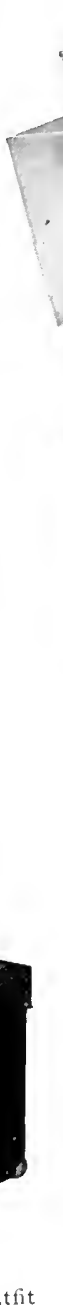

a
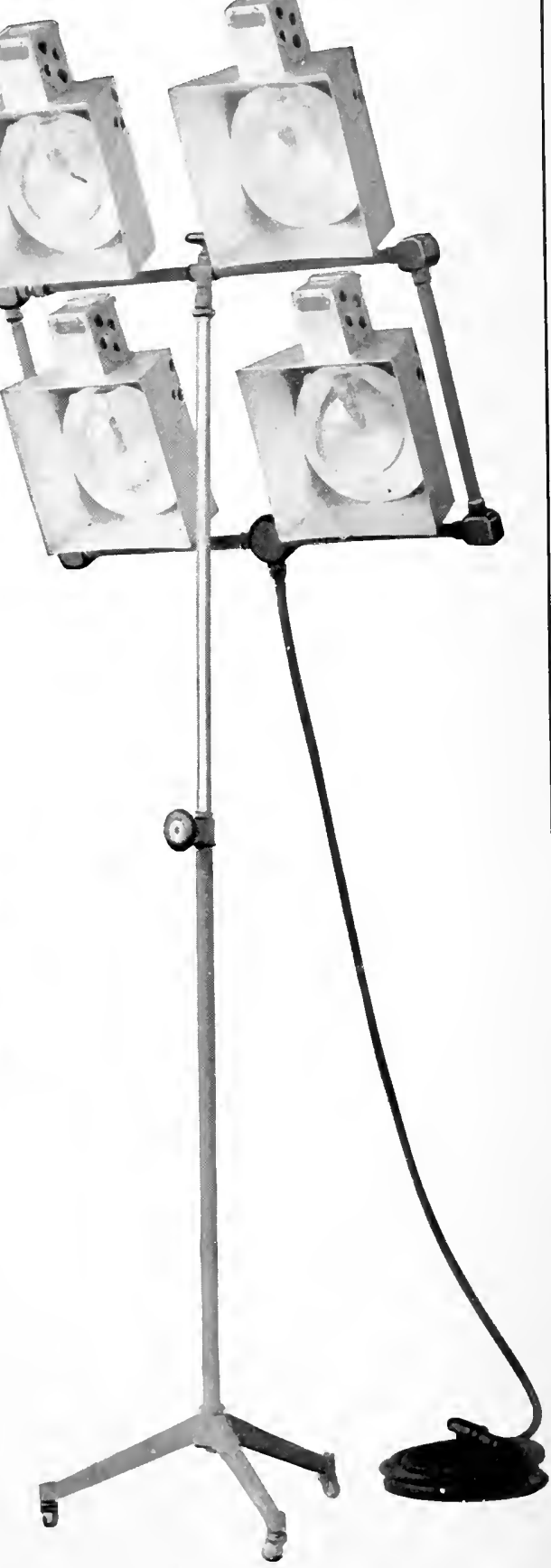

Ventlite Skilite No. 4

Front view at 10 . foot elevation, showing massive construction of Stand.

Furnished with 30 feet of stage cable. Master switch, Furnished with 30 feet of stage cable, Master switch, balance spring enabling easy adjustment up and down. 


\section{GENERAL CERAMICS STONEWARE}

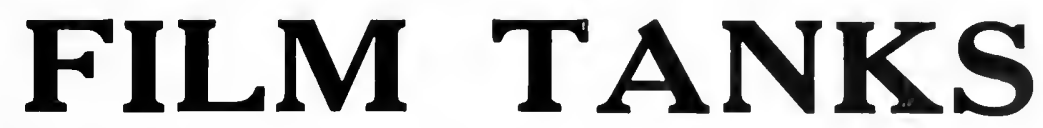

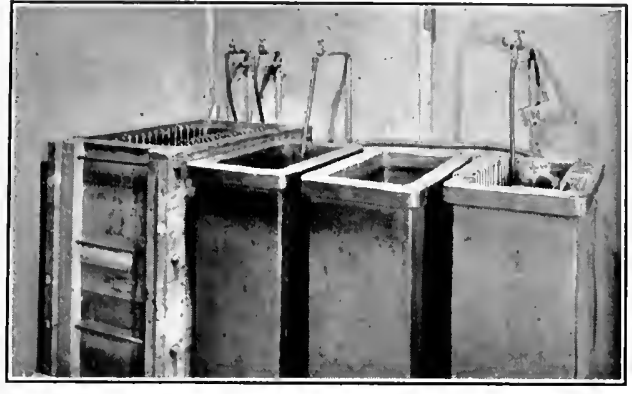

Eastman Kodak Co.'s Installation are made in (ONE S()I, H) PlEc 'E, acidprofof oromghout. There is 110 joint to patch up with cement.

General Ceramic Film Tanks are EVERLASTING

Afford Maximum Developing Capacity

Write Your Jobber for Illustrated Booklets. Complete Information.

\section{GENERAL CERAMICS COMPANY}
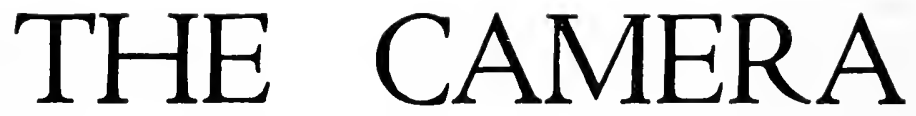

THE MONTHLY PHOTOGRAPHIC MAGAZINE

FOR ALL PHOTOGRAPHERS

TELLS WHAT YOU WANT TO KNOW IN PLAIN LANGUAGE

NOT TOO TECHNICAL-BUT JUST CLEAR

BEAUTIFULLY ILLUSTRATED HANDSOMELY PRINTED

$\$ 2.50$ per YEAR IN U. S. OR CANADA 25c per COPY

\section{CAMERA PUBLISHING CO.}

\section{FRANK V. CHAMBERS, Editor}

636 Franklin Spuare

Philadelphia Pa. 
Success in photographic negative making depends largely on the speed and reliability of the dry-plate used.

\section{Hammer Dry Plates}

hold the record of supremacy for all climates and temperatures.

HAMMER'S SPECIAL EXTRA FAST (RED LABEL) AND EXTRA FAST (BLUE LABEL) PLATES FOR FIELD AND STUDIO WORK, AND HAMMER'S EXTRA FAST ORTHOCHROMATIC AND D. C. ORTHOCHROMATIC PLATES FOR COLOR VALUE.

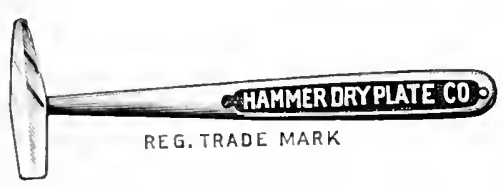

\section{HAMMER DRY PLATE CO.}

OHIO AVENUE AND MIAMI STREET ST. LOUIS, MO. 


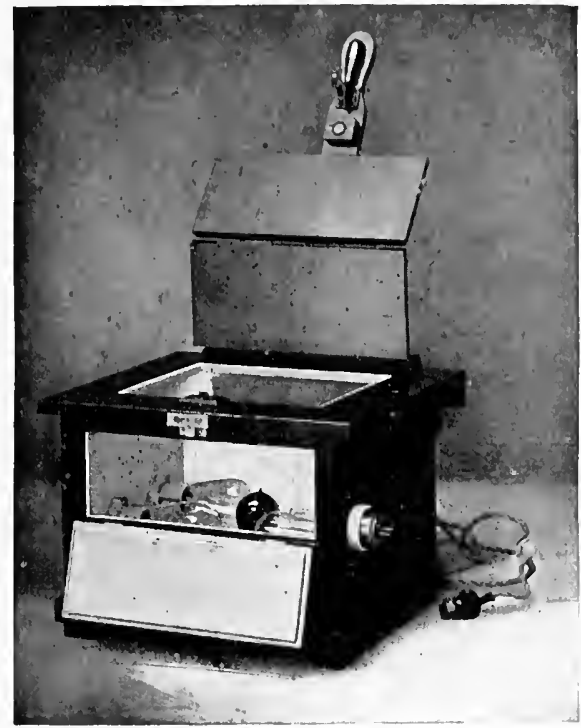

\section{ANSCO \\ $8 \times 10$ \\ Professional}

\section{Printing Machine}

Price:

Complete with lamps (four 40-watt Mazda and a ruby bulb)

United States . . $\$ 30.00$

Canada . . . 32.50

THE United States Government selected this compactly 1 built printer as the one best adapted for use in the motorlorry darkrooms operating on the battlefields of France.

The machine is simple in operation, rugged in construction, sure in performance. It will accomplish with ease and certainly all that is demanded of an $8 \times 10$ printing machine.

Perfect diffusion over the entire area of the light opening is assured by the ingenious method of illumination employed.

Ansco superior quality dominates in this machine as it does in all Ansco professional studio equipment.

\section{Ansco Company}

Binghamton, N. Y. 


\section{COPY Without ERROR is What EVERYBODY Wants}

\section{The PHOTOSTAT \\ (Reg. U. S. Pat. Off.)}

Makes Fac-simile Copies,

Directly upon sensitized paper,

At a possible speed of 1 Copy per Minute,

From any Colored Subject,

At Original Size, Enlarged or Reduced.

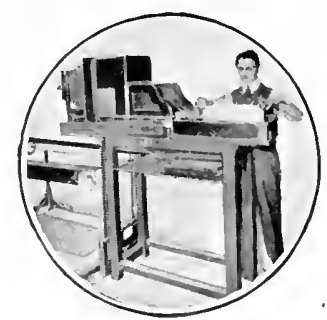

That are Permanent,

That are Legal Evidence in Court,

That are Waterproof,

That are Erasure Proof,

That do not need to be Checked.

The PHOTOSTAT makes these copies from:

Pencil Drawings,

Sketches, Tracings,

Patent Office Drawings,

Data Sheets,

Shipping Lists,

Contracts,

Wills,

Graphs,

Telegrams,

Illustrations for Salesmen,
Blue Prints,

Ink Drawings,

Maps,

Specifications,

Checks,

Drafts,

Records,

Leases,

Pages from Books,

Charts,

Cuts and Drawings for Advertising.

The PHOTOSTAT is manufactured by the Eastman Kodak Co. exclusively for COMMERCIAL CAMERA COMPANY ROCHESTER, NEW YORK

BOSTON, CHICAGO, NEW YORK CITY, PHILADELPHIA, PROVIDENCE, SAN FRANCISCO, WASHINGTON. 


\section{More Opportunities for Profitable Work}

Can be Realized on by you through the possession and use of

\section{VICTOR PORTABLE FLASH BAGS}

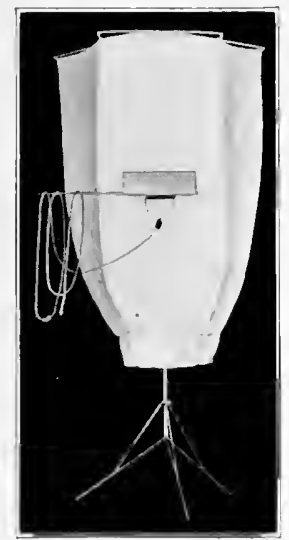

They supply instantaneous illumination for photographing store, factory, home and office interiors, groups and banquets.

These bags thoroughly diffuse and soften the flash. With them several exposures can be made without discharging the smoke.

Are quickly and easily set up, are lightweight and compact, yet very strongly and durably constructed.

Send for complete descriptive folder.

\section{Carry Your Light Where You Carry Your Camera}

By including in your outfit a bottle of

\section{VICTOR FLASH POWDER}

"The Light That's always available"

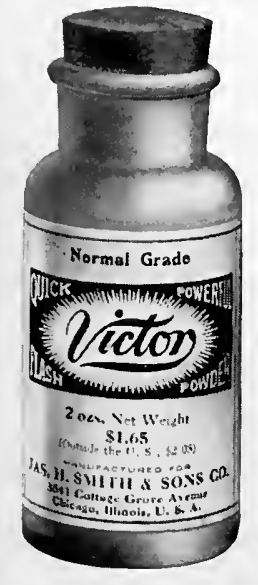

you have prepared in advance to successfully illuminate anything you may encounter regardless of its location.

It is the unequaled means of instantaneous illumination for all classes of work - from a portrait of "Baby" to a negative of a national convention.

Its extremely high illuminating quality, instantaneous combustion and cleanliness make it the most satisfactory and profitable operating light you can use.

\section{J. H. SMITH \& SONS CO.}


The final and perfecting step in refining coal tar developers produces

\section{MONOMETHYL PAR- AMIDOPHENOL SULPHATE}

Its pronounceable name is

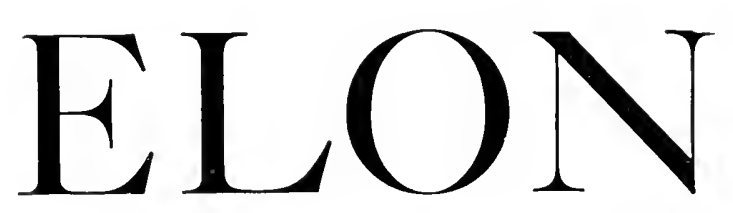

We make it-reve know it's right.

EASTMAN KODAK COMPANY, ROCHESTER, N. Y.

All dealers'. 
No matter how arrefully you work to favor your plate, you can get a better result on Film. And the unusual things-the one-time, impossible things, become simple when you use

\section{EASTMAN PORTRAIT FILM}

EASTMAN KODAK COMPANY, ROCHESTER, N. Y.

All Dealers'. 


\title{
If you want to know what is doing in Photography,
}

read the

\section{BULLETIN OF PHOTOGRAPHY}

The weekly magazine devoted to the interest of the business photographer

Articles of timely interest on salesmanship and advertising

Articles on Legal Subjects and free Legal Advice

Beautifully printed and illustrated

\author{
Price, Postpaid, $\$ 2.00$ per Year \\ Canadian Postage, 50c extra \\ Foreign Postage, $\$ 1.00$ extra
}

Order from your dealer or

Frank V. Chambers, Publisher

636 South Franklin Square

Philadelphia 



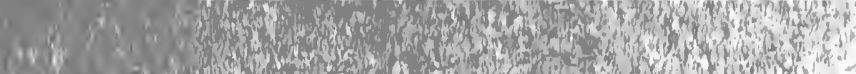

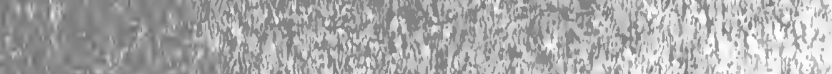
4. of

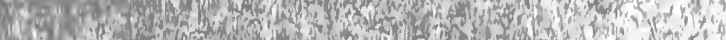
Whan (a)

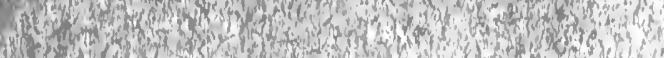

ats Nif

(f)

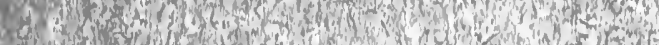

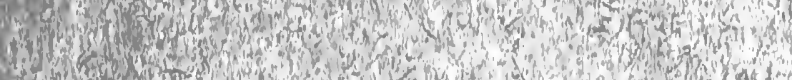

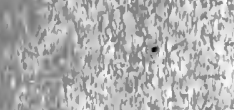

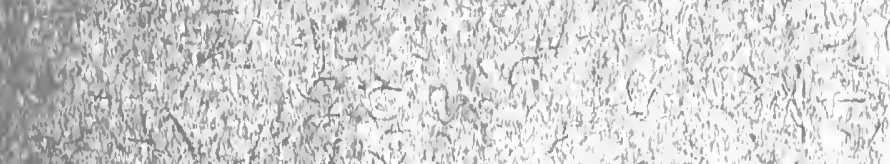

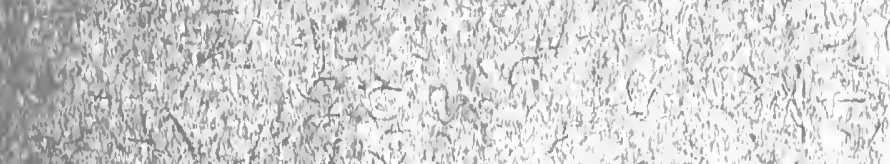

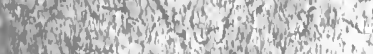

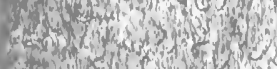
2.

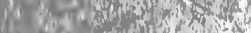

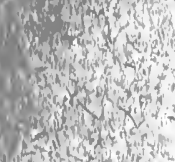

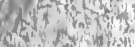

Gond

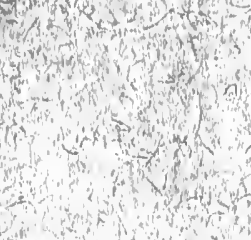

(x)

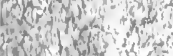

(i) $x^{2} y^{2}-1$

(6)

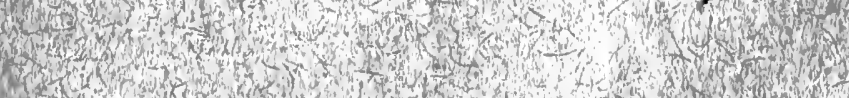

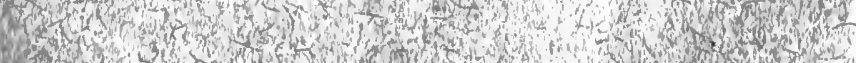
10. 19.

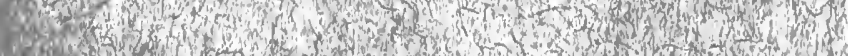

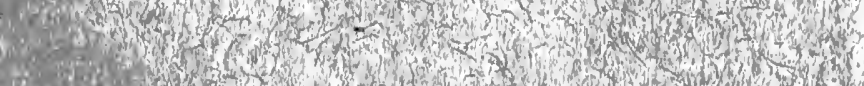

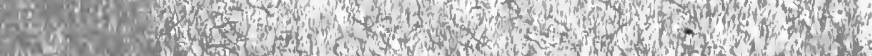

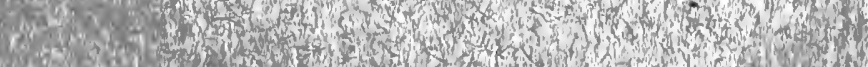

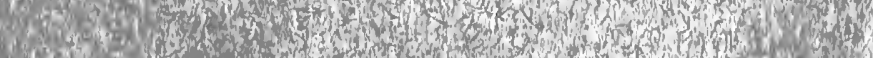

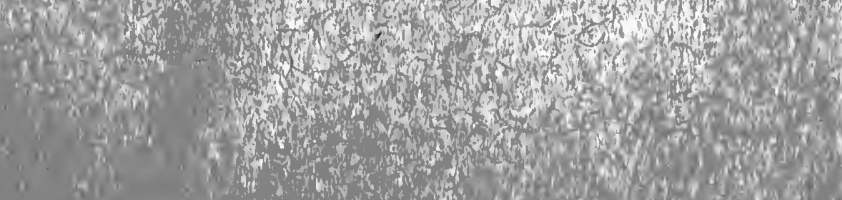


- 3 -

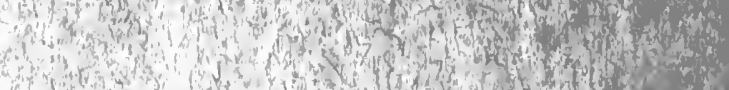

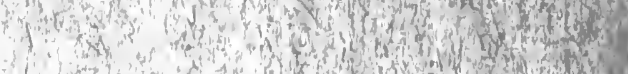

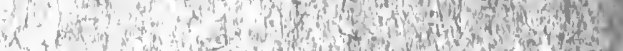

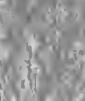

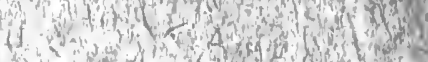

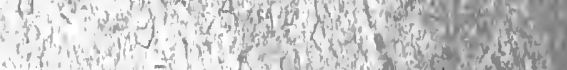

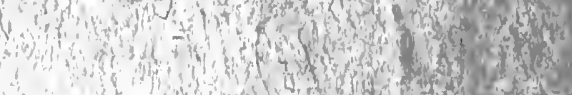

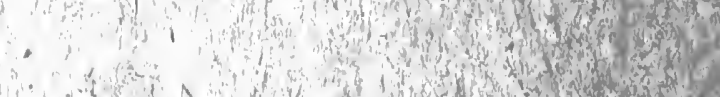
vic as

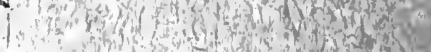

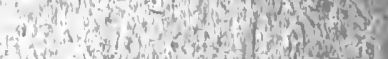

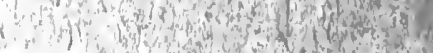

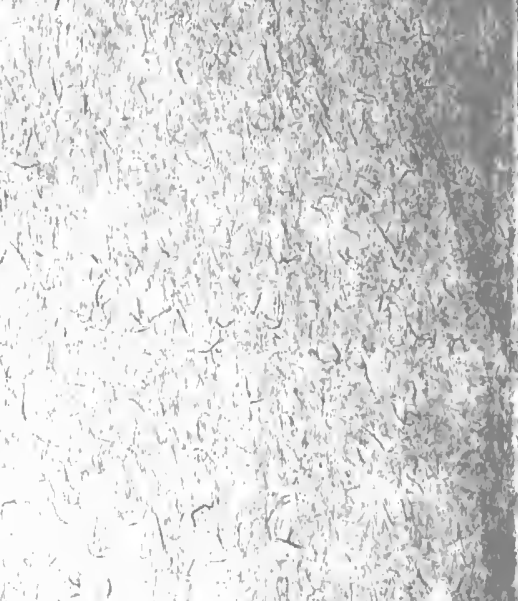

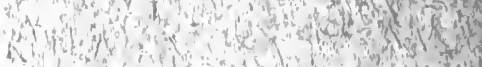

a. Henting की 4304

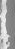



